\title{
CRITICAL NODE ANALYSIS FOR WATER DISTRIBUTION SYSTEMS USING FLOW DISTRIBUTION
}

\author{
A Thesis \\ presented to \\ the Faculty of California Polytechnic State University, \\ San Luis Obispo \\ In Partial Fulfillment \\ of the Requirements for the Degree \\ Master of Science in Civil and Environmental Engineering
}

by

Michael Hopkins

April 2012 
(C) 2012

Michael Hopkins

ALL RIGHTS RESERVED 


\section{COMMITTEE MEMBERSHIP}

TITLE:

AUTHOR:

DATE SUBMITTED:

COMMITTEE CHAIR:

COMMITTEE MEMBER:

COMMITTEE MEMBER:
Critical Node Analysis for Water Distribution Systems

using Flow Distribution

Michael Hopkins

April, 2012

Dr. Shihka Rahman, Associate Professor

Dr. Misgana Muleta, Assistant Professor

Dr. Eric Kasper, Professor 


\begin{abstract}
Critical Node Analysis for Water Distribution Systems using Flow Distribution Michael Hopkins
\end{abstract}

The expansive nature of water distribution system makes them susceptible to threats such as natural disasters and man-made destructions. Vulnerability assessment research efforts have increased since the passing of "Bioterrorism Preparedness and Response Act" in 2002 to harden WDS. This study aimed to develop a method that locates critical nodes without hydraulic analysis of every failure scenario, applicable for any size WDS, incorporates critical infrastructure, and capable of verifying method accuracy. The Flow Distribution method is the application of the gravity model, typically used to predict traffic flows in transportation engineering, to a distribution system. Flow distribution predicts the amount of demand and population that would be affected if any node in the system were disabled by solving for the distribution of each node's outflow. Flow Distribution is applied to the hypothetical city, Anytown, USA using the computer simulation program WaterCAD to model two different disaster scenarios. Results were verified by analyzing sixteen failure scenarios (one for each node) to measure the actual demand and population effect, which was then compared to the nodes predicted by Flow Distribution. Flow Distribution predicted the critical nodes with $70 \%$ accuracy and can still be improved with future work. 


\section{ACKNOWLEDGMENTS}

I would like to thank Dr. Misgana Muleta and Dr. Eric Kasper for agreeing to be on my thesis committee and to work with me. I am very grateful to have had Dr. Shihka Rahman as my thesis chair for all her support and guidance throughout the thesis process. This thesis would also not have been possible without the constant encouragement from my family. 


\section{TABLE OF CONTENTS}

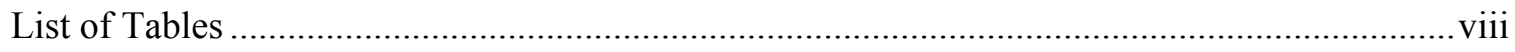

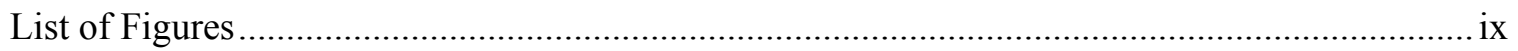

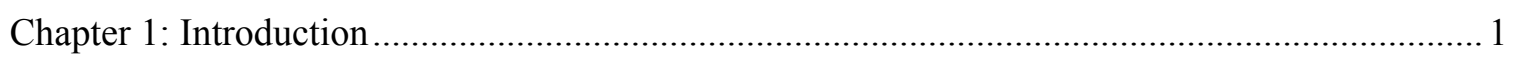

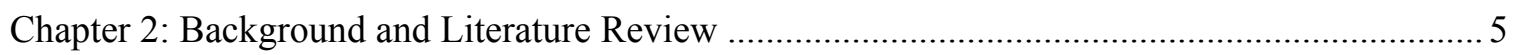

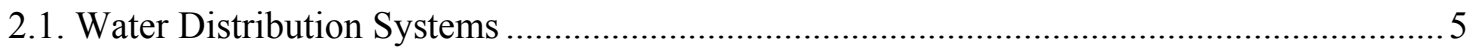

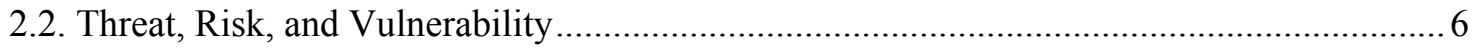

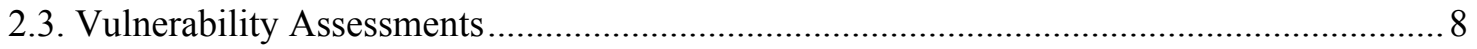

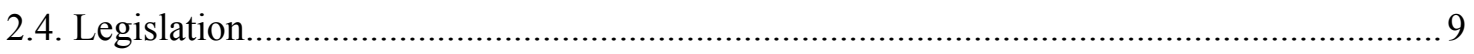

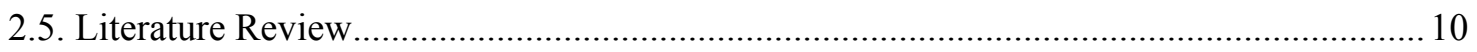

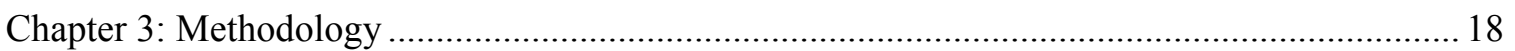

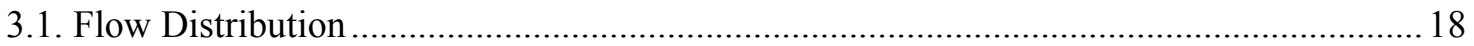

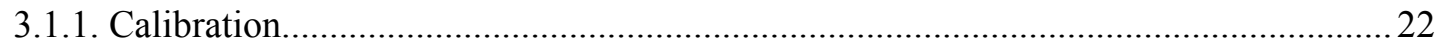

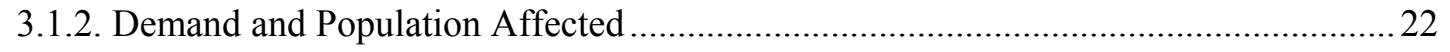

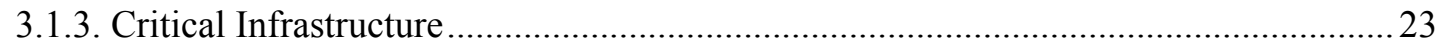

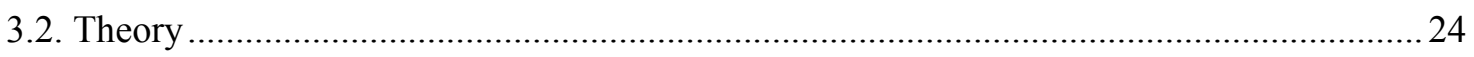

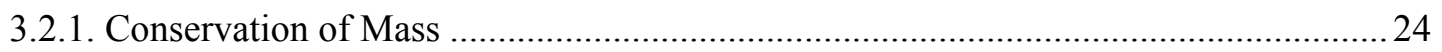

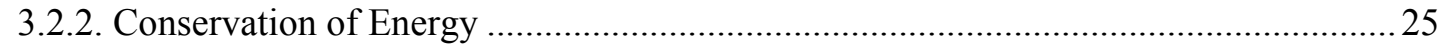

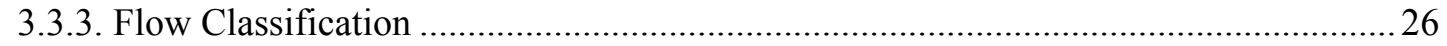

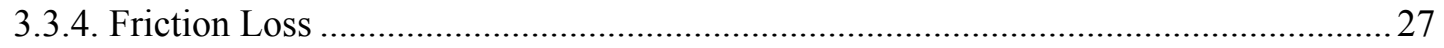

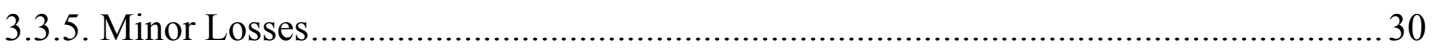

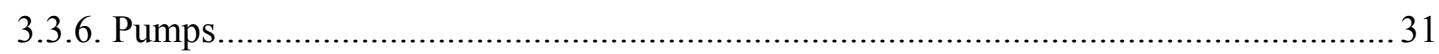

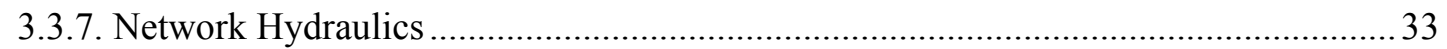

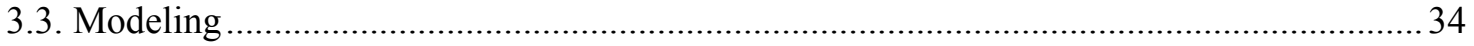

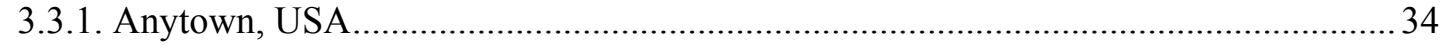

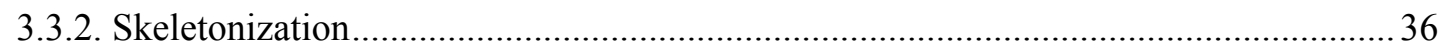

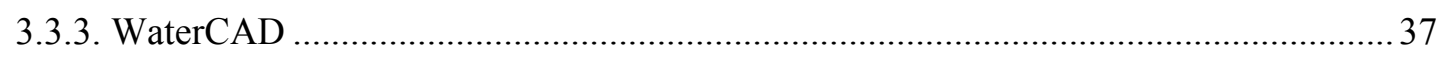

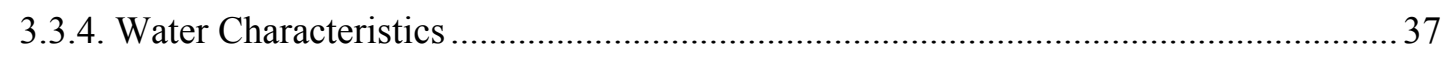

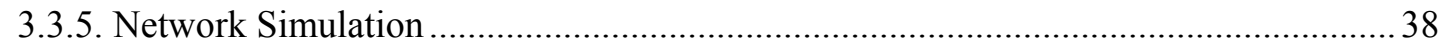

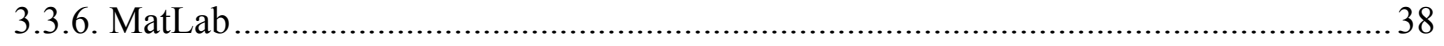

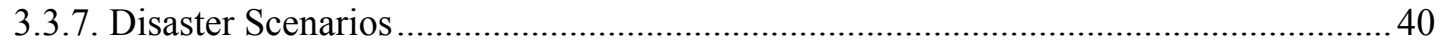

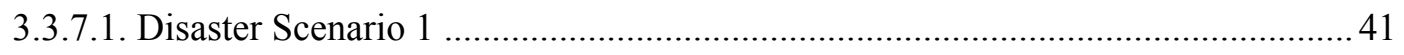

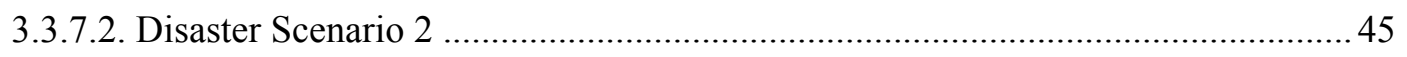

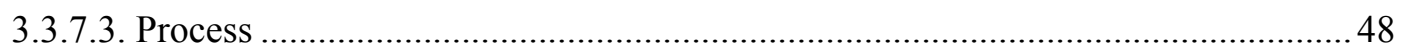

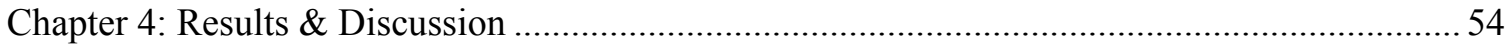

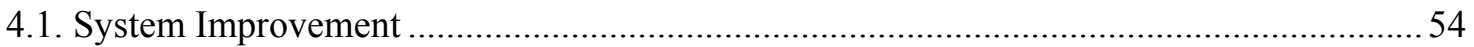




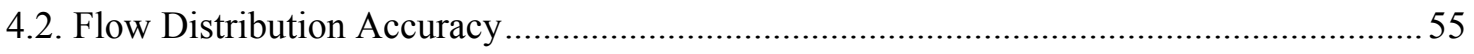

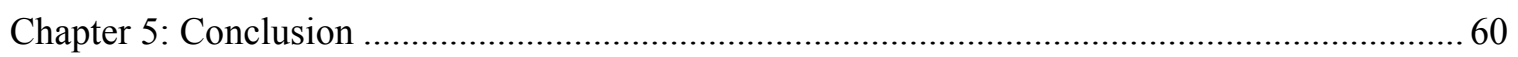

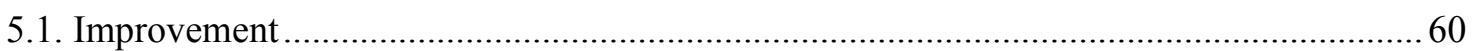

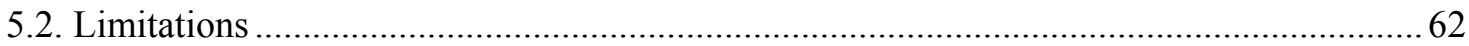

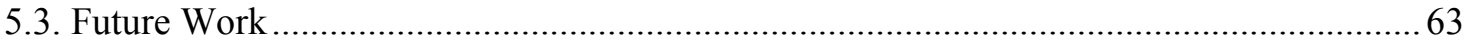

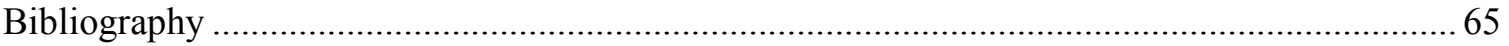

Appendix A: Matlab Code

Appendix B: Tank Calculation

Appendix C: Disaster Scenario 1

Appendix D: Disaster Scenario 2 


\section{LIST OF TABLES}

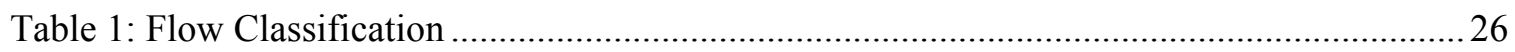

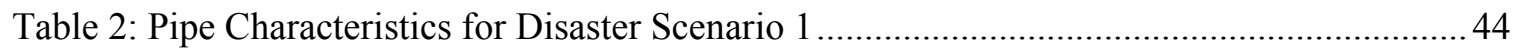

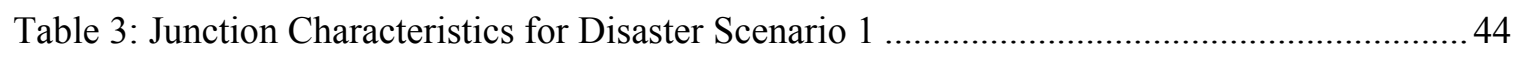

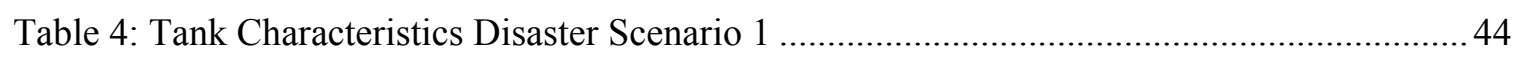

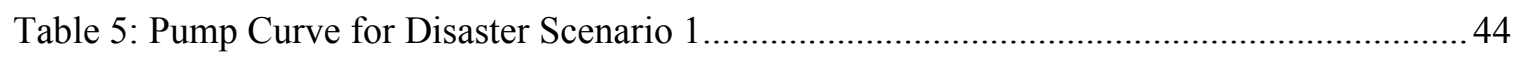

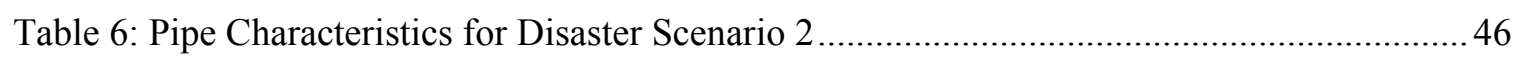

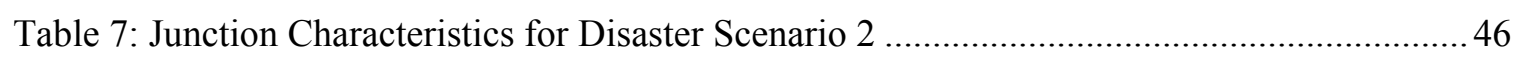

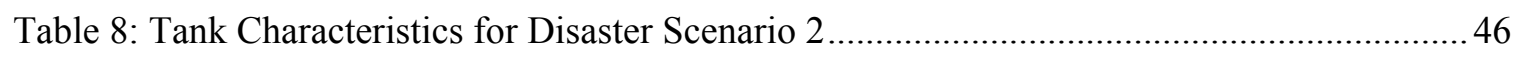

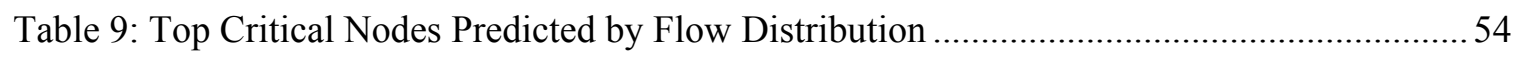

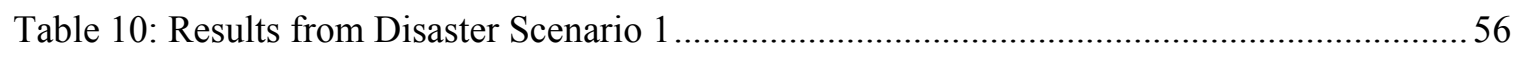

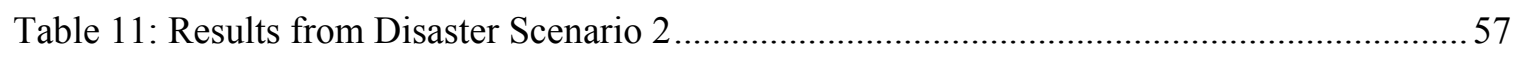

Table 12: Population Effect for Peak Hour 10 versus 24hr Period for Run 1..............................58

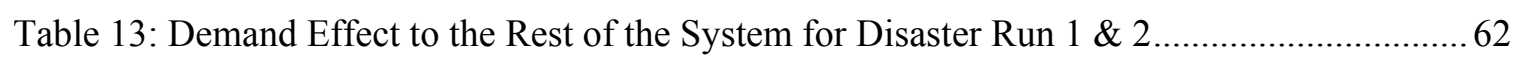




\section{LIST OF FIGURES}

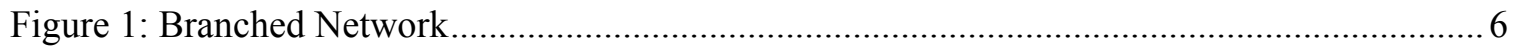

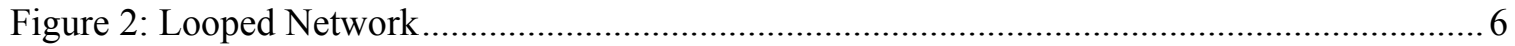

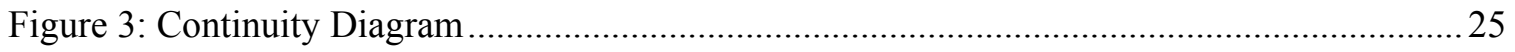

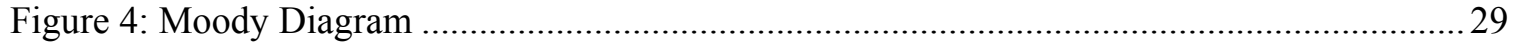

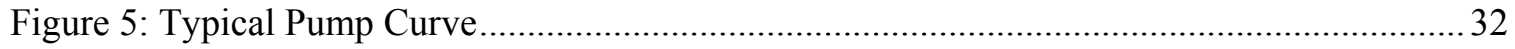

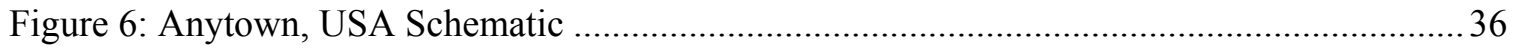

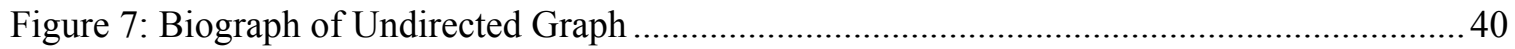

Figure 8: Tanks' Hydraulic Grade Line with Original Pump Curve ............................................. 43

Figure 9: Tanks' Hydraulic Grade Line with New Pump Curve ..................................................... 43

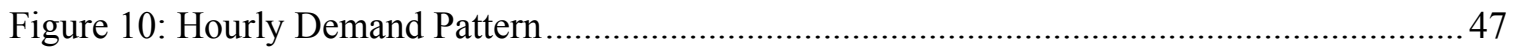

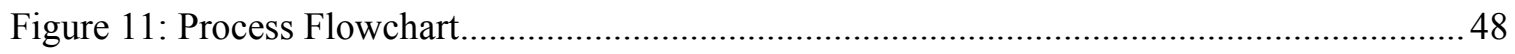

Figure 12: Failure Scenario with Junction 90 Out for Disaster Scenario 2 ................................. 51

Figure 13: Power Function for Pressure Dependent Demand .........................................................52 


\section{CHAPTER 1: INTRODUCTION}

The United States' economy and human development are powered by receiving water through distribution systems, which was identified by the President's Commission on Critical Infrastructure as one of the eight key infrastructures (Qiao et at. 2005). Water distribution systems (WDS) are crucial to our society because they deliver clean water from storage facilities to consumers through a complex and extensive pipe network. Distribution systems consist of a water supply source, treatment facility, and a pipe network. The extensive manner of distribution systems makes them susceptible to physical disruption and chemical/ biological contamination threats caused by natural disasters and terrorism.

Natural disasters such as earthquakes and hurricanes can compromise several WDS components. The 8.8 magnitude earthquake in Chile on February $27^{\text {th }}, 2010$ caused several pipe main and lateral breaks preventing the system from operating leaving many people without water for several days (Tank et al., 2010). The power, transportation, and telecommunication systems also suffered damages, but their effects were 'overshadowed' by the direct seismic damage on the water distribution system. (Tank et al., 2010)

Chemical and biological contamination through purposeful or accidental means can expose consumers knowingly or unknowingly to pathogens and contaminants that cause diseases and death. In 1984, a water supply tank in Dalles, Oregon was poisoned by a religious cult resulting in 751 cases of Salmonellosis (Clark \& Deininger, 2000). Lack of water quality monitoring throughout distribution systems allows toxins to be undetected for extended periods. The extensive pipe network creates numerous target access points for contaminants to penetrate the system. Although a major contamination has not occurred in the United States, the threat, accessibility to contaminant insertion points and the consequences of such an event make chemical contamination a considerable risk. 
Despite importance of WDS and consequence severity, it is not practical or feasible to safeguard our distribution systems against all possible disruption and chemical/ biological contamination threats. It is important to efficiently utilize available resources to protect the weakest links and/ or high-risk areas. Vulnerability assessments are a critical component in the preparation and evaluation of emergency management plan for protection of WDS. Vulnerability, for this study, refers to system deficiencies that enable adverse events or attacks to cause system failure. A system failure occurs when not all of the consumer demands are met. Vulnerability assessments are performed to evaluate potential threats, identify consequences, and develop countermeasures aimed at hardening (reducing vulnerability) the water distribution system. These assessments are used to target high-risk areas so resources can be focused to combat possible worst cases of adverse consequences. In the past, vulnerability assessments performed primarily focused on minimal damage and low cost threats such as vandalism or disgruntled employees (EPA, 2003).

After September 11, 2001, people recognized the threat of terrorist attacks and began investigating strategies to protect distribution systems against both terrorist attacks and natural disasters. One of the first measures enacted to help secure distribution systems was the passage of "The Public Health Security and Bioterrorism Preparedness and Response Act" in 2002. This law requires cities to perform a vulnerability assessment on their distribution system against a terrorist attack or intentional action.

Safeguarding our WDS has since become a priority and an abundant of research has resulted in the creation of several methods that satisfy partial or all of the vulnerability assessment components defined by the Environmental Protection Agency (EPA). Research found three main types of methods that could be used for a vulnerability assessment: (i) analytical/ optimization methods that solved for variables deemed important to WDS characterization, (ii) heuristic methods that subjectively ranked distribution components resulting in system classification, and (iii) simulation based methods which uses hydraulic analysis as a main 
catalyst to measure system vulnerability. Several of these research methods are discussed in the Literature Review section.

This study attempts to develop and presents a new method that can be applied to a vulnerability assessment with four main objectives. The first objective was to develop method that accurately identified critical nodes and/or pipes in a distribution system without performing hydraulic analysis on every possible failure scenario. For large distribution systems it would be incredibly time consuming and impractical to analyze every possible failure scenario. Critical nodes/pipes were defined as the nodes or pipes that if disabled would cause the greatest or worst system failure resulting in the most consumers to not be served or largest demand not be supplied. Secondly, the presented method was developed to be capable of incorporating critical infrastructure in the determination of critical nodes/ pipes. Hospitals, schools, and community centers are some examples of critical infrastructures that are imperative for protection, shelter, and support for a community during natural or man-made disasters. It was also desired to create a flexible and simple method that could be used by non-experts, city officials, and practicing engineers with different types of computer simulation programs and can be applied to any size WDS. The last objective was to create a program that allowed the results to be verified to check the accuracy and applicability of the developed method.

Current study applies the gravity model, typically used in the field of transportation engineering for trip distribution modeling, to water distribution systems. The gravity model is used to predict the distribution of trip destinations originating from one location to the remaining locations in a given area. When the gravity model is applied to distribution systems, it provides Flow Distribution. Flow Distribution, can calculate the outflow that any node or pipe will supply to the remaining the nodes/ pipes in the system. The information necessary to apply Flow Distribution includes pipe and node variables and parameters obtained from hydraulic analysis. The results derived from Flow Distribution can be used to predict the population and demand affected by each node if it were to be disabled, which quantifies the importance of each node or 
pipe within a system. These results can help direct available resources to the critical nodes and pipes to harden the system.

A hypothetical system, Anytown, USA, was used to apply Flow Distribution and determine its accuracy because of its resemblance to a real system and its wide use in other literature such as Walski et al. (1987) and Chastain (2006). The goal for Flow Distribution was to predict correctly the critical nodes that prevented most demand from being supplied and prevented the most population for receiving water for two different disaster scenarios. The two disaster scenarios, one featuring a disabled node and a fire flow and the other featuring a disabled node, fire flow, and non-operational pumps, were modeled in WaterCAD V8i. These hydraulic analyses were performed during normal operating conditions and the results were imported into Matlab where the Flow Distribution calculation was performed. The results were then imported into Excel for documentation and the top five critical nodes were identified. Flow Distribution was verified by analyzing the demand and population effects when each node was disabled in a failure scenario and comparing them to the effects predicted by Flow Distribution. Sixteen failure scenarios (one for each node) were created and analyzed in WaterCAD. If the critical nodes Flow Distribution predicted matched the actual critical nodes found by analyzing the sixteen failure scenarios, then the method was deemed valid.

In this thesis, Chapter 2 (Background and Literature Review) contains background information about water distribution systems, vulnerability assessments, current laws, and the literature review on previous relevant research. Chapter 3, Methodology, presents the development of the Flow Distribution method, as well as, the hydraulic theory, and the modeling considerations used to evaluate the new method. Chapter 4, Results \& Discussion, presents and interprets the results from evaluation of the Flow Distribution method. Chapter 5, Conclusion, includes implications of the results, recommendations for method improvement, and possible future works. 


\section{CHAPTER 2: BACKGROUND AND LITERATURE REVIEW}

\subsection{Water Distribution Systems}

Water distribution systems serve the community and help power the economy by delivering water from source(s) to its consumers. WDS are comprised of three primary components; water source, treatment, and distribution network. Water sources can be reservoirs, rivers, and groundwater wells. Water treatment facilities disinfect the water to drinking water quality standards prior to delivering it to its consumers. The distribution network is responsible for delivering water from the source or treatment facilities to its consumers at serviceable pressures and mainly consists of pipes, pumps, junctions (nodes), valves, fittings, and storage tanks.

WDS are required to supply water to domestic, commercial, and industrial entities above or at a threshold pressure with consumer demands that vary throughout the day, weak, season and year. The minimum pressure that should be observed at junctions throughout the system varies depending on the type of water consuming sector and regulations governing the distribution system, but a typical operating range is between 40-100 psi (AWWA, 2005). It is undesirable to have high pressures because its cause more leaks, breaks and causes water wastage.

The design of WDS including how the system supplies water to its consumers and the schematic layout is critical to their performance. WDS can be designed to supply to its consumers through gravity flow, using mechanical pumping, or both. Gravity flow can be used when there is an elevated water source (river or lake) with enough head to meet consumer demands. Gravity flow is rarely used to meet all demands in urban WDS because of the lack of practicality and flexibility. Gravity flow is more common in rural areas that lack pumping capability. A system could use pumps to supply to its consumers, but solely using pumps is problematic because it requires pumps to fluctuate constantly to satisfy the vastly varying consumer demands. Due to varying water demand patterns, most urban distribution systems utilize pumps with elevated 
storage tanks. These tanks help meet fluctuating consumer demands, accommodate fire flow during emergency conditions, and stabilize operating pressures. Typically, tanks are used during peak hours of the day and refilled during low demand times. Systems can also be designed to have loop or branch schematics. A branched network (Figure 1) includes several independent links with many terminals that prevents circulation of water throughout the entire system and water is supplied to end users through one pipe. One problem with a branched network is if one pipe is disabled even for routine maintenance, some consumer demands will not be met. A looped network (Figure 2) is one that has multiple pipes at every single node so that water can be supplied to any point through more than one pipe. The problem with a looped network is the additional cost of constructing and maintaining redundant pipes. Most networks are a combination of these two of schematic layouts.

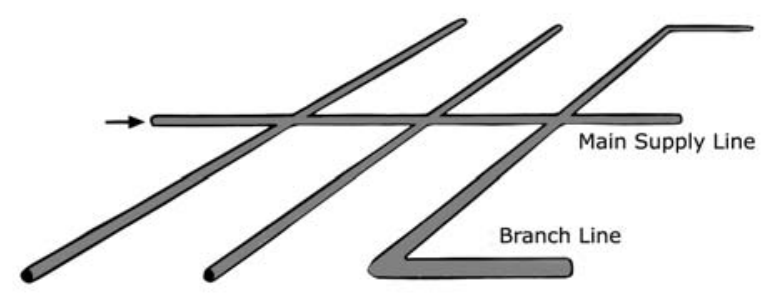

Figure 1: Branched Network

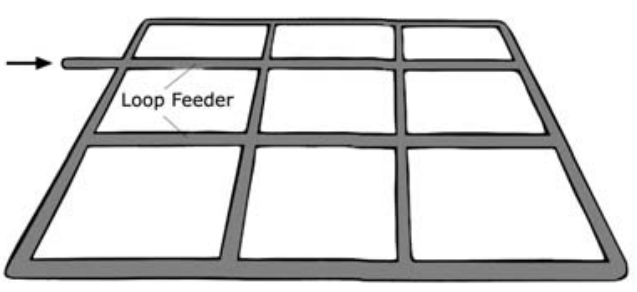

Figure 2: Looped Network

\subsection{Threat, Risk, and Vulnerability}

It is important to distinguish between the terms threat, vulnerability, and risk. A threat is the indication that an attack or event causing a system disruption such as broken pipes, failed nodes, and poor water quality may occur. Examples of threats to a WDS would be natural disasters, chemical contamination, and terrorist attacks.

Risk is a measure of the system's exposure to given threats or the likelihood an event or attack is successful. If all the pipes are underground and hard to access the likelihood for a terrorist to contaminate the distribution system is lower than if many spots such as storage tanks were easily accessible. 
Vulnerability, for WDS, refers to system deficiencies that enable the adverse event or attack to be successful. An example of a vulnerable system would be a branched network because if one link is disrupted, the rest of the system downstream will be affected. The threats, risks, and vulnerabilities are unique for each system. Haimes et al. (1998) identified seven key elements of WDS; (i) the physical components, (ii) management structure, (iii) operating rules and procedures, (iv) institutional structure, (v) control centers, (vi) laboratories, and (vii) maintenance and storage facilities. These seven components need to be properly protected against system specific threats, and the need of protection is identified through the evaluation of current vulnerabilities.

A system can be hardened by increasing a system's security, redundancy, reliability, and resilience. Security includes all efforts to prevent entry into the system such as fences, guards, and video surveillance. Hardening a WDS with just security would be difficult and inefficient because it requires an exuberant and impractical amount of work force and money to maintain the high alert necessary to prevent rare and unique events. Redundancy is the ability of the system to function with failed components without adverse system performance. Redundancy is any action of duplication including extra pipes, an additional gate to release water from a reservoir, or an extra pump. These duplications may not be necessary for the system to run during ideal conditions, but are crucial during any planned or unplanned disruption in the system from route maintenance to a simple pipe break to a significant system shutdown. All looped networks contain some amount of redundancy. Another approach to hardening a distribution system is increasing its resilience. A resilient system, after a performance disruption, would be restored to normal operating conditions swiftly due to quick recovery time. A disruption is certain to happen eventually, and a resilient system would ensure minimal outage time. Resilience is influenced more by the standards and operations of the distribution facility rather than the layout of the system. The reliability (robustness) refers to the system's degree of sensitivity. A very reliable system would be able to withstand some natural disasters and intentional attacks without adverse 
effects being observed by consumers. A number of studies have focused on quantifying system reliability.

\subsection{Vulnerability Assessments}

Vulnerability assessments evaluate system deficiencies so available resources can be effectively utilized to protect against system threats. The EPA identified several key components to vulnerability assessments. First, the possible negative events and their adverse consequences need to be identified and prioritized. Then critical assets such as schools, hospitals, and community centers that might be at risk during these events must be determined. Next, the likelihood of such events from occurring must be measured. Then the existing counter measures for these events should be evaluated. Lastly, with all the information collected, the current risks should be analyzed and from that, a prioritized plan for risk reduction can be developed (EPA, 2002).

Although every vulnerability assessment aims to evaluate system deficiencies, there are several different approaches and methodologies. One approach to assessing vulnerability is with a heuristic/ranking approach. Typically, this approach identifies criteria deemed critical to system operation, and then ranks every pertinent system component for each criterion. The ranking scores are then combined in some fashion to result in a list of the most vulnerable components in the distribution system. The main concerns with this approach are the ranking is subjective so the results vary depending on the person conducting the assessment, the inability to verify the results, and evaluation from someone who has working knowledge of the system. Another approach is to use numerical formulas to quantify a system's vulnerability. These methods typically use hydraulic data and complicated equations to solve for variables deemed crucial to network evaluation. These variables are typically used to quantify reliability, redundancy, resilience, or vulnerability. One problem with this approach is the complicated equations may not be utilized or interrupted properly by a non-experts or city officials. The simulation approach could also be 
used, which evaluates system performance under user-defined disaster scenarios. These disaster scenarios are modeled in a computer simulation program by skilled personnel and hydraulic performance is compared to normal operating conditions. Negatives to this approach are the results are typically valid only for the scenario modeled and subjective judgment from the modeler is required to create the disaster scenarios.

\subsection{Legislation}

Since the 1970's, laws have been passed mandating assessment and protection of water systems. One of the first was the 'Safe Drinking Water Act' (SDWA) passed in 1974, which mandated rural areas, cities, and large municipalities to assess water source contamination. Water communities were required to identify possible contamination origins and the systems vulnerability to contamination threats (Staudinger, et. al., 2006). In 1986, 'Critical Infrastructure Protection' executive order was passed addressing the implications that disruptions or incapacitations of the national infrastructure would have on the economy and security. The 'President's Commission on Critical Infrastructure' and water system operators were to evaluate system vulnerabilities to propose regulatory changes (Staudinger, et. al., 2006).

Although legislation has been implemented since the 1970's, most vulnerability studies focused on routine breaks, or threats of vandalism, and disgruntled employees rather than more costly threats like natural disasters and chemical/ biological contamination (EPA, 2003). Following the attacks on September 11, the EPA passed "The Public Health Security and Bioterrorism Preparedness and Response Act" in 2002. This law requires water communities (municipalities, cities, towns) serving over 3,300 customers to perform a vulnerability assessment on their distribution system against a terrorist attack or intentional action. The law demanded cities to, at least, evaluate the vulnerability of pipes, treatment and storage facilities, physical barriers, computer systems, use and handling of chemicals, system operation, and maintenance (EPA, 2002). Since methodology was not specified or required to perform the vulnerability 
assessment and satisfy the law, the passage of this law led to an abundance of research on different approaches and methods for vulnerability assessments of WDS.

\subsection{Literature Review}

This section discusses different methods focusing on varying aspects of WDS vulnerability. Although each method is different, they each address vulnerability of one of the seven elements of WDS identified by Haimes, et al. (1998) and/ or measure a system's vulnerability based on reliability, resilience, and redundancy.

Jacobs and Goulter (1991) assessed reliability of WDS without the evaluation of all possible mechanical pipe failures. Traditional reliability methods used procedures that solved for reachability and cut sets, and are not practical for large urban networks. Jacobs and Goulter (1991) solved for the probability of a given number of pipes failing simultaneously using empirical data as basis for their estimations. Next, the probability that the removal of a given number of pipes would fail the system was solved using simulation of failure scenarios. It was assumed that every pipe had an equal failure probability and that failures were distributed uniformly over the system. This method provided means for assessing distribution reliability, but failed to incorporate reliability to natural disasters and terrorist attacks.

Jowitt \& Chengchao (1993) developed a prediction method to identify the most influential pipe elements without performing hydraulic analysis for every possible failure scenario. Microflow Distribution was instituted to solve for the flow that each pipe, water source, or node supplied to each node in the system. Microflow Distribution required the use of the flow rates for each pipe, the node demands, and the inflow at each node. In addition, it was assumed that the inflows at each node were completely mixed meaning the flow to meet the demand of a supply node was a percentage of each connected pipe's flow. This analysis was performed on a simple network and the critical pipes were identified. The accuracy of the method was tested by hydraulically analyzing failure scenarios featuring one of the pipes in the system disabled to 
compare the actual results with the Microflow Distribution prediction. The use of Microflow Distribution correctly predicted the critical nodes with $60 \%$ accuracy. The accuracy could have been improved by calibrating the pressure dependent demand equation that was used. This method provides a basic approach for identifying critical failure scenarios without analyzing every possible failure scenario.

Ezell, Farr, \& Wiese (2000) developed a four-phrase process called the Infrastructure Risk Assessment Model (IRAM) to evaluate water distribution vulnerability. First, the risks are identified by dividing the distribution system components into categories; hierarchical structure, function, state, and vulnerability. The vulnerabilities are then subjectively ranked based on the components of exposure and accessibility. Next, scenarios are created to serve as initiating events in event trees or 'what if' risk models. A risk model helps to determine the sequences that lead to adverse consequences and are used to produce probability density functions. The risks are assessed using the Partitioned Multiobjective Risk Method (PMRM) to generate expected values of damages, losses, and consequences. IRAM concludes with generating alternatives to improve system performance. The decision maker involved in the execution of IRAM can then evaluate the risks and alternatives to decide the actions that are necessary to deem the system safe. Although IRAM provides a systematic approach to solve for the vulnerability of distribution systems, it requires an abundance of subjective user input about disaster scenarios and consequences that may be impossible to predict and may vary from person to person.

Bahadur et al. (2003) developed a ranking method to optimize chemical sensors locations in a distribution system using PipelineNet and Geographic Information System (GIS). Optimal locations for monitoring equipment were found by implementing scoring matrices for node variables, population density, and proximity to critical infrastructure (hospitals and schools). The node variables matrix considered flow, velocity, and pressure. Each component of the scoring matrix is ranked from one to ten. PipelineNet provides guidance in assigning scores, but also allows users to input values as necessary. The allocation of the score is determined by the user 
using Natural Breaks, Equal Interval, or Quantile, and all three were used in this model. The nodes with the highest scores were deemed suitable candidates for chemical sensor equipment locations. This method was applied to a hypothetical system with several parameters being approximated and the ninth hour of a 24 hour extended period simulation time was used for the analysis. This method demonstrates that population and critical infrastructure can be implemented in the criteria for suitable monitoring locations. This research did not provide any information on the accuracy of the strategy used.

Kalungi and Tanyimboh (2003) describe the importance of using both redundancy and reliability to measure a system's performance. The reliability of a system is assessed using Critical Head Driven Simulation Method rather than a demand driven analysis during normal conditions. A demand driven analysis assumes nodal demands will be provided regardless of the pressure in the system. The head driven analysis used defines every node as either no-flow, partial flow (pressures between $\mathrm{H}_{\min } \& \mathrm{H}_{\mathrm{res}}, \mathrm{H}_{\text {res }}$ can be set to a desirable pressure below which flow cannot be fully satisfied with typical values being about $14-15 \mathrm{~m}$ ), fully satisfied flow, and key partial-flow nodes (nodes that affect outflows of other nodes). The redundancy calculation is based on the performance of the system with any given pipe, valve, pump or tank disabled. The main problem with this assessment is the redundancy equation requires a separate calculation for each network disturbance being analyzed. This would be entirely impractical for majority of WDS to solve for all possible combination of disabled network components.

Little (2004) describes a holistic strategy that identifies and quantifies the amount of risk in any urban infrastructure. First step is to identify the possible risks. Risk is defined as the 'probability of an adverse event multiplied by the consequences of that event'. To help identify risks one can ask What can go wrong? What is the likelihood it would go wrong? and What are the consequences if it did go wrong?. A decision matrix can be used to identify which risks are unacceptable and require countermeasures. For this assessment the decision matrix ranks the likelihood and the consequences to identify which risks need attention. This research aimed to 
identify a process and concepts that should be implemented to harden all instructure systems. There is not scientific proof behind this heuristic approach, but this could still be effective if it were used by knowledgeable and experienced decision makers.

Lippai and Wright (2005) performed a criticality analysis on a water distribution system. Analysis was first performed under normal operating conditions to record the demand, head, pressure at each node. Failure scenarios, which consisted of one pipe closure, were then analyzed. The pressure percent difference between normal and failure conditions was then multipled by the demand at each node to find the penalty at the demand junction due to a failed component. Failure scenarios were run for eighty percent of the pipes and their pipe penalties were summed and the pipes with the highest number were deemed to be the most critical. The main problem with this method is it requires hydraulic analysis of every failure scenario, which would be impratical for large urban distribution systems.

Qiao et al. (2005) presented a quantitative approach to optimize security resources for WDS using a cost-based approach. The cost of a proposed attack and the consequences of the attack were estimated. Components in a distribution system were deemed resilient if economic consequences were small in comparison to the attack cost. The attack consequences were estimated using Pressure-Based Heuristic, which consists of disabling the node with the lowest pressure until all the nodes are above the threshold pressure. The basis of the method consisted of solving main four equations. The solution provides the minimum resilience across all network subsets, constraint for minimum resilience, constraint for budget limit for security investment and solves for the attack cost. A Genetic Algorithm was used to generate new constraints, which were then evaluated in a hydraulic simulator, and if the constraints were violated then the process was repeated. The Genetic Algorithm results can help decide the allocation of security funds to create a more resilient system.

Chastain (2006) developed a method to optimize sensor monitoring station locations to minimize contaminant exposure to consumers. This procedure was modeled in WaterCAD using 
a generic town called Anytown, USA (Walski et al., 1987), which has been used to test several other methods. First step created a contamination scenario based on design basis threat by identifying the contaminant and its properties, mass of the contaminant, duration of injection, and when the contaminant was exposed to the system. Next, simulations were run in WaterCAD with point source injections at every junction. The nodes that detected a contaminant concentration greater than the threshold were recorded in an evaluation matrix. The concentration threshold was predetermined based on the pollutant simulated and limits of available detection technology. The evaluation matrix identifies how many nodes detect a concentration greater than the threshold for each time step. A ranking algorithm was used to identify nodes that minimized time of detection and limit the exposure to customers. This research provides a method that seems feasible for cities and communities to adopt easily, but the population density and critical infrastructure should be considered when seeking optimum sensor locations.

Jun et al. (2006) developed an algorithm that calculates the impact of pipe failures and valve placements throughout water distribution systems to improve their serviceability and reliability. The impact of each pipe failure (considered to be a pipe or valve failure) has on the system is calculated by considering the number of pipes that need to be disabled to isolate the broken pipe. The more pipes that need to be shut down to isolate the disabled pipe, the more consumers must be without water. The algorithm also takes into account critical infrastructure (hospital, school, community centers, etc.) that are affected by a pipe break by assigning each critical facility an equivalent number of customers (i.e. one school could equal one thousand households). This study mainly considered routine pipe break down and not disaster scenarios that could result in multiple pipes being disabled at one time, but could easily be used as part of a vulnerability assessment.

Wang \& $\mathrm{Au}(2008)$ quantify the reliability of WDS for various consumers after a seismic event and identifies critical pipes in the system. Reliability of a system to supply to consumers was emphasized to vary spatially and was dependent upon system configuration. Critical pipes 
were defined as ones that significantly affected the water supply to critical infrastructure. Critical links were found by using two probability equations, Damage Consequence Index (DCI) and Upgrade Benefit Index (UBI). The DCI reflects the consequence from damaging a pipe and UBI is a measure of a pipes impact on certain consumers. These two equations were implemented to simulate a hypothetical system. Monte Carlo simulations were used with GIRAFFE (Graphical Iterative Response Analysis of Flow Following Earthquakes) and MatLab to evaluate the seismic performance of the hypothetical system. A cost-benefit analysis was conducted with the use of the "efficient frontier", which diagrams the most efficient and effective upgrade option. This method would only be useful if the effects of seismic activity on WDS, specifically on the critical infrastructure, were the primary concern.

The EPA released the 'Threat Ensemble Vulnerability Assessment and Sensor Placement Optimization Tool' (TEVA-SPOT) developed by Sandia University, which optimizes sensor locations for large distribution systems to protect against chemical contamination (Berry et al., 2009). TEVA-SPOT offers a range of modeling inputs making it flexible and adaptable to different systems and modeling objectives. The modeling process includes inputting sensor characteristics, defining the design basis threat, selecting the impact measures for the contaminant warning system, planning utility response to detection, identifying practical sensor locations, and evaluating sensor locations. TEVA-SPOT uses Monte Carlo simulations to help create disaster scenarios seamlessly by quickly solving trial and error calculations. TEVA-SPOT is a powerful and effective program that can optimize chemical sensors, but does not consider physical disruptions in its assessment.

Nazif and Karamouz (2009) calculated the reliability, resiliency, and vulnerability using the System Readiness Index (SRI) to evaluate WDS readiness to one or more water main breaks. The index is based upon calculating the reliability, resiliency, and vulnerability using probability and system failure data. The critical nodes (nodes with high demand and/or pressure variations) were then selected. The nodes with water demands in the twentieth percentile and nodes with the 
highest head loss were deemed the critical nodes. The critical nodes were revised during the simulation if the hydraulic state remained unchanged. Failure scenarios were generated and using Probabilistic Neural Network (PNN) structure the SRI was calculated. The result of the SRI calculation was a class rate score ranging from one to five, and these classes corresponded to a probability of failure. The results between normal and disaster situation were compared using the demand pressure relationship (Pressure Dependent Demands) at critical nodes.

Baoyu, Xinhua, and Yuan (2009), presented the Vulnerability Assessment Model for Regional Water Distribution System (VAMRWDS) to identify sub-region and entire distribution system vulnerability to chemical contamination. The method uses the theory of Monte-Carlo stochastic simulation to generate random values for variables with uncertainty such as bulk and wall reaction coefficients. Once the necessary information is gathered such as demand patterns, chlorine concentrations, and bulk and wall reaction coefficients the data is analyzed in EPANET2. After the simulation, four variables that quantify hydraulic and water quality aspects of WDS are calculated. These factors are junction flow weight, supply level weigh, residual chlorine weights, and water age weight. These factors are used to calculate the vulnerability index for each node on the sum of weighted coefficients that are predefined for each WDS. The value of the vulnerability index indicates the system's risk level.

The literature review shows the variability of approaches and the methodologies previously developed. Examples of simulation, analytical/optimization, and ranking approaches were discussed in Kalungi and Tanyimboh (2003), Jowitt \& Chengchao (1993), and Ezell, Farr, \& Wiese (2000) (as well as others) research. As previously mentioned, vulnerability assessments should include evaluation of all the present risks and threats, as well include all the components stated by the EPA, but only a few methods were all an inclusive vulnerability assessment and focused on one component of system vulnerability and/ or considered only one threat (i.e. chemical contamination). 
Despite the abundance of developed methods, the gravity model, which is typically used in the field of transportation engineering to predict the flow of traffic from one zone to another, has not been applied to water distribution system to determine critical nodes or pipes. The main objectives of this current research are to develop a method to locate critical nodes or pipes without analyzing every failure scenario, incorporate critical infrastructure, be adaptable to other systems, and be able to verify the accuracy. It was initially hypothesized that the gravity model due to its accuracy, acceptance in the transportation engineering community, and flexibility would allow these objectives to be met. The following chapter, Methodology, presents the development and application of the method in detail. 


\section{CHAPTER 3: METHODOLOGY}

Present study aimed at developing a method that would identify critical nodes in a water distribution system. An integral part of identifying critical nodes is determining how the outflow of each node is distributed to the rest of the system. The distribution of outflow for each node can be used to predict how much demand or population will be affected if any node were to be disabled. This study believed that the gravity model, which is typically used in the field of transportation engineering for trip distribution, could be modified and applied to a WDS. This section presents the theory, development, and execution of the method, as well as, the fundamentals of WDS hydraulics and the process developed and programs used to apply and verify the model.

\subsection{Flow Distribution}

The basis of the gravity model is Newton's Law of Gravitation (Eq. 1), which states that every mass in the universe attracts every other mass with a force that is proportional to the product of the masses and inversely proportional to the distance squared between the masses. This equation is part of classical mechanics and was published in July $5^{\text {th }} 1687$ in 'Netwon's Philsohiae Natrualis Prinipia Mathematica' (Transportation, 1983). Then late in the $19^{\text {th }}$ century theories by H.C. Carey and work by E.G. Ravestein and E.C. Young showed that gravitational function applies to human migration (Transportation, 1983). One of the first applications of the gravity model with human interaction was done by W.J. Reilly in the field of retail trade (Reilly, 1953). It was not until the 1920's when Swedish Investigator Pallin used the gravity model to determine traffic flaws and used a distance exponent of two to solve for trip distribution (Transportation, 1983). Then a short time later, Alan Voorhees adapted the concepts of Netwon's equation and applied them to predict traffic patterns based on land used in "A General Theory of Traffic Movement” (Voorhees, 1955). 


$$
\begin{aligned}
& \qquad F=G \frac{m_{1} m_{2}}{r^{2}} \\
& \mathrm{~F}=\text { Force (pull) between the masses } \\
& \mathrm{G}=\text { Gravitational constant } \\
& m_{1}=\text { Mass of object one } \\
& m_{2}=\text { Mass of object two }
\end{aligned}
$$

As stated previously, the objective of the gravity model is to solve for the number of trips that will travel between two zones. To solve for the number of cars that will travel from their origin to other zones, the number of trips that each zone attracts, the number of trip produced by the origin, the impedance (friction) factor, and sometimes a socioeconomic factor must be known. The impedance factor is typically a function of the travel time, which is most commonly used, or cost associated between the two zones. The socioeconomic factor includes the economic and social factors that influence the movement of people. The gravity model equation (Eq. 2) is shown below.

$$
\begin{gathered}
\qquad T_{i j}=P_{i} * \frac{A_{j} F_{i j} k_{i j}}{\sum_{i=n}\left(A_{j} F_{i j} k_{i j}\right)} \\
\mathrm{T}_{i j}=\text { Number of trips from zone } i \text { to zone } j \\
\mathrm{P}_{i}=\text { Number of trip productions generated from zone } i \\
\mathrm{~A}_{j}=\text { Number of trips attracted by zone } j \\
\mathrm{~F}_{i j}=\text { Friction Factor from zone } i \text { to zone } j \\
\mathrm{k}_{i j}=\text { Socioeconomic factor from zone } i \text { to zone } j
\end{gathered}
$$

Travel time represents the spatial separation between the zones. The farther away something is the less likely or less attracted someone is to travel there. Multiple routes can be used to arrive at the same destination and the path that results in the least amount of time is the path used for the travel time calculation. The friction factor can be calculated several ways and usually a trial and error process is performed. The general formula that is typically used is provided (Eq. 3). The value of $\alpha$ is usually around two but varies depending on the purpose of the 
trip. All gravity models require calibration to ensure that the theoretical relationships match existing conditions. One limitation of the gravity model is it cannot be confirmed scientifically and is an observation-based model.

$$
\begin{gathered}
\qquad F_{i j}=C_{i j}{ }^{-\alpha} \\
\mathrm{C}_{i j}=\text { Time travel from zone } i \text { to zone } j \\
\alpha=\text { calibration factor (usually around 2) }
\end{gathered}
$$

The application of the gravity model to water distribution system was believed to be feasible and reasonable for several reasons. The first being the primary objective of the gravity model applied to transportation systems matches the goal of solving for the distribution of node outflow. Instead of solving for the distribution of traffic outflow to every destination, gravity model applied to a distribution system would solve for the distribution of outflow at every node. Although the water distribution systems lack the human interaction that the gravity model replicates, the principals of the theory should still apply. The outflow of a node is more likely to supply to a node with close proximity and relatively low resistance factor, than a node across the entire system with a relatively high resistance factor. Despite not being able to confirm the gravity model mathematically, its flexibility and applicability make it the most commonly used trip distribution method. The gravity model has also already been applied to several other fields including economics and marketing.

To apply the gravity model to a water distribution application, the variables required adjustment. Instead of solving for the number cars moving from one region to another, trip distribution, the goal was to solve for the flow 'supplied' by one junction (demand node) to another, coined Flow Distribution. 'Supplied' in this context means the water is a junction's outflow. The number of trip productions from a zone was substituted by the outflow of the node. Demand replaced the number of trips attracted by a zone. The friction factor from one zone to another was modeled by taking the path of least resistance, and is explained in detail in the subsequent paragraph. The socioeconomic factor was not used in this study's application of Flow 
Distribution, but could be utilized to implement critical infrastructure. The modified gravity model or Flow Distribution equation is shown in Eq. 4.

$$
\begin{aligned}
& \qquad F_{i j}=O_{i} * \frac{D_{j} I_{i j}}{\sum\left(D_{j} I_{i j}\right)} \\
& \mathrm{F}_{i j}=\text { Flow supplied from junction } i \text { to junction } j \\
& \mathrm{O}_{i}=\text { Outflow at junction } i \\
& D_{j}=\text { Demand at junction } j \\
& \mathrm{I}_{i j}=\text { Impedance from junction } i \text { to junction } j
\end{aligned}
$$

The impedance variable is a function of the pipe resistance factor and was calculated with the equation shown below (Eq. 5). Resistance factor refers to the pipe characteristics that contribute to friction loss. Three methods can be used to calculate friction loss: Hazen-Williams equation, Manning's equation, and Darcy-Weisbach equation. Hazen-Williams (Eq. 6) was used because, as will be discussed shortly, the hypothetical city used to test the gravity model had the C-factor coefficients available for the pipes. If another method were to be used, information on the Darcy's friction factor or Manning's roughness coefficient would have been necessary. The minimum sum of resistance factors from one node to another is used, which assumes that all the flow that one node provides to another is supplied through the route of minimum resistance. As stated previously, $\alpha$ is typically found through calibration, but for this study, it was assumed a value of two.

$$
I_{i j}=\frac{1}{\min \sum R_{i j}^{\alpha}}
$$

$\mathrm{R}=$ Pipe resistance for each pipe

$\alpha=$ Calibration factor (assumed to be 2)

$$
R=\left[\frac{\phi L}{C^{1.85} D^{4.87}}\right]
$$

$\phi=4.73$ for U.S. Units \& 10.66 for SI units

$$
\mathrm{D}=\text { Diameter of pipe (ft or } \mathrm{m})
$$




$$
\begin{aligned}
& \mathrm{C}=\text { Hazen-Williams roughness coefficient } \\
& \mathrm{L}=\text { Length }(\mathrm{ft} \text { or } \mathrm{m})
\end{aligned}
$$

\subsubsection{Calibration}

Calibrating the gravity model consists of identifying the trip types occurring for each zone. Then for each type of trip, a different calibration factor is used. A crucial part of gravity model calibration is properly identifying and linking trips to the correct trip type so the proper calibration factor is used. The calibration factors are solved using an iterative approach by adjusting the calibration factor until the model data closely resembles observed data.

This study hypothesized that the results yielded from Flow Distribution using the standard $\alpha$ factor of two would produce results accurate enough to determine if Flow Distribution is suitable to determine critical nodes in a distribution system. The calibration of $\alpha$ would correlate the node outflows that Flow Distribution predicts to the modeled or actual node outflows. Calibrating Flow Distribution would be difficult because of the dynamic variables that constantly change throughout the 24-hour simulation and was believed to be outside the scope of this research. Several methods and approaches could be utilized for calibration when using Flow Distribution and recommended for future research.

\subsubsection{Demand and Population Affected}

Applying Flow Distribution calculates the amount of flow that each node supplies to every other node. A simple equation (Eq. 7) was applied to predict the amount of demand and population affected if a node were disabled. The amount of flow that node ' $i$ ' supplies to node ' $j$ ' is divided by the inflow of node ' $j$ ' and then multiplied by the population or demand at node ' $j$ '.

$$
\operatorname{DemAff} f_{i j}=\frac{F_{i j}}{I_{j}} * D_{j}
$$

$\operatorname{DemAff}_{i j}=$ Predicted demand affected by node $i$ on node $j$

$\mathrm{F}_{i j}=$ Flow distributed from node $i$ to node $j$ 


$$
\begin{aligned}
& \mathrm{I}_{j}=\text { Inflow at node } j \\
& \mathrm{D}_{j}=\text { Demand at node } j
\end{aligned}
$$

If the population affected were desired, the equation would be multiplied by the population at node $j$ instead of the demand at node $j$.

This research is aware of the simplicity of the equation and that it assumes that if a node were to be disabled than all the water that previously passed through it would not reach any of the nodes in the distribution system. In practice, it is possible for a WDS with an average degree of redundancy and pressure to redirect the water to meet the demands of the system. This equation was not expected to solve for the actual demand or population affected, but to determine the nodes that would have the most impact. This study assumes that nodes that supplied the most demand and/ or served the most population in the distribution system would cause the greatest impact to the system because it would force the greatest quantity of water to be rerouted to meet the demands of the system (that might or might not be possible).

\subsubsection{Critical Infrastructure}

Critical infrastructure in a water distribution system includes facilities that are vital to the function of the city or is valued high by the city. For example, school, hospitals, fire departments, and community centers may be considered critical infrastructure. This research wanted to incorporate a way to value nodes that supplied to critical infrastructure. Implementing a critical infrastructure factor is important because a node's importance is not solely dependent on the demand and population it supplies. The ramifications for the demand of a node that supplies to a critical infrastructure may be greater than a node that solely supplies to the general population. For example, a node that supplies water to a hospital that cannot meet its demands would be more detrimental then a node supplying water to a golf course, especially during a disaster scenario.

One way to accomplish this is to adopt Jun's (Jun, et al., 2008) method that assigns an equivalent number of customers to each critical infrastructure (i.e. one school could equal one 
thousand households). The equivalent number would be based on the modeler's judgment and may be difficult to quantify. Another way incorporate the importance of critical infrastructure is to develop a factor that would be used in the Flow Distribution equation in place of the socioeconomic factor that is used in the gravity model.

Although critical infrastructure is important, it was not modeled and implemented in this research because a hypothetical system was used. If a real distribution system is modeled critical infrastructure should be considered and Flow Distribution allows several different ways for critical infrastructure to be incorporated.

\subsection{Theory}

The main way to show whether the gravity model could be used to identify critical nodes in a distribution system was to apply it to a hypothetical city, simulate disaster scenarios, and compare the predicted and measured results. Before the model, programs, and process used to test Flow Distribution are discussed, the theory behind the analysis tools are explained in the next sections. The following paragraphs will explain the basic hydraulic principles such as the conservation of mass and energy, friction and minor losses, pumps, network hydraulics.

\subsubsection{Conservation of Mass}

Network analysis was derived primarily from two basic laws of physics, the Law of Conservation of Mass, and the Law of Conservation of Energy. These basic laws can be applied to any control volume of fluid and the energy and mass within that system must be conserved. The basic idea of The Law of Conservation of Mass or continuity states the inflow minus the outflow equals the storage within the control volume. For pipe flow, this means what goes in must come out. Figure 3 helps explain the continuity equation for pipe flow. For this continuity equation to be valid, it is assumed that water is incompressible. 


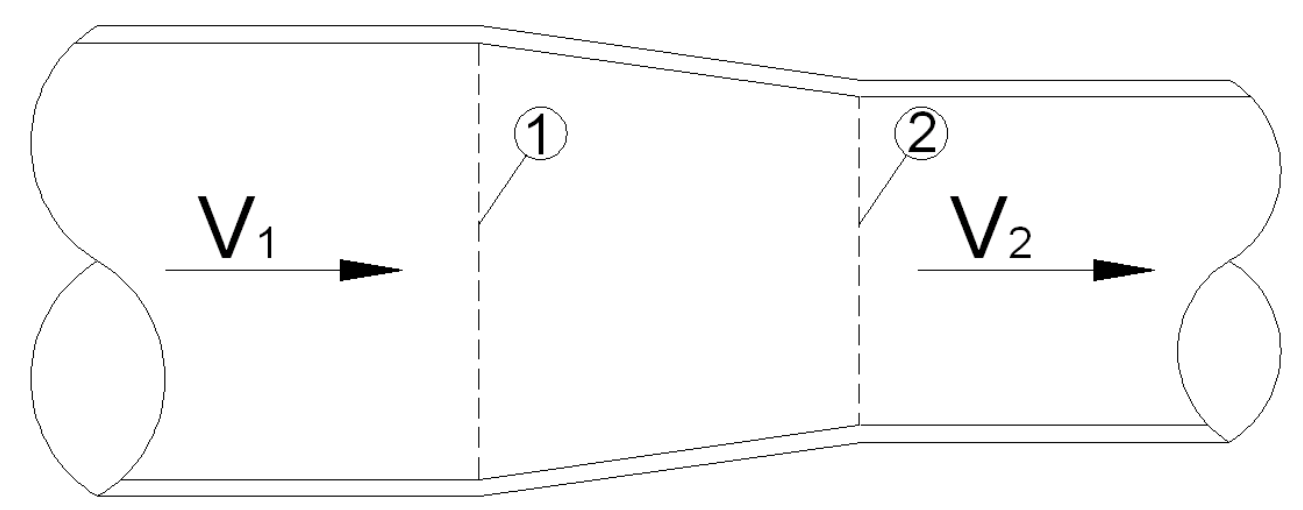

Figure 3: Continuity Diagram

$$
\begin{gathered}
A_{1} V_{1}=A_{2} V_{2} \\
\mathrm{~V}=\text { average velocity }(\mathrm{ft} / \mathrm{sec}) \\
\mathrm{A}=\text { cross-sectional area }\left(\mathrm{ft}^{2}\right)
\end{gathered}
$$

\subsubsection{Conservation of Energy}

The Principle of Conservation of Energy states energy can neither be created nor be destroyed. Thus, the energy difference between two points is the same regardless of the path taken. The energy in pipe flow is typically described in terms of head. The energy at any point in a distribution system is the sum of three components, pressure head, velocity head, and elevation head. In a frictionless environment, the energy between two points can be described with the following equation.

$$
\begin{aligned}
& \frac{P_{1}}{\gamma}+\frac{V_{1}^{2}}{2 g}+z_{1}=\frac{P_{2}}{\gamma}+\frac{V_{2}^{2}}{2 g}+z_{2} \\
& \mathrm{P}=\text { Pressure }(\mathrm{psf} \text { or } \mathrm{Pa}) \\
& \mathrm{V}=\text { Velocity }(\mathrm{ft} / \mathrm{sec}, \mathrm{m} / \mathrm{s}) \\
& \mathrm{z}=\text { Elevation }(\mathrm{ft}, \mathrm{m}) \\
& \mathrm{g}=\text { gravitational acceleration constant }\left(32.2 \mathrm{ft} / \mathrm{sec}^{2}, 9.81 \mathrm{~m} / \mathrm{sec}^{2}\right) \\
& \mathrm{Y}=\text { Specific weight of water }\left(\mathrm{lb} / \mathrm{ft}^{3}, \mathrm{~N} / \mathrm{m}^{3}\right)
\end{aligned}
$$




\subsubsection{Flow Classification}

Water flow is influenced by several different factors including time, space, viscosity, and gravity. This subsection will describe the various classifications for both pipe and open channel flow, and discuss the classifications that are standard for pipe hydraulics. Table 1 below shows the various classifications for both pipe flow and open channel flow and the subsequent paragraph defines each term.

Table 1: Flow Classification

\begin{tabular}{cl}
\hline Classification Criteria & Flow Classification \\
\hline \hline Time & $\begin{array}{l}\text { Steady Flow } \\
\text { Unsteady Flow }\end{array}$ \\
\hline & Uniform Flow \\
Space & Nonuniform Flow \\
& Gradually Varied \\
& Rapidly Varied \\
\hline \multirow{2}{*}{ Viscosity } & Laminar \\
& Turbulent \\
& Transitional \\
\hline & Subcritical \\
Gravity & Critical \\
& Supercritcal
\end{tabular}

Steady flow occurs when the velocity does not vary in magnitude or in direction with respect to time at any point in the flow. Unsteady flow happens when the velocity at a point in the flow varies in magnitude or direction with respect to time. Flow is uniform flow when the velocity is constant (both magnitude and direction) at every point and the flow is non-uniform if the velocity is not the same at every point. Gradually varied and rapidly varied flows are the two types of non-uniform flow. Rapidly varied flow occurs when there is a substantial depth of flow and hence velocity changes over short distance and gradually varied flow occurs when the depth and velocity of flow changes gradually over a long distance. Both rapidly varied and gradually varied flow are typically used when describing open channel flow. Turbulent flow is created by eddies of varying size within the flow creating vigorous mixing. A fully turbulent flow is random, 
chaotic, and cannot be repeated. Laminar flow travels smoothly and in regular paths. Transitional flow is when the flow is in between laminar flow and turbulent flow. Reynold's number, discussed later, can be used to determine if the flow is laminar or turbulent. Subcritical, critical, and supercritical are typically used to describe open channel flows and can be distinguished by the Froude number. Subcritical flow has high flow depth and low velocity while supercritical flow has low depth with high flow velocity.

Pipe flow is typically pressurized resulting in the classification of steady, turbulent or laminar, and non-uniform flow. It is possible for pipe flow to act similar to open channel flow if the pipe is not full and is gravity driven, but typically, pipe flow refers to full conduit flow under pressure.

\subsubsection{Friction Loss}

As water flows through a pipe, friction loss will occur. Three different formulas are widely used for this computation of friction loss: Darcy-Weisbach, Hazen-Williams, and Manning's equation. In 1845, Julius Weisbach published the Darcy Weisbach equation, which uses dimensional analysis and a friction factor $f$ to account for pipe characteristics such as

material and roughness (Brown, 2000). The Darcy Weisbach (Eq. 10) is most commonly used in Europe.

$$
\begin{gathered}
\qquad h_{L}=f \frac{L V^{2}}{D 2 g} \\
\mathrm{f}=\text { friction factor } \\
\mathrm{L}=\text { Length of pipe }(\mathrm{ft}, \mathrm{m}) \\
\mathrm{V}=\text { Average velocity }(\mathrm{ft} / \mathrm{sec}, \mathrm{m} / \mathrm{sec}) \\
\mathrm{D}=\text { Diameter of pipe }(\mathrm{ft}, \mathrm{m}) \\
\mathrm{g}=\text { Gravitational acceleration }\left(\mathrm{ft} / \mathrm{sec}^{2}, \mathrm{~m} / \mathrm{sec}^{2}\right)
\end{gathered}
$$


Friction factor can be found using several equations. One of the first and most common formulas is Colebrook-White's equation (Eq. 11).The friction factor is most widely commonly found using the Moody diagram (Figure 4). To solve for the friction factor using the Moody diagram, Reynolds number (Eq. 12), the pipe roughness height, and pipe diameter must be known. One disadvantage in using the Darcy-Weisbach equation is that the friction factor usually requires an iterative approach to be solved.

$$
\begin{aligned}
& \frac{1}{\sqrt{f}}=-0.86 \ln \left(\frac{\varepsilon}{3.7 D}+\frac{2.51}{R e \sqrt{f}}\right) \\
& f=\text { friction factor } \\
& \varepsilon=\text { relative roughness }(\mathrm{ft}, \mathrm{m}) \\
& R e=\text { Reynolds Number } \\
& \qquad R e=\frac{V D}{v} \\
& \mathrm{~V}=\text { Average Velocity }(\mathrm{ft} / \mathrm{sec}, \mathrm{m} / \mathrm{sec}) \\
& \mathrm{D}=\text { Diameter }(\mathrm{ft}, \mathrm{m}) \\
& \nu=\text { Kinematic Viscosity }\left(\mathrm{ft}^{2} / \mathrm{sec}, \mathrm{m}^{2} / \mathrm{sec}\right)
\end{aligned}
$$




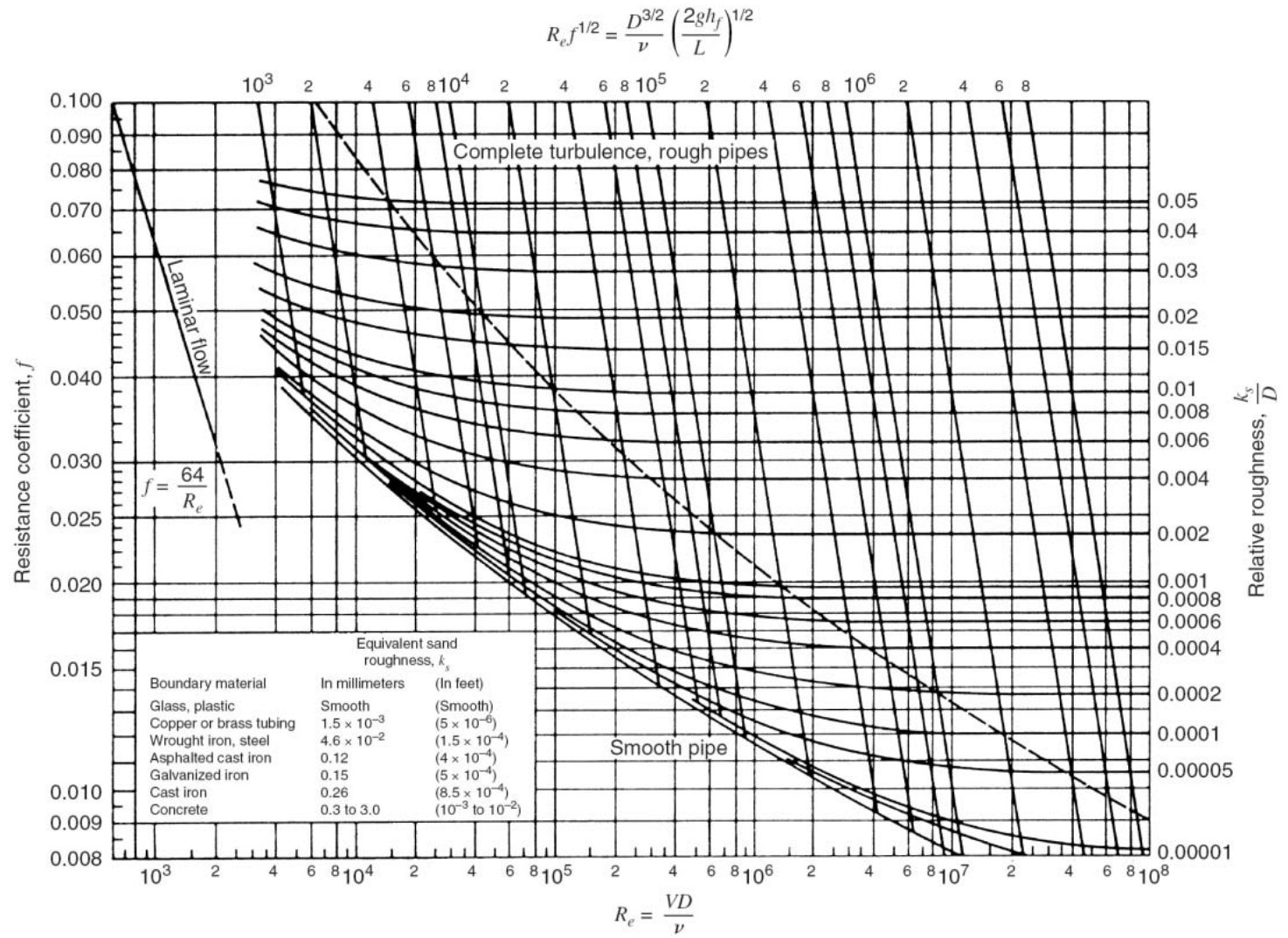

Figure 4: Moody Diagram

Hazen-Williams equation is an empirically based equation and uses similar variables as the Darcy-Weisbach, but except a C-factor based on pipe material, diameter and condition is used in place of a friction factor. C-factors can be found in tables and the higher the factor the lower the friction loss. The Hazen-Williams equation was formed in the early 1900's by Gardner Williams and Alan Hazen. The Hazen-Williams equation (Eq. 13) is the most commonly used friction loss formula in the United States (Martorano, 2006).

$$
h_{L}=\frac{\varphi L}{C^{1.852} D^{4.87}} Q^{1.852}
$$

$$
\begin{aligned}
& \mathrm{C}=\text { Hazen-Williams roughness coefficient } \\
& \mathrm{L}=\text { Length of pipe }(\mathrm{ft}, \mathrm{m}) \\
& \mathrm{Q}=\text { Flow rate }(\mathrm{cfs}, \mathrm{cms}) \\
& \mathrm{D}=\text { Diameter }(\mathrm{ft}, \mathrm{m})
\end{aligned}
$$




$$
\varphi=\text { Unit conversion factor (4.73 for English units, } 10.7 \text { for SI) }
$$

Robert Manning developed another empirically based formula in 1889 known as Manning's equation (Fishenich, 2000). Manning's equation utilizes roughness coefficients that can be found in tables, and the higher the coefficient the rougher the material. Manning's equation is primarily used for open-channel flow, and is rarely used for distribution systems, mainly used in Australia. Manning's equations is shown below.

$$
\begin{aligned}
& \qquad h_{L}=\frac{C_{f} L(n Q)^{2}}{D^{5.33}} \\
& \mathrm{C}_{\mathrm{f}}=\text { Unit conversion factor (4.66 for English units, } 10.29 \text { for SI) } \\
& L=\text { Length (ft, m) } \\
& n=\text { Manning's coefficient } \\
& Q=\text { Flow rate (cfs, cms) } \\
& D=\text { Diameter (ft, m) }
\end{aligned}
$$

Hazen-Williams was the friction loss formula used in present study as it is most commonly used in the United States, and the C-Factors for the test city were given.

\subsubsection{Minor Losses}

Minor losses are caused by valves, fittings, bends and other accessories in WDS. Minor losses can be calculated by multiplying the velocity head by a minor loss coefficient as shown in Eq. 15. Minor loss coefficients are determined experimentally by the manufacturer of the equipment.

$$
\begin{gathered}
h_{l m}=K_{L} \frac{V^{2}}{2 g} \\
K_{L}=\text { minor loss coefficient }
\end{gathered}
$$

In water distribution systems, losses due to friction are generally much greater than minor losses. Due to their relative insignificance, modelers frequently choose to neglect minor losses (Walski, et al., 2007). Minor losses in this study were ignored because of their relative 
insignificance and lack of information about the hypothetical city (Anytown). Minor losses can be included in the resistance equation (Eq. 16) by adding the below equation.

$$
\left[\frac{K_{L}}{2 g\left(\frac{\pi}{4} D^{2}\right)^{2}}\right]
$$

\subsubsection{Pumps}

The most common input of energy into a system is through pumping. Pumps are crucial to any distribution system that cannot supply acceptable pressures to consumer through the sole use of gravity flow. The most common pump used in water distribution system is a centrifugal pump because of their low cost, simplicity and reliability (Mays, 2005).

Pump selection is typically dictated by rotational speed, discharge capacity, pumping head, power input, and efficiency. Pump efficiencies influence the pump operating cost, and the higher the efficiency the cheaper the cost of operation. Pump efficiency is determined by the ratio of power delivered to the water to power input to the pump. The manufacturer develops and provides pump curves like the one shown in Figure 5. Pump curves show the head versus discharge relationship as well as the pump efficiencies. The pump curves for a pump of specific

diameter/ size operating at a single speed can be approximated by using that quadratic equation (Equation 17). 


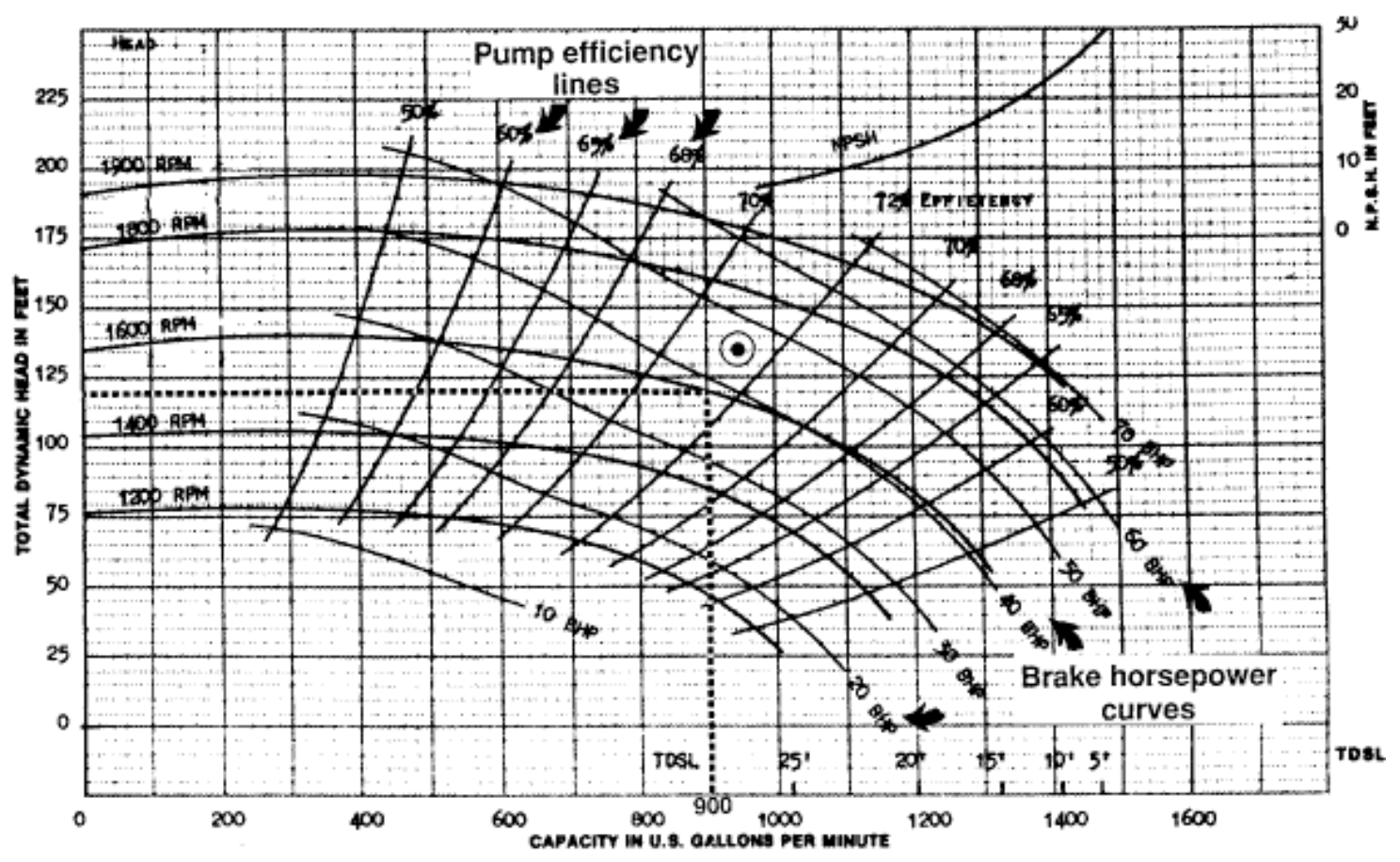

Figure 5: Typical Pump Curve

$$
E_{p}=A Q^{2}+B Q=H_{c}
$$

$$
\begin{aligned}
& E_{P}=\text { Pump head }(\mathrm{ft}, \mathrm{m}) \\
& \mathrm{A}, \mathrm{B}=\text { Pump Coefficients } \\
& \mathrm{Q}=\text { Pump Discharge }(\mathrm{cfs}, \mathrm{cms}) \\
& \mathrm{H}_{\mathrm{c}}=\text { Pump Cutoff Head }(\mathrm{ft}, \mathrm{m})
\end{aligned}
$$

Many pumps have motors that spin at a constant speed regardless of the head and flow demands of the system. If the system demand has highly variable demands, these pumps become extremely inefficient. To counteract that, many distribution systems utilize variable frequency drives (VFDs) that change the speed of the impeller(s) based upon system demands. To predict the VFD outputs the affinity laws (Eqs. 18-20) must be utilized in the design and pump selection.

$$
\begin{gathered}
\frac{Q_{1}}{Q_{2}}=\frac{n_{1}}{n_{2}} \\
\frac{H_{1}}{H_{2}}=\left(\frac{n_{1}}{n_{2}}\right)^{2}
\end{gathered}
$$




$$
\begin{gathered}
\frac{P_{1}}{P_{2}}=\left(\frac{n_{1}}{n_{2}}\right)^{3} \\
\mathrm{Q}=\text { Pump Discharge }(\mathrm{cfs}, \mathrm{cms}) \\
\mathrm{H}=\text { Pump Head }(\mathrm{ft}, \mathrm{m}) \\
\mathrm{P}=\text { Pump Power }(\mathrm{hp}, \mathrm{kW}) \\
n=\text { Impeller Rotational Speed (rpm) }
\end{gathered}
$$

Many situations require two or more pumps to increase the amount of flow, pressure or both to meet the demands of the water system. A pump in series usually refers to multiple impellers installed inline in the same pump or a booster pump installed further down the pipeline. Either way, the head-capacity pump curve is obtained by adding the heads of the individual pumps or impellers together, while the flow rate remains the same. A pump in parallel refers to pumps that are not inline but their discharge flows into a common pipe or header. When pumps are in parallel, the flow rates for each pump are added together while the head remains the same.

\subsubsection{Network Hydraulics}

Distribution systems consist of a large set of pipes and nodes that has to be solved with a number of energy and continuity equations. Energy equation each loop and a continuity equation for each node must be solved. A small to medium size distribution system could require thousands of equations to be solved simultaneously. A systematic approach was first developed by Hardy Cross in 1936 (Ormsbee, 2006). This method divides the system into several closed loops, assumes initial flow rates to satisfy, and then uses successive iterations to solve for a flow correction until convergence. Several other methods have been developed with the advancement of computers, which solve the system of equations by utilizing matrices. The linear theory method is one of the most commonly used and most efficient matrix based methods. In 1972, Wood and Charles presented the linear theory, which solves for the continuity and head loss equations simultaneously (Ormsbee, 2006). This technique consists of a very stable procedure and nearly always converges on a solution. 


\subsection{Modeling}

This section will detail the hypothetical city that was chosen for analysis and the programs utilized to apply and test Flow Distribution method.

\subsubsection{Anytown, USA}

The hypothetical city chosen to apply Flow Distribution was Anytown, USA. This hypothetical community was developed for the 'Battle of the Networks', a series of sessions that occurred at the "Computer in Water Resources" conference held in Buffalo, New York in 1985. It was the intention that Anytown would resemble and function like many real systems and solutions to the problems developed for the conference sessions could be applied to actual systems (Walski, et al., 1987).

Even though Anytown was the hypothetical city chosen for this study to apply Flow Distribution, several other options were also available such as creating a new hypothetical city, using a real water distribution system with GIS, or using a different model that has already been used for other research. Creating a new city is difficult because the schematic layout, component characteristics, demands patterns, and pump curves would need to be designed. It is important that the system used resembled a real system and creating a new model city seemed unnecessary since many other models already exist. Using a real WDS presents challenges as well because of the increased security concerns, obtaining water distribution layout, demand patterns, and component information is very difficult. Even if all that data were obtained, a connectivity analysis would need to be performed to ensure that all the pipes and nodes are properly connected. The model would also have to be calibrated so the observed data is the same as the modeled data. Skeletonization (explained later) would also be necessary so the analysis would be manageable.

Anytown was chosen instead of other model cities because of its resemblance to a real system. It has elevated storage, pumping station, pre-designed pumps to account for varying 
demands, and was simple enough to perform the detailed analysis that was desired yet complicated enough that the critical nodes could not be easily identified. Anytown has been used to simulate a real distribution system when testing other methods. Anytown consists of one reservoir, two storage tanks, one pumping station, sixteen demand nodes, and forty pipes. The pumping station consists of two operational constant speed centrifugal pumps in parallel. Three pumps are shown, but the system was designed to meet demands with only two operational pumps. Figure 6 is a schematic layout of the city.

It may be advantageous to solve for the nodes that affect the most population, not demand, because nodes with the highest demand may be supplying water to industrial or commercial entities with minimal human consumption. Based on Anytown's average daily demand and the amount of water of water used per person stated by the EPA of 183 gallons per day (EPA, 2004), Anytown was calculated to have a population of 50,000 people. Using Excel, a random population value was assigned to each node, independent of the node's demand. Realistically, the amount of demand and population supplied are related, but using this approach would show that if they aren't Flow Distribution could still be applied. 


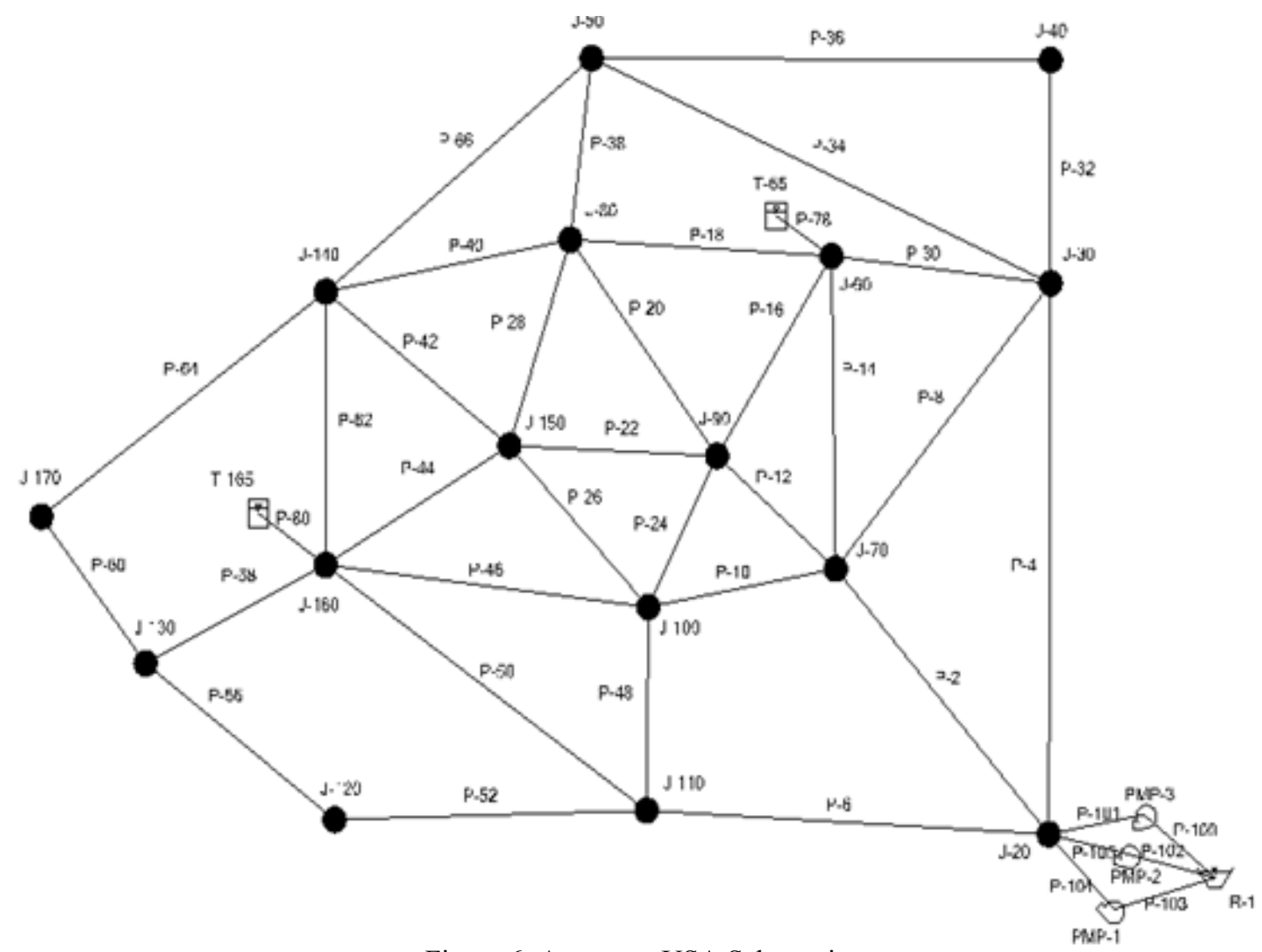

Figure 6: Anytown, USA Schematic

\subsubsection{Skeletonization}

For most urban distribution systems, water is extracted from a very large number of demand nodes. It would unreasonable to analyze a system with that degree of detail. If one were to model a real distribution system, skelontization would need to be implemented. Skelonitzation is the process of eliminating insignificant parts of a distribution system that do not affect the behavior of system. When a pipe or node is eliminated the flow and demand are distributed to the nearby nodes. For example, pipes in a neighborhood that supply water to each household, once eliminated, their flow may be distributed to a few nodes at street intersections. Modeling judgment plays a key role in determining which pipes should be eliminated because definitive criteria does not exist for determining whether something should be included in the model analysis. Almost all models are skeletonized to some degree and should always be considered so 
modeling is feasible with a practical amount of detail. Anytown is a model city that only consists of larger diameter pipe, meaning skeletonization has already been implemented.

\subsubsection{WaterCAD}

In order to model Anytown and solve its complex set of equations, a computer simulation program was required. Several viable options are commercially available such as the United States Environmental Protection Agency's EPANET, Bentley's WaterCAD, and MWH's H2Onet. Any water distribution analysis program can be used for the proposed method. EPANET seemed to be the program of choice in most studies because of its free availability to the public.

WaterCAD allows users to design and analyze water distribution systems with its unique scenario management center, easy-to-use interface, versatility, and conversion capability between CAD, GIS, and other databases (Bentley, 2012). The scenario management tool allows the modeler to configure, analyze, and visualize multiple scenarios within one file. WaterCAD is capable of performing steady state and extended period simulations, as well as, offer three options for calculating friction loss through a pipe.

WaterCAD V8i was chosen because it is user friendly and is available at Cal Poly. The researchers also had familiarity with the program and it can be used in congruence with GIS. GIS is a program designed to store, manage, and analyze geographically referenced data sources to reveal trends, patterns, and relationships. GIS programs are commonly used by cities and counties to store the needed information to apply this method. WaterCAD would allow cities and counties to import their GIS data.

\subsubsection{Water Characteristics}

To simulate real world conditions, water characteristics needed to be considered. Water temperature affects several water characteristics such as specific weight and viscosity. For this simulation, the standard WaterCAD temperature of sixty-eight degree Fahrenheit was assumed constant throughout the entire distribution system. At 68 degrees, the kinematic velocity is 1.004 
$\mathrm{x} 10^{-6}$ and a specific weight of $62.314 \mathrm{lb} / \mathrm{ft}^{3}$. It is also assumed that the temperature of the water remains constant throughout the day, which is a simplification because over a 24 -hour period the temperature will fluctuate. Despite the fluctuation the same value was used because if the fluctuations in temperature were considered the results would vary minimally.

\subsubsection{Network Simulation}

WaterCAD is capable of performing two types of simulations, steady state and extendedperiod. Steady-state simulation is the simplest simulation type and solves the system of equations as if the system is in equilibrium. In other words, the dynamic variables such as pipe flows, junction demands, and tank elevations are kept constant. Steady-state simulations are commonly used to model peak demands or a short time period.

Extended-period simulations break up the simulation into time-steps. Each time step may feature different values for the dynamic variables (tank levels, pump operation, and junction demand). Real distribution systems have variable properties especially demand patterns; the amount of water that is consumed in the morning when everyone is getting ready for work is different at midnight. An extended period simulation models the variability of real water distribution systems, and was the simulation chosen for this study. The extended-period simulation was chosen for this analysis because of its capability to model varying demands. The total simulation time was 24 hours with a one-hour time-step.

\subsubsection{MatLab}

One limitation with WaterCAD is it does not allow you to modify the flex tables (tables that store system information) to create your own equations and solve for different variables. A different program had to be utilized to implement Flow Distribution. This program needed to run an analysis on information that could be imported from WaterCAD and then the results exported to Excel for documentation. Many computing languages would accomplish this task, but Matlab was the program chosen because of its availability and working experience of the researcher. 
Matlab was created by Cleve Moler in 1976 as a simple educational program, but it did not become commercially available until 1984 (Haigh, 2008). Matlab is one of the most popular programs with students in the applied mathematics and engineering industries. Matlab features hundreds of built in commands that allow users to solve complex numerical equations without the need for tricky and time-consuming programming. Matlab also allows users to document easily their results with 2D and 3D graphics.

Matlab was used to perform the Flow Distribution aspect of the method. The Matlab program automatically imports the necessary information from the specified Excel file, runs the Flow Distribution, and exports the results to Excel. The most important aspect of the Matlab code was the use of undirected biograph. This was used to solve for the minimum path of resistance. Two options were available, directed and undirected. Directed restricts the path from only going in the current direction of pipe flow and undirected allows the path to go in any direction. Undirected was chosen because when a pipe or node is disabled water is not restricted (unless by a valve) to meet the demands of a node by traveling in the opposite direction it was during normal operating conditions. Figure 7 shows the undirected graph that Matlab generated. The numbers next to each line are the calculated resistance value. The code in its entirety is provided in Appendix A. 


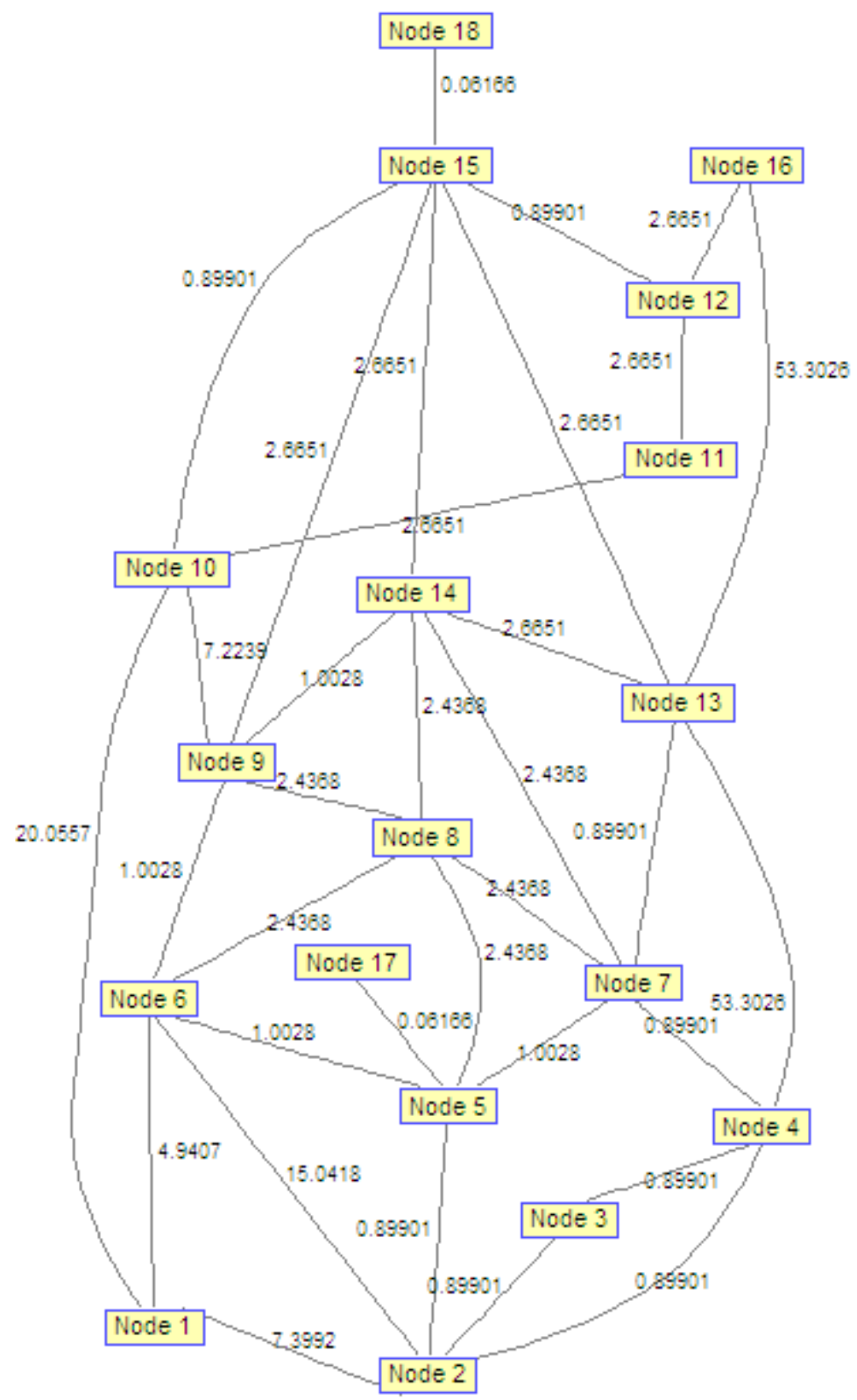

Figure 7: Biograph of Undirected Graph

\subsubsection{Disaster Scenarios}

To apply and test the Flow Distribution method two different disaster scenarios were modeled. As stated previously, disaster scenario incorporates possible adverse effects of a real life disaster such as fires, nonoperational pumps, unconnected tanks, and disabled nodes. Disaster scenarios are system specific and if this method were to be applied to a real system, the disaster 
scenarios would need to be developed by the modeler, and should reflect feasible threats and possible risks that exist for that system.

It is impossible to predict correctly the adverse effects caused by natural disasters or terrorist attacks. A few adverse effects are junctions and nodes can be disabled, fires can start, and the region can be without power. This research wanted to model disaster scenarios that were feasible and likely to occur to any distribution system. The other goal was to create different disaster scenarios that would should Flow Distribution is suitable for a variety of disaster scenarios.

Although it is impossible to predict the adverse effects of damaging events, this study wanted to model a disruption that would cause a system failure. Disruptions from natural disasters or terrorist attacks can be modeled in several ways including disabling one junction or pipe, a random set of junctions or pipes, and a group of adjacent pipes or junctions. Other studies used pipe break data, or accessibility information to equate probabilities for each pipe and/ or junction failure. For this research, the probability for a node failure was the same for each junction because the goal was to determine the critical nodes regardless of the probability of their failure occurring. The modeler, as a conclusion of the study, could deem the critical nodes predicted by Flow Distribution unlikely to fail and not use its resources to strengthen that part of the system. For this research, the disaster scenarios were created to feature one disabled node, meaning Flow distribution would be solving for the most critical nodes not pipes or group of pipes or nodes. One node was deemed appropriate because Anytown, and most models of real distribution systems, features a skeletonized network, meaning one junction or pipe failure is really the loss of flow/ demand of multiple pipes and nodes.

\subsubsection{Disaster Scenario 1}

The first disaster scenario would model a moderate disaster, only one node would be disabled, and one fire would be created at node 120 of 1000 gallons per minute (gpm). Node 120 
and 1000 gpm were chosen because this node and fire flow was one of critical fires listed in the 'Battle of the Networks' (Walski, et al., 1987), so it seemed appropriate to use for a disaster scenario.

Most of Anytown's characteristics were unchanged for this simulation, except the pump curves were modified to meet equilibrium. With the original pump curves, the tanks did not fill up to their original starting elevation at the end of a 24-hour period and were drained (Figure 8). This is not realistic because storage tanks are designed to store water throughout the day and these tanks only stored water for a few hours, were empty the rest of the time, and never refilled to their original water level. The pump curves were adjusted using trial and error until the water level in each tank started at the same elevation every day for an entire week simulation (Figure 9). 


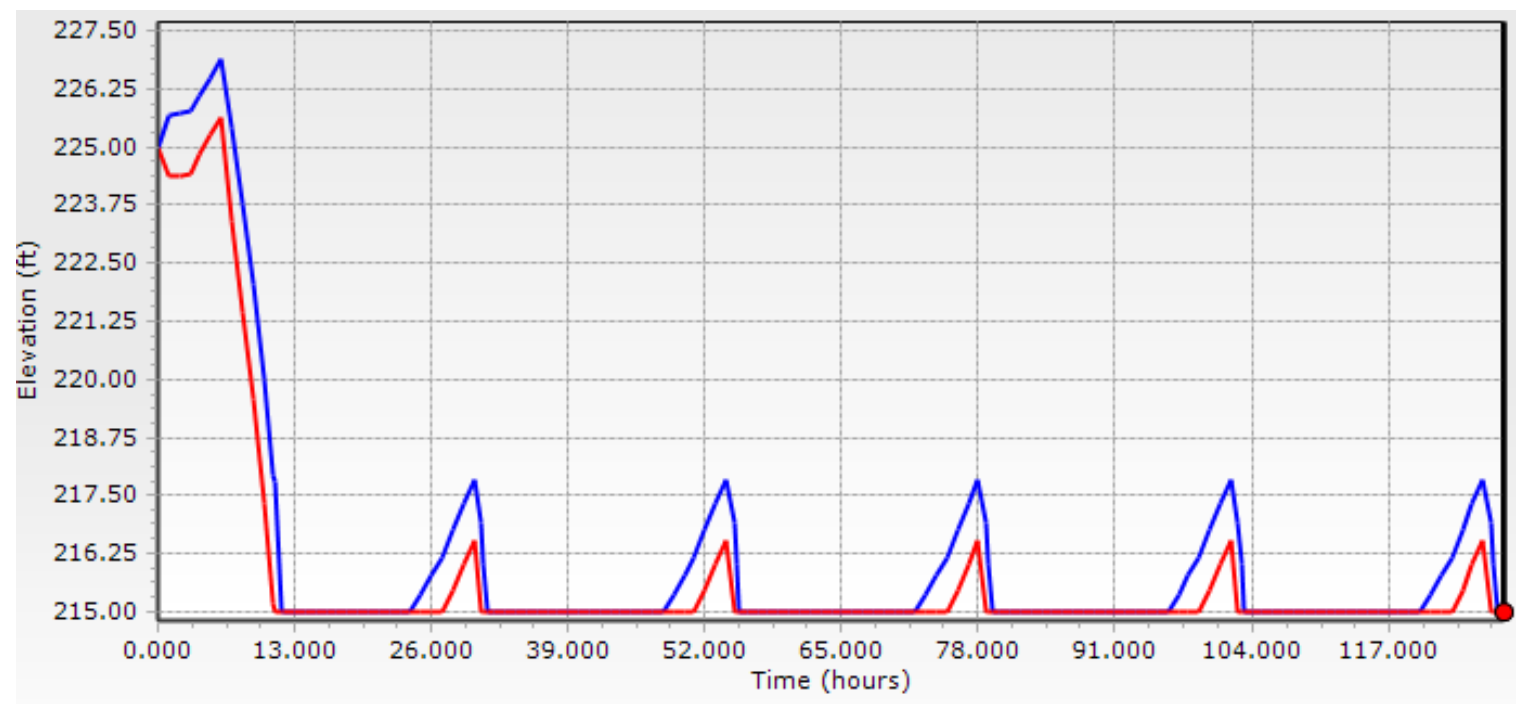

- T-65 - Full Load - Hydraulic Grade — T-165 - Full Load - Hydraulic Grade

Figure 8: Tanks' Hydraulic Grade Line with Original Pump Curve

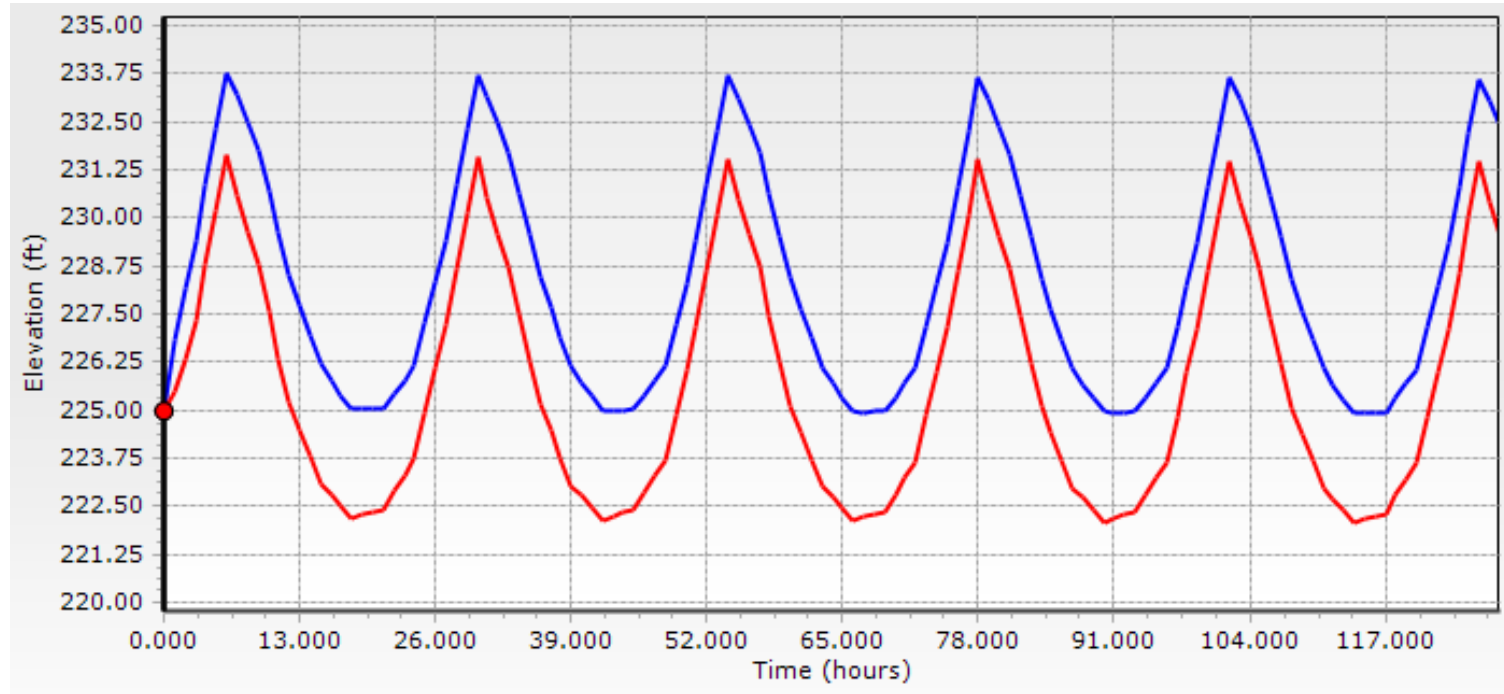

T-65 - Full Load - Hydraulic Grade — T-165 - Full Load - Hydraulic Grade

Figure 9: Tanks’ Hydraulic Grade Line with New Pump Curve

The tables on the following page (Table 2 - Table 5) display the pipe, junction, and tank characteristics, as well as the new pump curve that was developed and previously discussed. 
Table 2: Pipe Characteristics for Disaster Scenario 1

Pipe Length (ft) Diameter (in.) C-Factor

$\begin{array}{cccc}\text { P-2 } & 12,000.00 & 16 & 70 \\ \text { P-4 } & 12,000.00 & 12 & 120\end{array}$

$\begin{array}{llll}\text { P-4 } & 12,000.00 & 12 & 120\end{array}$

$\begin{array}{llll}P-6 & 12,000.00 & 12 & 70\end{array}$

$\begin{array}{lll}\text { P-8 } & 9,000.00 \quad 12\end{array}$

$\begin{array}{lll}\text { P-10 } & 600 & 12\end{array}$

P-12 $600 \quad 10$

P-14 600

P-16 600

P-18 600

P-20 600

P-22 600

P-24 600

P-26 600

P-28 600

P-30 600

P-32 600

P-34 600

P-36 600

P-38 600

P-40 600

P-42 600

P-44 600

P-46 600

P-48 600

P-50 600

P-52 600

P-56 600

P-58 600

P-60 600

P-62 600

P-64 12,000.00

P-66 12,000.00

P-78 100

P-80 100

P-100 1

P-101 1

P-102 1

P-103

P-104

P-105
70
70

70

70

70

70

70

70

70

70

70

70

120

120

120

120

120

120

120

120

120

70

120

120

120

120

120

120

120

120

120

120

130

130

130

130

130

130
Table 3: Junction Characteristics for Disaster Scenario 1

\begin{tabular}{ccc}
\hline $\begin{array}{c}\text { Node } \\
\text { Number }\end{array}$ & $\begin{array}{c}\text { Elevation } \\
\text { (ft.) }\end{array}$ & $\begin{array}{c}\text { Average Demand } \\
\text { (gal/min) }\end{array}$ \\
\hline J-20 & 50 & 500 \\
J-30 & 50 & 200 \\
J-40 & 50 & 200 \\
J-50 & 50 & 200 \\
J-60 & 50 & 500 \\
J-70 & 50 & 500 \\
J-80 & 50 & 500 \\
J-90 & 50 & 1,000 \\
J-100 & 50 & 500 \\
J-110 & 50 & 500 \\
J-120 & 50 & 200 \\
J-130 & 50 & 200 \\
J-140 & 50 & 200 \\
J-150 & 50 & 200 \\
J-160 & 50 & 800 \\
J-170 & 50 & 200
\end{tabular}

Table 4: Tank Characteristics Disaster Scenario 1

\begin{tabular}{ccccc} 
Tank & $\begin{array}{c}\text { Min. } \\
\text { Elev. }(\mathrm{ft})\end{array}$ & $\begin{array}{c}\text { Initial } \\
\text { Elev. }(\mathrm{ft})\end{array}$ & $\begin{array}{c}\text { Max. } \\
\text { Elev. }(\mathrm{ft})\end{array}$ & Dia. $(\mathrm{ft})$ \\
\hline T-165 & 215 & 225 & 250 & 90 \\
T-65 & 215 & 225 & 250 & 90
\end{tabular}

Table 5: Pump Curve for Disaster Scenario 1

Flow (gpm) Head (ft)

\begin{tabular}{cc}
\hline 0 & 375 \\
2,500 & 365 \\
5,000 & 337.5 \\
7,500 & 287.5 \\
10,000 & 226.25
\end{tabular}




\subsubsection{Disaster Scenario 2}

This research wanted to simulate a scenario that disabled power to an entire region leaving the distribution system to meet demands only by gravity flow from the elevated storage tanks. Anytown was designed to supply demand through the congruent operation of pumps and tanks. Hence, several model characteristics were adjusted to satisfy demands and pressures were satisfied under gravity flow during normal operating conditions.

Tank sizes and elevations were adjusted so that the pressures would not drop below the threshold pressure (40 psi for this analysis), tanks would not empty, and demands would be met for the entire 24-hour period. It was desired for the normal operating condition to meet the necessary demands and demands not met to be recorded only in the failure scenarios. Each tank diameter was increased from ninety feet to one hundred and fifty feet. The tank sizing calculation can be found in Appendix B. Tank elevations were adjusted using a trial and error process until the nodes received reasonable pressures during normal operating conditions. It was desired to have the pressures at the nodes be above the threshold for the 24 hour period, but not exceed it by an impractical amount. The minimum elevation for both tanks was adjusted from a level of $215 \mathrm{ft}$.

to $135 \mathrm{ft}$., and the initial elevation was changed to $185 \mathrm{ft}$. to $225 \mathrm{ft}$. The tank elevations were lowered so that the pressures recorded at the nodes during the normal operating condition did not exceed the threshold pressure by an unreasonable amount (over $100 \mathrm{psi}$ ).

Table 6 - Table 8 list the adjusted pipe, junction, and tank characteristics for Disaster Scenario 2 that were modeled in WaterCAD. 
Table 6: Pipe Characteristics for Disaster Scenario 2

Pipe Length (ft) Diameter (in.) C-Factor

\begin{tabular}{cccc}
\hline P-2 & 12,000 & 16 & 70 \\
P-4 & 12,000 & 12 & 120
\end{tabular}

P-6 12,000

$\begin{array}{lll}\text { P-8 } & 9,000 & 12\end{array}$

P-10 $600 \quad 12$

P-12 $600 \quad 10$

P-14 600

P-16 600

P-18 600

P-20 600

P-22 600

P-24 600

P-26 600

P-28

P-30

P-32

P-34

P-36

P-38

P-40

P-42

P-44

P-46

P-48

P-50

P-52

P-56

P-58

P-60

P-62

P-64

P-66

P-78

P-80

12

12

12

10

12

10

12

10

10

10

12

10

10

10

10

10

10

10

8

8

8

8

70

70

70

70

70

70

70

70

70

70

70

70

120

120

120

120

120

120

120

120

120

70

120

120

120

120

120

120

120

120

120

12

12

120
Table 7: Junction Characteristics for Disaster Scenario 2

\begin{tabular}{ccc}
\hline $\begin{array}{c}\text { Node } \\
\text { Number }\end{array}$ & $\begin{array}{c}\text { Elevation } \\
\text { (ft.) }\end{array}$ & $\begin{array}{c}\text { Average Demand } \\
\text { (gal/min) }\end{array}$ \\
\hline J-20 & 50 & 500 \\
J-30 & 50 & 200 \\
J-40 & 50 & 200 \\
J-50 & 50 & 200 \\
J-60 & 50 & 500 \\
J-70 & 50 & 500 \\
J-80 & 50 & 500 \\
J-90 & 50 & 1,000 \\
J-100 & 50 & 500 \\
J-110 & 50 & 500 \\
J-120 & 50 & 200 \\
J-130 & 50 & 200 \\
J-140 & 50 & 200 \\
J-150 & 50 & 200 \\
J-160 & 50 & 800 \\
J-170 & 50 & 200 \\
& &
\end{tabular}

Table 8: Tank Characteristics for Disaster Scenario 2

\begin{tabular}{ccccc}
\hline Tank & $\begin{array}{c}\text { Min. Elev. } \\
(\mathrm{ft})\end{array}$ & $\begin{array}{c}\text { Initial } \\
\text { Elev. }(\mathrm{ft})\end{array}$ & $\begin{array}{c}\text { Max. Elev. } \\
(\mathrm{ft})\end{array}$ & $\begin{array}{c}\text { Dia. } \\
(\mathrm{ft})\end{array}$ \\
\hline T-165 & 135 & 185 & 195 & 150 \\
T-65 & 135 & 185 & 195 & 150
\end{tabular}


Fire flows were incorporated into both disaster scenarios to simulate a disaster and to show the impact of disabled nodes on firefighting/ emergency management. In a redundant distribution system, when a node is disabled the flow is rerouted so the other nodes still receive their required pressure and meet their necessary demands. When a node is disabled, pressures at the other nodes in the system become higher. With fire demands however, stress is added to the system, which can cause pressure drops at other nodes in the system.

For both disaster scenarios, extended period simulations were used and the demand pattern (Figure 10) is shown below.

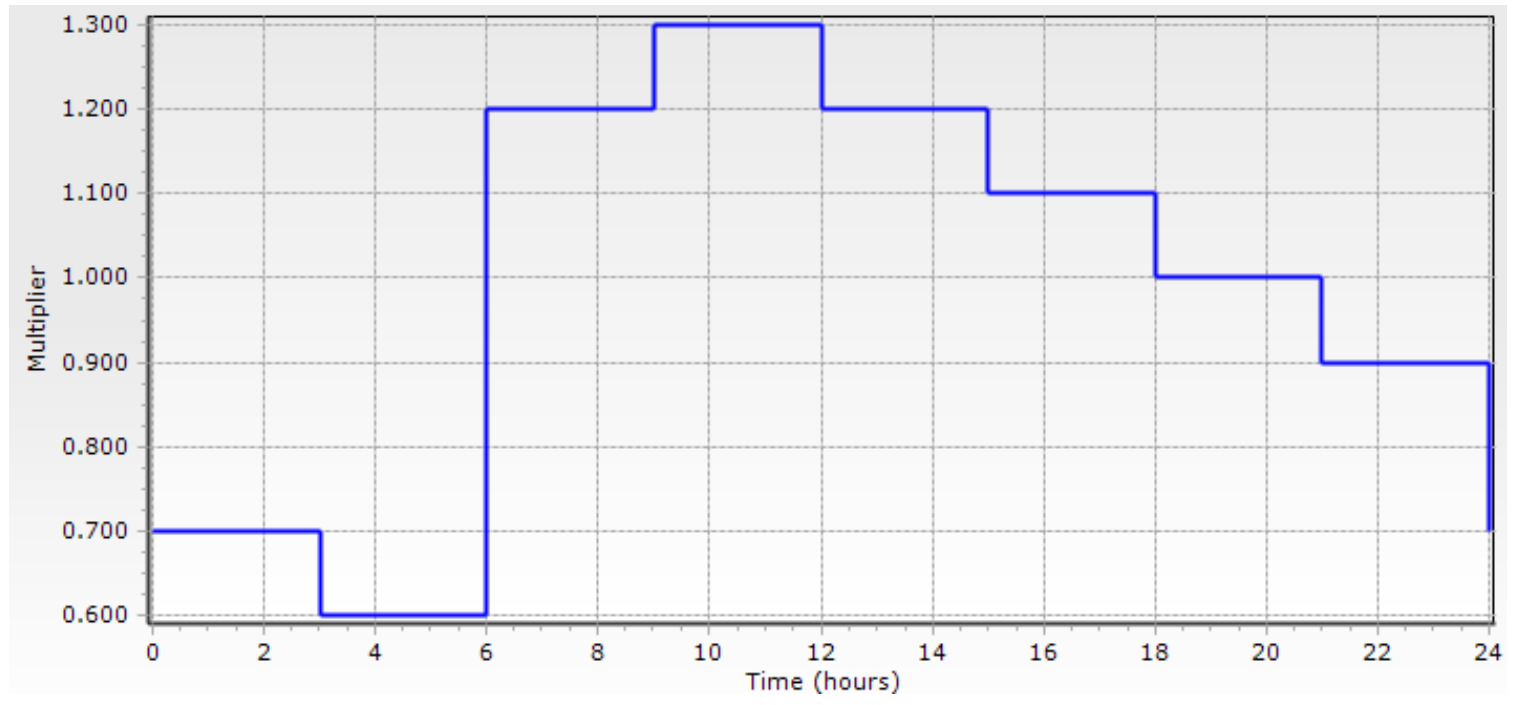

Figure 10: Hourly Demand Pattern

The original topography for Anytown consisted of varying elevations for the nodes, specifically it had a few nodes at a higher elevations then the rest. To ensure that those nodes experienced pressures above $40 \mathrm{psi}$, the rest of the nodes in the system had pressures well above 40 psi. When disaster scenarios were run, only the elevated node pressures dropped below 40 psi. To see the impact of disabled nodes across the entire system, not just with a few elevated nodes all node elevations were set to $50 \mathrm{ft}$. The node elevation change was done for both disaster scenarios for consistency. 


\subsubsection{Process}

For each disaster scenario, the same process was used to apply and test the accuracy of the method. The process consisted of using WaterCAD, Matlab, and Excel to analyze, document, and display the desired results.

Figure 11 is a schematic of the process that was used and the following paragraphs will describe the process in detail. The blue background in the schematic denotes the process used to apply Flow Distribution and the green background shows the additional steps taken to test the accuracy of the method.

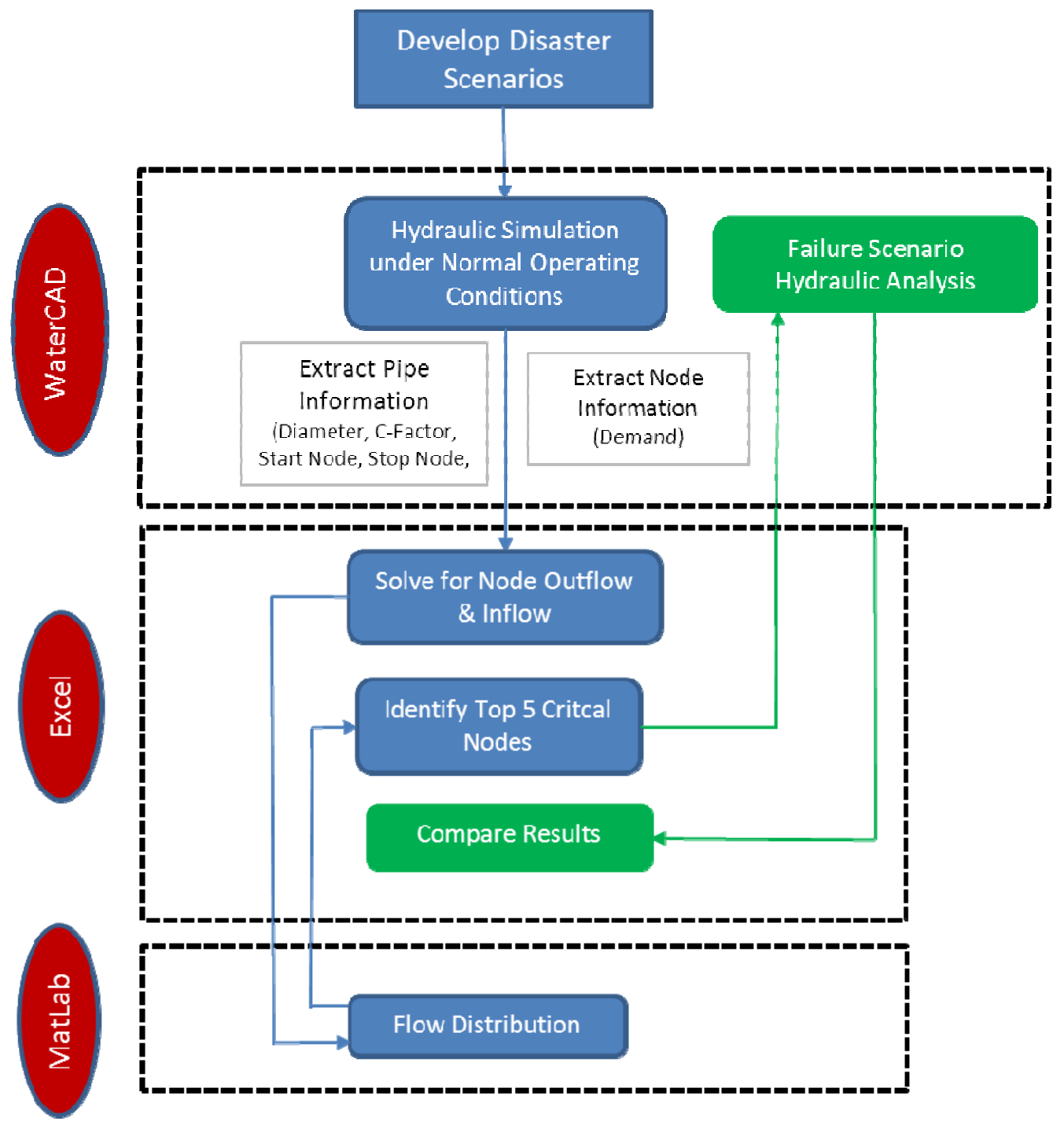

Figure 11: Process Flowchart 
The first step in this process was previously discussed and that was to develop disaster scenarios to be modeled. The next step was to perform a hydraulic simulation of normal operating conditions in WaterCAD. Normal operating condition is meant to simulate a typical day with average demands and without failed pipes or nodes. For Flow Distribution to predict the critical nodes, the water sources in the normal operating condition and disaster scenario need to be the same. For example, if the same normal operating condition was used for Flow Distribution the predicted nodes would be exactly same, but the actual would be different because the water is routed through the system differently since the sources are different for the two scenarios. This research used two different normal operating conditions, one for each scenario.

Hydraulic information from the normal operating condition was necessary for the Flow Distribution analysis. The variables needed from WaterCAD include information about the pipes and junctions consisting of either static or dynamic variables. Static variables remain constant during the entire analysis. Static variables necessary for analysis include pipe length, diameter, and C-factor. Dynamic variables may change during each time step. Dynamic variables necessary for analysis are the start and stop node for each pipe, pipe flow, junction demand, outflow, and inflow. Flow Distribution can only analyze one time step, so the time step chosen needed to represent the entire simulation for analysis. For this research, the peak demand hours were deemed the most suitable. Peak hours for Anytown were the hours nine through twelve. The tenth hour was arbitrarily chosen for the analysis and the necessary information from this time step was exported from WaterCAD to MS Excel.

In Excel, a simple formula was written to calculate the total outflow and inflow at every node using the flow rate start node and stop node information for each pipe. The necessary information (Length, C-Factor, diameter, start node, stop node, demand, node outflow, and node inflow) was then imported into Matlab, which first calculated the resistance factors for each pipe using equation 6. Next, Matlab calculated the path of least resistance for each pair of nodes. The demand and population affected are also calculated using equation 7 . The results were then 
exported back into Excel. The results were tabulated and summarized to document the five nodes (arbitrarily chosen) that Flow Distribution predicted to be the most critical nodes.

If this analysis were to be used as a part of a vulnerability assessment, this would conclude the critical node analysis and the results should be used to develop countermeasures. This study wanted to verify the accuracy of the developed method. The accuracy of Flow Distribution was verified by comparing the amount demand supplied and population served during normal operating condition to all possible failure scenarios. As previously stated, each disaster scenario incorporated one disabled node, and to verify the results, sixteen failure scenarios (one for each node) were modeled to measure the impact of each node disabled.

Disabled nodes can be modeled by isolating that node, meaning that the pipes connected to that node are still operational, but that node does not receive any flow. This would not have much effect on the system except for the demand that the disabled node normally supplies to would not be met. In addition, disabled nodes could be modeled by having the pipes connected to the disabled node leak. Leaking pipes would force the system to supply the water that the pipe carries during normal operating conditions. This study decided to model node failures by stopping flows in all pipes directly connected to the disabled nodes, isolating the node and pipes from the system. This seemed reasonable because it seemed likely for the effects of either disaster event to cause more than pipe and/ or junction to be disabled. Adjacent pipes and junction seem logical to fail at once because the cause and conditions of the failure pipe or junction (i.e. ground shaking, bad soil conditions, high winds, explosions) would be more like seen at other nearby pipes and junctions. The pipes and nodes were isolated from the system because it seems reasonable to believe that a distribution system would have enough valves to isolate the failed region to prevent leaking. Although it would take time for the valves to be closed, node failures were modeled in this way.

The demand and population for every hour of simulation during the normal operating condition were previously calculated and the results were saved in Excel. To calculate the 
demand and population affected during each disaster scenario, sixteen failure scenarios were created and analyzed in WaterCAD. A failure scenario incorporated the fire flow demand that the disaster scenario featured and one disabled node. Figure 12 is a schematic of a failure scenario that features junction 90 disabled for disaster scenario 2 at hour twenty-four of simulation.

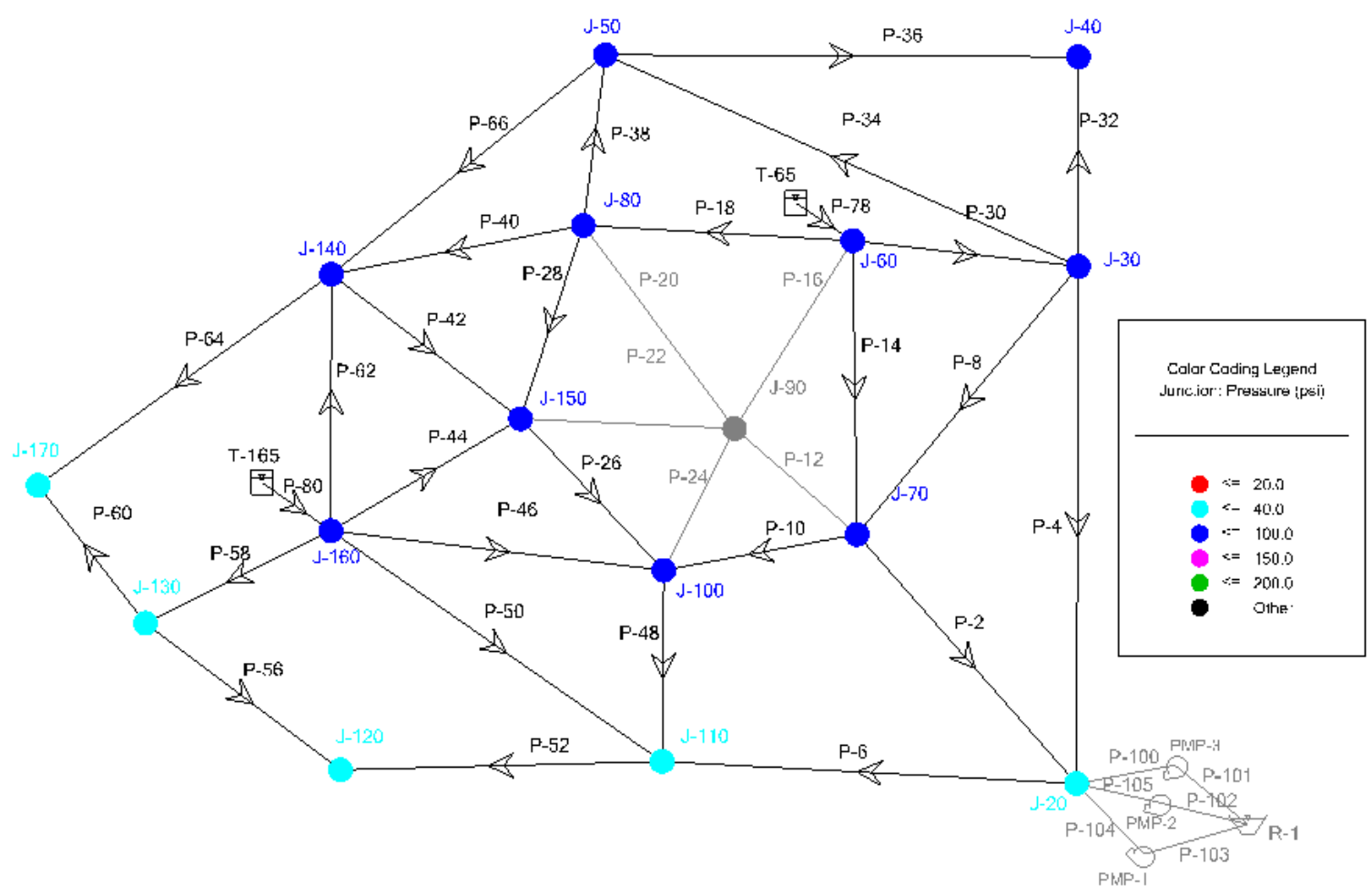

Figure 12: Failure Scenario with Junction 90 Out for Disaster Scenario 2

The light blue nodes represent nodes that are below the chosen threshold pressure value of 40 psi. These nodes are not capable of supplying the necessary demand to consumers. To measure the change in demand between the normal operating condition and failure scenario, pressure dependent demands were implemented during the failure scenarios. If the pressure was above the threshold, the demand was recorded as unaffected and if the pressures dropped below the threshold pressure it was assumed that the demand was not completely met. The modeler could assume that the demand at a node with a pressure less than the threshold pressure is zero. For this research, when the pressure dropped below the threshold pressure, only a portion of the demand was supplied to the node. The method is based upon a user-defined power function 
(Figure 13), and the default power value 0.5 was used for this model. Equation 21 is the piecewise pressure dependent demand equation.

$$
\frac{D_{\text {sup }}}{D_{\text {req }}}=\left\{\begin{array}{lc}
0 & P \leq 0 \\
\left(\frac{P_{a c t}}{P_{t}}\right)^{0.5} & 0 \leq P \leq P_{t} \\
1 & P \geq P_{t}
\end{array}\right.
$$

$$
\begin{aligned}
& D_{\text {sup }}=\text { Demand supplied to node } \\
& D_{\text {req }}=\text { Demand required at node } \\
& P_{\text {act }}=\text { Pressure observed at node } \\
& P_{t}=\text { Threshold Pressure (40psi) }
\end{aligned}
$$

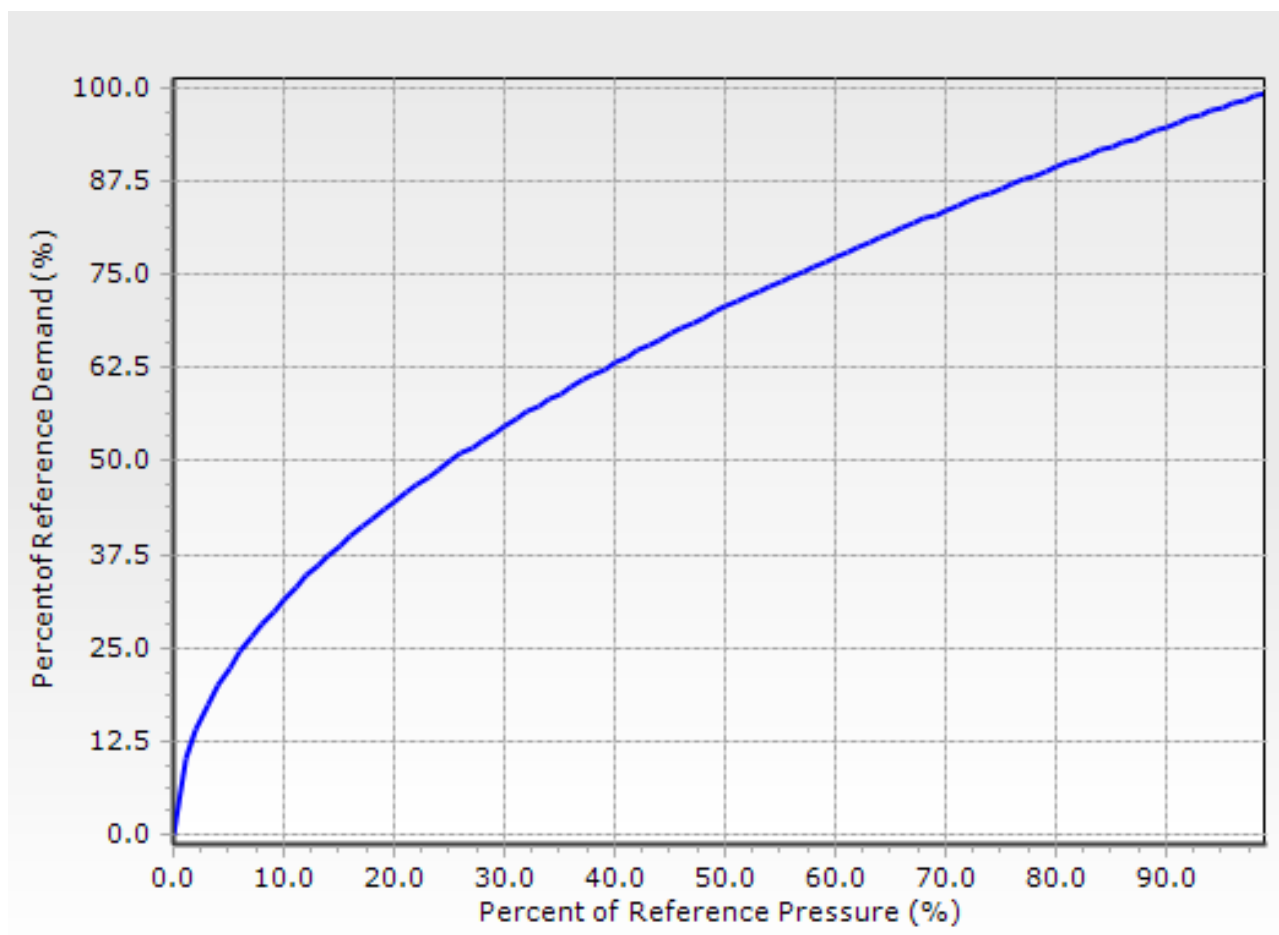

Figure 13: Power Function for Pressure Dependent Demand

Using pressure dependent demands, the demand for each node, for every hour, for each failure scenario was exported to Excel. In Excel, the difference in demand between the normal operating conditions and each failure scenario was calculated. The difference in population between the failure scenario and normal condition for an individual node was calculated using 
Equation 22. This allowed for a comparison in the population served between normal conditions and failure scenarios as well.

$$
\text { Pop Diff }=\text { Pop }_{\text {Ser }}-\left(\frac{D}{D_{N O C}} * \text { Pop } p_{S e r}\right)
$$

Pop Diff $=$ Population difference at node between normal operating conditions and failure scenario Pop $_{\text {Ser }}=$ Population served at node during normal conditions $\mathrm{D}=$ Demand supplied to node $\mathrm{D}_{\mathrm{NOC}}=$ Demand supplied to node during normal operating conditions The best-case scenario was that Flow Distribution predicted the same critical nodes as the actual critical nodes found after analyzing every failure scenario. The process just described was used for the analysis of both disaster scenarios. To see all the data including the WaterCAD and Matlab outputs, see Appendix C and Appendix D. The results are presented and discussed in detail in the following chapter. 


\section{CHAPTER 4: RESULTS \& DISCUSSION}

This chapter presents the results from Flow Distribution for disaster scenario one and disaster scenario two and discusses their impact. It will also compare the results of Flow Distribution to the actual critical nodes found by analyzing failure scenarios, as well as, compare the accuracy of Flow Distribution to other research.

\subsection{System Improvement}

If Flow Distribution were to be used as part of a vulnerability assessment then, the results in Table 9, which shows the critical nodes that Flow Distribution predicted, would be used to evaluate how the current resources could be allocated to bolster the system's reliability. From these results, logic, modeler judgment, and risk probability analysis can be utilized to decide if countermeasures are necessary to strengthen weak points found in the system.

Table 9: Top Critical Nodes Predicted by Flow Distribution

Disaster Scenario 1

\begin{tabular}{ccc|cc} 
& \multicolumn{2}{c}{ Disaster Scenario 1 } & \multicolumn{2}{c}{ Disaster Scenario 2 } \\
\hline Junction & $\begin{array}{c}\text { Expected Populaton } \\
\text { Effect (ppl) }\end{array}$ & $\begin{array}{c}\text { Expected Demand } \\
\text { Effect (gpm) }\end{array}$ & $\begin{array}{c}\text { Expected Populaton } \\
\text { Effect (ppl) }\end{array}$ & $\begin{array}{c}\text { Expected Demand } \\
\text { Effect (gpm) }\end{array}$ \\
\hline J-20 & 22,811 & 3,910 & 3069 & 650 \\
J-30 & 8,622 & 1,017 & 5923 & 593 \\
J-40 & 7,089 & 372 & 6100 & 260 \\
J-50 & 8,914 & 582 & 6486 & 310 \\
J-60 & 5,620 & 1,170 & 14510 & 2588 \\
J-70 & 5,646 & 1,738 & 1851 & 860 \\
J-80 & 7,520 & 982 & 6499 & 840 \\
J-90 & 6,164 & 1,312 & 6082 & 1300 \\
$\mathrm{~J}-100$ & 1,873 & 808 & 1640 & 818 \\
$\mathrm{~J}-110$ & 6,008 & 1,044 & 5149 & 746 \\
$\mathrm{~J}-120$ & 5,039 & 273 & 4949 & 260 \\
$\mathrm{~J}-130$ & 5,597 & 391 & 6194 & 458 \\
$\mathrm{~J}-140$ & 5,729 & 335 & 6707 & 454 \\
$\mathrm{~J}-150$ & 4,518 & 312 & 5419 & 539 \\
$\mathrm{~J}-160$ & 3,951 & 1,282 & 19844 & 3146 \\
$\mathrm{~J}-170$ & 1,901 & 260 & 2009 & 273
\end{tabular}


The top critical nodes are not the same based on the demand and population affected, thus to assess the results from Flow Distribution one would need to take precedence over the other. For this study, the demand affected took precedence over the population affected (Table 9). The demand affected was believed to represent the system more realistically than the population affected because the population at each node was randomly generated in Excel. Adding up the affected demand from each scenario for each junction, the results show that junctions 20,60 , and 160 significantly affect more demand than the rest of the nodes. To improve system reliability, additional pipes could be added between the supply tanks/ reservoir to other nodes in the system. Since nodes 20,60 \& 160 all supply water to the system, an additional supply source would decrease the effect that each of those nodes has on the system.

\subsection{Flow Distribution Accuracy}

The preceding section discussed how the results from Flow Distribution can be used to identify locations for system improvement. This section focuses on the effectiveness of Flow Distribution to identify the critical nodes. Table 10 and

Table 11 document the results from Disaster Scenario 1 and 2. Columns (3) and (6) are the expected population and demand effect, respectively, calculated using the Flow Distribution equation in Matlab. Columns (4) and (7) are the actual population and demand affected after analyzing the sixteen failure scenarios in WaterCAD. The highlighted cells represent the five largest numbers in each respective column.

Flow Distribution predicted Junctions 20,60, 70, 90, and 160 to affect the most demand if they were disabled during a Disaster Scenario 1. The results after analyzing all the failure scenarios show junctions 20,30, 70, 90, and 110 will affect the most demand (Table 10). Flow Distribution only correctly predicted three out of five critical nodes. The program was more successful predicting the critical nodes for population. Junctions $20,30,50,70$, and 80 were predicted to cause the most population to be without water if disabled. The junctions that actually 
caused the most disturbances were junctions $20,30,50,70$, and 110. Flow distribution correctly predicted four out of five critical nodes for effects in population.

Table 10: Results from Disaster Scenario 1

\begin{tabular}{|c|c|c|c|c|c|c|c|}
\hline $\begin{array}{l}\text { Junction } \\
\text { (1) } \\
\end{array}$ & $\begin{array}{l}\text { Population } \\
\text { (ppl) } \\
(2) \\
\end{array}$ & $\begin{array}{c}\text { Expected Populaton } \\
\text { Effect (ppl) } \\
\text { (3) }\end{array}$ & $\begin{array}{l}\text { Actual Population } \\
\text { Effect (ppl) } \\
(4)\end{array}$ & $\begin{array}{l}\text { Demand } \\
\text { (gpm) } \\
\text { (5) }\end{array}$ & $\begin{array}{l}\text { Expected Demand } \\
\text { Effect (gpm) } \\
(6)\end{array}$ & $\begin{array}{c}\text { Demand Effect } \\
\text { (gpm) } \\
\text { (7) }\end{array}$ & $\begin{array}{c}\text { Outflow } \\
\text { (8) }\end{array}$ \\
\hline$J-20$ & 3069 & 22,937 & 48,259 & 650 & 3,905 & 140,579 & 5803 \\
\hline $\mathrm{J}-30$ & 1421 & 8,629 & 11,443 & 260 & 1,016 & 32,285 & 1787 \\
\hline $\mathrm{J}-40$ & 6100 & 7,091 & 6,124 & 260 & 372 & 5,028 & 301 \\
\hline$J-50$ & 5953 & 8,920 & 6,279 & 260 & 581 & 6,079 & 691 \\
\hline$J-60$ & 2297 & 5,626 & 2,808 & 650 & 1,169 & 14,040 & 1132 \\
\hline $\mathrm{J}-70$ & 827 & 5,688 & 10,643 & 650 & 1,737 & 43,214 & 1930 \\
\hline $\mathrm{J}-80$ & 4189 & 7,534 & 4,225 & 650 & 982 & 12,464 & 636 \\
\hline J-90 & 6082 & 6,082 & 6,082 & 1300 & 1,300 & 24,700 & 0 \\
\hline$J-100$ & 716 & 1,915 & 743 & 650 & 810 & 12,468 & 294 \\
\hline $\mathrm{J}-110$ & 4642 & 6,014 & 6,975 & 650 & 1,044 & 20,491 & 562 \\
\hline $\mathrm{J}-120$ & 4949 & 5,040 & 4,949 & 260 & 273 & 4,940 & 19 \\
\hline J-130 & 5170 & 5,599 & 5,184 & 260 & 392 & 4,984 & 196 \\
\hline $\mathrm{J}-140$ & 5248 & 5,738 & 5,488 & 260 & 336 & 5,894 & 109 \\
\hline $\mathrm{J}-150$ & 4330 & 4,571 & 4,588 & 260 & 326 & 5,891 & 52 \\
\hline $\mathrm{J}-160$ & 1487 & 3,960 & 1,520 & 1040 & 1,282 & 19,846 & 437 \\
\hline $\mathrm{J}-170$ & 1901 & 1,901 & 2,182 & 260 & 260 & 5,895 & 0 \\
\hline
\end{tabular}

For Disaster Scenario 2, Flow Distribution predicted that Junctions 60, 70, 80, 90, and 160 would be the top five nodes that would affect the most demand in the distribution system. After the failure scenarios were analyzed, the top five most critical nodes were junctions 60,70 , 80,90 , and 160 (Table 11). This method correctly predicted all five nodes that would affect the most demand. Flow Distribution was not as successful in selecting the top nodes to affect population, as it predicted junctions $60,50,80,140$, and 160 , and the actual nodes that affected the most population were junctions $40,50,60,90$, and 160 . Only three of the five critical nodes were successfully predicted. 
Table 11: Results from Disaster Scenario 2

\begin{tabular}{|c|c|c|c|c|c|c|c|}
\hline $\begin{array}{c}\text { Junction } \\
\text { (1) }\end{array}$ & $\begin{array}{c}\text { Population } \\
\text { (2) }\end{array}$ & $\begin{array}{c}\text { Expected } \\
\text { Populaton Effect } \\
\text { (3) }\end{array}$ & $\begin{array}{c}\text { Actual Population } \\
\text { Effect } \\
(4) \\
\end{array}$ & $\begin{array}{c}\text { Demand } \\
\text { (gpm) } \\
(5)\end{array}$ & $\begin{array}{l}\text { Expected Demand } \\
\text { Effect (gpm) } \\
\text { (6) }\end{array}$ & $\begin{array}{c}\text { Demand Effect } \\
(\mathrm{gpm}) \\
(7)\end{array}$ & $\begin{array}{c}\text { Outflow } \\
(8)\end{array}$ \\
\hline $\mathrm{J}-20$ & 3069 & 3,069 & 3,097 & 650 & 650 & 12,434 & 0 \\
\hline$J-30$ & 1421 & 5,923 & 1,571 & 260 & 593 & 5,386 & 611 \\
\hline $\mathrm{J}-40$ & 6100 & 6,100 & 6,131 & 260 & 260 & 5,038 & 0 \\
\hline$J-50$ & 5953 & 6,486 & 6,025 & 260 & 310 & 5,186 & 84 \\
\hline$J-60$ & 2297 & 14,510 & 18,504 & 650 & 2588 & 64,993 & 3115 \\
\hline $\mathrm{J}-70$ & 827 & 1,851 & 902 & 650 & 860 & 12,580 & 405 \\
\hline $\mathrm{J}-80$ & 4189 & 6,499 & 4,249 & 650 & 840 & 12,534 & 380 \\
\hline J-90 & 6082 & 6,082 & 6,087 & 1300 & 1300 & 24,714 & 0 \\
\hline$J-100$ & 716 & 1,640 & 754 & 650 & 818 & 12,459 & 302 \\
\hline $\mathrm{J}-110$ & 4642 & 5,149 & 4,676 & 650 & 746 & 12,446 & 305 \\
\hline $\mathrm{J}-120$ & 4949 & 4,949 & 4,949 & 260 & 260 & 4,940 & 0 \\
\hline$J-130$ & 5170 & 6,194 & 5,260 & 260 & 458 & 5,196 & 547 \\
\hline $\mathrm{J}-140$ & 5248 & 6,707 & 5,334 & 260 & 454 & 5,222 & 336 \\
\hline $\mathrm{J}-150$ & 4330 & 5,419 & 4,413 & 260 & 539 & 5,217 & 433 \\
\hline $\mathrm{J}-160$ & 1487 & 19,844 & 14,779 & 1040 & 3146 & 59,716 & 3515 \\
\hline $\mathrm{J}-170$ & 1901 & 2,009 & 1,973 & 260 & 273 & 5,168 & 27 \\
\hline
\end{tabular}

For both scenarios, the values for the expected demand affected and the actual demand effect were not equivalent because the expected demand effect was calculated for only one hour and the actual was the calculated for the entire 24-hour period. It was assumed that the nodes that affected the most demand and population in the hour chosen (tenth hour of simulation) would be the same nodes that would affect the most demand and population during the rest of the simulation. This assumption was checked by running Flow Distribution analysis for every hour of simulation for Disaster Scenario 1. The results were then summed to get the total expected demand and population effect for the 24-hour simulation period. Table 12 documents the results for run 1 , ninety percent of the nodes that were predicted to be the critical nodes for peak hour 10 were the same when Flow Distribution was analyzed for every hour of simulation. Since the results varied little between the analyzing only the peak hour versus the entire simulation, the assumption previously stated was deemed valid. 
Table 12: Population Effect for Peak Hour 10 versus 24hr Period for Run 1

\begin{tabular}{rcccc}
\hline Junction & $\begin{array}{c}\text { Population } \\
\text { Effected for 24hr } \\
\text { Period (ppl) }\end{array}$ & $\begin{array}{c}\text { Population Effect } \\
\text { for Peak Hour 10 } \\
(\mathrm{ppl})\end{array}$ & $\begin{array}{c}\text { Population Effected } \\
\text { for 24hr Period } \\
(\mathrm{gpm})\end{array}$ & $\begin{array}{c}\text { Population Effect } \\
\text { for Peak Hour 10 } \\
\text { (gpm) }\end{array}$ \\
\hline $\mathrm{J}-20$ & 571979 & 22811 & 78682 & 3910 \\
$\mathrm{~J}-30$ & 240446 & 8622 & 23573 & 1017 \\
$\mathrm{~J}-40$ & 169075 & 7089 & 7668 & 372 \\
$\mathrm{~J}-50$ & 221146 & 8914 & 12481 & 582 \\
$\mathrm{~J}-60$ & 146082 & 5620 & 23728 & 1170 \\
$\mathrm{~J}-70$ & 192568 & 5646 & 41701 & 1738 \\
$\mathrm{~J}-80$ & 176145 & 7520 & 19161 & 982 \\
$\mathrm{~J}-90$ & 150313 & 6164 & 25210 & 1312 \\
$\mathrm{~J}-100$ & 59875 & 1873 & 17161 & 808 \\
$\mathrm{~J}-110$ & 159245 & 6008 & 22774 & 1044 \\
$\mathrm{~J}-120$ & 125890 & 5039 & 6012 & 273 \\
$\mathrm{~J}-130$ & 127327 & 5597 & 6960 & 391 \\
$\mathrm{~J}-140$ & 145811 & 5729 & 7772 & 335 \\
$\mathrm{~J}-150$ & 118315 & 4518 & 8142 & 312 \\
$\mathrm{~J}-160$ & 131768 & 3951 & 25712 & 1282 \\
$\mathrm{~J}-170$ & 43873 & 1901 & 4800 & 260 \\
\end{tabular}

Although there are several ways to improve Flow Distribution's accuracy (discussed in Chapter 5: Conclusion), it predicted the critical nodes correctly $70 \%$ of the time. Of all the research conducted, only Jowitt \& Chengchao (1993) solved for the critical nodes in the distribution system, and verified their results. Jowitt's method predicted the critical nodes $70 \%$ of the time. Intuition may suggest that the most critical node would be the one with the most outflow or demand. It seems plausible to believe that the node with the most outflow supplies the most water to the system or disabling the node that supplies the largest demand will globally affect the demand of the system the most. In a redundant system flow can be rerouted when the node with the most outflow is disabled rendering that node to not be critical. The node with the most demand may not have any outflow and nodes with less demand may have more outflow so when disabled it will affect more demand throughout the system. The result tables (Table 10 and Table 11) support this because the outflow and demand for each node are shown and the most critical nodes were not only the nodes with the highest outflow or demand. Using outflow to 
predict the most critical nodes, it would have correctly selected the critical node $55 \%$ of the time. Selecting the nodes with the highest demand or population would have correctly predicted the critical nodes $60 \%$ of the time. Considering this, the accuracy of Flow Distribution can be improved and its accuracy is comparable or better than the methods just mentioned provides evidence that this method is reasonably effective and accurate. 


\section{CHAPTER 5: CONCLUSION}

The objectives for this research were to develop a method that identified critical nodes and/ or pipes without analyzing every failure scenario, was flexible for application to different WDS, capable of incorporating critical infrastructure, and the results were verifiable. The primary advantage of using Flow Distribution is it can identify the critical nodes without analyzing any failure scenarios and analyzing only the normal conditions of the disaster scenarios, and for this study, it predicted the critical nodes with $70 \%$ accuracy. Flow Distribution is not a complicated method and is an adaptation of the gravity model, widely used in transportation engineering studies, applied to WDS. Even though critical infrastructure was not implemented in this analysis, Flow Distribution allows for incorporation of critical infrastructure in the analysis. The last objective was met because the accuracy was verified by applying two different disaster scenarios and analyzing each failure scenario then comparing the predicted nodes to the actual critical nodes.

The purpose of Flow Distribution is to be used as part of a vulnerability assessment to determine weak aspects in the system and it is not meant to be an all-inclusive method covering every necessary aspect of a vulnerability assessment. However, this newly developed method provides a simple quantitative method for vulnerability assessment as opposed to the complicated quantitative and qualitative methods used in practice.

\subsection{Improvement}

Despite the overall success of Flow Distribution, there were several ways it could be improved including calibrating and solving for a more appropriate number of critical nodes.

Calibration is an important part of the gravity model because it correlates the theoretical outflows to the actual or modeled outflows. As stated in the Methodology chapter the calibration factor, alpha, in the Flow Distribution equation was assigned the standard factor of two in place of calibration for the reasons previously stated. If calibration were performed for this analysis, it 
would be expected that the predicted values would be closer to the simulated values. If Flow Distribution were to be applied to a real system, calibration would be required. Several different calibration methods exist for calibrating the gravity model, and can be applied to Flow Distribution and the accuracy should be vastly improved.

The accuracy of Flow Distribution could also be improved by adding a gradient term or factor to the Flow Distribution equation. The current equation only accounts for the influences that friction has on the path water takes in a distribution system. However, the head difference between nodes is another contributing factor because water is more likely to travel to nodes with a positive head difference. Information necessary for a gradient factor can be determined from the schematic information of the distribution system and should be easy to implement with Flow Distribution

During the development of the Flow Distribution experiment, choosing to predict the top five critical nodes was an arbitrary decision. After performing the analysis, two or three nodes significantly affected the distribution system more than the rest of the nodes. Flow Distribution correctly predicted the top three critical nodes $83 \%$ of the time and the top two critical nodes with $100 \%$ accuracy. Predicting the top four and five nodes was more difficult for Flow Distribution because the population and demand effect values were relatively close (within $10 \%$ ) with the remaining junctions. It was unreasonable to think that an uncalibrated Flow Distribution program would distinguish between several nodes with such subtle differences. Using Flow Distribution to predict the top two or three nodes would have yielded better results and been more appropriate for this model. Flow Distribution works best in identifying outliers or nodes that if disabled would affect the system significantly.

Anytown is also a highly redundant system and the effects of disabled nodes are not as prevalent as they would be in a less redundant system. The table below (Table 13) supports this statement because it shows the demand effects to the rest of the system not including the demand of the node disabled. The junctions that caused the most problems were the ones that supplied 
water to the system from either a reservoir or tank. With high redundancy, water is easily rerouted so it can be delivered to the nodes by a different route when a node is disabled. It is possible with this level of redundancy, Anytown only has a few critical nodes, and the rest have minimal effect on the system.

Table 13: Demand Effect to the Rest of the System for Disaster Run $1 \& 2$

\begin{tabular}{cccc|ccc}
\hline & \multicolumn{3}{c}{ Run 1 } & \multicolumn{3}{c}{ Run 2 } \\
Junction & $\begin{array}{c}\text { Demand Effect } \\
\text { (gpm) }\end{array}$ & $\begin{array}{c}\text { Total Demand at } \\
\text { node (gpm) }\end{array}$ & $\begin{array}{c}\text { Demand Effect to rest } \\
\text { of system (gpm) }\end{array}$ & $\begin{array}{c}\text { Demand Effect } \\
\text { (gpm) }\end{array}$ & $\begin{array}{c}\text { Total Demand at } \\
\text { node (gpm) }\end{array}$ & $\begin{array}{c}\text { Demand Effect to rest of } \\
\text { system (gpm) }\end{array}$ \\
\hline J-20 & 140,579 & 12,350 & 128,229 & 12,434 & 12,350 & 84 \\
J-30 & 32,285 & 4,940 & 27,345 & 5,386 & 4,940 & 446 \\
J-40 & 5,028 & 4,940 & 88 & 5,038 & 4,940 & 98 \\
J-50 & 6,079 & 4,940 & 1,139 & 5,186 & 4,940 & 246 \\
J-60 & 14,040 & 12,350 & 1,690 & 64,993 & 12,350 & 52,643 \\
J-70 & 39,593 & 12,350 & 27,243 & 12,580 & 12,350 & 230 \\
J-80 & 12,464 & 12,350 & 114 & 12,534 & 12,350 & 184 \\
J-90 & 24,700 & 24,700 & 0 & 24,714 & 24,700 & 14 \\
J-100 & 12,468 & 12,350 & 118 & 12,459 & 12,350 & 109 \\
J-110 & 20,491 & 12,350 & 8,141 & 12,446 & 12,350 & 96 \\
J-120 & 4,940 & 4,940 & 0 & 4,940 & 4,940 & 0 \\
J-130 & 4,984 & 4,940 & 44 & 5,196 & 4,940 & 256 \\
J-140 & 5,894 & 4,940 & 954 & 5,222 & 4,940 & 282 \\
J-150 & 5,891 & 4,940 & 951 & 5,217 & 4,940 & 277 \\
J-160 & 19,846 & 19,760 & 86 & 59,716 & 19,760 & 39,956 \\
J-170 & 5,895 & 4,940 & 955 & 5,168 & 4,940 & 228
\end{tabular}

\subsection{Limitations}

The application of Flow Distribution for vulnerability assessments has limitations. First, the normal operating scenario must resemble the disaster scenario in terms of the major water sources. If the same normal operating scenario had been used for the both disaster scenarios, the same five nodes would have been predicted to be the most critical, but as we saw, the critical nodes were different for the two disaster scenarios. This means a different disaster scenario must be created every time the water sources are changed for Flow Distribution to be effective.

Another limitation to this method is it will only analyze the detrimental effects of one disabled node or a group of nodes skeletonized to one node. It is conceivable for a disaster event to disable more than one demand node or multiple skeletonized groups at a time. The most detrimental node combination may not necessarily be the most critical nodes that were calculated 
using the Flow Distribution method. This method does not consider the possible interactions that may occur if multiple nodes are disabled at a time. This method already assumes the nodes that supply the most demand or population to its direct consumers and to the downstream nodes in the system during normal operating conditions will affect the most demand or population when disabled. This assumption was correct $70 \%$ when one node was disabled, and the accuracy would most likely decrease exponentially if it were to be used to predict a combination of disabled nodes.

This program is also limited because only one time step is used for the analysis. To analyze the entire simulation, each time step must be analyzed separately. In theory, the critical nodes calculated by the program may change depending on which time step is used for the analysis. This method assumes that the critical nodes calculated by the method for the hour chosen, peak in this case, are the same for all other time steps.

\subsection{Future Work}

Although Flow Distribution produced fairly accurate results, additional research can be utilized to expand on this method including calibrating, application to a real system, and use with other methods to complete a vulnerability assessment. As stated previously, several approaches can be used to calibrate the gravity model and additional research could be utilized to determine which approaches, if any, yield the most accurate results for Flow Distribution. Applying Flow Distribution to a real system would add complications to the analysis including a connectivity analysis, skeletonization, and data management, and would test one of this research's objectives of creating a method that could be applied to any system. This research could be taken a step further by not only applying it to a real system, but using it as part of a vulnerability assessment to determine the feasibility of using Flow Distribution as part of a vulnerability assessment. One of the objectives of this research was to develop a method that allowed critical infrastructure to be incorporated. Critical infrastructure was not incorporated in this research, and future work could 
determine the most effective and efficient method of incorporating critical infrastructure in the Flow Distribution analysis.

In the field of vulnerability assessments for water distribution systems, future work is needed. The literature review shows that an agreed upon method does not exist. It would be advantageous if the numerous methods were consolidated to form an agreed upon assessment program that covered all the required components of a vulnerability assessment stated by the EPA. Currently, each community performs a vulnerability assessment with different methodology making it impossible to compare results. A standard assessment would allow vulnerability comparison among various WDS, as well as, laws to be passed allowing only a certain amount of system vulnerability within a WDS. 


\section{BIBLIOGRAPHY}

AWWA. (1992). Distribution System Requirements for Fire Protection. Denver: American Water Works Association.

AWWA. (2005). Computer Modeling of Water Distribution Systems. Denver, CO : American Water Works Association.

Bahadur, R., Samuels, W. B., Grayman, W., Amstutz, D., \& Pickus, J. (2003). PipelineNet: A Model for Monitoring Introduced Contaminants in a Distribution System. Proceedings, World Water \& Environmental Resources Congress. Reston, VA: ASCE.

Banks, J. E. (2002). Introduction to Transportation Engineering. New York: McGraw Hill.

Baoyu, Z., Xinhua, Z., \& Yuan, Z. (2009). Vulnerability Assessment of Regional Water Distribution Systems. International Conference on Environmental Science and Information and Application Technology, (pp. 473-477).

Bentley. (2012). Water Distribution Modeling and Management. Retrieved February 2012, from Bentley: http://www.bentley.com/en-US/Products/WaterCAD/Features-List.htm

Berry, J., Bowan, E., \& Riesen, L. A. (2009, October). User's Manual TEVA-SPOT Toolkit. Albuquerque, New Mexico, United States: EPA.

Brown, G. (2000, June 07). The History of the Darcy-Weisbach Equation. Retrieved from Henry Darcy and his Law: http://biosystems.okstate.edu/darcy/DarcyWeisbach/DarcyWeisbachHistory.htm

Chastain, J. R. (2006). Methodology for Locating Monitoring Stations to Detect Contamination in Potable Water Distribution Systems. Journal of Infrastructure Systems, 252-259.

Clark, R. M., \& Deininger, R. A. (2000). Protectiving the Nation's Critical Infrastructure: The Vulnerability of U.S. Water Supply Systems. Journal of Contingencies and Crisis Management, 73-80.

EPA. (2002, June). Baseline Threat Information for Vulnerability Assessments of Community Water Systems. Washington D.C., United States: EPA.

EPA. (2002, June 12). Public Health Security and Bioterrorism Prepardness and Response Act of 2002. Public Law. Washington D.C.: EPA.

EPA. (2003). EPA Nees to Assess the Quality of Vulnerability Assessments Related to the Security of the Nation's Water Supply. EPA.

EPA. (2004). Environmental Protection Agency. Retrieved March 31, 2012, from How We Use Water in the Unites States: http://www.epa.gov/watrhome/you/chap1.html

Ezell, B. C., Farr, J. V., \& Wiese, I. (2000). Infrastructure Risk Analysis Model. ASCE Journal of Infrastructure Systems, 114-117. 
Fishenich, D. C. (2000). Robert Manning (A Historical Perspective). Emlip.

Haigh, T. (2008). Cleve Moler: Mathematical Software Pioneer and Creator of Matlab. IEE Annals of the History of Computing, 87-91.

Haimes, Y. Y., Matalas, N. C., Lambert, J. H., Jackson, B. A., \& Fellows, J. F. (1998). Reducing Vulnerability of Water Supply Systems to Attack. Journal of Infrastructure Systems, 164177.

Jacobs, P., \& Goulter, I. (1991). Estimation of Maximum Cut-Set Size for Water Network Failure. Journal of Water Resources Planning and Management, 588-604.

Jones, G. F. (2011). Gravity-Driven Water Flow in Networks. Hoboken: John Wiley \& Sons.

Jowitt, P. W., \& Chengchao, X. (1993). Predicting Pipe Failure Effects in Water Distribution Networks. Journal of Water Resources Planning and Management.

Jun, H., Loganathan, G. V., Kim, J. H., \& Park, S. (2008). Identifying Pipes and Valves of High Importance for Efficient Operation and Maintenance of Water Distribution Systems. Water Resources Management, 719-736.

Kalungi, P., \& Tanyimboh, T. T. (2003). Redundancy Model for Water Distribution Systems. Reliability Engineering and System Safety, 275-286.

Lippai, I., \& Wright, L. (2005). Criticality Analysis Case Study: Zone 7 Water Distribution System. The Pipeline Division Specialty Conference (pp. 662-673). ASCE.

Little, R. G. (2004). Holistic Strategy for Urban Security. Journal of Infrastructure Systems, 5259.

Martorano, S. (2006). Calcuating Friction Loss: Darcy Weisbach Formula vs. Hazen-Williams. Viking.

Mays, L. W. (2005). Water Resources Engineering. New Jersey: John Wiley \& Sons.

Nazif, S., \& Karamouz, M. (2009). Algorithm for Assessment of Water Distribution System's Readiness: Planning for Disasters. Journal of Water Resources Planning and Management, 244-252.

Ormsbee, L. E. (2006). The History of Water Distribution Network Analysis: The Computer Age. Water Distribution System Analysis Symposium 2006. ASCE.

Qiao, J., Jeong, D., Lawley, M., Richard, J.-P. P., Abraham, D. M., \& Yih, Y. (2005). Allocating Security Resources to a Water Supply Network. IIE Transactions.

Reilly, W. (1953). Law of Retail Gravitation. Fillsburg Publishers.

Shinstine, D. S., Ahmed, I., \& Lansey, K. E. (2002). Reliability/ Availability Analysis of Municipal Water Distribution Networks: Case Studies. Journal of Water Resources Planning and Management, 140-151. 
Staudinger, T. J., England, E. C., \& Bleckmann, C. (2006). Comparative Analysis of Water Vulnerability Assessment Methodologies. Journal of Infrastructure Systems, 96-106.

Tank, A., Cooper, T., Dueñas-Osorio, L., Eidinger, J., Fullerton, J., Imbsen, R., et al. (2010). 27 February 2010 Mw8.8 Offshore Maule, Chile Earthquake. Technical Council on Lifeline Earthquake Engineering (TCLEE).

Transportation, U. D. (1983). Calibrating \& Testing a Gravity Model for any Size Urban Area. Federal Highway Adminstration.

Voorhees, A. M. (1955). A General Theory of Traffic Movement. Institute of Traffic Engineering.

Walski, T. M., Brill, E. D., Gessler, J., ASCE, Goulter, I. C., Jeppson, R. M., et al. (1987). Battle of the Network Models: Epilogue. Journal of Water Resources Planning and Management, 191-203.

Walski, T. M., Chase, D. V., Savic, D. A., Grayman, W., Beckwith, S., \& Koelle, E. (2007). Advanced Water Distribution Modeling and Mangement. Bentley Institute Press.

Wang, Y., \& Au, S.-K. (2008). Spatial Distribution of Water Supply Reliability and Critical Links of Water Supply to Crucial Water Consumers under an Earthquake. Reliability Engineering and System Safety. 
Appendix A: Matlab Code 


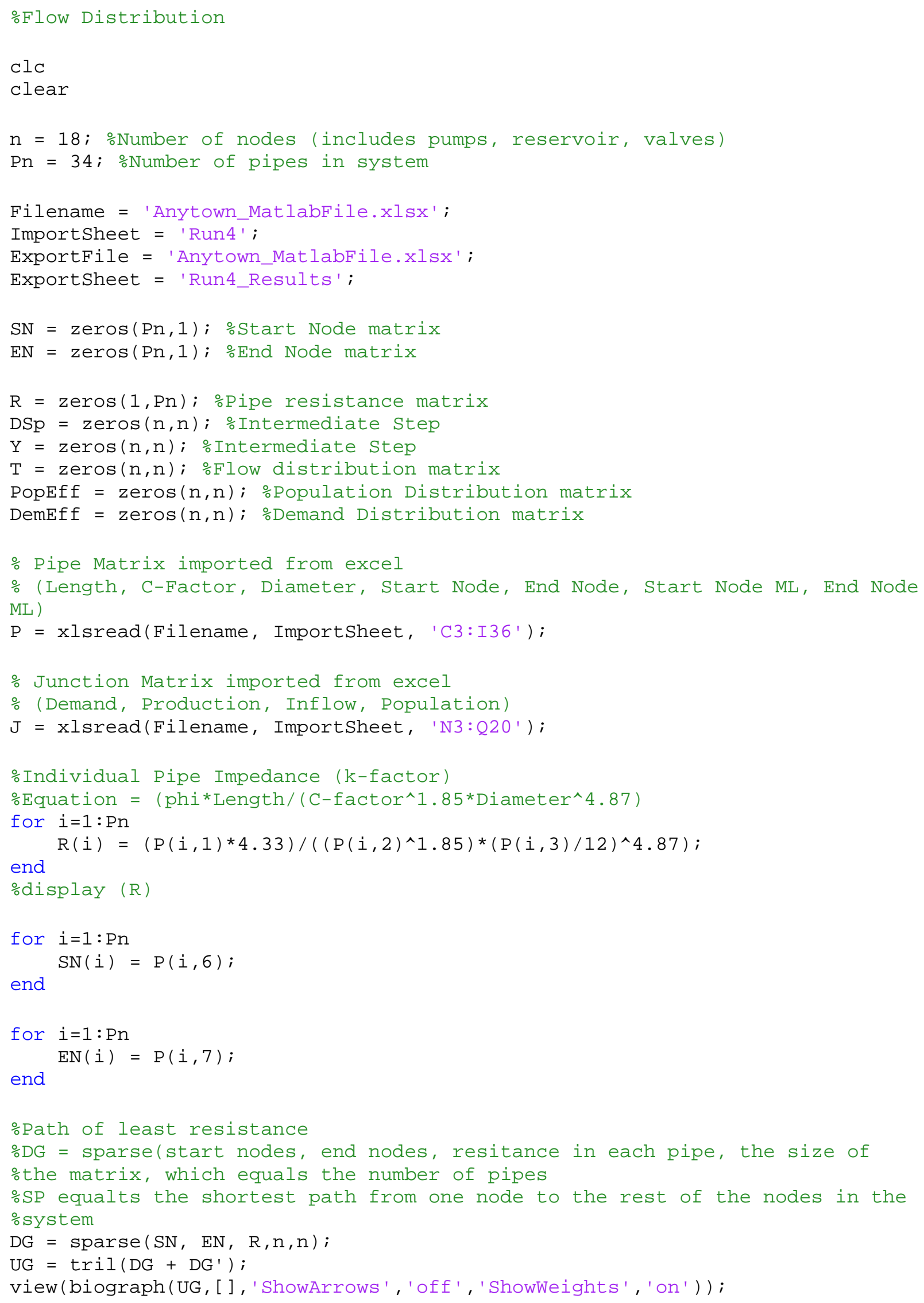




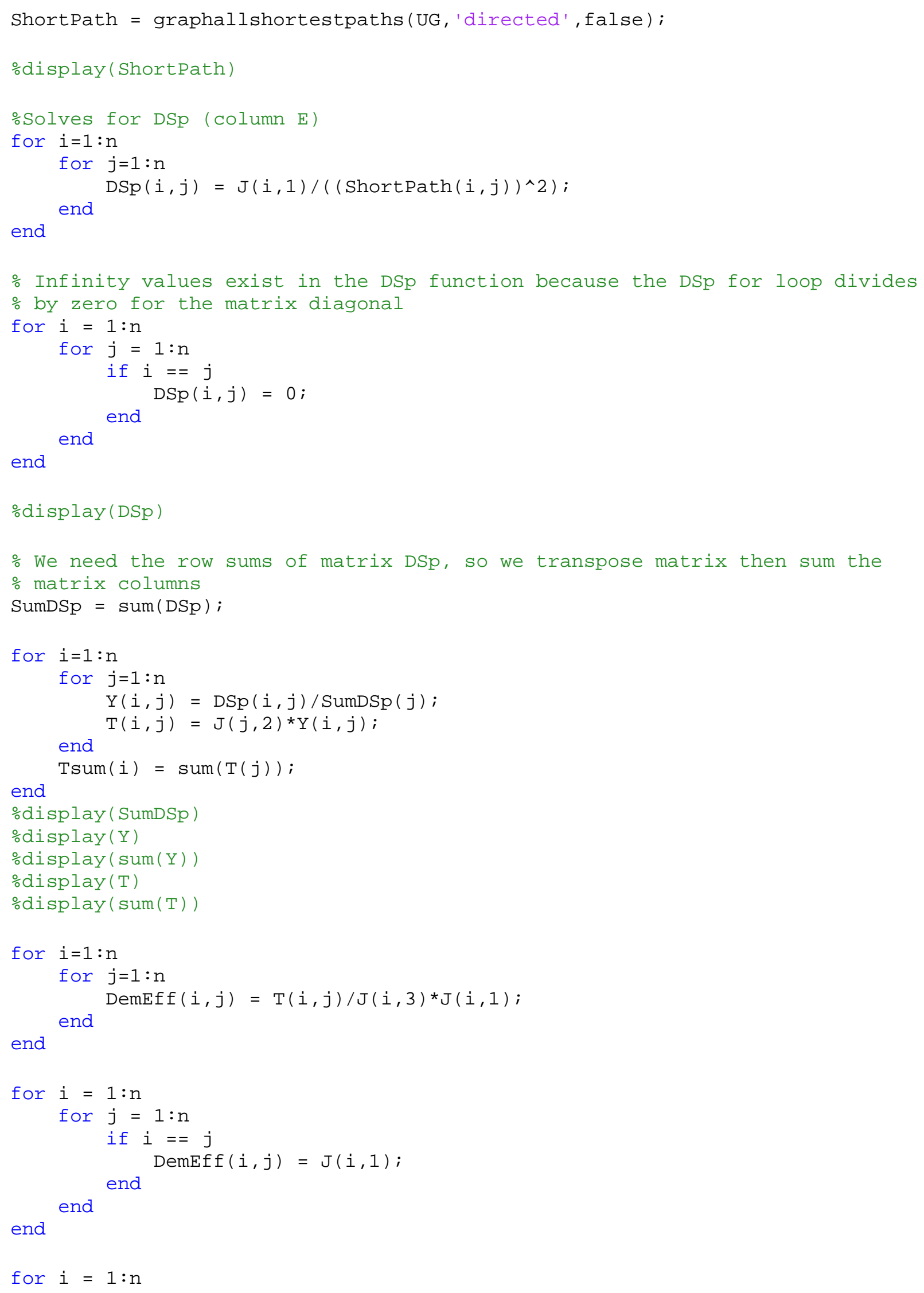




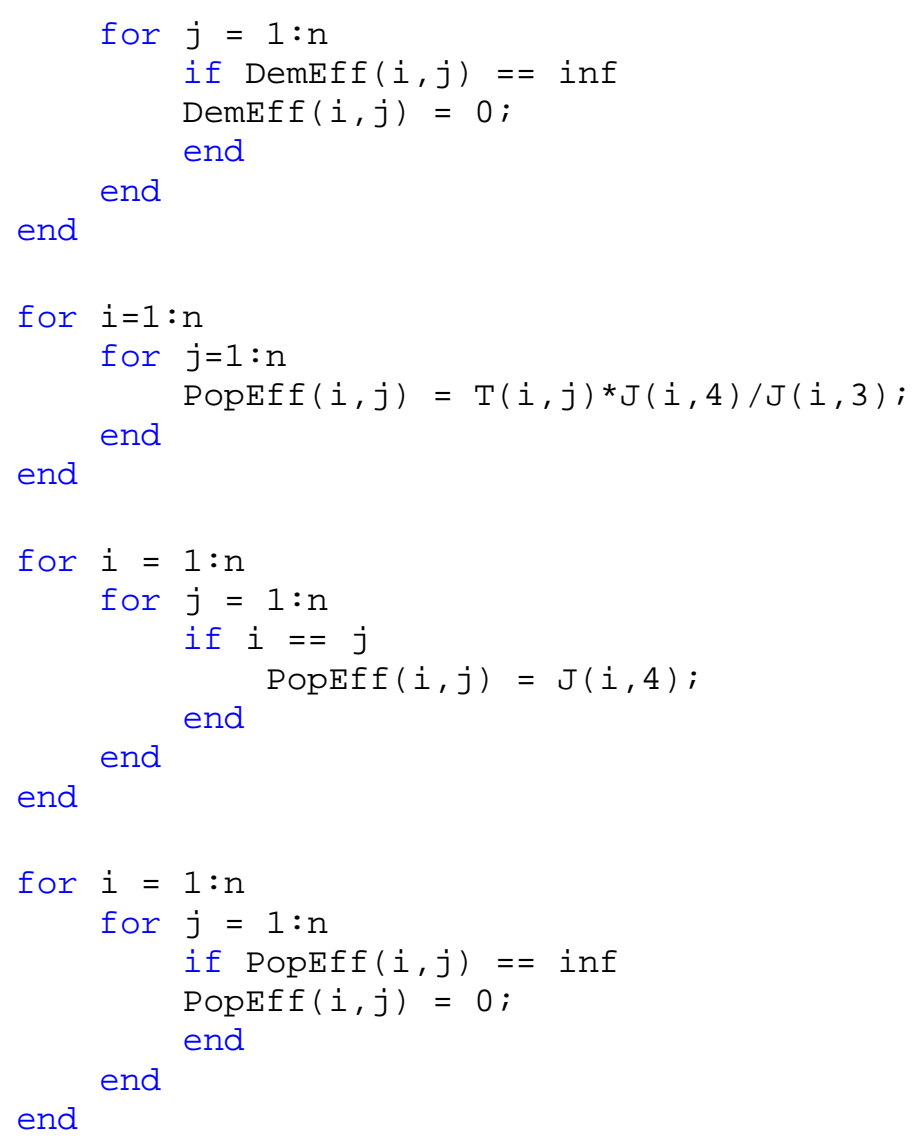


Appendix B: Tank Sizing 


\section{Appendix C: Disaster Scenario 1}

Normal Operating Conditions

Failure Scenario 'J-20 Out'

Failure Scenario 'J-30 Out'

Failure Scenario 'J-40 Out'

Failure Scenario 'J-50 Out'

Failure Scenario 'J-60 Out'

Failure Scenario 'J-70 Out'

Failure Scenario 'J-80 Out'

Failure Scenario 'J-90 Out'

Failure Scenario 'J-100 Out'

Failure Scenario 'J-100 Out'

Failure Scenario 'J-110 Out'

Failure Scenario 'J-120 Out'

Failure Scenario 'J-130 Out'

Failure Scenario 'J-140 Out'

Failure Scenario 'J-150 Out'

Failure Scenario 'J-160 Out'

Failure Scenario 'J-170 Out' 


\section{Normal Operating Conditions}

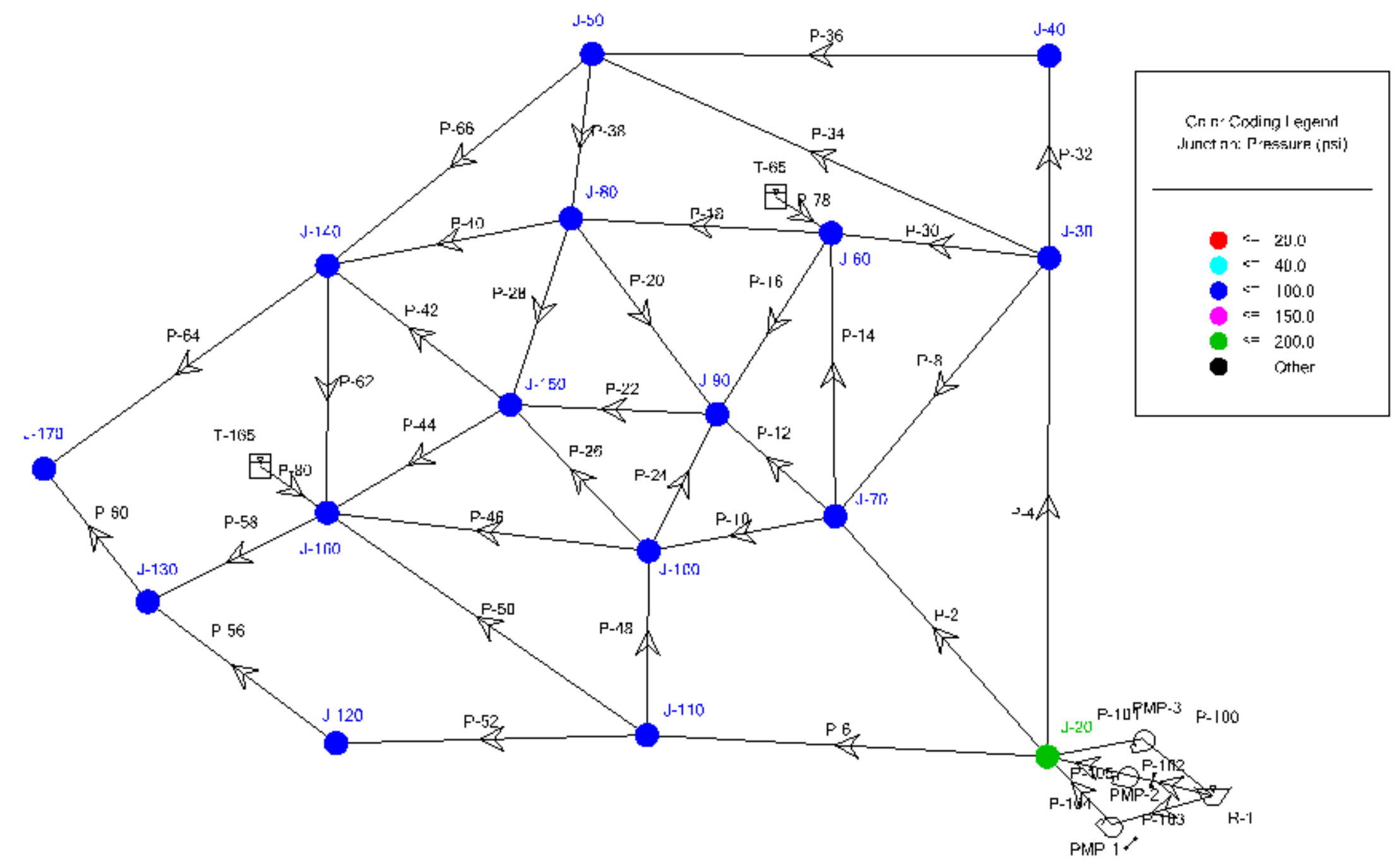


Pipe Information Imported into Matlab from WaterCAD

\begin{tabular}{|c|c|c|c|c|c|c|c|c|c|}
\hline No. & Pipe & $\begin{array}{l}\text { Length } \\
(\mathrm{ft})\end{array}$ & C-Factor & $\begin{array}{l}\text { Dia. } \\
\text { (in.) }\end{array}$ & $\begin{array}{l}\text { Start } \\
\text { Node }\end{array}$ & $\begin{array}{l}\text { Stop } \\
\text { Node }\end{array}$ & $\begin{array}{l}\text { Start } \\
\text { Node }\end{array}$ & $\begin{array}{l}\text { Stop } \\
\text { Node }\end{array}$ & $\begin{array}{l}\text { Flow } \\
\text { (gpm }\end{array}$ \\
\hline 1 & P-2 & 12000 & 70 & 16 & $J-20$ & $\mathrm{~J}-70$ & 1 & 6 & 2,568 \\
\hline 2 & P-4 & 12000 & 120 & 12 & $\mathrm{~J}-20$ & $\mathrm{~J}-30$ & 1 & 2 & 2,064 \\
\hline 3 & P-6 & 12000 & 70 & 12 & $J-20$ & $\mathrm{~J}-110$ & 1 & 10 & 1,224 \\
\hline 4 & P-8 & 9000 & 70 & 12 & $\mathrm{~J}-30$ & $\mathrm{~J}-70$ & 2 & 6 & 40 \\
\hline 5 & P-10 & 600 & 70 & 12 & $\mathrm{~J}-70$ & $\mathrm{~J}-100$ & 6 & 9 & 922 \\
\hline 6 & P-12 & 600 & 70 & 10 & $\mathrm{~J}-70$ & J-90 & 6 & 8 & 578 \\
\hline 7 & P-14 & 600 & 70 & 12 & $\mathrm{~J}-70$ & $J-60$ & 6 & 5 & 458 \\
\hline 8 & P-16 & 600 & 70 & 10 & $J-60$ & J-90 & 5 & 8 & 488 \\
\hline 9 & P-18 & 600 & 70 & 12 & $J-60$ & $\mathrm{~J}-80$ & 5 & 7 & 714 \\
\hline 10 & P-20 & 600 & 70 & 10 & $J-80$ & J-90 & 7 & 8 & 187 \\
\hline 11 & P-22 & 600 & 70 & 10 & $\mathrm{~J}-90$ & $\mathrm{~J}-150$ & 8 & 14 & 26 \\
\hline 12 & P-24 & 600 & 70 & 10 & J-100 & J-90 & 9 & 8 & 73 \\
\hline 13 & P-26 & 600 & 70 & 12 & J-100 & $\mathrm{J}-150$ & 9 & 14 & 128 \\
\hline 14 & P-28 & 600 & 70 & 10 & $\mathrm{~J}-80$ & $\mathrm{~J}-150$ & 7 & 14 & 189 \\
\hline 15 & P-30 & 600 & 120 & 10 & $\mathrm{~J}-30$ & $\mathrm{~J}-60$ & 2 & 5 & 527 \\
\hline 16 & P-32 & 600 & 120 & 10 & $\mathrm{~J}-30$ & $\mathrm{~J}-40$ & 2 & 3 & 572 \\
\hline 17 & P-34 & 600 & 120 & 10 & $\mathrm{~J}-30$ & $J-50$ & 2 & 4 & 665 \\
\hline 18 & P-36 & 600 & 120 & 10 & $\mathrm{~J}-40$ & $J-50$ & 3 & 4 & 312 \\
\hline 19 & P-38 & 600 & 120 & 10 & $J-50$ & $\mathrm{~J}-80$ & 4 & 7 & 637 \\
\hline 20 & P-40 & 600 & 120 & 10 & $\mathrm{~J}-80$ & $\mathrm{~J}-140$ & 7 & 13 & 324 \\
\hline 21 & P-42 & 600 & 120 & 8 & $\mathrm{~J}-150$ & $\mathrm{~J}-140$ & 14 & 13 & 2 \\
\hline 22 & P-44 & 600 & 120 & 8 & J-150 & $\mathrm{J}-160$ & 14 & 15 & 81 \\
\hline 23 & P-46 & 600 & 120 & 8 & $\mathrm{~J}-100$ & $\mathrm{~J}-160$ & 9 & 15 & 114 \\
\hline 24 & P-48 & 600 & 70 & 8 & J-110 & $\mathrm{J}-100$ & 10 & 9 & 43 \\
\hline 25 & P-50 & 600 & 120 & 10 & J-110 & $\mathrm{J}-160$ & 10 & 15 & 249 \\
\hline 26 & P-52 & 600 & 120 & 8 & $\mathrm{~J}-110$ & $\mathrm{~J}-120$ & 10 & 11 & 282 \\
\hline 27 & P-56 & 600 & 120 & 8 & $\mathrm{~J}-120$ & $\mathrm{~J}-130$ & 11 & 12 & 22 \\
\hline 28 & P-58 & 600 & 120 & 10 & $\mathrm{~J}-160$ & $\mathrm{~J}-130$ & 15 & 12 & 432 \\
\hline 29 & P-60 & 600 & 120 & 8 & $\mathrm{~J}-130$ & $\mathrm{~J}-170$ & 12 & 16 & 194 \\
\hline 30 & P-62 & 600 & 120 & 8 & $\mathrm{~J}-140$ & $\mathrm{~J}-160$ & 13 & 15 & 81 \\
\hline 31 & P-64 & 12000 & 120 & 8 & $\mathrm{~J}-140$ & $\mathrm{~J}-170$ & 13 & 16 & 66 \\
\hline 32 & P-66 & 12000 & 120 & 8 & $J-50$ & $\mathrm{~J}-140$ & 4 & 13 & 80 \\
\hline 33 & P-78 & 100 & 120 & 12 & $T-65$ & $\mathrm{~J}-60$ & 17 & 5 & 867 \\
\hline 34 & P-80 & 100 & 120 & 12 & T-165 & $\mathrm{J}-160$ & 18 & 15 & 947 \\
\hline 35 & P-100 & 1 & 130 & 6 & PMP-3 & $\mathrm{J}-20$ & 22 & 1 & 0 \\
\hline 36 & P-101 & 1 & 130 & 6 & PMP-3 & $\mathrm{R}-1$ & 22 & 19 & 0 \\
\hline 37 & P-102 & 1 & 130 & 6 & $\mathrm{R}-1$ & PMP-2 & 19 & 21 & 3,253 \\
\hline 38 & P-103 & 1 & 130 & 6 & R-1 & PMP-1 & 19 & 20 & 3,253 \\
\hline 39 & P-104 & 1 & 130 & 6 & PMP-1 & $J-20$ & 20 & 1 & 3,253 \\
\hline 40 & P-105 & 1 & 130 & 6 & PMP-2 & $J-20$ & 21 & 1 & 3,253 \\
\hline \multicolumn{10}{|c|}{ Matlab Input } \\
\hline
\end{tabular}




\section{Junction Information Imported into Matlab}

\begin{tabular}{cc|cccc|} 
Junc. & $\begin{array}{c}\text { Matlab } \\
\text { ID }\end{array}$ & $\begin{array}{c}\text { Demand } \\
\text { (gpm) }\end{array}$ & $\begin{array}{c}\text { Node } \\
\text { Outflow }\end{array}$ & $\begin{array}{c}\text { Inflow } \\
\text { (gpm) }\end{array}$ & Pop \\
\hline J-20 & 1 & 650 & 5856 & 6506 & 3069 \\
J-30 & 2 & 260 & 1804 & 2064 & 1421 \\
J-40 & 3 & 260 & 312 & 572 & 6100 \\
J-50 & 4 & 260 & 717 & 977 & 5953 \\
J-60 & 5 & 650 & 1202 & 1852 & 2297 \\
J-70 & 6 & 650 & 1958 & 2608 & 827 \\
J-80 & 7 & 650 & 700 & 1351 & 4189 \\
J-90 & 8 & 1,300 & 26 & 1326 & 6082 \\
J-100 & 9 & 650 & 315 & 965 & 716 \\
J-110 & 10 & 650 & 574 & 1224 & 4642 \\
J-120 & 11 & 260 & 22 & 282 & 4949 \\
J-130 & 12 & 260 & 194 & 454 & 5170 \\
J-140 & 13 & 260 & 147 & 406 & 5248 \\
J-150 & 14 & 260 & 83 & 343 & 4330 \\
J-160 & 15 & 1,040 & 432 & 1472 & 1487 \\
J-170 & 16 & 260 & 0 & 260 & 1901 \\
T-65 & 17 & 0 & 867 & 0 & 0 \\
T-165 & 18 & 0 & 947 & 0 & 0 \\
R-1 & 19 & 0 & 6506 & 0 & 0 \\
PMP-1 & 20 & 0 & 3253 & 3253 & 0 \\
PMP-2 & 21 & 0 & 3253 & 3253 & 0 \\
PMP-3 & 22 & 0 & 0 & 0 & 0 \\
& & & Matlab Input &
\end{tabular}

Node inflow and outflow were calculated using the 'Sumif' command in Excel. For each junction, only the flows that had start and stop nodes equal to the junction in question were summed to solve for the outflow and inflow. 
Flow Distribution Results: Demand Affected

\begin{tabular}{c|cccccccccccccccc} 
& $\mathrm{J}-20$ & $\mathrm{~J}-30$ & $\mathrm{~J}-40$ & $\mathrm{~J}-50$ & $\mathrm{~J}-60$ & $\mathrm{~J}-70$ & $\mathrm{~J}-80$ & $\mathrm{~J}-90$ & $\mathrm{~J}-100$ & $\mathrm{~J}-110$ & $\mathrm{~J}-120$ & $\mathrm{~J}-130$ & $\mathrm{~J}-140$ & $\mathrm{~J}-150$ & $\mathrm{~J}-160$ & $\mathrm{~J}-170$ \\
\hline $\mathrm{J}-20$ & 650 & 1 & 0 & 0 & 1 & 3 & 0 & 0 & 0 & 0 & 0 & 0 & 0 & 0 & 0 & 0 \\
$\mathrm{~J}-30$ & 27 & 260 & 9 & 14 & 21 & 9 & 3 & 0 & 1 & 0 & 0 & 0 & 0 & 0 & 0 & 0 \\
$\mathrm{~J}-40$ & 76 & 122 & 260 & 50 & 19 & 14 & 12 & 0 & 2 & 1 & 0 & 0 & 1 & 0 & 1 & 0 \\
$\mathrm{~J}-50$ & 44 & 72 & 19 & 260 & 11 & 8 & 29 & 0 & 1 & 1 & 0 & 0 & 2 & 0 & 1 & 0 \\
$\mathrm{~J}-60$ & 248 & 236 & 16 & 24 & 650 & 215 & 76 & 0 & 11 & 3 & 0 & 1 & 6 & 2 & 3 & 0 \\
$\mathrm{~J}-70$ & 255 & 37 & 5 & 7 & 82 & 650 & 13 & 0 & 30 & 3 & 0 & 1 & 2 & 3 & 3 & 0 \\
$\mathrm{~J}-80$ & 249 & 81 & 22 & 132 & 158 & 74 & 650 & 0 & 6 & 5 & 0 & 2 & 35 & 4 & 7 & 0 \\
$\mathrm{~J}-90$ & 883 & 94 & 16 & 38 & 107 & 200 & 70 & 1300 & 39 & 12 & 1 & 4 & 10 & 15 & 13 & 0 \\
$\mathrm{~J}-100$ & 477 & 43 & 7 & 10 & 55 & 413 & 16 & 0 & 650 & 12 & 1 & 4 & 3 & 30 & 17 & 0 \\
$\mathrm{~J}-110$ & 147 & 7 & 2 & 4 & 6 & 16 & 6 & 0 & 5 & 650 & 3 & 11 & 2 & 2 & 119 & 0 \\
$\mathrm{~J}-120$ & 62 & 3 & 1 & 1 & 2 & 4 & 2 & 0 & 1 & 12 & 260 & 4 & 1 & 0 & 5 & 0 \\
$\mathrm{~J}-130$ & 63 & 3 & 1 & 2 & 3 & 7 & 2 & 0 & 2 & 16 & 1 & 260 & 1 & 1 & 51 & 0 \\
$\mathrm{~J}-140$ & 105 & 19 & 5 & 18 & 24 & 19 & 69 & 0 & 2 & 5 & 0 & 1 & 260 & 2 & 7 & 0 \\
$\mathrm{~J}-150$ & 169 & 12 & 3 & 7 & 12 & 50 & 12 & 0 & 39 & 6 & 0 & 2 & 3 & 260 & 8 & 0 \\
$\mathrm{~J}-160$ & 381 & 21 & 6 & 13 & 18 & 52 & 19 & 0 & 19 & 314 & 4 & 98 & 9 & 7 & 1040 & 0 \\
$\mathrm{~J}-170$ & 67 & 3 & 1 & 1 & 2 & 5 & 2 & 0 & 1 & 5 & 1 & 4 & 1 & 0 & 6 & 260 \\
\hline Total & 3,905 & 1,016 & 372 & 581 & 1,169 & 1,737 & 982 & 1,300 & 810 & 1,044 & 273 & 392 & 336 & 326 & 1,282 & 260
\end{tabular}


Flow Distribution Results: Population Affected

\begin{tabular}{c|cccccccccccccccc} 
& $\mathrm{J}-20$ & $\mathrm{~J}-30$ & $\mathrm{~J}-40$ & $\mathrm{~J}-50$ & $\mathrm{~J}-60$ & $\mathrm{~J}-70$ & $\mathrm{~J}-80$ & $\mathrm{~J}-90$ & $\mathrm{~J}-100$ & $\mathrm{~J}-110$ & $\mathrm{~J}-120$ & $\mathrm{~J}-130$ & $\mathrm{~J}-140$ & $\mathrm{~J}-150$ & $\mathrm{~J}-160$ & $\mathrm{~J}-170$ \\
\hline $\mathrm{J}-20$ & 3069 & 5 & 1 & 2 & 4 & 12 & 2 & 0 & 2 & 1 & 0 & 0 & 0 & 0 & 1 & 0 \\
$\mathrm{~J}-30$ & 147 & 1421 & 50 & 76 & 113 & 47 & 18 & 0 & 4 & 2 & 0 & 0 & 2 & 1 & 2 & 0 \\
$\mathrm{~J}-40$ & 1780 & 2872 & 6100 & 1171 & 436 & 335 & 286 & 0 & 36 & 24 & 2 & 8 & 34 & 11 & 27 & 0 \\
$\mathrm{~J}-50$ & 1017 & 1641 & 446 & 5953 & 249 & 192 & 654 & 0 & 20 & 19 & 2 & 6 & 44 & 10 & 22 & 0 \\
$\mathrm{~J}-60$ & 878 & 835 & 57 & 85 & 2297 & 760 & 267 & 0 & 37 & 9 & 1 & 3 & 20 & 6 & 11 & 0 \\
$\mathrm{~J}-70$ & 325 & 48 & 6 & 9 & 104 & 827 & 17 & 0 & 38 & 3 & 0 & 1 & 2 & 4 & 4 & 0 \\
$\mathrm{~J}-80$ & 1607 & 522 & 142 & 851 & 1019 & 475 & 4189 & 0 & 41 & 35 & 3 & 11 & 224 & 24 & 44 & 0 \\
$\mathrm{~J}-90$ & 4133 & 440 & 74 & 179 & 501 & 934 & 329 & 6082 & 183 & 56 & 5 & 17 & 47 & 68 & 63 & 0 \\
$\mathrm{~J}-100$ & 525 & 48 & 8 & 11 & 61 & 455 & 18 & 0 & 716 & 13 & 1 & 4 & 3 & 33 & 19 & 0 \\
$\mathrm{~J}-110$ & 1049 & 53 & 14 & 29 & 42 & 112 & 41 & 0 & 36 & 4642 & 24 & 82 & 17 & 13 & 849 & 0 \\
$\mathrm{~J}-120$ & 1185 & 48 & 13 & 24 & 35 & 83 & 30 & 0 & 22 & 222 & 4949 & 69 & 11 & 8 & 100 & 0 \\
$\mathrm{~J}-130$ & 1260 & 63 & 17 & 35 & 50 & 135 & 50 & 0 & 43 & 317 & 29 & 5170 & 21 & 16 & 1020 & 0 \\
$\mathrm{~J}-140$ & 2111 & 389 & 106 & 357 & 475 & 380 & 1394 & 0 & 47 & 92 & 6 & 29 & 5248 & 33 & 132 & 0 \\
$\mathrm{~J}-150$ & 2814 & 194 & 45 & 108 & 198 & 832 & 198 & 0 & 653 & 96 & 6 & 30 & 45 & 4330 & 138 & 0 \\
$\mathrm{~J}-160$ & 545 & 31 & 8 & 18 & 26 & 74 & 28 & 0 & 28 & 449 & 6 & 140 & 13 & 10 & 1487 & 0 \\
$\mathrm{~J}-170$ & 494 & 20 & 5 & 10 & 15 & 34 & 12 & 0 & 9 & 33 & 5 & 29 & 4 & 3 & 42 & 1901 \\
\hline Total & 22,937 & 8,629 & 7,091 & 8,920 & 5,626 & 5,688 & 7,534 & 6,082 & 1,915 & 6,014 & 5,040 & 5,599 & 5,738 & 4,571 & 3,960 & 1,901
\end{tabular}


Demand during Normal Operating Conditions

\begin{tabular}{|c|c|c|c|c|c|c|c|c|c|c|c|c|c|c|c|}
\hline $\mathrm{J}-20$ & $\mathrm{~J}-30$ & $\mathrm{~J}-40$ & $J-50$ & $\mathrm{~J}-60$ & $\mathrm{~J}-70$ & $\mathrm{~J}-80$ & J-90 & $\mathrm{J}-100$ & $\mathrm{~J}-110$ & $\mathrm{~J}-120$ & $\mathrm{~J}-130$ & $\mathrm{~J}-140$ & $\mathrm{~J}-150$ & $\mathrm{~J}-160$ & $\mathrm{~J}-170$ \\
\hline 350 & 140 & 140 & 140 & 350 & 350 & 350 & 700 & 350 & 350 & 140 & 140 & 140 & 140 & 560 & 140 \\
\hline 350 & 140 & 140 & 140 & 350 & 350 & 350 & 700 & 350 & 350 & 140 & 140 & 140 & 140 & 560 & 140 \\
\hline 350 & 140 & 140 & 140 & 350 & 350 & 350 & 700 & 350 & 350 & 140 & 140 & 140 & 140 & 560 & 140 \\
\hline 300 & 120 & 120 & 120 & 300 & 300 & 300 & 600 & 300 & 300 & 120 & 120 & 120 & 120 & 480 & 120 \\
\hline 300 & 120 & 120 & 120 & 300 & 300 & 300 & 600 & 300 & 300 & 120 & 120 & 120 & 120 & 480 & 120 \\
\hline 300 & 120 & 120 & 120 & 300 & 300 & 300 & 600 & 300 & 300 & 120 & 120 & 120 & 120 & 480 & 120 \\
\hline 600 & 240 & 240 & 240 & 600 & 600 & 600 & 1200 & 600 & 600 & 240 & 240 & 240 & 240 & 960 & 240 \\
\hline 600 & 240 & 240 & 240 & 600 & 600 & 600 & 1200 & 600 & 600 & 240 & 240 & 240 & 240 & 960 & 240 \\
\hline 600 & 240 & 240 & 240 & 600 & 600 & 600 & 1200 & 600 & 600 & 240 & 240 & 240 & 240 & 960 & 240 \\
\hline 650 & 260 & 260 & 260 & 650 & 650 & 650 & 1300 & 650 & 650 & 260 & 260 & 260 & 260 & 1040 & 260 \\
\hline 650 & 260 & 260 & 260 & 650 & 650 & 650 & 1300 & 650 & 650 & 260 & 260 & 260 & 260 & 1040 & 260 \\
\hline 650 & 260 & 260 & 260 & 650 & 650 & 650 & 1300 & 650 & 650 & 260 & 260 & 260 & 260 & 1040 & 260 \\
\hline 600 & 240 & 240 & 240 & 600 & 600 & 600 & 1200 & 600 & 600 & 240 & 240 & 240 & 240 & 960 & 240 \\
\hline 600 & 240 & 240 & 240 & 600 & 600 & 600 & 1200 & 600 & 600 & 240 & 240 & 240 & 240 & 960 & 240 \\
\hline 600 & 240 & 240 & 240 & 600 & 600 & 600 & 1200 & 600 & 600 & 240 & 240 & 240 & 240 & 960 & 240 \\
\hline 550 & 220 & 220 & 220 & 550 & 550 & 550 & 1100 & 550 & 550 & 220 & 220 & 220 & 220 & 880 & 220 \\
\hline 550 & 220 & 220 & 220 & 550 & 550 & 550 & 1100 & 550 & 550 & 220 & 220 & 220 & 220 & 880 & 220 \\
\hline 550 & 220 & 220 & 220 & 550 & 550 & 550 & 1100 & 550 & 550 & 220 & 220 & 220 & 220 & 880 & 220 \\
\hline 500 & 200 & 200 & 200 & 500 & 500 & 500 & 1000 & 500 & 500 & 200 & 200 & 200 & 200 & 800 & 200 \\
\hline 500 & 200 & 200 & 200 & 500 & 500 & 500 & 1000 & 500 & 500 & 200 & 200 & 200 & 200 & 800 & 200 \\
\hline 500 & 200 & 200 & 200 & 500 & 500 & 500 & 1000 & 500 & 500 & 200 & 200 & 200 & 200 & 800 & 200 \\
\hline 450 & 180 & 180 & 180 & 450 & 450 & 450 & 900 & 450 & 450 & 180 & 180 & 180 & 180 & 720 & 180 \\
\hline 450 & 180 & 180 & 180 & 450 & 450 & 450 & 900 & 450 & 450 & 180 & 180 & 180 & 180 & 720 & 180 \\
\hline 450 & 180 & 180 & 180 & 450 & 450 & 450 & 900 & 450 & 450 & 180 & 180 & 180 & 180 & 720 & 180 \\
\hline 350 & 140 & 140 & 140 & 350 & 350 & 350 & 700 & 350 & 350 & 140 & 140 & 140 & 140 & 560 & 140 \\
\hline 12,350 & 4,940 & 4,940 & 4,940 & 12,350 & 12,350 & 12,350 & 24,700 & 12,350 & 12,350 & 4,940 & 4,940 & 4,940 & 4,940 & 19,760 & 4,940 \\
\hline
\end{tabular}


Failure Scenario 'J-20 Out'

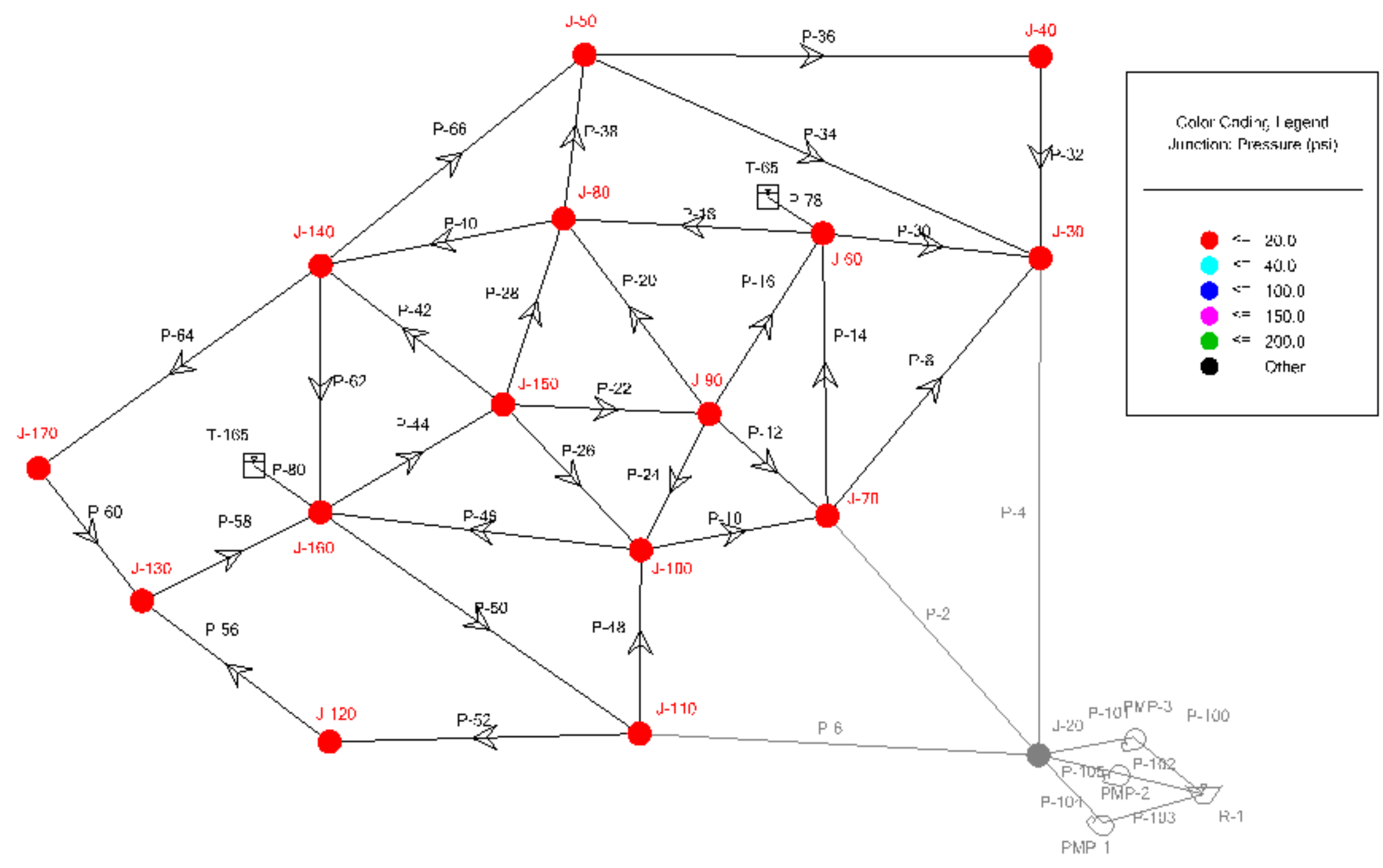


Demand Supplied

\begin{tabular}{|c|c|c|c|c|c|c|c|c|c|c|c|c|c|c|c|c|}
\hline $\begin{array}{l}\text { Time } \\
\text { (hrs) }\end{array}$ & $J-20$ & $\mathrm{~J}-30$ & $\mathrm{~J}-40$ & $J-50$ & $J-60$ & $\mathrm{~J}-70$ & $\mathrm{~J}-80$ & J-90 & J-100 & $\mathrm{J}-110$ & $\mathrm{~J}-120$ & $\mathrm{~J}-130$ & J-140 & $\mathrm{J}-150$ & $\mathrm{~J}-160$ & $\mathrm{~J}-170$ \\
\hline 0 & 0 & 140 & 500 & 140 & 350 & 350 & 350 & 700 & 350 & 350 & 1140 & 500 & 140 & 140 & 560 & 140 \\
\hline 1 & 0 & 140 & 500 & 140 & 350 & 350 & 350 & 700 & 350 & 350 & 1130 & 500 & 140 & 140 & 560 & 140 \\
\hline 2 & 0 & 140 & 500 & 140 & 350 & 350 & 350 & 700 & 350 & 350 & 1107 & 495 & 140 & 140 & 560 & 139 \\
\hline 3 & 0 & 0 & 0 & 0 & 0 & 0 & 0 & 0 & 0 & 0 & 0 & 0 & 0 & 0 & 0 & 0 \\
\hline 4 & 0 & 0 & 0 & 0 & 0 & 0 & 0 & 0 & 0 & 0 & 0 & 0 & 0 & 0 & 0 & 0 \\
\hline 5 & 0 & 0 & 0 & 0 & 0 & 0 & 0 & 0 & 0 & 0 & 0 & 0 & 0 & 0 & 0 & 0 \\
\hline 6 & 0 & 0 & 0 & 0 & 0 & 0 & 0 & 0 & 0 & 0 & 0 & 0 & 0 & 0 & 0 & 0 \\
\hline 7 & 0 & 0 & 0 & 0 & 0 & 0 & 0 & 0 & 0 & 0 & 0 & 0 & 0 & 0 & 0 & 0 \\
\hline 8 & 0 & 0 & 0 & 0 & 0 & 0 & 0 & 0 & 0 & 0 & 0 & 0 & 0 & 0 & 0 & 0 \\
\hline 9 & 0 & 0 & 0 & 0 & 0 & 0 & 0 & 0 & 0 & 0 & 0 & 0 & 0 & 0 & 0 & 0 \\
\hline 10 & 0 & 0 & 0 & 0 & 0 & 0 & 0 & 0 & 0 & 0 & 0 & 0 & 0 & 0 & 0 & 0 \\
\hline 11 & 0 & 0 & 0 & 0 & 0 & 0 & 0 & 0 & 0 & 0 & 0 & 0 & 0 & 0 & 0 & 0 \\
\hline 12 & 0 & 0 & 0 & 0 & 0 & 0 & 0 & 0 & 0 & 0 & 0 & 0 & 0 & 0 & 0 & 0 \\
\hline 13 & 0 & 0 & 0 & 0 & 0 & 0 & 0 & 0 & 0 & 0 & 0 & 0 & 0 & 0 & 0 & 0 \\
\hline 14 & 0 & 0 & 0 & 0 & 0 & 0 & 0 & 0 & 0 & 0 & 0 & 0 & 0 & 0 & 0 & 0 \\
\hline 15 & 0 & 0 & 0 & 0 & 0 & 0 & 0 & 0 & 0 & 0 & 0 & 0 & 0 & 0 & 0 & 0 \\
\hline 16 & 0 & 0 & 0 & 0 & 0 & 0 & 0 & 0 & 0 & 0 & 0 & 0 & 0 & 0 & 0 & 0 \\
\hline 17 & 0 & 0 & 0 & 0 & 0 & 0 & 0 & 0 & 0 & 0 & 0 & 0 & 0 & 0 & 0 & 0 \\
\hline 18 & 0 & 0 & 0 & 0 & 0 & 0 & 0 & 0 & 0 & 0 & 0 & 0 & 0 & 0 & 0 & 0 \\
\hline 19 & 0 & 0 & 0 & 0 & 0 & 0 & 0 & 0 & 0 & 0 & 0 & 0 & 0 & 0 & 0 & 0 \\
\hline 20 & 0 & 0 & 0 & 0 & 0 & 0 & 0 & 0 & 0 & 0 & 0 & 0 & 0 & 0 & 0 & 0 \\
\hline 21 & 0 & 0 & 0 & 0 & 0 & 0 & 0 & 0 & 0 & 0 & 0 & 0 & 0 & 0 & 0 & 0 \\
\hline 22 & 0 & 0 & 0 & 0 & 0 & 0 & 0 & 0 & 0 & 0 & 0 & 0 & 0 & 0 & 0 & 0 \\
\hline 23 & 0 & 0 & 0 & 0 & 0 & 0 & 0 & 0 & 0 & 0 & 0 & 0 & 0 & 0 & 0 & 0 \\
\hline 24 & 0 & 0 & 0 & 0 & 0 & 0 & 0 & 0 & 0 & 0 & 0 & 0 & 0 & 0 & 0 & 0 \\
\hline Total & 0 & 420 & 1500 & 420 & 1050 & 1050 & 1050 & 2100 & 1050 & 1050 & 3377 & 1495 & 420 & 420 & 1680 & 419 \\
\hline
\end{tabular}




\section{'J-20 Out’ Results}

\begin{tabular}{|c|c|c|c|c|c|c|}
\hline \multirow[b]{2}{*}{ Node } & \multicolumn{2}{|c|}{ Demand Supplied } & \multirow[b]{2}{*}{$\begin{array}{l}\text { Demand } \\
\text { Effected }\end{array}$} & \multicolumn{2}{|c|}{ Population Served } & \multirow[b]{2}{*}{$\begin{array}{c}\text { Population } \\
\text { Effected } \\
(7) \\
\end{array}$} \\
\hline & $\begin{array}{c}\text { Normal } \\
\text { Conditions } \\
\text { (2) }\end{array}$ & $\begin{array}{c}\text { Failure } \\
\text { Scenario } \\
\text { J-20 Out } \\
\text { (3) }\end{array}$ & & \begin{tabular}{|c} 
Normal \\
Conditions \\
$(5)$ \\
\end{tabular} & $\begin{array}{c}\text { Failure } \\
\text { Scenario } \\
\text { J-20 Out } \\
\text { (6) }\end{array}$ & \\
\hline $\mathrm{J}-20$ & 12350 & 0 & 12350 & 3069 & 0 & 3069 \\
\hline $\mathrm{J}-30$ & 4940 & 420 & 4520 & 1421 & 121 & 1301 \\
\hline $\mathrm{J}-40$ & 4940 & 1500 & 3440 & 6100 & 1852 & 4248 \\
\hline$J-50$ & 4940 & 420 & 4520 & 5953 & 506 & 5447 \\
\hline$J-60$ & 12350 & 1050 & 11300 & 2297 & 195 & 2102 \\
\hline $\mathrm{J}-70$ & 12350 & 1050 & 11300 & 827 & 70 & 757 \\
\hline $\mathrm{J}-80$ & 12350 & 1050 & 11300 & 4189 & 356 & 3832 \\
\hline$J-90$ & 24700 & 2100 & 22600 & 6082 & 517 & 5565 \\
\hline $\mathrm{J}-100$ & 12350 & 1050 & 11300 & 716 & 61 & 655 \\
\hline $\mathrm{J}-110$ & 12350 & 1050 & 11300 & 4642 & 395 & 4247 \\
\hline $\mathrm{J}-120$ & 4940 & 3377 & 1563 & 4949 & 3383 & 1566 \\
\hline $\mathrm{J}-130$ & 4940 & 1495 & 3445 & 5170 & 1565 & 3605 \\
\hline $\mathrm{J}-140$ & 4940 & 420 & 4520 & 5248 & 446 & 4802 \\
\hline $\mathrm{J}-150$ & 4940 & 420 & 4520 & 4330 & 368 & 3962 \\
\hline J-160 & 19760 & 1680 & 18080 & 1487 & 126 & 1360 \\
\hline J-170 & 4940 & 419 & 4521 & 1901 & 161 & 1740 \\
\hline
\end{tabular}

The equations below were used for every failure scenario.

Column 4 = Column(2) - Column(3)

Column $6=$ [Column(3)/ Column(2)]*Column 5

Column 7 = Column(5) - Column (6) 
Failure Scenario 'J-30 Out'

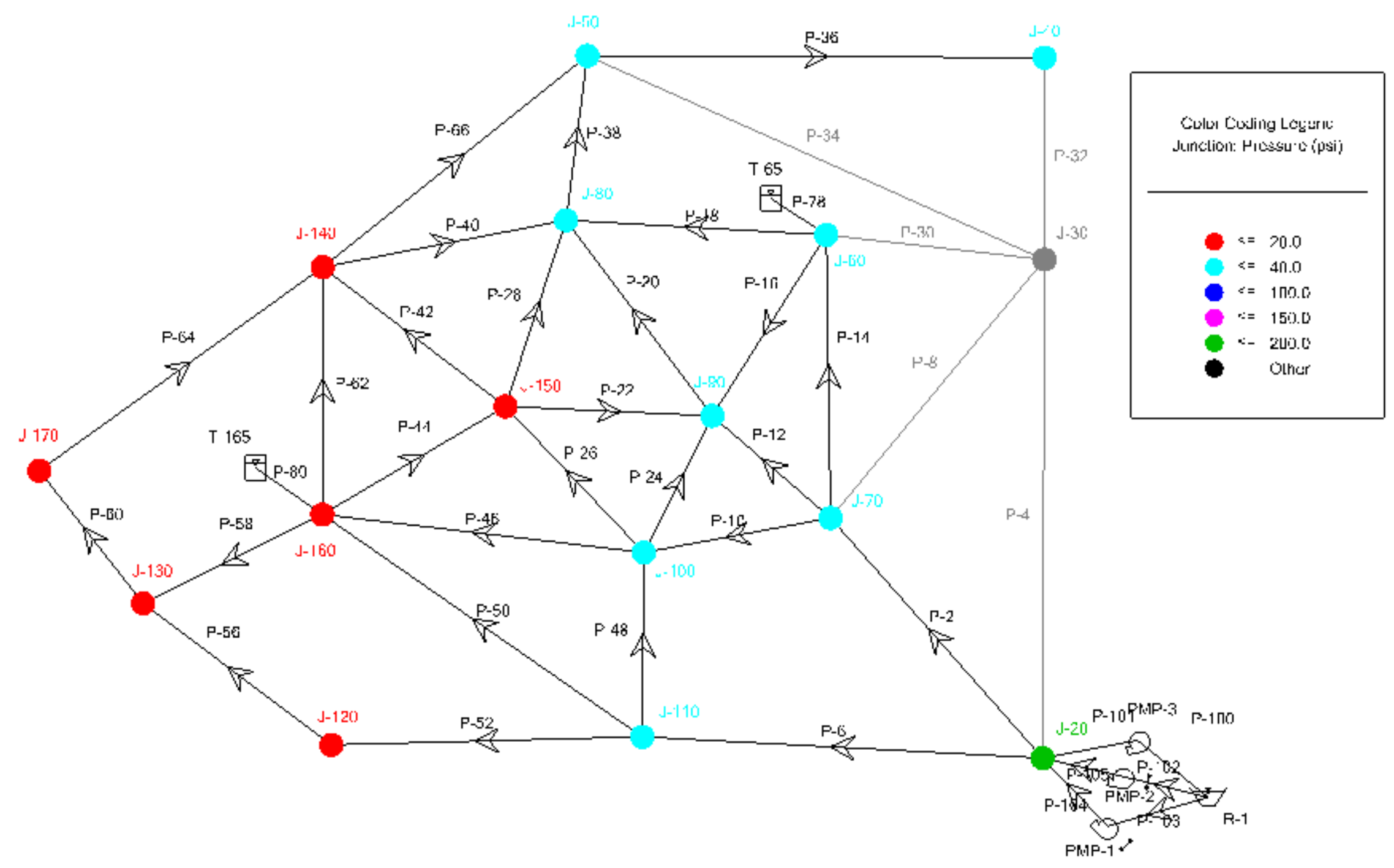




\section{Demand Supplied}

\begin{tabular}{|c|c|c|c|c|c|c|c|c|c|c|c|c|c|c|c|c|}
\hline $\begin{array}{l}\text { Time } \\
\text { (hrs) }\end{array}$ & $\mathrm{J}-20$ & $\mathrm{~J}-30$ & $\mathrm{~J}-40$ & $J-50$ & $\mathrm{~J}-60$ & $\mathrm{~J}-70$ & $\mathrm{~J}-80$ & J-90 & $\mathrm{J}-100$ & $\mathrm{~J}-110$ & $\mathrm{~J}-120$ & $\mathrm{~J}-130$ & $\mathrm{~J}-140$ & $\mathrm{~J}-150$ & $\mathrm{~J}-160$ & $\mathrm{~J}-170$ \\
\hline 0 & 350 & 0.00 & 500 & 140 & 350 & 350 & 350 & 700 & 350 & 350 & 1140 & 500 & 140 & 140 & 560 & 140 \\
\hline 1 & 350 & 0.00 & 500 & 140 & 350 & 350 & 350 & 700 & 350 & 350 & 1140 & 500 & 140 & 140 & 560 & 140 \\
\hline 2 & 350 & 0.00 & 500 & 140 & 350 & 350 & 350 & 700 & 350 & 350 & 1140 & 500 & 140 & 140 & 560 & 140 \\
\hline 3 & 300 & 0.00 & 500 & 120 & 300 & 300 & 300 & 600 & 300 & 300 & 1120 & 500 & 120 & 120 & 480 & 120 \\
\hline 4 & 300 & 0.00 & 500 & 120 & 300 & 300 & 300 & 600 & 300 & 300 & 1120 & 500 & 120 & 120 & 480 & 120 \\
\hline 5 & 300 & 0.00 & 500 & 120 & 300 & 300 & 300 & 600 & 300 & 300 & 1120 & 500 & 120 & 120 & 480 & 120 \\
\hline 6 & 600 & 0.00 & 500 & 240 & 600 & 600 & 600 & 1200 & 600 & 600 & 1240 & 500 & 240 & 240 & 960 & 240 \\
\hline 7 & 600 & 0.00 & 500 & 240 & 600 & 600 & 600 & 1200 & 600 & 600 & 1240 & 500 & 240 & 240 & 960 & 240 \\
\hline 8 & 600 & 0.00 & 322 & 156 & 402 & 435 & 394 & 796 & 401 & 403 & 786 & 320 & 157 & 158 & 628 & 153 \\
\hline 9 & 650 & 0.00 & 304 & 159 & 413 & 450 & 403 & 816 & 411 & 414 & 755 & 302 & 161 & 162 & 643 & 157 \\
\hline 10 & 650 & 0.00 & 304 & 159 & 413 & 450 & 403 & 816 & 411 & 414 & 755 & 302 & 161 & 162 & 643 & 157 \\
\hline 11 & 650 & 0.00 & 304 & 159 & 413 & 450 & 403 & 816 & 411 & 414 & 755 & 302 & 161 & 162 & 643 & 157 \\
\hline 12 & 600 & 0.00 & 322 & 156 & 402 & 435 & 394 & 796 & 401 & 403 & 786 & 320 & 157 & 158 & 628 & 153 \\
\hline 13 & 600 & 0.00 & 322 & 156 & 402 & 435 & 394 & 796 & 401 & 403 & 786 & 320 & 157 & 158 & 628 & 153 \\
\hline 14 & 600 & 0.00 & 322 & 156 & 402 & 435 & 394 & 796 & 401 & 403 & 786 & 320 & 157 & 158 & 628 & 153 \\
\hline 15 & 550 & 0.00 & 342 & 151 & 390 & 418 & 383 & 773 & 389 & 391 & 820 & 340 & 153 & 154 & 611 & 149 \\
\hline 16 & 550 & 0.00 & 342 & 151 & 390 & 418 & 383 & 773 & 389 & 391 & 820 & 340 & 153 & 154 & 611 & 149 \\
\hline 17 & 550 & 0.00 & 342 & 151 & 390 & 418 & 383 & 773 & 389 & 391 & 820 & 340 & 153 & 154 & 611 & 149 \\
\hline 18 & 500 & 0.00 & 364 & 146 & 376 & 400 & 370 & 747 & 375 & 376 & 858 & 361 & 148 & 148 & 590 & 144 \\
\hline 19 & 500 & 0.00 & 364 & 146 & 376 & 400 & 370 & 747 & 375 & 376 & 858 & 361 & 148 & 148 & 590 & 144 \\
\hline 20 & 500 & 0.00 & 364 & 147 & 376 & 400 & 370 & 747 & 375 & 376 & 858 & 361 & 148 & 148 & 590 & 144 \\
\hline 21 & 450 & 0.00 & 388 & 141 & 361 & 381 & 355 & 716 & 359 & 360 & 900 & 385 & 142 & 142 & 567 & 139 \\
\hline 22 & 450 & 0.00 & 388 & 141 & 361 & 381 & 355 & 716 & 359 & 360 & 900 & 385 & 142 & 142 & 567 & 139 \\
\hline 23 & 450 & 0.00 & 388 & 141 & 361 & 381 & 355 & 716 & 359 & 360 & 900 & 385 & 142 & 142 & 567 & 139 \\
\hline 24 & 350 & 0.00 & 446 & 126 & 321 & 334 & 317 & 638 & 320 & 320 & 999 & 443 & 127 & 127 & 506 & 124 \\
\hline Total & 12350 & 0 & 9,928 & 3,802 & 9,699 & 10,171 & 9,576 & 19,278 & 9,676 & 9,705 & 23,402 & 9,887 & 3,827 & 3,837 & 15,291 & 3,763 \\
\hline
\end{tabular}




\section{'J-30 Out' Results}

\begin{tabular}{|c|c|c|c|c|c|c|}
\hline \multirow[b]{2}{*}{ Node } & \multicolumn{2}{|c|}{ Demand Supplied } & \multirow[b]{2}{*}{$\begin{array}{l}\text { Demand } \\
\text { Effected }\end{array}$} & \multicolumn{2}{|c|}{ Population Served } & \multirow[b]{2}{*}{$\begin{array}{c}\text { Population } \\
\text { Effected }\end{array}$} \\
\hline & $\begin{array}{c}\text { Normal } \\
\text { Conditions }\end{array}$ & $\begin{array}{l}\text { Failure } \\
\text { Scenario } \\
\text { J-30 Out }\end{array}$ & & $\begin{array}{c}\text { Normal } \\
\text { Conditions }\end{array}$ & $\begin{array}{l}\text { Failure } \\
\text { Scenario } \\
\text { J-30 Out }\end{array}$ & \\
\hline$(1)$ & (2) & (3) & (4) & (5) & (6) & (7) \\
\hline $\mathrm{J}-20$ & 12350 & 12350 & 0 & 3069 & 3069 & 0 \\
\hline $\mathrm{J}-30$ & 4940 & 0 & 4940 & 1421 & 0 & 1421 \\
\hline $\mathrm{J}-40$ & 4940 & 9928 & -4988 & 6100 & 12259 & -6159 \\
\hline$J-50$ & 4940 & 3802 & 1138 & 5953 & 4582 & 1371 \\
\hline $\mathrm{J}-60$ & 12350 & 9699 & 2651 & 2297 & 1804 & 493 \\
\hline $\mathrm{J}-70$ & 12350 & 10171 & 2179 & 827 & 681 & 146 \\
\hline $\mathrm{J}-80$ & 12350 & 9576 & 2774 & 4189 & 3248 & 941 \\
\hline $\mathrm{J}-90$ & 24700 & 19278 & 5422 & 6082 & 4747 & 1335 \\
\hline $\mathrm{J}-100$ & 12350 & 9676 & 2674 & 716 & 561 & 155 \\
\hline $\mathrm{J}-110$ & 12350 & 9705 & 2645 & 4642 & 3648 & 994 \\
\hline$J-120$ & 4940 & 23402 & -18462 & 4949 & 23445 & -18496 \\
\hline $\mathrm{J}-130$ & 4940 & 9887 & -4947 & 5170 & 10347 & -5177 \\
\hline$J-140$ & 4940 & 3827 & 1113 & 5248 & 4066 & 1182 \\
\hline$J-150$ & 4940 & 3837 & 1103 & 4330 & 3363 & 967 \\
\hline $\mathrm{J}-160$ & 19760 & 15291 & 4469 & 1487 & 1151 & 336 \\
\hline $\mathrm{J}-170$ & 4940 & 3763 & 1177 & 1901 & 1448 & 453 \\
\hline
\end{tabular}


Failure Scenario 'J-40 Out'

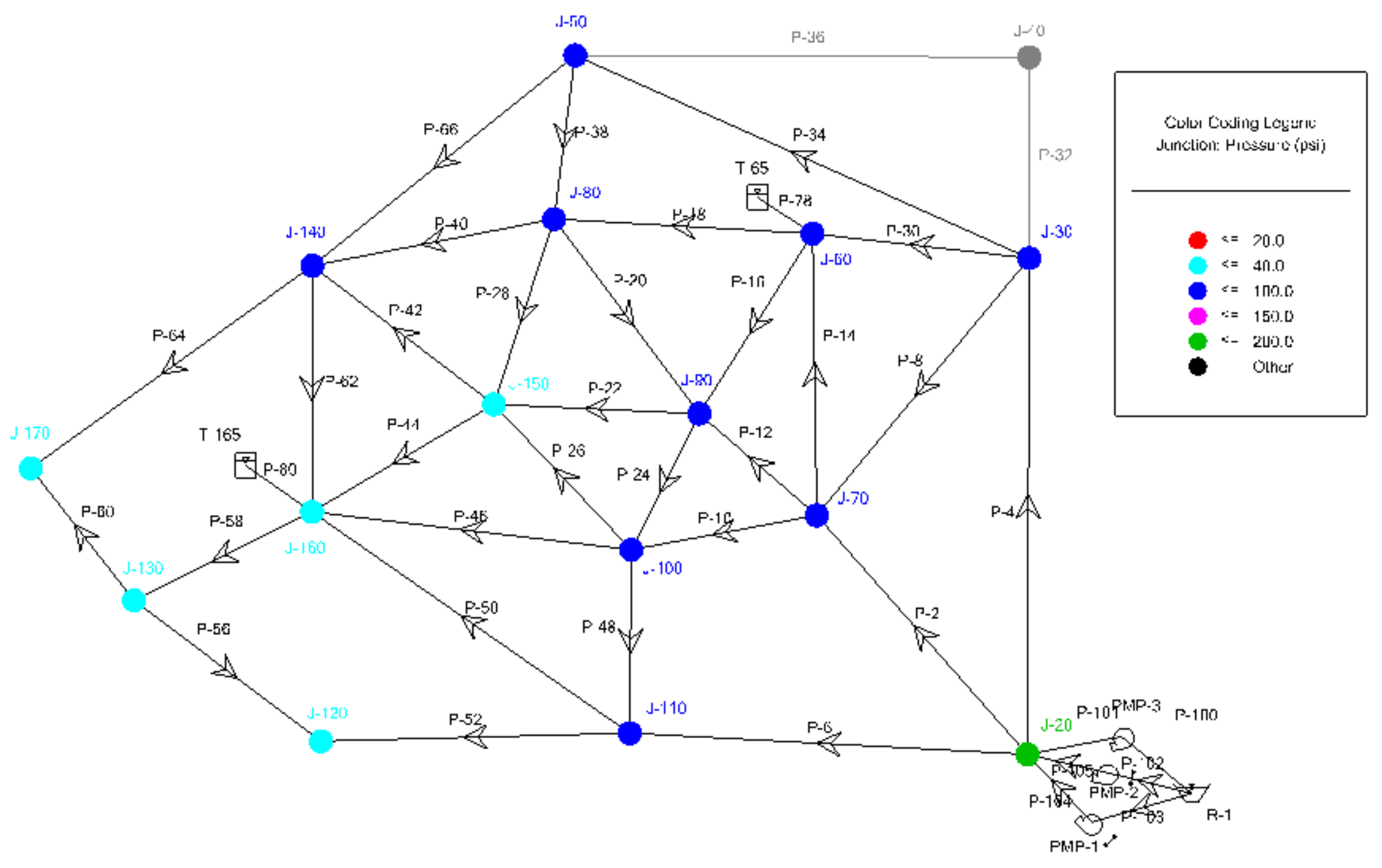




\section{Demand Supplied}

\begin{tabular}{|c|c|c|c|c|c|c|c|c|c|c|c|c|c|c|c|c|}
\hline $\begin{array}{c}\text { Time } \\
\text { (hours) }\end{array}$ & $J-20$ & $\mathrm{~J}-30$ & $\mathrm{~J}-40$ & $J-50$ & $J-60$ & $\mathrm{~J}-70$ & $\mathrm{~J}-80$ & $J-90$ & $\mathrm{~J}-100$ & $\mathrm{~J}-110$ & $\mathrm{~J}-120$ & $\mathrm{~J}-130$ & $\mathrm{~J}-140$ & $\mathrm{~J}-150$ & $\mathrm{~J}-160$ & $\mathrm{~J}-170$ \\
\hline 0 & 350 & 140 & 0 & 140 & 350 & 350 & 350 & 700 & 350 & 350 & 1140 & 500 & 140 & 140 & 560 & 140 \\
\hline 1 & 350 & 140 & 0 & 140 & 350 & 350 & 350 & 700 & 350 & 350 & 1140 & 500 & 140 & 140 & 560 & 140 \\
\hline 2 & 350 & 140 & 0 & 140 & 350 & 350 & 350 & 700 & 350 & 350 & 1140 & 500 & 140 & 140 & 560 & 140 \\
\hline 3 & 300 & 120 & 0 & 120 & 300 & 300 & 300 & 600 & 300 & 300 & 1120 & 500 & 120 & 120 & 480 & 120 \\
\hline 4 & 300 & 120 & 0 & 120 & 300 & 300 & 300 & 600 & 300 & 300 & 1120 & 500 & 120 & 120 & 480 & 120 \\
\hline 5 & 300 & 120 & 0 & 120 & 300 & 300 & 300 & 600 & 300 & 300 & 1120 & 500 & 120 & 120 & 480 & 120 \\
\hline 6 & 600 & 240 & 0 & 240 & 600 & 600 & 600 & 1200 & 600 & 600 & 1240 & 500 & 240 & 240 & 960 & 240 \\
\hline 7 & 600 & 240 & 0 & 240 & 600 & 600 & 600 & 1200 & 600 & 600 & 1240 & 500 & 240 & 240 & 960 & 240 \\
\hline 8 & 600 & 240 & 0 & 240 & 600 & 600 & 600 & 1200 & 600 & 600 & 1240 & 500 & 240 & 240 & 960 & 240 \\
\hline 9 & 650 & 260 & 0 & 260 & 650 & 650 & 650 & 1300 & 650 & 650 & 1260 & 500 & 260 & 260 & 1040 & 260 \\
\hline 10 & 650 & 260 & 0 & 260 & 650 & 650 & 650 & 1300 & 650 & 650 & 1260 & 500 & 260 & 260 & 1040 & 260 \\
\hline 11 & 650 & 260 & 0 & 260 & 650 & 650 & 650 & 1300 & 650 & 650 & 1260 & 500 & 260 & 260 & 1040 & 260 \\
\hline 12 & 600 & 240 & 0 & 240 & 600 & 600 & 600 & 1200 & 600 & 600 & 1240 & 500 & 240 & 240 & 960 & 240 \\
\hline 13 & 600 & 240 & 0 & 240 & 600 & 600 & 600 & 1200 & 600 & 600 & 1240 & 500 & 240 & 240 & 960 & 240 \\
\hline 14 & 600 & 240 & 0 & 240 & 600 & 600 & 600 & 1200 & 600 & 600 & 1240 & 500 & 240 & 240 & 960 & 240 \\
\hline 15 & 550 & 220 & 0 & 220 & 550 & 550 & 550 & 1100 & 550 & 550 & 1220 & 500 & 220 & 220 & 880 & 220 \\
\hline 16 & 550 & 220 & 0 & 220 & 550 & 550 & 550 & 1098 & 548 & 542 & 1151 & 478 & 218 & 219 & 861 & 210 \\
\hline 17 & 550 & 220 & 0 & 220 & 550 & 550 & 550 & 1098 & 548 & 542 & 1151 & 478 & 218 & 219 & 861 & 210 \\
\hline 18 & 500 & 200 & 0 & 200 & 500 & 500 & 500 & 1000 & 500 & 500 & 1200 & 500 & 200 & 200 & 800 & 200 \\
\hline 19 & 500 & 200 & 0 & 200 & 500 & 500 & 500 & 1000 & 500 & 500 & 1200 & 500 & 200 & 200 & 800 & 200 \\
\hline 20 & 500 & 200 & 0 & 200 & 500 & 500 & 500 & 1000 & 500 & 500 & 1200 & 500 & 200 & 200 & 800 & 200 \\
\hline 21 & 450 & 180 & 0 & 180 & 450 & 450 & 450 & 900 & 450 & 450 & 1180 & 500 & 180 & 180 & 720 & 180 \\
\hline 22 & 450 & 180 & 0 & 180 & 450 & 450 & 450 & 900 & 450 & 450 & 1180 & 500 & 180 & 180 & 720 & 180 \\
\hline 23 & 450 & 180 & 0 & 180 & 450 & 450 & 450 & 900 & 450 & 450 & 1180 & 500 & 180 & 180 & 720 & 180 \\
\hline 24 & 350 & 140 & 0 & 140 & 350 & 350 & 350 & 700 & 350 & 350 & 1140 & 500 & 140 & 140 & 560 & 140 \\
\hline Total & 12,350 & 4,940 & 0 & 4,940 & 12,350 & 12,350 & 12,350 & 24,696 & 12,346 & 12,334 & 29,802 & 12,456 & 4,936 & 4,938 & 19,722 & 4,920 \\
\hline
\end{tabular}


'J-40 Out' Results

\begin{tabular}{|c|c|c|c|c|c|c|}
\hline \multirow[b]{2}{*}{ Node } & \multicolumn{2}{|c|}{ Demand Supplied } & \multirow[b]{2}{*}{$\begin{array}{l}\text { Demand } \\
\text { Effected }\end{array}$} & \multicolumn{2}{|c|}{ Population Served } & \multirow[b]{2}{*}{$\begin{array}{c}\text { Population } \\
\text { Effected }\end{array}$} \\
\hline & $\begin{array}{c}\text { Normal } \\
\text { Conditions }\end{array}$ & $\begin{array}{c}\text { Failure } \\
\text { Scenario } \\
\text { J-40 Out }\end{array}$ & & \begin{tabular}{||c} 
Normal \\
Conditions
\end{tabular} & $\begin{array}{c}\text { Failure } \\
\text { Scenario } \\
\text { J-40 Out }\end{array}$ & \\
\hline (1) & (2) & (3) & (4) & (5) & (6) & (7) \\
\hline$J-20$ & 12350 & 12350 & 0 & 3069 & 3069 & 0 \\
\hline$J-30$ & 4940 & 4940 & 0 & 1421 & 1421 & 0 \\
\hline$J-40$ & 4940 & 0 & 4940 & 6100 & 0 & 6100 \\
\hline $\mathrm{J}-50$ & 4940 & 4940 & 0 & 5953 & 5953 & 0 \\
\hline $\mathrm{J}-60$ & 12350 & 12350 & 0 & 2297 & 2297 & 0 \\
\hline$J-70$ & 12350 & 12350 & 0 & 827 & 827 & 0 \\
\hline$J-80$ & 12350 & 12350 & 0 & 4189 & 4189 & 0 \\
\hline$J-90$ & 24700 & 24696 & 4 & 6082 & 6081 & 1 \\
\hline$J-100$ & 12350 & 12346 & 4 & 716 & 716 & 0 \\
\hline $\mathrm{J}-110$ & 12350 & 12334 & 16 & 4642 & 4636 & 6 \\
\hline$J-120$ & 4940 & 29802 & -24862 & 4949 & 29857 & -24908 \\
\hline$J-130$ & 4940 & 12456 & -7516 & 5170 & 13035 & -7865 \\
\hline J-140 & 4940 & 4936 & 4 & 5248 & 5244 & 4 \\
\hline$J-150$ & 4940 & 4938 & 2 & 4330 & 4329 & 2 \\
\hline$J-160$ & 19760 & 19722 & 38 & 1487 & 1484 & 3 \\
\hline $\mathrm{J}-170$ & 4940 & 4920 & 20 & 1901 & 1894 & 8 \\
\hline
\end{tabular}




\section{Failure Scenario ‘J-50’ Out}

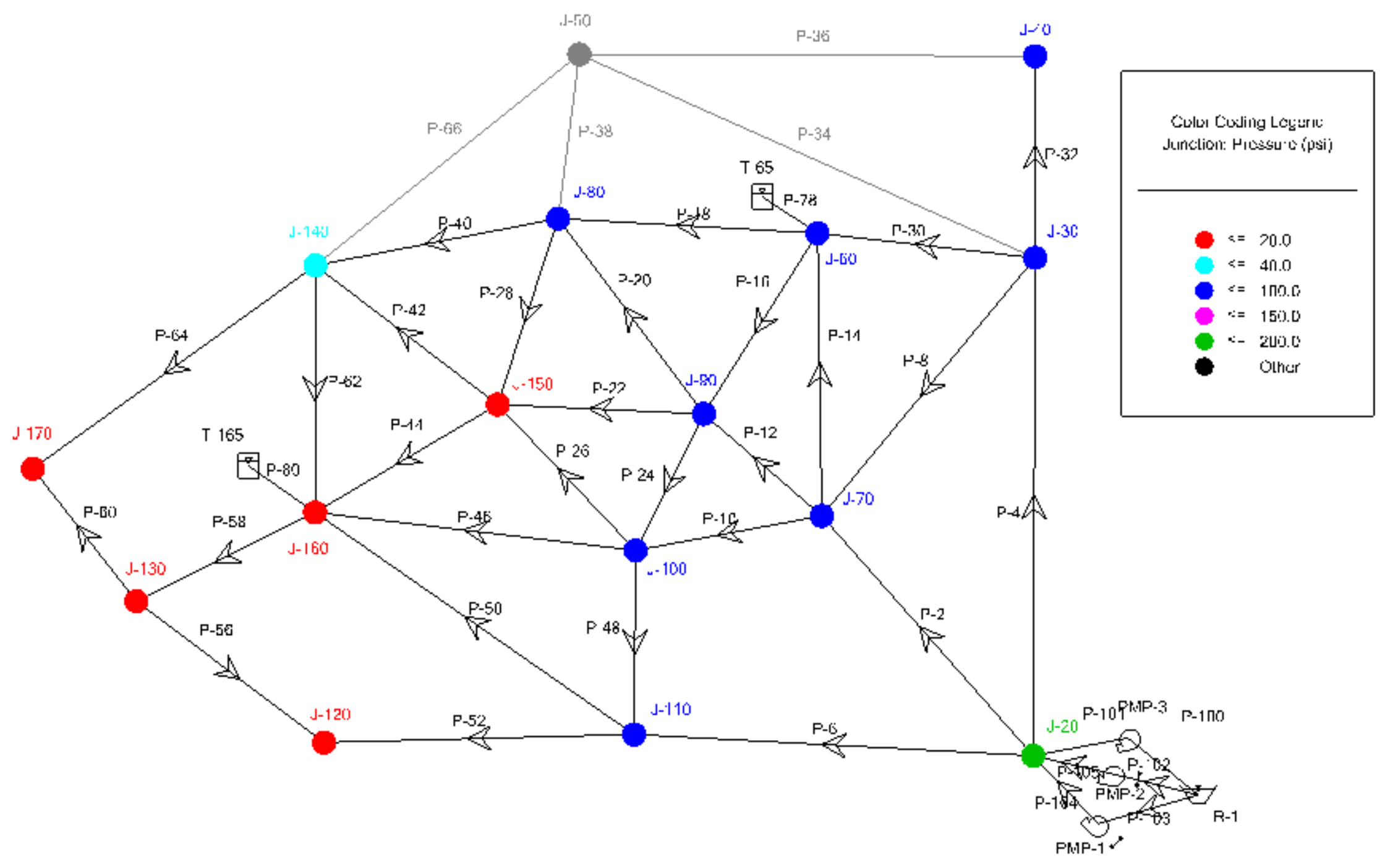




\section{Demand Supplied}

\begin{tabular}{|c|c|c|c|c|c|c|c|c|c|c|c|c|c|c|c|c|}
\hline $\begin{array}{c}\text { Time } \\
\text { (hours) }\end{array}$ & $\mathrm{J}-20$ & $\mathrm{~J}-30$ & $J-40$ & $\mathrm{~J}-50$ & $J-60$ & $\mathrm{~J}-70$ & $\mathrm{~J}-80$ & J-90 & $\mathrm{J}-100$ & $\mathrm{~J}-110$ & $\mathrm{~J}-120$ & $\mathrm{~J}-130$ & $\mathrm{~J}-140$ & $\mathrm{~J}-150$ & $\mathrm{~J}-160$ & $\mathrm{~J}-170$ \\
\hline 0 & 350 & 140 & 500 & 0 & 350 & 350 & 350 & 700 & 350 & 350 & 1140 & 500 & 140 & 140 & 560 & 140 \\
\hline 1 & 350 & 140 & 500 & 0 & 350 & 350 & 350 & 700 & 350 & 350 & 1140 & 500 & 140 & 140 & 560 & 140 \\
\hline 2 & 350 & 140 & 500 & 0 & 350 & 350 & 350 & 700 & 350 & 350 & 1140 & 500 & 140 & 140 & 560 & 140 \\
\hline 3 & 300 & 120 & 500 & 0 & 300 & 300 & 300 & 600 & 300 & 300 & 1120 & 500 & 120 & 120 & 480 & 120 \\
\hline 4 & 300 & 120 & 500 & 0 & 300 & 300 & 300 & 600 & 300 & 300 & 1120 & 500 & 120 & 120 & 480 & 120 \\
\hline 5 & 300 & 120 & 500 & 0 & 300 & 300 & 300 & 600 & 300 & 300 & 1120 & 500 & 120 & 120 & 480 & 120 \\
\hline 6 & 600 & 240 & 500 & 0 & 600 & 600 & 600 & 1200 & 600 & 600 & 1240 & 500 & 240 & 240 & 960 & 240 \\
\hline 7 & 600 & 240 & 500 & 0 & 600 & 600 & 600 & 1200 & 600 & 600 & 1240 & 500 & 240 & 240 & 960 & 240 \\
\hline 8 & 600 & 240 & 500 & 0 & 600 & 600 & 600 & 1200 & 600 & 600 & 1240 & 500 & 240 & 240 & 960 & 240 \\
\hline 9 & 650 & 260 & 500 & 0 & 650 & 650 & 650 & 1300 & 650 & 650 & 1260 & 500 & 260 & 260 & 1040 & 260 \\
\hline 10 & 650 & 260 & 500 & 0 & 650 & 650 & 650 & 1300 & 650 & 650 & 1260 & 500 & 260 & 260 & 1040 & 260 \\
\hline 11 & 650 & 260 & 500 & 0 & 650 & 650 & 650 & 1300 & 650 & 650 & 1260 & 500 & 260 & 260 & 1040 & 260 \\
\hline 12 & 600 & 240 & 500 & 0 & 600 & 600 & 600 & 1200 & 600 & 600 & 1240 & 500 & 240 & 240 & 960 & 240 \\
\hline 13 & 600 & 240 & 500 & 0 & 600 & 600 & 600 & 1200 & 600 & 600 & 1240 & 500 & 240 & 240 & 960 & 240 \\
\hline 14 & 600 & 240 & 498 & 0 & 567 & 577 & 546 & 1093 & 546 & 540 & 1065 & 435 & 217 & 217 & 856 & 209 \\
\hline 15 & 550 & 220 & 500 & 0 & 546 & 550 & 528 & 1057 & 528 & 522 & 1108 & 461 & 210 & 210 & 829 & 203 \\
\hline 16 & 550 & 220 & 500 & 0 & 546 & 550 & 528 & 1057 & 528 & 522 & 1108 & 461 & 210 & 210 & 829 & 203 \\
\hline 17 & 550 & 220 & 500 & 0 & 546 & 550 & 528 & 1057 & 528 & 522 & 1108 & 461 & 210 & 210 & 829 & 203 \\
\hline 18 & 500 & 200 & 500 & 0 & 500 & 500 & 500 & 1000 & 500 & 500 & 1171 & 494 & 200 & 200 & 800 & 198 \\
\hline 19 & 500 & 200 & 500 & 0 & 500 & 500 & 500 & 1000 & 500 & 500 & 1171 & 494 & 200 & 200 & 800 & 198 \\
\hline 20 & 500 & 200 & 500 & 0 & 500 & 500 & 500 & 1000 & 500 & 500 & 1171 & 494 & 200 & 200 & 800 & 198 \\
\hline 21 & 450 & 180 & 500 & 0 & 450 & 450 & 450 & 900 & 450 & 450 & 1180 & 500 & 180 & 180 & 720 & 180 \\
\hline 22 & 450 & 180 & 500 & 0 & 450 & 450 & 450 & 900 & 450 & 450 & 1180 & 500 & 180 & 180 & 720 & 180 \\
\hline 23 & 450 & 180 & 500 & 0 & 450 & 450 & 450 & 900 & 450 & 450 & 1180 & 500 & 180 & 180 & 720 & 180 \\
\hline 24 & 350 & 140 & 500 & 0 & 350 & 350 & 350 & 700 & 350 & 350 & 1140 & 500 & 140 & 140 & 560 & 140 \\
\hline Total & 12350 & 4,940 & 12,498 & 0 & 12,305 & 12,327 & 12,230 & 24,464 & 12,230 & 12,206 & 29,342 & 12,300 & 4,887 & 4,887 & 19,503 & 4,852 \\
\hline
\end{tabular}




\section{'J-50 Out' Results}

\begin{tabular}{|c|c|c|c|c|c|c|}
\hline \multirow[b]{2}{*}{ Node } & \multicolumn{2}{|c|}{ Demand Supplied } & \multirow[b]{2}{*}{$\begin{array}{l}\text { Demand } \\
\text { Effected }\end{array}$} & \multicolumn{2}{|c|}{ Population Served } & \multirow[b]{2}{*}{$\begin{array}{c}\text { Population } \\
\text { Effected }\end{array}$} \\
\hline & $\begin{array}{c}\text { Normal } \\
\text { Conditions }\end{array}$ & $\begin{array}{l}\text { Failure } \\
\text { Scenario } \\
\text { J-50 Out }\end{array}$ & & $\begin{array}{c}\text { Normal } \\
\text { Conditions }\end{array}$ & $\begin{array}{l}\text { Failure } \\
\text { Scenario } \\
\text { J-50 Out }\end{array}$ & \\
\hline (1) & (2) & (3) & (4) & (5) & (6) & (7) \\
\hline $\mathrm{J}-20$ & 12350 & 12350 & 0 & 3069 & 3069 & 0 \\
\hline $\mathrm{J}-30$ & 4940 & 4940 & 0 & 1421 & 1421 & 0 \\
\hline $\mathrm{J}-40$ & 4940 & 12498 & -7558 & 6100 & 15432 & -9332 \\
\hline J-50 & 4940 & 0 & 4940 & 5953 & 0 & 5953 \\
\hline J-60 & 12350 & 12305 & 45 & 2297 & 2288 & 8 \\
\hline J-70 & 12350 & 12327 & 23 & 827 & 826 & 2 \\
\hline $\mathrm{J}-80$ & 12350 & 12230 & 120 & 4189 & 4148 & 41 \\
\hline J-90 & 24700 & 24464 & 236 & 6082 & 6024 & 58 \\
\hline $\mathrm{J}-100$ & 12350 & 12230 & 120 & 716 & 709 & 7 \\
\hline $\mathrm{J}-110$ & 12350 & 12206 & 144 & 4642 & 4588 & 54 \\
\hline $\mathrm{J}-120$ & 4940 & 29342 & -24402 & 4949 & 29397 & -24447 \\
\hline $\mathrm{J}-130$ & 4940 & 12300 & -7360 & 5170 & 12872 & -7702 \\
\hline $\mathrm{J}-140$ & 4940 & 4887 & 53 & 5248 & 5192 & 56 \\
\hline$J-150$ & 4940 & 4887 & 53 & 4330 & 4284 & 46 \\
\hline $\mathrm{J}-160$ & 19760 & 19503 & 257 & 1487 & 1468 & 19 \\
\hline $\mathrm{J}-170$ & 4940 & 4852 & 88 & 1901 & 1868 & 34 \\
\hline
\end{tabular}


Failure Scenario 'J-60 Out'

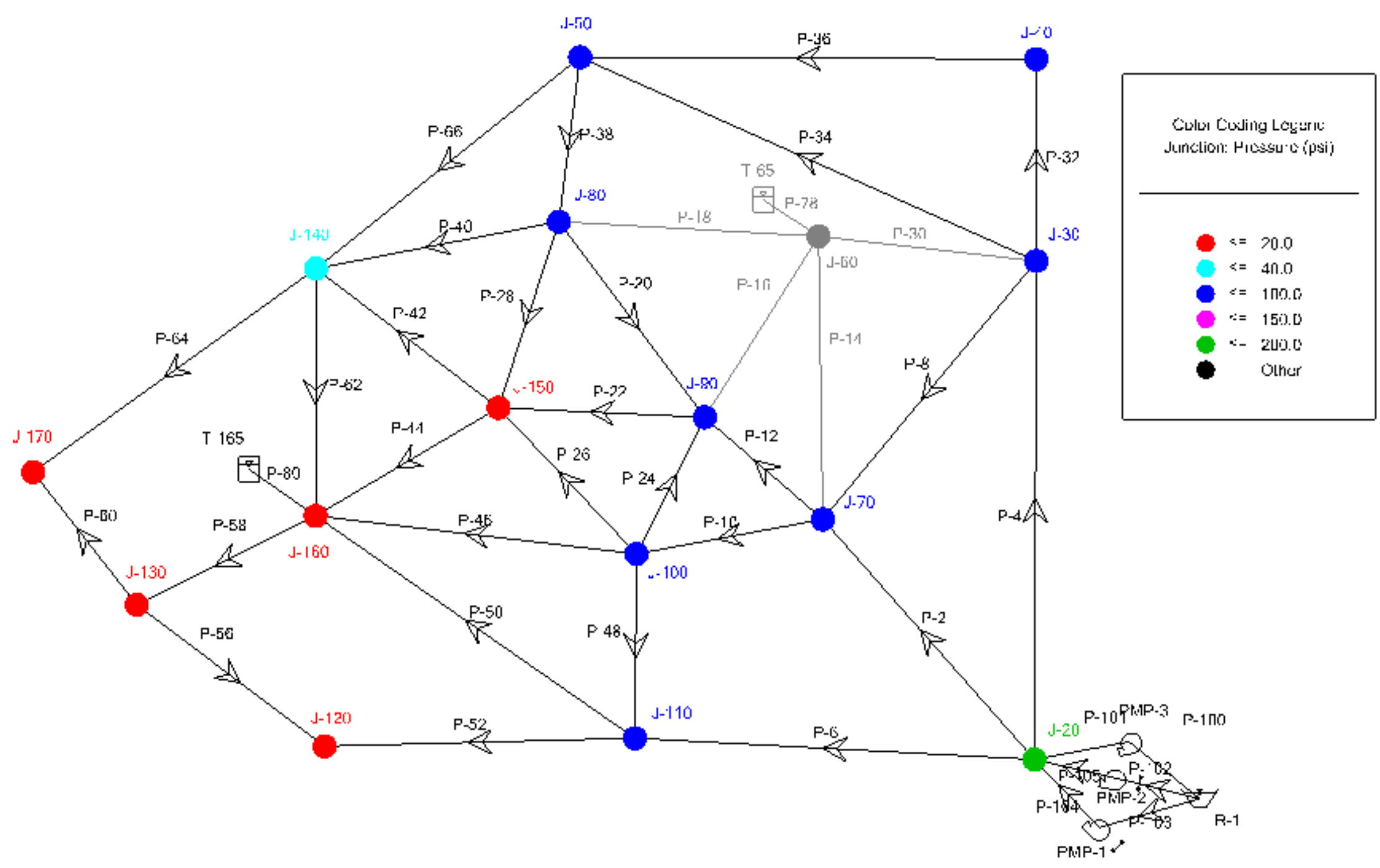




\section{Demand Supplied}

\begin{tabular}{|c|c|c|c|c|c|c|c|c|c|c|c|c|c|c|c|c|}
\hline $\begin{array}{c}\text { Time } \\
\text { (hours) }\end{array}$ & $\mathrm{J}-20$ & $\mathrm{~J}-30$ & $\mathrm{~J}-40$ & J-50 & $J-60$ & $\mathrm{~J}-70$ & $\mathrm{~J}-80$ & J-90 & J-100 & $\mathrm{J}-110$ & $\mathrm{~J}-120$ & $\mathrm{~J}-130$ & $\mathrm{~J}-140$ & $\mathrm{~J}-150$ & $\mathrm{~J}-160$ & J-170 \\
\hline 0 & 350 & 140 & 500 & 140 & 0 & 350 & 350 & 700 & 350 & 350 & 1140 & 500 & 140 & 140 & 560 & 140 \\
\hline 1 & 350 & 140 & 500 & 140 & 0 & 350 & 350 & 700 & 350 & 350 & 1140 & 500 & 140 & 140 & 560 & 140 \\
\hline 2 & 350 & 140 & 500 & 140 & 0 & 350 & 350 & 700 & 350 & 350 & 1140 & 500 & 140 & 140 & 560 & 140 \\
\hline 3 & 300 & 120 & 500 & 120 & 0 & 300 & 300 & 600 & 300 & 300 & 1120 & 500 & 120 & 120 & 480 & 120 \\
\hline 4 & 300 & 120 & 500 & 120 & 0 & 300 & 300 & 600 & 300 & 300 & 1120 & 500 & 120 & 120 & 480 & 120 \\
\hline 5 & 300 & 120 & 500 & 120 & 0 & 300 & 300 & 600 & 300 & 300 & 1120 & 500 & 120 & 120 & 480 & 120 \\
\hline 6 & 600 & 240 & 500 & 240 & 0 & 600 & 600 & 1200 & 600 & 600 & 1240 & 500 & 240 & 240 & 960 & 240 \\
\hline 7 & 600 & 240 & 500 & 240 & 0 & 600 & 600 & 1200 & 600 & 600 & 1240 & 500 & 240 & 240 & 960 & 240 \\
\hline 8 & 600 & 240 & 500 & 240 & 0 & 600 & 600 & 1200 & 600 & 600 & 1240 & 500 & 240 & 240 & 960 & 240 \\
\hline 9 & 650 & 260 & 500 & 260 & 0 & 650 & 650 & 1300 & 650 & 650 & 1260 & 500 & 260 & 260 & 1040 & 260 \\
\hline 10 & 650 & 260 & 500 & 260 & 0 & 650 & 650 & 1300 & 650 & 650 & 1260 & 500 & 260 & 260 & 1040 & 260 \\
\hline 11 & 650 & 255 & 477 & 246 & 0 & 633 & 584 & 1165 & 584 & 577 & 1065 & 429 & 232 & 232 & 914 & 223 \\
\hline 12 & 600 & 240 & 497 & 237 & 0 & 600 & 566 & 1129 & 565 & 559 & 1103 & 451 & 225 & 225 & 887 & 216 \\
\hline 13 & 600 & 240 & 497 & 237 & 0 & 600 & 566 & 1129 & 565 & 559 & 1103 & 451 & 225 & 225 & 887 & 216 \\
\hline 14 & 600 & 240 & 497 & 237 & 0 & 600 & 566 & 1129 & 565 & 559 & 1103 & 451 & 225 & 225 & 887 & 216 \\
\hline 15 & 550 & 220 & 500 & 220 & 0 & 550 & 548 & 1094 & 547 & 541 & 1149 & 477 & 218 & 218 & 860 & 210 \\
\hline 16 & 550 & 220 & 500 & 220 & 0 & 550 & 548 & 1094 & 547 & 541 & 1149 & 477 & 218 & 218 & 860 & 210 \\
\hline 17 & 550 & 220 & 500 & 220 & 0 & 550 & 548 & 1094 & 547 & 541 & 1149 & 477 & 218 & 218 & 860 & 210 \\
\hline 18 & 500 & 200 & 500 & 200 & 0 & 500 & 500 & 1000 & 500 & 500 & 1200 & 500 & 200 & 200 & 800 & 200 \\
\hline 19 & 500 & 200 & 500 & 200 & 0 & 500 & 500 & 1000 & 500 & 500 & 1200 & 500 & 200 & 200 & 800 & 200 \\
\hline 20 & 500 & 200 & 500 & 200 & 0 & 500 & 500 & 1000 & 500 & 500 & 1200 & 500 & 200 & 200 & 800 & 200 \\
\hline 21 & 450 & 180 & 500 & 180 & 0 & 450 & 450 & 900 & 450 & 450 & 1180 & 500 & 180 & 180 & 720 & 180 \\
\hline 22 & 450 & 180 & 500 & 180 & 0 & 450 & 450 & 900 & 450 & 450 & 1180 & 500 & 180 & 180 & 720 & 180 \\
\hline 23 & 450 & 180 & 500 & 180 & 0 & 450 & 450 & 900 & 450 & 450 & 1180 & 500 & 180 & 180 & 720 & 180 \\
\hline 24 & 350 & 140 & 500 & 140 & 0 & 350 & 350 & 700 & 350 & 350 & 1140 & 500 & 140 & 140 & 560 & 140 \\
\hline Total & 12350 & 4,935 & 12,468 & 4,917 & 0 & 12,333 & 12,176 & 24,334 & 12,170 & 12,127 & 29,121 & 12,213 & 4,861 & 4,861 & 19,355 & 4,801 \\
\hline
\end{tabular}


'J-60 Out' Results

\begin{tabular}{|c|c|c|c|c|c|c|}
\hline \multirow[b]{2}{*}{ Node } & \multicolumn{2}{|c|}{ Demand Supplied } & \multirow[b]{2}{*}{$\begin{array}{l}\text { Demand } \\
\text { Effected }\end{array}$} & \multicolumn{2}{|c|}{ Population Served } & \multirow[b]{2}{*}{$\begin{array}{c}\text { Population } \\
\text { Effected }\end{array}$} \\
\hline & $\begin{array}{c}\text { Normal } \\
\text { Conditions }\end{array}$ & $\begin{array}{l}\text { Failure } \\
\text { Scenario } \\
\text { J-60 Out }\end{array}$ & & $\begin{array}{c}\text { Normal } \\
\text { Conditio } \\
\text { ns }\end{array}$ & $\begin{array}{l}\text { Failure } \\
\text { Scenario } \\
\text { J-60 Out }\end{array}$ & \\
\hline (1) & (2) & (3) & (4) & (5) & (6) & (7) \\
\hline $\mathrm{J}-20$ & 12350 & 12350 & 0 & 3069 & 3069 & 0 \\
\hline $\mathrm{J}-30$ & 4940 & 4935 & 5 & 1421 & 1420 & 1 \\
\hline $\mathrm{J}-40$ & 4940 & 12468 & -7528 & 6100 & 15395 & -9295 \\
\hline$J-50$ & 4940 & 4917 & 23 & 5953 & 5926 & 28 \\
\hline $\mathrm{J}-60$ & 12350 & 0 & 12350 & 2297 & 0 & 2297 \\
\hline $\mathrm{J}-70$ & 12350 & 12333 & 17 & 827 & 826 & 1 \\
\hline $\mathrm{J}-80$ & 12350 & 12176 & 174 & 4189 & 4130 & 59 \\
\hline $\mathrm{J}-90$ & 24700 & 24334 & 366 & 6082 & 5992 & 90 \\
\hline $\mathrm{J}-100$ & 12350 & 12170 & 180 & 716 & 706 & 10 \\
\hline $\mathrm{J}-110$ & 12350 & 12127 & 223 & 4642 & 4558 & 84 \\
\hline $\mathrm{J}-120$ & 4940 & 29121 & -24181 & 4949 & 29175 & -24226 \\
\hline $\mathrm{J}-130$ & 4940 & 12213 & -7273 & 5170 & 12781 & -7611 \\
\hline $\mathrm{J}-140$ & 4940 & 4861 & 79 & 5248 & 5164 & 84 \\
\hline $\mathrm{J}-150$ & 4940 & 4861 & 79 & 4330 & 4261 & 69 \\
\hline$J-160$ & 19760 & 19355 & 405 & 1487 & 1456 & 30 \\
\hline $\mathrm{J}-170$ & 4940 & 4801 & 139 & 1901 & 1848 & 54 \\
\hline
\end{tabular}


Failure Scenario 'J-70 Out'

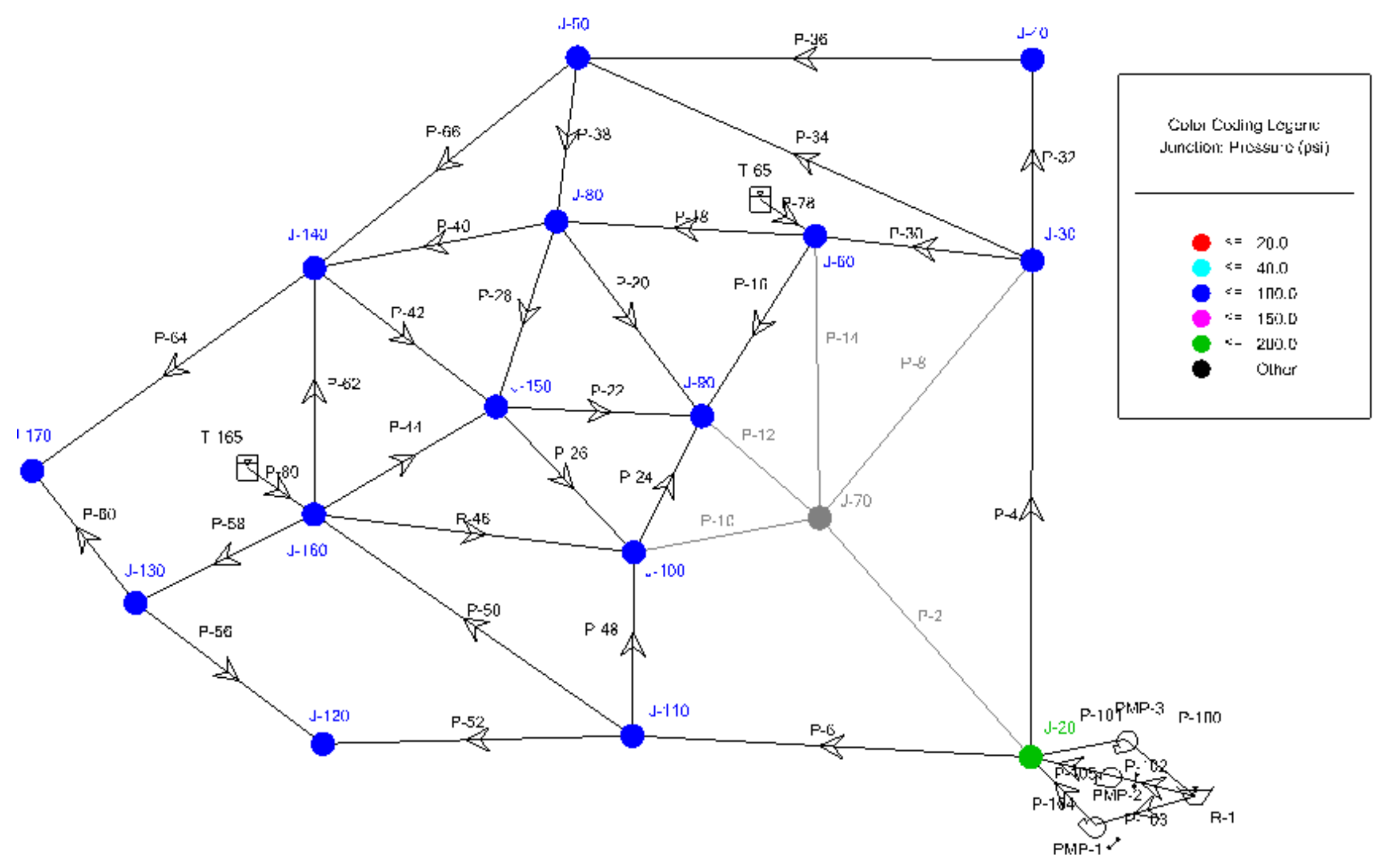




\section{Demand Supplied}

\begin{tabular}{|c|c|c|c|c|c|c|c|c|c|c|c|c|c|c|c|c|}
\hline $\begin{array}{c}\text { Time } \\
\text { (hours) }\end{array}$ & $\mathrm{J}-20$ & $\mathrm{~J}-30$ & $\mathrm{~J}-40$ & $J-50$ & $\mathrm{~J}-60$ & $\mathrm{~J}-70$ & $\mathrm{~J}-80$ & J-90 & $\mathrm{J}-100$ & $\mathrm{~J}-110$ & $\mathrm{~J}-120$ & $\mathrm{~J}-130$ & $\mathrm{~J}-140$ & $\mathrm{~J}-150$ & $\mathrm{~J}-160$ & $\mathrm{~J}-170$ \\
\hline 0 & 350 & 140 & 500 & 140 & 350 & 0 & 350 & 700 & 350 & 350 & 1140 & 500 & 140 & 140 & 560 & 140 \\
\hline 1 & 350 & 140 & 500 & 140 & 350 & 0 & 350 & 700 & 350 & 350 & 1140 & 500 & 140 & 140 & 560 & 140 \\
\hline 2 & 350 & 140 & 500 & 140 & 350 & 0 & 350 & 700 & 350 & 350 & 1140 & 500 & 140 & 140 & 560 & 140 \\
\hline 3 & 300 & 120 & 500 & 120 & 300 & 0 & 300 & 600 & 300 & 300 & 1120 & 500 & 120 & 120 & 480 & 120 \\
\hline 4 & 300 & 120 & 500 & 120 & 300 & 0 & 300 & 600 & 300 & 300 & 1120 & 500 & 120 & 120 & 480 & 120 \\
\hline 5 & 300 & 120 & 500 & 120 & 300 & 0 & 300 & 600 & 300 & 300 & 1120 & 500 & 120 & 120 & 480 & 120 \\
\hline 6 & 600 & 240 & 500 & 240 & 600 & 0 & 600 & 1200 & 600 & 600 & 1240 & 500 & 240 & 240 & 960 & 240 \\
\hline 7 & 600 & 240 & 500 & 240 & 600 & 0 & 600 & 1200 & 600 & 600 & 1240 & 500 & 240 & 240 & 960 & 240 \\
\hline 8 & 600 & 163 & 330 & 157 & 375 & 0 & 369 & 722 & 360 & 371 & 721 & 293 & 145 & 144 & 575 & 141 \\
\hline 9 & 650 & 169 & 315 & 162 & 385 & 0 & 378 & 739 & 369 & 381 & 692 & 277 & 149 & 148 & 589 & 144 \\
\hline 10 & 650 & 169 & 315 & 162 & 385 & 0 & 378 & 739 & 369 & 381 & 692 & 277 & 149 & 148 & 589 & 144 \\
\hline 11 & 650 & 169 & 315 & 162 & 385 & 0 & 378 & 739 & 369 & 381 & 692 & 277 & 149 & 148 & 589 & 144 \\
\hline 12 & 600 & 163 & 330 & 157 & 375 & 0 & 369 & 722 & 360 & 371 & 721 & 293 & 145 & 144 & 575 & 141 \\
\hline 13 & 600 & 163 & 330 & 157 & 375 & 0 & 369 & 722 & 360 & 371 & 721 & 293 & 145 & 144 & 575 & 141 \\
\hline 14 & 600 & 163 & 330 & 157 & 375 & 0 & 369 & 722 & 360 & 371 & 721 & 293 & 145 & 144 & 575 & 141 \\
\hline 15 & 550 & 157 & 346 & 151 & 363 & 0 & 358 & 703 & 351 & 360 & 753 & 312 & 141 & 141 & 560 & 137 \\
\hline 16 & 550 & 157 & 346 & 151 & 363 & 0 & 358 & 703 & 351 & 360 & 753 & 312 & 141 & 141 & 560 & 137 \\
\hline 17 & 550 & 157 & 346 & 151 & 363 & 0 & 358 & 703 & 351 & 360 & 753 & 312 & 141 & 141 & 560 & 137 \\
\hline 18 & 500 & 150 & 365 & 145 & 350 & 0 & 346 & 680 & 340 & 347 & 789 & 332 & 137 & 136 & 542 & 133 \\
\hline 19 & 500 & 150 & 365 & 145 & 350 & 0 & 346 & 680 & 340 & 347 & 789 & 332 & 137 & 136 & 542 & 133 \\
\hline 20 & 500 & 150 & 365 & 145 & 350 & 0 & 346 & 680 & 340 & 347 & 789 & 332 & 137 & 136 & 542 & 133 \\
\hline 21 & 450 & 142 & 386 & 138 & 335 & 0 & 332 & 654 & 327 & 332 & 829 & 355 & 131 & 131 & 521 & 128 \\
\hline 22 & 450 & 142 & 386 & 138 & 335 & 0 & 332 & 654 & 327 & 332 & 829 & 355 & 131 & 131 & 521 & 128 \\
\hline 23 & 450 & 142 & 386 & 138 & 335 & 0 & 332 & 654 & 327 & 332 & 829 & 355 & 131 & 131 & 521 & 128 \\
\hline 24 & 350 & 124 & 436 & 122 & 298 & 0 & 296 & 586 & 293 & 296 & 923 & 409 & 118 & 117 & 467 & 115 \\
\hline Total & 12350 & 3,890 & 9,992 & 3,798 & 9,247 & 0 & 9,164 & 18,102 & 9,044 & 9,190 & 22,256 & 9,409 & 3,632 & 3,621 & 14,443 & 3,565 \\
\hline
\end{tabular}




\begin{tabular}{|c|c|c|c|c|c|c|}
\hline \multirow[b]{2}{*}{ Node } & \multicolumn{2}{|c|}{ Demand Supplied } & \multirow[b]{2}{*}{$\begin{array}{l}\text { Demand } \\
\text { Effected }\end{array}$} & \multicolumn{2}{|c|}{ Population Served } & \multirow[b]{2}{*}{$\begin{array}{c}\text { Population } \\
\text { Effected }\end{array}$} \\
\hline & $\begin{array}{c}\text { Normal } \\
\text { Conditions }\end{array}$ & $\begin{array}{l}\text { Failure } \\
\text { Scenario } \\
\text { J-70 Out }\end{array}$ & & $\begin{array}{c}\text { Normal } \\
\text { Conditions }\end{array}$ & $\begin{array}{l}\text { Failure } \\
\text { Scenario } \\
\text { J-70 Out }\end{array}$ & \\
\hline (1) & (2) & (3) & (4) & (5) & (6) & (7) \\
\hline $\mathrm{J}-20$ & 12350 & 12350 & 0 & 3069 & 3069 & 0 \\
\hline $\mathrm{J}-30$ & 4940 & 3890 & 1050 & 1421 & 1119 & 302 \\
\hline $\mathrm{J}-40$ & 4940 & 9992 & -5052 & 6100 & 12338 & -6238 \\
\hline$J-50$ & 4940 & 3798 & 1142 & 5953 & 4577 & 1376 \\
\hline $\mathrm{J}-60$ & 12350 & 9247 & 3103 & 2297 & 1720 & 577 \\
\hline $\mathrm{J}-70$ & 12350 & 0 & 12350 & 827 & 0 & 827 \\
\hline $\mathrm{J}-80$ & 12350 & 9164 & 3186 & 4189 & 3108 & 1081 \\
\hline $\mathrm{J}-90$ & 24700 & 18102 & 6598 & 6082 & 4458 & 1625 \\
\hline$J-100$ & 12350 & 9044 & 3306 & 716 & 524 & 192 \\
\hline $\mathrm{J}-110$ & 12350 & 9190 & 3160 & 4642 & 3454 & 1188 \\
\hline$J-120$ & 4940 & 22256 & -17316 & 4949 & 22297 & -17348 \\
\hline J-130 & 4940 & 9409 & -4469 & 5170 & 9846 & -4677 \\
\hline J-140 & 4940 & 3632 & 1308 & 5248 & 3859 & 1390 \\
\hline J-150 & 4940 & 3621 & 1319 & 4330 & 3174 & 1156 \\
\hline $\mathrm{J}-160$ & 19760 & 14443 & 5317 & 1487 & 1087 & 400 \\
\hline $\mathrm{J}-170$ & 4940 & 3565 & 1375 & 1901 & 1372 & 529 \\
\hline
\end{tabular}


Failure Scenario 'J-80 Out'

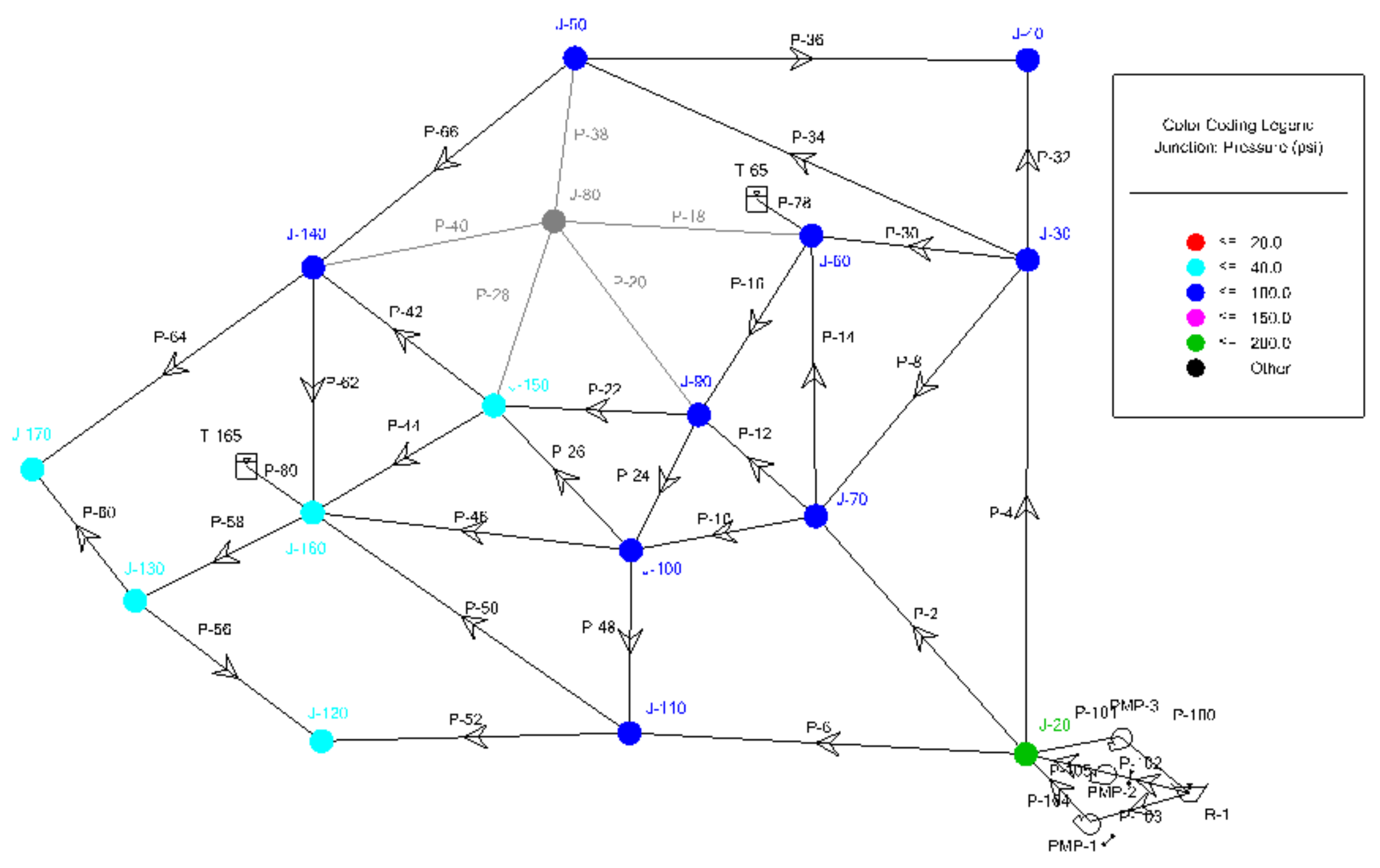




\section{Demand Supplied}

\begin{tabular}{|c|c|c|c|c|c|c|c|c|c|c|c|c|c|c|c|c|}
\hline $\begin{array}{l}\text { Time } \\
\text { (hours) }\end{array}$ & $J-20$ & J-30 & $\mathrm{J}-40$ & $J-50$ & $\mathrm{~J}-60$ & $\mathrm{~J}-70$ & $\mathrm{~J}-80$ & J-90 & $\mathrm{J}-100$ & $\mathrm{~J}-110$ & $\mathrm{~J}-120$ & $\mathrm{~J}-130$ & $\mathrm{~J}-140$ & J-150 & $\mathrm{J}-160$ & J-170 \\
\hline 0 & 350 & 140 & 500 & 140 & 350 & 350 & 0 & 700 & 350 & 350 & 1140 & 500 & 140 & 140 & 560 & 140 \\
\hline 1 & 350 & 140 & 500 & 140 & 350 & 350 & 0 & 700 & 350 & 350 & 1140 & 500 & 140 & 140 & 560 & 140 \\
\hline 2 & 350 & 140 & 500 & 140 & 350 & 350 & 0 & 700 & 350 & 350 & 1140 & 500 & 140 & 140 & 560 & 140 \\
\hline 3 & 300 & 120 & 500 & 120 & 300 & 300 & 0 & 600 & 300 & 300 & 1120 & 500 & 120 & 120 & 480 & 120 \\
\hline 4 & 300 & 120 & 500 & 120 & 300 & 300 & 0 & 600 & 300 & 300 & 1120 & 500 & 120 & 120 & 480 & 120 \\
\hline 5 & 300 & 120 & 500 & 120 & 300 & 300 & 0 & 600 & 300 & 300 & 1120 & 500 & 120 & 120 & 480 & 120 \\
\hline 6 & 600 & 240 & 500 & 240 & 600 & 600 & 0 & 1200 & 600 & 600 & 1240 & 500 & 240 & 240 & 960 & 240 \\
\hline 7 & 600 & 240 & 500 & 240 & 600 & 600 & 0 & 1200 & 600 & 600 & 1240 & 500 & 240 & 240 & 960 & 240 \\
\hline 8 & 600 & 240 & 500 & 240 & 600 & 600 & 0 & 1200 & 600 & 600 & 1240 & 500 & 240 & 240 & 960 & 240 \\
\hline 9 & 650 & 260 & 500 & 260 & 650 & 650 & 0 & 1300 & 650 & 650 & 1260 & 500 & 260 & 260 & 1040 & 260 \\
\hline 10 & 650 & 260 & 500 & 260 & 650 & 650 & 0 & 1300 & 650 & 650 & 1260 & 500 & 260 & 260 & 1040 & 260 \\
\hline 11 & 650 & 260 & 500 & 260 & 650 & 650 & 0 & 1300 & 650 & 650 & 1260 & 500 & 260 & 260 & 1040 & 260 \\
\hline 12 & 600 & 240 & 500 & 240 & 600 & 600 & 0 & 1200 & 600 & 600 & 1240 & 500 & 240 & 240 & 960 & 240 \\
\hline 13 & 600 & 240 & 500 & 240 & 600 & 600 & 0 & 1200 & 600 & 600 & 1240 & 500 & 240 & 240 & 960 & 240 \\
\hline 14 & 600 & 240 & 500 & 240 & 600 & 600 & 0 & 1200 & 600 & 600 & 1240 & 500 & 240 & 240 & 960 & 240 \\
\hline 15 & 550 & 220 & 500 & 220 & 550 & 550 & 0 & 1100 & 550 & 550 & 1220 & 500 & 220 & 220 & 880 & 220 \\
\hline 16 & 550 & 220 & 500 & 220 & 550 & 550 & 0 & 1100 & 548 & 539 & 1143 & 475 & 215 & 217 & 855 & 209 \\
\hline 17 & 550 & 220 & 500 & 220 & 550 & 550 & 0 & 1100 & 548 & 539 & 1143 & 475 & 215 & 217 & 855 & 209 \\
\hline 18 & 500 & 200 & 500 & 200 & 500 & 500 & 0 & 1000 & 500 & 500 & 1200 & 500 & 200 & 200 & 800 & 200 \\
\hline 19 & 500 & 200 & 500 & 200 & 500 & 500 & 0 & 1000 & 500 & 500 & 1200 & 500 & 200 & 200 & 800 & 200 \\
\hline 20 & 500 & 200 & 500 & 200 & 500 & 500 & 0 & 1000 & 500 & 500 & 1200 & 500 & 200 & 200 & 800 & 200 \\
\hline 21 & 450 & 180 & 500 & 180 & 450 & 450 & 0 & 900 & 450 & 450 & 1180 & 500 & 180 & 180 & 720 & 180 \\
\hline 22 & 450 & 180 & 500 & 180 & 450 & 450 & 0 & 900 & 450 & 450 & 1180 & 500 & 180 & 180 & 720 & 180 \\
\hline 23 & 450 & 180 & 500 & 180 & 450 & 450 & 0 & 900 & 450 & 450 & 1180 & 500 & 180 & 180 & 720 & 180 \\
\hline 24 & 350 & 140 & 500 & 140 & 350 & 350 & 0 & 700 & 350 & 350 & 1140 & 500 & 140 & 140 & 560 & 140 \\
\hline Total & 12,350 & 4,940 & 12,500 & 4,940 & 12,350 & 12,350 & 0 & 24,700 & 12,346 & 12,328 & 29,786 & 12,450 & 4,930 & 4,934 & 19,710 & 4,918 \\
\hline
\end{tabular}


'J-80 Out' Results

\begin{tabular}{|c|c|c|c|c|c|c|}
\hline \multirow[b]{2}{*}{ Node } & \multicolumn{2}{|c|}{ Demand Supplied } & \multirow[b]{2}{*}{$\begin{array}{l}\text { Demand } \\
\text { Effected }\end{array}$} & \multicolumn{2}{|c|}{ Population Served } & \multirow[b]{2}{*}{$\begin{array}{l}\text { Population } \\
\text { Effected }\end{array}$} \\
\hline & $\begin{array}{l}\text { Normal } \\
\text { Conditions }\end{array}$ & $\begin{array}{l}\text { Failure } \\
\text { Scenario } \\
\text { J-80 Out }\end{array}$ & & $\begin{array}{c}\text { Normal } \\
\text { Conditions }\end{array}$ & $\begin{array}{l}\text { Failure } \\
\text { Scenario } \\
\text { J-80 Out }\end{array}$ & \\
\hline (1) & (2) & (3) & (4) & (5) & (6) & (7) \\
\hline $\mathrm{J}-20$ & 12350 & 12350 & 0 & 3069 & 3069 & 0 \\
\hline $\mathrm{J}-30$ & 4940 & 4940 & 0 & 1421 & 1421 & 0 \\
\hline $\mathrm{J}-40$ & 4940 & 12500 & -7560 & 6100 & 15435 & -9335 \\
\hline$J-50$ & 4940 & 4940 & 0 & 5953 & 5953 & 0 \\
\hline $\mathrm{J}-60$ & 12350 & 12350 & 0 & 2297 & 2297 & 0 \\
\hline $\mathrm{J}-70$ & 12350 & 12350 & 0 & 827 & 827 & 0 \\
\hline $\mathrm{J}-80$ & 12350 & 0 & 12350 & 4189 & 0 & 4189 \\
\hline J-90 & 24700 & 24700 & 0 & 6082 & 6082 & 0 \\
\hline $\mathrm{J}-100$ & 12350 & 12346 & 4 & 716 & 716 & 0 \\
\hline $\mathrm{J}-110$ & 12350 & 12328 & 22 & 4642 & 4634 & 8 \\
\hline$J-120$ & 4940 & 29786 & -24846 & 4949 & 29841 & -24892 \\
\hline J-130 & 4940 & 12450 & -7510 & 5170 & 13029 & -7859 \\
\hline J-140 & 4940 & 4930 & 10 & 5248 & 5238 & 11 \\
\hline $\mathrm{J}-150$ & 4940 & 4934 & 6 & 4330 & 4325 & 5 \\
\hline J-160 & 19760 & 19710 & 50 & 1487 & 1483 & 4 \\
\hline $\mathrm{J}-170$ & 4940 & 4918 & 22 & 1901 & 1893 & 8 \\
\hline
\end{tabular}


Failure Scenario 'J-90 Out'

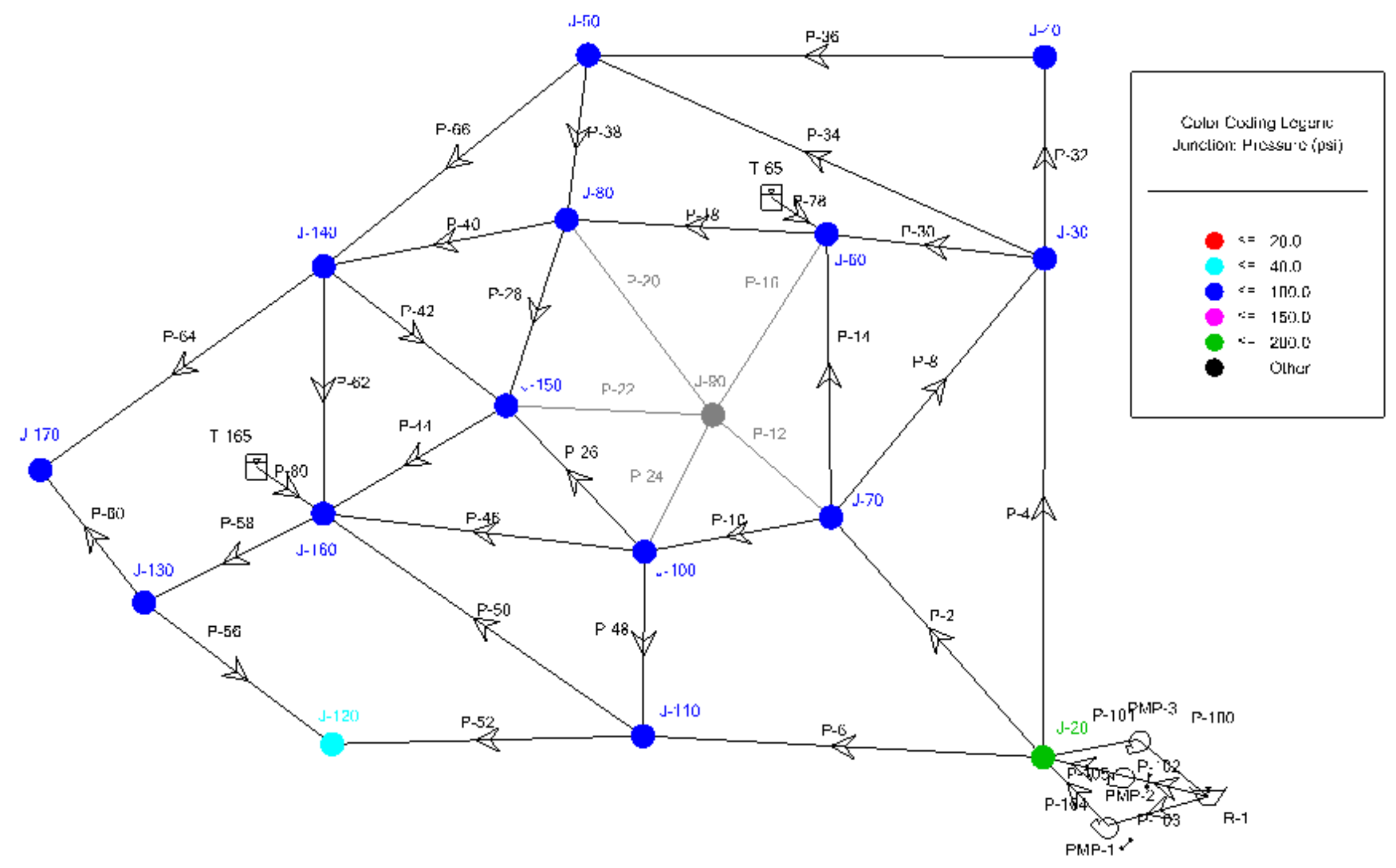




\section{Demand Supplied}

\begin{tabular}{|c|c|c|c|c|c|c|c|c|c|c|c|c|c|c|c|c|}
\hline $\begin{array}{c}\text { Time } \\
\text { (hours) }\end{array}$ & $\mathrm{J}-20$ & $\mathrm{~J}-30$ & $\mathrm{~J}-40$ & $J-50$ & $J-60$ & $\mathrm{~J}-70$ & $\mathrm{~J}-80$ & J-90 & $\mathrm{J}-100$ & $\mathrm{~J}-110$ & $\mathrm{~J}-120$ & $\mathrm{~J}-130$ & $\mathrm{~J}-140$ & $\mathrm{~J}-150$ & $\mathrm{~J}-160$ & $\mathrm{~J}-170$ \\
\hline 0 & 350 & 140 & 500 & 140 & 350 & 350 & 350 & 0 & 350 & 350 & 1140 & 500 & 140 & 140 & 560 & 140 \\
\hline 1 & 350 & 140 & 500 & 140 & 350 & 350 & 350 & 0 & 350 & 350 & 1140 & 500 & 140 & 140 & 560 & 140 \\
\hline 2 & 350 & 140 & 500 & 140 & 350 & 350 & 350 & 0 & 350 & 350 & 1140 & 500 & 140 & 140 & 560 & 140 \\
\hline 3 & 300 & 120 & 500 & 120 & 300 & 300 & 300 & 0 & 300 & 300 & 1120 & 500 & 120 & 120 & 480 & 120 \\
\hline 4 & 300 & 120 & 500 & 120 & 300 & 300 & 300 & 0 & 300 & 300 & 1120 & 500 & 120 & 120 & 480 & 120 \\
\hline 5 & 300 & 120 & 500 & 120 & 300 & 300 & 300 & 0 & 300 & 300 & 1120 & 500 & 120 & 120 & 480 & 120 \\
\hline 6 & 600 & 240 & 500 & 240 & 600 & 600 & 600 & 0 & 600 & 600 & 1240 & 500 & 240 & 240 & 960 & 240 \\
\hline 7 & 600 & 240 & 500 & 240 & 600 & 600 & 600 & 0 & 600 & 600 & 1240 & 500 & 240 & 240 & 960 & 240 \\
\hline 8 & 600 & 240 & 500 & 240 & 600 & 600 & 600 & 0 & 600 & 600 & 1240 & 500 & 240 & 240 & 960 & 240 \\
\hline 9 & 650 & 260 & 500 & 260 & 650 & 650 & 650 & 0 & 650 & 650 & 1260 & 500 & 260 & 260 & 1040 & 260 \\
\hline 10 & 650 & 260 & 500 & 260 & 650 & 650 & 650 & 0 & 650 & 650 & 1260 & 500 & 260 & 260 & 1040 & 260 \\
\hline 11 & 650 & 260 & 500 & 260 & 650 & 650 & 650 & 0 & 650 & 650 & 1260 & 500 & 260 & 260 & 1040 & 260 \\
\hline 12 & 600 & 240 & 500 & 240 & 600 & 600 & 600 & 0 & 600 & 600 & 1240 & 500 & 240 & 240 & 960 & 240 \\
\hline 13 & 600 & 240 & 500 & 240 & 600 & 600 & 600 & 0 & 600 & 600 & 1240 & 500 & 240 & 240 & 960 & 240 \\
\hline 14 & 600 & 240 & 500 & 240 & 600 & 600 & 600 & 0 & 600 & 600 & 1240 & 500 & 240 & 240 & 960 & 240 \\
\hline 15 & 550 & 220 & 500 & 220 & 550 & 550 & 550 & 0 & 550 & 550 & 1220 & 500 & 220 & 220 & 880 & 220 \\
\hline 16 & 550 & 220 & 500 & 220 & 550 & 550 & 550 & 0 & 550 & 550 & 1220 & 500 & 220 & 220 & 880 & 220 \\
\hline 17 & 550 & 220 & 500 & 220 & 550 & 550 & 550 & 0 & 550 & 550 & 1220 & 500 & 220 & 220 & 880 & 220 \\
\hline 18 & 500 & 200 & 500 & 200 & 500 & 500 & 500 & 0 & 500 & 500 & 1200 & 500 & 200 & 200 & 800 & 200 \\
\hline 19 & 500 & 200 & 500 & 200 & 500 & 500 & 500 & 0 & 500 & 500 & 1200 & 500 & 200 & 200 & 800 & 200 \\
\hline 20 & 500 & 200 & 500 & 200 & 500 & 500 & 500 & 0 & 500 & 500 & 1200 & 500 & 200 & 200 & 800 & 200 \\
\hline 21 & 450 & 180 & 500 & 180 & 450 & 450 & 450 & 0 & 450 & 450 & 1180 & 500 & 180 & 180 & 720 & 180 \\
\hline 22 & 450 & 180 & 500 & 180 & 450 & 450 & 450 & 0 & 450 & 450 & 1180 & 500 & 180 & 180 & 720 & 180 \\
\hline 23 & 450 & 180 & 500 & 180 & 450 & 450 & 450 & 0 & 450 & 450 & 1180 & 500 & 180 & 180 & 720 & 180 \\
\hline 24 & 350 & 140 & 500 & 140 & 350 & 350 & 350 & 0 & 350 & 350 & 1140 & 500 & 140 & 140 & 560 & 140 \\
\hline Total & 12350 & 4,940 & 12,500 & 4,940 & 12,350 & 12,350 & 12,350 & 0 & 12,350 & 12,350 & 29,940 & 12,500 & 4,940 & 4,940 & 19,760 & 4,940 \\
\hline
\end{tabular}




\section{'J-90 Out' Results}

\begin{tabular}{|c|c|c|c|c|c|c|}
\hline \multirow[b]{2}{*}{ Node } & \multicolumn{2}{|c|}{ Demand Supplied } & \multirow[b]{2}{*}{$\begin{array}{l}\text { Demand } \\
\text { Effected }\end{array}$} & \multicolumn{2}{|c|}{ Population Served } & \multirow[b]{2}{*}{$\begin{array}{c}\text { Population } \\
\text { Effected }\end{array}$} \\
\hline & $\begin{array}{c}\text { Normal } \\
\text { Conditions }\end{array}$ & $\begin{array}{c}\text { Failure } \\
\text { Scenario } \\
\text { J-90 Out }\end{array}$ & & $\begin{array}{l}\text { Normal } \\
\text { Conditions }\end{array}$ & $\begin{array}{c}\text { Failure } \\
\text { Scenario } \\
\text { J-90 Out }\end{array}$ & \\
\hline (1) & (2) & (3) & (4) & (5) & (6) & (7) \\
\hline$J-20$ & 12350 & 12350 & 0 & 3069 & 3069 & 0 \\
\hline$J-30$ & 4940 & 4940 & 0 & 1421 & 1421 & 0 \\
\hline $\mathrm{J}-40$ & 4940 & 12500 & -7560 & 6100 & 15435 & -9335 \\
\hline$J-50$ & 4940 & 4940 & 0 & 5953 & 5953 & 0 \\
\hline$J-60$ & 12350 & 12350 & 0 & 2297 & 2297 & 0 \\
\hline J-70 & 12350 & 12350 & 0 & 827 & 827 & 0 \\
\hline $\mathrm{J}-80$ & 12350 & 12350 & 0 & 4189 & 4189 & 0 \\
\hline J-90 & 24700 & 0 & 24700 & 6082 & 0 & 6082 \\
\hline$J-100$ & 12350 & 12350 & 0 & 716 & 716 & 0 \\
\hline $\mathrm{J}-110$ & 12350 & 12350 & 0 & 4642 & 4642 & 0 \\
\hline J-120 & 4940 & 29940 & -25000 & 4949 & 29996 & -25046 \\
\hline $\mathrm{J}-130$ & 4940 & 12500 & -7560 & 5170 & 13081 & -7912 \\
\hline $\mathrm{J}-140$ & 4940 & 4940 & 0 & 5248 & 5248 & 0 \\
\hline $\mathrm{J}-150$ & 4940 & 4940 & 0 & 4330 & 4330 & 0 \\
\hline$J-160$ & 19760 & 19760 & 0 & 1487 & 1487 & 0 \\
\hline $\mathrm{J}-170$ & 4940 & 4940 & 0 & 1901 & 1901 & 0 \\
\hline
\end{tabular}




\section{Failure Scenario 'J-100 Out'}

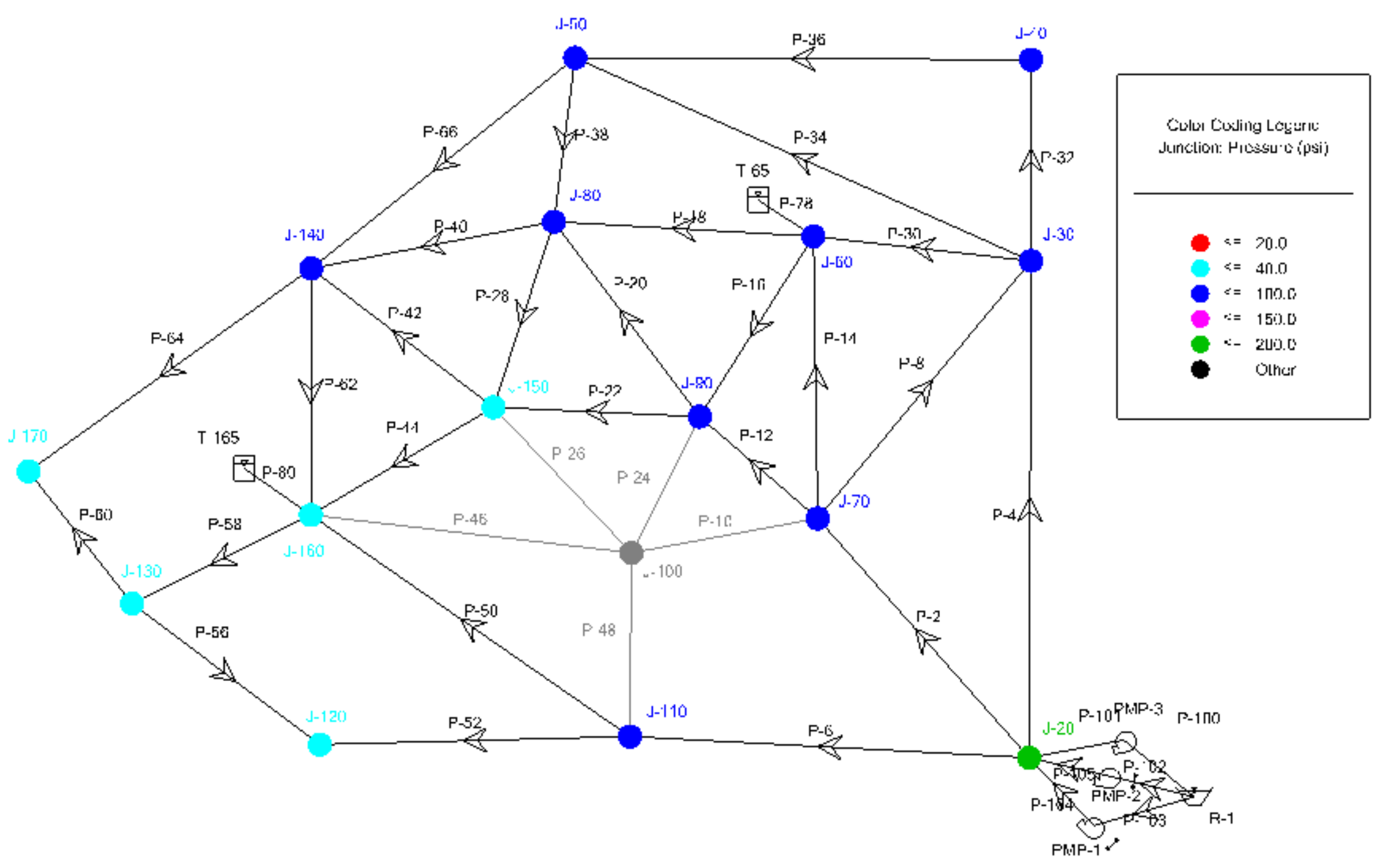




\section{Demand Supplied}

\begin{tabular}{|c|c|c|c|c|c|c|c|c|c|c|c|c|c|c|c|c|}
\hline $\begin{array}{l}\text { Time } \\
\text { (hours) }\end{array}$ & $J-20$ & J-30 & $\mathrm{J}-40$ & $\mathrm{~J}-50$ & J-60 & $\mathrm{J}-70$ & $\mathrm{~J}-80$ & J-90 & $\mathrm{J}-100$ & $\mathrm{~J}-110$ & $\mathrm{~J}-120$ & $\mathrm{~J}-130$ & $\mathrm{~J}-140$ & $\mathrm{~J}-150$ & $\mathrm{~J}-160$ & $\mathrm{~J}-170$ \\
\hline 0 & 350 & 140 & 500 & 140 & 350 & 350 & 350 & 700 & 0 & 350 & 1140 & 500 & 140 & 140 & 560 & 140 \\
\hline 1 & 350 & 140 & 500 & 140 & 350 & 350 & 350 & 700 & 0 & 350 & 1140 & 500 & 140 & 140 & 560 & 140 \\
\hline 2 & 350 & 140 & 500 & 140 & 350 & 350 & 350 & 700 & 0 & 350 & 1140 & 500 & 140 & 140 & 560 & 140 \\
\hline 3 & 300 & 120 & 500 & 120 & 300 & 300 & 300 & 600 & 0 & 300 & 1120 & 500 & 120 & 120 & 480 & 120 \\
\hline 4 & 300 & 120 & 500 & 120 & 300 & 300 & 300 & 600 & 0 & 300 & 1120 & 500 & 120 & 120 & 480 & 120 \\
\hline 5 & 300 & 120 & 500 & 120 & 300 & 300 & 300 & 600 & 0 & 300 & 1120 & 500 & 120 & 120 & 480 & 120 \\
\hline 6 & 600 & 240 & 500 & 240 & 600 & 600 & 600 & 1200 & 0 & 600 & 1240 & 500 & 240 & 240 & 960 & 240 \\
\hline 7 & 600 & 240 & 500 & 240 & 600 & 600 & 600 & 1200 & 0 & 600 & 1240 & 500 & 240 & 240 & 960 & 240 \\
\hline 8 & 600 & 240 & 500 & 240 & 600 & 600 & 600 & 1200 & 0 & 600 & 1240 & 500 & 240 & 240 & 960 & 240 \\
\hline 9 & 650 & 260 & 500 & 260 & 650 & 650 & 650 & 1300 & 0 & 650 & 1260 & 500 & 260 & 260 & 1040 & 260 \\
\hline 10 & 650 & 260 & 500 & 260 & 650 & 650 & 650 & 1300 & 0 & 650 & 1260 & 500 & 260 & 260 & 1040 & 260 \\
\hline 11 & 650 & 260 & 500 & 260 & 650 & 650 & 650 & 1300 & 0 & 650 & 1260 & 500 & 260 & 260 & 1040 & 260 \\
\hline 12 & 600 & 240 & 500 & 240 & 600 & 600 & 600 & 1200 & 0 & 600 & 1240 & 500 & 240 & 240 & 960 & 240 \\
\hline 13 & 600 & 240 & 500 & 240 & 600 & 600 & 600 & 1200 & 0 & 600 & 1240 & 500 & 240 & 240 & 960 & 240 \\
\hline 14 & 600 & 240 & 500 & 240 & 600 & 600 & 600 & 1200 & 0 & 600 & 1240 & 500 & 240 & 240 & 960 & 240 \\
\hline 15 & 550 & 220 & 500 & 220 & 550 & 550 & 550 & 1100 & 0 & 550 & 1220 & 500 & 220 & 220 & 880 & 220 \\
\hline 16 & 550 & 220 & 500 & 220 & 550 & 550 & 550 & 1100 & 0 & 533 & 1134 & 472 & 220 & 220 & 850 & 208 \\
\hline 17 & 550 & 220 & 500 & 220 & 550 & 550 & 550 & 1100 & 0 & 533 & 1134 & 472 & 220 & 220 & 850 & 208 \\
\hline 18 & 500 & 200 & 500 & 200 & 500 & 500 & 500 & 1000 & 0 & 500 & 1200 & 500 & 200 & 200 & 800 & 200 \\
\hline 19 & 500 & 200 & 500 & 200 & 500 & 500 & 500 & 1000 & 0 & 500 & 1200 & 500 & 200 & 200 & 800 & 200 \\
\hline 20 & 500 & 200 & 500 & 200 & 500 & 500 & 500 & 1000 & 0 & 500 & 1200 & 500 & 200 & 200 & 800 & 200 \\
\hline 21 & 450 & 180 & 500 & 180 & 450 & 450 & 450 & 900 & 0 & 450 & 1180 & 500 & 180 & 180 & 720 & 180 \\
\hline 22 & 450 & 180 & 500 & 180 & 450 & 450 & 450 & 900 & 0 & 450 & 1180 & 500 & 180 & 180 & 720 & 180 \\
\hline 23 & 450 & 180 & 500 & 180 & 450 & 450 & 450 & 900 & 0 & 450 & 1180 & 500 & 180 & 180 & 720 & 180 \\
\hline 24 & 350 & 140 & 500 & 140 & 350 & 350 & 350 & 700 & 0 & 350 & 1140 & 500 & 140 & 140 & 560 & 140 \\
\hline Total & 12,350 & 4,940 & 12,500 & 4,940 & 12,350 & 12,350 & 12,350 & 24,700 & 0 & 12,316 & 29,768 & 12,444 & 4,940 & 4,940 & 19,700 & 4,916 \\
\hline
\end{tabular}


'J-100 Out' Results

\begin{tabular}{|c|c|c|c|c|c|c|}
\hline \multirow[b]{2}{*}{ Node } & \multicolumn{2}{|c|}{ Demand Supplied } & \multirow[b]{2}{*}{$\begin{array}{l}\text { Demand } \\
\text { Effected }\end{array}$} & \multicolumn{2}{|c|}{ Population Served } & \multirow[b]{2}{*}{$\begin{array}{c}\text { Population } \\
\text { Effected }\end{array}$} \\
\hline & $\begin{array}{c}\text { Normal } \\
\text { Conditions }\end{array}$ & $\begin{array}{l}\text { Failure } \\
\text { Scenario } \\
\text { J-100 Out }\end{array}$ & & $\begin{array}{c}\text { Normal } \\
\text { Conditions }\end{array}$ & $\begin{array}{l}\text { Failure } \\
\text { Scenario } \\
\text { J-100 Out }\end{array}$ & \\
\hline (1) & (2) & (3) & (4) & (5) & (6) & (7) \\
\hline$J-20$ & 12350 & 12350 & 0 & 3069 & 3069 & 0 \\
\hline$J-30$ & 4940 & 4940 & 0 & 1421 & 1421 & 0 \\
\hline$J-40$ & 4940 & 12500 & -7560 & 6100 & 15435 & -9335 \\
\hline$J-50$ & 4940 & 4940 & 0 & 5953 & 5953 & 0 \\
\hline J-60 & 12350 & 12350 & 0 & 2297 & 2297 & 0 \\
\hline J-70 & 12350 & 12350 & 0 & 827 & 827 & 0 \\
\hline $\mathrm{J}-80$ & 12350 & 12350 & 0 & 4189 & 4189 & 0 \\
\hline J-90 & 24700 & 24700 & 0 & 6082 & 6082 & 0 \\
\hline $\mathrm{J}-100$ & 12350 & 0 & 12350 & 716 & 0 & 716 \\
\hline $\mathrm{J}-110$ & 12350 & 12316 & 34 & 4642 & 4629 & 13 \\
\hline $\mathrm{J}-120$ & 4940 & 29768 & -24828 & 4949 & 29823 & -24874 \\
\hline $\mathrm{J}-130$ & 4940 & 12444 & -7504 & 5170 & 13023 & -7853 \\
\hline $\mathrm{J}-140$ & 4940 & 4940 & 0 & 5248 & 5248 & 0 \\
\hline $\mathrm{J}-150$ & 4940 & 4940 & 0 & 4330 & 4330 & 0 \\
\hline $\mathrm{J}-160$ & 19760 & 19700 & 60 & 1487 & 1482 & 5 \\
\hline $\mathrm{J}-170$ & 4940 & 4916 & 24 & 1901 & 1892 & 9 \\
\hline
\end{tabular}




\section{Failure Scenario 'J-110 Out'}

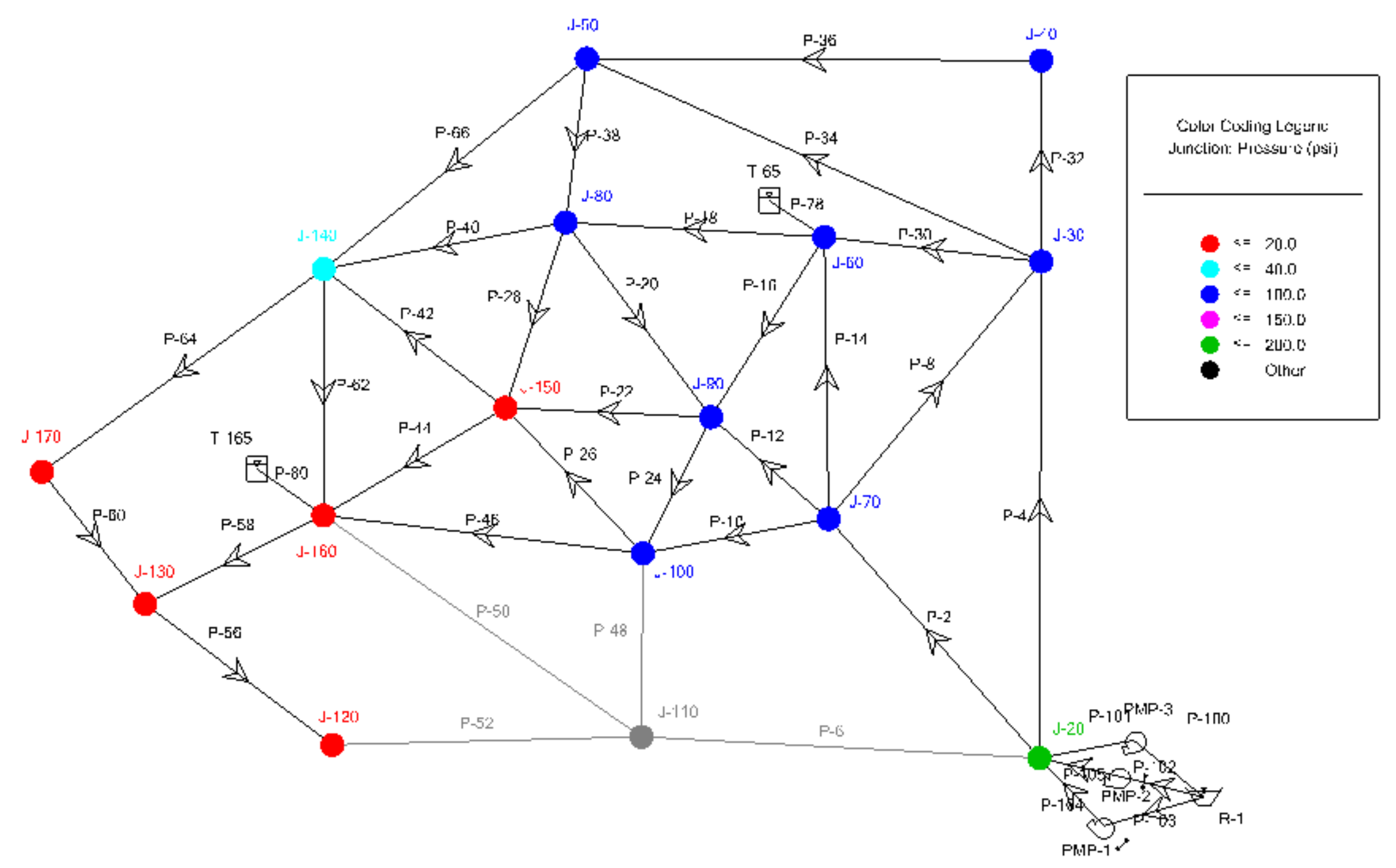




\section{Demand Supplied}

\begin{tabular}{|c|c|c|c|c|c|c|c|c|c|c|c|c|c|c|c|c|}
\hline $\begin{array}{c}\text { Time } \\
\text { (hours) }\end{array}$ & $J-20$ & J-30 & $\mathrm{J}-40$ & $\mathrm{~J}-50$ & $\mathrm{~J}-60$ & J-70 & $\mathrm{J}-80$ & J-90 & $\mathrm{J}-100$ & $\mathrm{~J}-110$ & $\mathrm{~J}-120$ & $\mathrm{~J}-130$ & $\mathrm{~J}-140$ & $\mathrm{~J}-150$ & $\mathrm{~J}-160$ & $\mathrm{~J}-170$ \\
\hline 0 & 350 & 140 & 500 & 140 & 350 & 350 & 350 & 700 & 350 & 0 & 1140 & 500 & 140 & 140 & 560 & 140 \\
\hline 1 & 350 & 140 & 500 & 140 & 350 & 350 & 350 & 700 & 350 & 0 & 1140 & 500 & 140 & 140 & 560 & 140 \\
\hline 2 & 350 & 140 & 500 & 140 & 350 & 350 & 350 & 700 & 350 & 0 & 1140 & 500 & 140 & 140 & 560 & 140 \\
\hline 3 & 300 & 120 & 500 & 120 & 300 & 300 & 300 & 600 & 300 & 0 & 1120 & 500 & 120 & 120 & 480 & 120 \\
\hline 4 & 300 & 120 & 500 & 120 & 300 & 300 & 300 & 600 & 300 & 0 & 1120 & 500 & 120 & 120 & 480 & 120 \\
\hline 5 & 300 & 120 & 500 & 120 & 300 & 300 & 300 & 600 & 300 & 0 & 1120 & 500 & 120 & 120 & 480 & 120 \\
\hline 6 & 600 & 240 & 500 & 240 & 600 & 600 & 600 & 1200 & 600 & 0 & 1240 & 500 & 240 & 240 & 960 & 240 \\
\hline 7 & 600 & 240 & 500 & 240 & 600 & 600 & 600 & 1200 & 600 & 0 & 1240 & 500 & 240 & 240 & 960 & 240 \\
\hline 8 & 600 & 240 & 500 & 240 & 600 & 600 & 600 & 1200 & 600 & 0 & 1240 & 500 & 240 & 240 & 960 & 240 \\
\hline 9 & 650 & 260 & 500 & 260 & 650 & 650 & 650 & 1300 & 650 & 0 & 1260 & 500 & 260 & 260 & 1040 & 260 \\
\hline 10 & 650 & 260 & 500 & 260 & 650 & 650 & 650 & 1300 & 650 & 0 & 1260 & 500 & 260 & 260 & 1040 & 260 \\
\hline 11 & 650 & 218 & 409 & 212 & 527 & 544 & 513 & 1021 & 508 & 0 & 792 & 348 & 201 & 202 & 767 & 181 \\
\hline 12 & 600 & 210 & 428 & 205 & 510 & 524 & 497 & 991 & 493 & 0 & 828 & 369 & 195 & 196 & 748 & 177 \\
\hline 13 & 600 & 210 & 428 & 205 & 510 & 524 & 497 & 991 & 493 & 0 & 828 & 369 & 195 & 196 & 748 & 177 \\
\hline 14 & 600 & 210 & 428 & 205 & 510 & 524 & 497 & 991 & 493 & 0 & 828 & 369 & 195 & 196 & 748 & 177 \\
\hline 15 & 550 & 201 & 449 & 197 & 491 & 503 & 480 & 957 & 476 & 0 & 867 & 391 & 189 & 190 & 726 & 172 \\
\hline 16 & 550 & 201 & 449 & 197 & 491 & 503 & 480 & 957 & 476 & 0 & 867 & 391 & 189 & 190 & 726 & 172 \\
\hline 17 & 550 & 201 & 449 & 197 & 491 & 503 & 480 & 957 & 476 & 0 & 867 & 391 & 189 & 190 & 726 & 172 \\
\hline 18 & 500 & 192 & 472 & 188 & 469 & 480 & 460 & 918 & 457 & 0 & 909 & 415 & 181 & 182 & 699 & 166 \\
\hline 19 & 500 & 192 & 472 & 188 & 469 & 480 & 460 & 918 & 457 & 0 & 909 & 415 & 181 & 182 & 699 & 166 \\
\hline 20 & 500 & 192 & 472 & 188 & 469 & 480 & 460 & 918 & 457 & 0 & 909 & 415 & 181 & 182 & 699 & 166 \\
\hline 21 & 450 & 180 & 497 & 178 & 446 & 450 & 438 & 874 & 435 & 0 & 955 & 442 & 173 & 173 & 669 & 159 \\
\hline 22 & 450 & 180 & 497 & 178 & 446 & 450 & 438 & 874 & 435 & 0 & 955 & 442 & 173 & 173 & 669 & 159 \\
\hline 23 & 450 & 180 & 497 & 178 & 446 & 450 & 438 & 874 & 435 & 0 & 955 & 442 & 173 & 173 & 669 & 159 \\
\hline 24 & 350 & 140 & 500 & 140 & 350 & 350 & 350 & 700 & 350 & 0 & 1140 & 500 & 140 & 140 & 560 & 140 \\
\hline Total & 2350 & 4,727 & 11,947 & 4,676 & 11,675 & 11,815 & 11,538 & 23,041 & 11,491 & 0 & 25,629 & 11,199 & 4,575 & 4,585 & 17,933 & 4,363 \\
\hline
\end{tabular}




\section{'J-110 Out' Results}

\begin{tabular}{|c|c|c|c|c|c|c|}
\hline \multirow[b]{2}{*}{ Node } & \multicolumn{2}{|c|}{ Demand Supplied } & \multirow[b]{2}{*}{$\begin{array}{l}\text { Demand } \\
\text { Effected }\end{array}$} & \multicolumn{2}{|c|}{ Population Served } & \multirow[b]{2}{*}{$\begin{array}{c}\text { Population } \\
\text { Effected }\end{array}$} \\
\hline & $\begin{array}{c}\text { Normal } \\
\text { Conditions }\end{array}$ & $\begin{array}{l}\text { Failure } \\
\text { Scenario } \\
\text { J-110 Out }\end{array}$ & & $\begin{array}{c}\text { Normal } \\
\text { Conditions }\end{array}$ & $\begin{array}{l}\text { Failure } \\
\text { Scenario } \\
\text { J-110 Out }\end{array}$ & \\
\hline$(1)$ & (2) & (3) & (4) & (5) & (6) & (7) \\
\hline $\mathrm{J}-20$ & 12350 & 12350 & 0 & 3069 & 3069 & 0 \\
\hline $\mathrm{J}-30$ & 4940 & 4727 & 213 & 1421 & 1360 & 61 \\
\hline $\mathrm{J}-40$ & 4940 & 11947 & -7007 & 6100 & 14752 & -8652 \\
\hline$J-50$ & 4940 & 4676 & 264 & 5953 & 5635 & 318 \\
\hline $\mathrm{J}-60$ & 12350 & 11675 & 675 & 2297 & 2171 & 126 \\
\hline $\mathrm{J}-70$ & 12350 & 11815 & 535 & 827 & 792 & 36 \\
\hline $\mathrm{J}-80$ & 12350 & 11538 & 812 & 4189 & 3913 & 275 \\
\hline $\mathrm{J}-90$ & 24700 & 23041 & 1659 & 6082 & 5674 & 409 \\
\hline $\mathrm{J}-100$ & 12350 & 11491 & 859 & 716 & 666 & 50 \\
\hline $\mathrm{J}-110$ & 12350 & 0 & 12350 & 4642 & 0 & 4642 \\
\hline $\mathrm{J}-120$ & 4940 & 25629 & -20689 & 4949 & 25677 & -20727 \\
\hline$J-130$ & 4940 & 11199 & -6259 & 5170 & 11720 & -6550 \\
\hline $\mathrm{J}-140$ & 4940 & 4575 & 365 & 5248 & 4861 & 388 \\
\hline J-150 & 4940 & 4585 & 355 & 4330 & 4019 & 311 \\
\hline J-160 & 19760 & 17933 & 1827 & 1487 & 1349 & 137 \\
\hline J-170 & 4940 & 4363 & 577 & 1901 & 1679 & 222 \\
\hline
\end{tabular}




\section{Failure Scenario 'J-120 Out'}

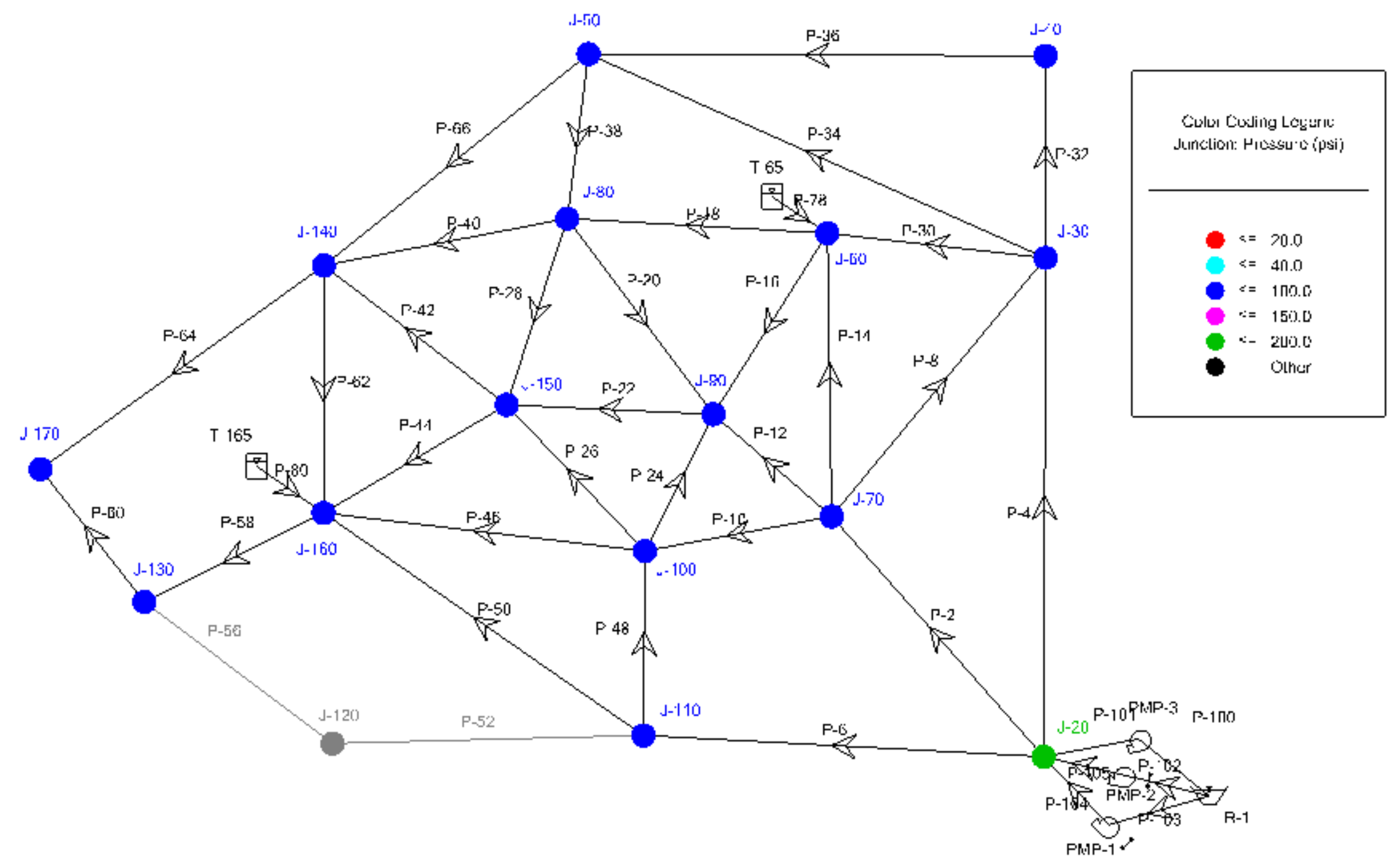




\section{Demand Supplied}

\begin{tabular}{|c|c|c|c|c|c|c|c|c|c|c|c|c|c|c|c|c|}
\hline $\begin{array}{c}\text { Time } \\
\text { (hours) }\end{array}$ & $\mathrm{J}-20$ & $\mathrm{~J}-30$ & $\mathrm{~J}-40$ & $J-50$ & $J-60$ & $\mathrm{~J}-70$ & $\mathrm{~J}-80$ & $\mathrm{~J}-90$ & $\mathrm{~J}-100$ & $\mathrm{~J}-110$ & $\mathrm{~J}-120$ & $\mathrm{~J}-130$ & $\mathrm{~J}-140$ & $\mathrm{~J}-150$ & $\mathrm{~J}-160$ & $\mathrm{~J}-170$ \\
\hline 0 & 350 & 140 & 500 & 140 & 350 & 350 & 350 & 700 & 350 & 350 & 0 & 500 & 140 & 140 & 560 & 140 \\
\hline 1 & 350 & 140 & 500 & 140 & 350 & 350 & 350 & 700 & 350 & 350 & 0 & 500 & 140 & 140 & 560 & 140 \\
\hline 2 & 350 & 140 & 500 & 140 & 350 & 350 & 350 & 700 & 350 & 350 & 0 & 500 & 140 & 140 & 560 & 140 \\
\hline 3 & 300 & 120 & 500 & 120 & 300 & 300 & 300 & 600 & 300 & 300 & 0 & 500 & 120 & 120 & 480 & 120 \\
\hline 4 & 300 & 120 & 500 & 120 & 300 & 300 & 300 & 600 & 300 & 300 & 0 & 500 & 120 & 120 & 480 & 120 \\
\hline 5 & 300 & 120 & 500 & 120 & 300 & 300 & 300 & 600 & 300 & 300 & 0 & 500 & 120 & 120 & 480 & 120 \\
\hline 6 & 600 & 240 & 500 & 240 & 600 & 600 & 600 & 1200 & 600 & 600 & 0 & 500 & 240 & 240 & 960 & 240 \\
\hline 7 & 600 & 240 & 500 & 240 & 600 & 600 & 600 & 1200 & 600 & 600 & 0 & 500 & 240 & 240 & 960 & 240 \\
\hline 8 & 600 & 240 & 500 & 240 & 600 & 600 & 600 & 1200 & 600 & 600 & 0 & 500 & 240 & 240 & 960 & 240 \\
\hline 9 & 650 & 260 & 500 & 260 & 650 & 650 & 650 & 1300 & 650 & 650 & 0 & 500 & 260 & 260 & 1040 & 260 \\
\hline 10 & 650 & 260 & 500 & 260 & 650 & 650 & 650 & 1300 & 650 & 650 & 0 & 500 & 260 & 260 & 1040 & 260 \\
\hline 11 & 650 & 260 & 500 & 260 & 650 & 650 & 650 & 1300 & 650 & 650 & 0 & 500 & 260 & 260 & 1040 & 260 \\
\hline 12 & 600 & 240 & 500 & 240 & 600 & 600 & 600 & 1200 & 600 & 600 & 0 & 500 & 240 & 240 & 960 & 240 \\
\hline 13 & 600 & 240 & 500 & 240 & 600 & 600 & 600 & 1200 & 600 & 600 & 0 & 500 & 240 & 240 & 960 & 240 \\
\hline 14 & 600 & 240 & 500 & 240 & 600 & 600 & 600 & 1200 & 600 & 600 & 0 & 500 & 240 & 240 & 960 & 240 \\
\hline 15 & 550 & 220 & 500 & 220 & 550 & 550 & 550 & 1100 & 550 & 550 & 0 & 500 & 220 & 220 & 880 & 220 \\
\hline 16 & 550 & 220 & 500 & 220 & 550 & 550 & 550 & 1100 & 550 & 550 & 0 & 500 & 220 & 220 & 880 & 220 \\
\hline 17 & 550 & 220 & 500 & 220 & 550 & 550 & 550 & 1100 & 550 & 550 & 0 & 500 & 220 & 220 & 880 & 220 \\
\hline 18 & 500 & 200 & 500 & 200 & 500 & 500 & 500 & 1000 & 500 & 500 & 0 & 500 & 200 & 200 & 800 & 200 \\
\hline 19 & 500 & 200 & 500 & 200 & 500 & 500 & 500 & 1000 & 500 & 500 & 0 & 500 & 200 & 200 & 800 & 200 \\
\hline 20 & 500 & 200 & 500 & 200 & 500 & 500 & 500 & 1000 & 500 & 500 & 0 & 500 & 200 & 200 & 800 & 200 \\
\hline 21 & 450 & 180 & 500 & 180 & 450 & 450 & 450 & 900 & 450 & 450 & 0 & 500 & 180 & 180 & 720 & 180 \\
\hline 22 & 450 & 180 & 500 & 180 & 450 & 450 & 450 & 900 & 450 & 450 & 0 & 500 & 180 & 180 & 720 & 180 \\
\hline 23 & 450 & 180 & 500 & 180 & 450 & 450 & 450 & 900 & 450 & 450 & 0 & 500 & 180 & 180 & 720 & 180 \\
\hline 24 & 350 & 140 & 500 & 140 & 350 & 350 & 350 & 700 & 350 & 350 & 0 & 500 & 140 & 140 & 560 & 140 \\
\hline Total & 12350 & 4,940 & 12,500 & 4,940 & 12,350 & 12,350 & 12,350 & 24,700 & 12,350 & 12,350 & 0 & 12,500 & 4,940 & 4,940 & 19,760 & 4,940 \\
\hline
\end{tabular}




\begin{tabular}{|c|c|c|c|c|c|c|}
\hline \multirow[b]{2}{*}{ Node } & \multicolumn{2}{|c|}{ Demand Supplied } & \multirow[b]{2}{*}{$\begin{array}{l}\text { Demand } \\
\text { Effected }\end{array}$} & \multicolumn{2}{|c|}{ Population Served } & \multirow[b]{2}{*}{$\begin{array}{c}\text { Population } \\
\text { Effected }\end{array}$} \\
\hline & $\begin{array}{c}\text { Normal } \\
\text { Conditions }\end{array}$ & $\begin{array}{l}\text { Failure } \\
\text { Scenario } \\
\text { J-120 Out }\end{array}$ & & $\begin{array}{c}\text { Normal } \\
\text { Conditions }\end{array}$ & $\begin{array}{l}\text { Failure } \\
\text { Scenario } \\
\text { J-120 Out }\end{array}$ & \\
\hline (1) & (2) & (3) & (4) & (5) & (6) & (7) \\
\hline$J-20$ & 12350 & 12350 & 0 & 3069 & 3069 & 0 \\
\hline$J-30$ & 4940 & 4940 & 0 & 1421 & 1421 & 0 \\
\hline$J-40$ & 4940 & 12500 & -7560 & 6100 & 15435 & -9335 \\
\hline J-50 & 4940 & 4940 & 0 & 5953 & 5953 & 0 \\
\hline$J-60$ & 12350 & 12350 & 0 & 2297 & 2297 & 0 \\
\hline$J-70$ & 12350 & 12350 & 0 & 827 & 827 & 0 \\
\hline$J-80$ & 12350 & 12350 & 0 & 4189 & 4189 & 0 \\
\hline J-90 & 24700 & 24700 & 0 & 6082 & 6082 & 0 \\
\hline J-100 & 12350 & 12350 & 0 & 716 & 716 & 0 \\
\hline $\mathrm{J}-110$ & 12350 & 12350 & 0 & 4642 & 4642 & 0 \\
\hline $\mathrm{J}-120$ & 4940 & 0 & 4940 & 4949 & 0 & 4949 \\
\hline J-130 & 4940 & 12500 & -7560 & 5170 & 13081 & -7912 \\
\hline $\mathrm{J}-140$ & 4940 & 4940 & 0 & 5248 & 5248 & 0 \\
\hline $\mathrm{J}-150$ & 4940 & 4940 & 0 & 4330 & 4330 & 0 \\
\hline$J-160$ & 19760 & 19760 & 0 & 1487 & 1487 & 0 \\
\hline$J-170$ & 4940 & 4940 & 0 & 1901 & 1901 & 0 \\
\hline
\end{tabular}




\section{Failure Scenario 'J-130 Out'}

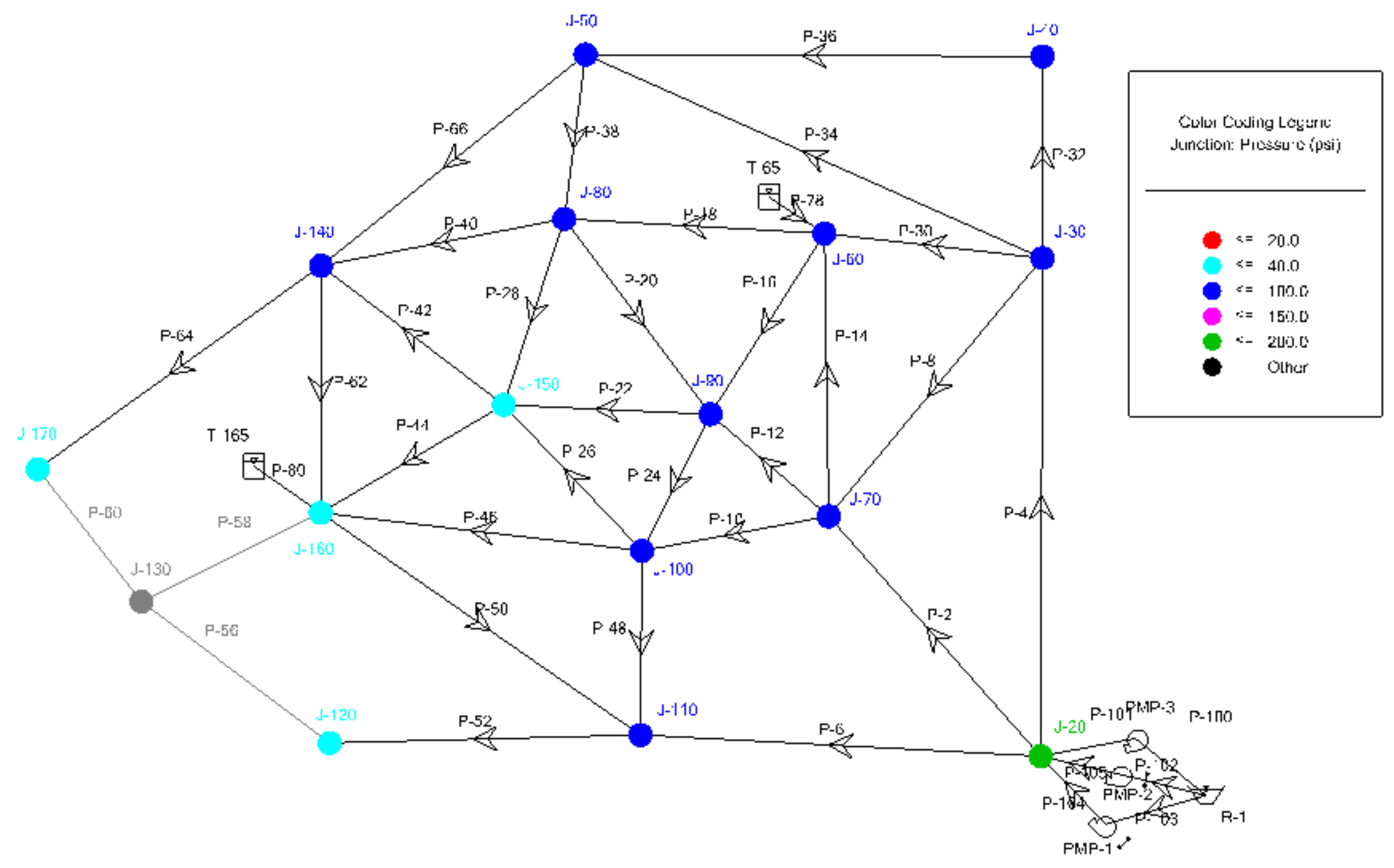




\section{Demand Supplied'}

\begin{tabular}{|c|c|c|c|c|c|c|c|c|c|c|c|c|c|c|c|c|}
\hline $\begin{array}{l}\text { Time } \\
\text { (hours) }\end{array}$ & $J-20$ & $\mathrm{~J}-30$ & $\mathrm{~J}-40$ & J-50 & $\mathrm{J}-60$ & J-70 & $\mathrm{J}-80$ & J-90 & $\mathrm{J}-100$ & $\mathrm{~J}-110$ & $\mathrm{~J}-120$ & $\mathrm{~J}-130$ & $\mathrm{~J}-140$ & $\mathrm{~J}-150$ & $\mathrm{~J}-160$ & J-170 \\
\hline 0 & 350 & 140 & 500 & 140 & 350 & 350 & 350 & 700 & 350 & 350 & 1140 & 0 & 140 & 140 & 560 & 140 \\
\hline 1 & 350 & 140 & 500 & 140 & 350 & 350 & 350 & 700 & 350 & 350 & 1140 & 0 & 140 & 140 & 560 & 140 \\
\hline 2 & 350 & 140 & 500 & 140 & 350 & 350 & 350 & 700 & 350 & 350 & 1140 & 0 & 140 & 140 & 560 & 140 \\
\hline 3 & 300 & 120 & 500 & 120 & 300 & 300 & 300 & 600 & 300 & 300 & 1120 & 0 & 120 & 120 & 480 & 120 \\
\hline 4 & 300 & 120 & 500 & 120 & 300 & 300 & 300 & 600 & 300 & 300 & 1120 & 0 & 120 & 120 & 480 & 120 \\
\hline 5 & 300 & 120 & 500 & 120 & 300 & 300 & 300 & 600 & 300 & 300 & 1120 & 0 & 120 & 120 & 480 & 120 \\
\hline 6 & 600 & 240 & 500 & 240 & 600 & 600 & 600 & 1200 & 600 & 600 & 1240 & 0 & 240 & 240 & 960 & 240 \\
\hline 7 & 600 & 240 & 500 & 240 & 600 & 600 & 600 & 1200 & 600 & 600 & 1240 & 0 & 240 & 240 & 960 & 240 \\
\hline 8 & 600 & 240 & 500 & 240 & 600 & 600 & 600 & 1200 & 600 & 600 & 1240 & 0 & 240 & 240 & 960 & 240 \\
\hline 9 & 650 & 260 & 500 & 260 & 650 & 650 & 650 & 1300 & 650 & 650 & 1260 & 0 & 260 & 260 & 1040 & 260 \\
\hline 10 & 650 & 260 & 500 & 260 & 650 & 650 & 650 & 1300 & 650 & 650 & 1260 & 0 & 260 & 260 & 1040 & 260 \\
\hline 11 & 650 & 260 & 500 & 260 & 650 & 650 & 650 & 1300 & 650 & 650 & 1260 & 0 & 260 & 260 & 1040 & 260 \\
\hline 12 & 600 & 240 & 500 & 240 & 600 & 600 & 600 & 1200 & 600 & 600 & 1240 & 0 & 240 & 240 & 960 & 240 \\
\hline 13 & 600 & 240 & 500 & 240 & 600 & 600 & 600 & 1200 & 600 & 600 & 1240 & 0 & 240 & 240 & 960 & 240 \\
\hline 14 & 600 & 240 & 500 & 240 & 600 & 600 & 600 & 1200 & 600 & 600 & 1240 & 0 & 240 & 240 & 960 & 240 \\
\hline 15 & 550 & 220 & 500 & 220 & 550 & 550 & 550 & 1100 & 550 & 550 & 1220 & 0 & 220 & 220 & 880 & 220 \\
\hline 16 & 550 & 220 & 500 & 220 & 550 & 550 & 550 & 1100 & 550 & 548 & 1108 & 0 & 220 & 220 & 876 & 204 \\
\hline 17 & 550 & 220 & 500 & 220 & 550 & 550 & 550 & 1100 & 550 & 548 & 1108 & 0 & 220 & 220 & 876 & 204 \\
\hline 18 & 500 & 200 & 500 & 200 & 500 & 500 & 500 & 1000 & 500 & 500 & 1200 & 0 & 200 & 200 & 800 & 200 \\
\hline 19 & 500 & 200 & 500 & 200 & 500 & 500 & 500 & 1000 & 500 & 500 & 1200 & 0 & 200 & 200 & 800 & 200 \\
\hline 20 & 500 & 200 & 500 & 200 & 500 & 500 & 500 & 1000 & 500 & 500 & 1200 & 0 & 200 & 200 & 800 & 200 \\
\hline 21 & 450 & 180 & 500 & 180 & 450 & 450 & 450 & 900 & 450 & 450 & 1180 & 0 & 180 & 180 & 720 & 180 \\
\hline 22 & 450 & 180 & 500 & 180 & 450 & 450 & 450 & 900 & 450 & 450 & 1180 & 0 & 180 & 180 & 720 & 180 \\
\hline 23 & 450 & 180 & 500 & 180 & 450 & 450 & 450 & 900 & 450 & 450 & 1180 & 0 & 180 & 180 & 720 & 180 \\
\hline 24 & 350 & 140 & 500 & 140 & 350 & 350 & 350 & 700 & 350 & 350 & 1140 & 0 & 140 & 140 & 560 & 140 \\
\hline Total & 12350 & 4,940 & 12,500 & 4,940 & 12,350 & 12,350 & 12,350 & 24,700 & 12,350 & 12,346 & 29,716 & 0 & 4,940 & 4,940 & 19,752 & 4,908 \\
\hline
\end{tabular}


'J-130 Out' Results

\begin{tabular}{|c|c|c|c|c|c|c|}
\hline \multirow[b]{2}{*}{ Node } & \multicolumn{2}{|c|}{ Demand Supplied } & \multirow[b]{2}{*}{$\begin{array}{l}\text { Demand } \\
\text { Effected }\end{array}$} & \multicolumn{2}{|c|}{ Population Served } & \multirow[b]{2}{*}{$\begin{array}{c}\text { Population } \\
\text { Effected }\end{array}$} \\
\hline & $\begin{array}{c}\text { Normal } \\
\text { Conditions }\end{array}$ & $\begin{array}{l}\text { Failure } \\
\text { Scenario } \\
\text { J-130 Out }\end{array}$ & & \begin{tabular}{||c} 
Normal \\
Conditions
\end{tabular} & $\begin{array}{l}\text { Failure } \\
\text { Scenario } \\
\text { J-130 Out }\end{array}$ & \\
\hline (1) & (2) & (3) & (4) & (5) & (6) & (7) \\
\hline $\mathrm{J}-20$ & 12350 & 12350 & 0 & 3069 & 3069 & 0 \\
\hline $\mathrm{J}-30$ & 4940 & 4940 & 0 & 1421 & 1421 & 0 \\
\hline $\mathrm{J}-40$ & 4940 & 12500 & -7560 & 6100 & 15435 & -9335 \\
\hline$J-50$ & 4940 & 4940 & 0 & 5953 & 5953 & 0 \\
\hline$J-60$ & 12350 & 12350 & 0 & 2297 & 2297 & 0 \\
\hline $\mathrm{J}-70$ & 12350 & 12350 & 0 & 827 & 827 & 0 \\
\hline $\mathrm{J}-80$ & 12350 & 12350 & 0 & 4189 & 4189 & 0 \\
\hline J-90 & 24700 & 24700 & 0 & 6082 & 6082 & 0 \\
\hline$J-100$ & 12350 & 12350 & 0 & 716 & 716 & 0 \\
\hline $\mathrm{J}-110$ & 12350 & 12346 & 4 & 4642 & 4641 & 2 \\
\hline$J-120$ & 4940 & 29716 & -24776 & 4949 & 29771 & -24822 \\
\hline $\mathrm{J}-130$ & 4940 & 0 & 4940 & 5170 & 0 & 5170 \\
\hline $\mathrm{J}-140$ & 4940 & 4940 & 0 & 5248 & 5248 & 0 \\
\hline J-150 & 4940 & 4940 & 0 & 4330 & 4330 & 0 \\
\hline $\mathrm{J}-160$ & 19760 & 19752 & 8 & 1487 & 1486 & 1 \\
\hline $\mathrm{J}-170$ & 4940 & 4908 & 32 & 1901 & 1889 & 12 \\
\hline
\end{tabular}




\section{Failure Scenario 'J-140 Out'}

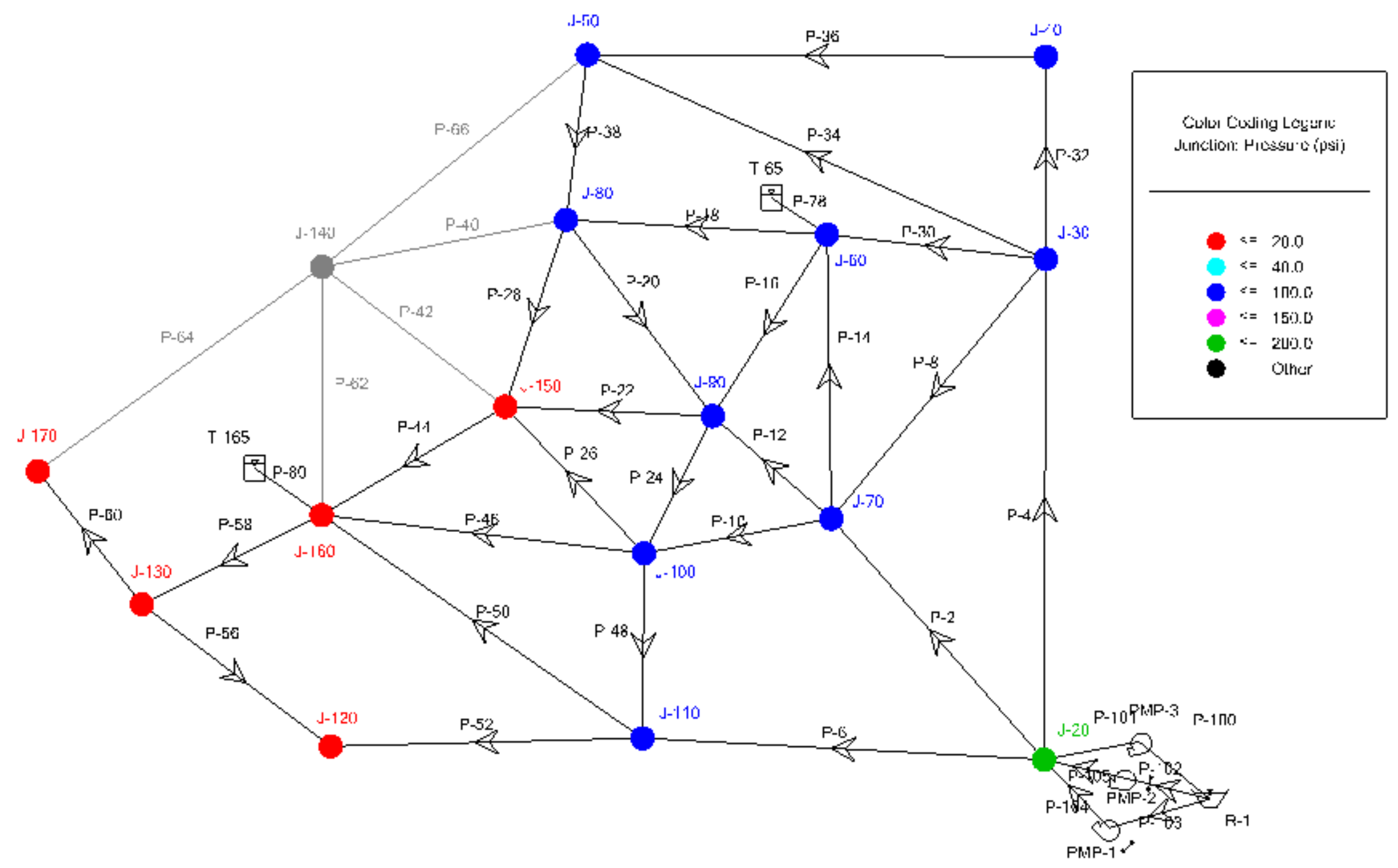




\section{Demand Supplied}

\begin{tabular}{|c|c|c|c|c|c|c|c|c|c|c|c|c|c|c|c|c|}
\hline $\begin{array}{c}\text { Time } \\
\text { (hours) }\end{array}$ & $\mathrm{J}-20$ & J-30 & $\mathrm{J}-40$ & $J-50$ & J-60 & J-70 & $\mathrm{J}-80$ & J-90 & $\mathrm{J}-100$ & $\mathrm{~J}-110$ & $\mathrm{~J}-120$ & $\mathrm{~J}-130$ & $\mathrm{~J}-140$ & $\mathrm{~J}-150$ & $\mathrm{~J}-160$ & J-170 \\
\hline 0 & 350 & 140 & 500 & 140 & 350 & 350 & 350 & 700 & 350 & 350 & 1140 & 500 & 0 & 140 & 560 & 140 \\
\hline 1 & 350 & 140 & 500 & 140 & 350 & 350 & 350 & 700 & 350 & 350 & 1140 & 500 & 0 & 140 & 560 & 140 \\
\hline 2 & 350 & 140 & 500 & 140 & 350 & 350 & 350 & 700 & 350 & 350 & 1140 & 500 & 0 & 140 & 560 & 140 \\
\hline 3 & 300 & 120 & 500 & 120 & 300 & 300 & 300 & 600 & 300 & 300 & 1120 & 500 & 0 & 120 & 480 & 120 \\
\hline 4 & 300 & 120 & 500 & 120 & 300 & 300 & 300 & 600 & 300 & 300 & 1120 & 500 & 0 & 120 & 480 & 120 \\
\hline 5 & 300 & 120 & 500 & 120 & 300 & 300 & 300 & 600 & 300 & 300 & 1120 & 500 & 0 & 120 & 480 & 120 \\
\hline 6 & 600 & 240 & 500 & 240 & 600 & 600 & 600 & 1200 & 600 & 600 & 1240 & 500 & 0 & 240 & 960 & 240 \\
\hline 7 & 600 & 240 & 500 & 240 & 600 & 600 & 600 & 1200 & 600 & 600 & 1240 & 500 & 0 & 240 & 960 & 240 \\
\hline 8 & 600 & 240 & 500 & 240 & 600 & 600 & 600 & 1200 & 600 & 600 & 1240 & 500 & 0 & 240 & 960 & 240 \\
\hline 9 & 650 & 260 & 500 & 260 & 650 & 650 & 650 & 1300 & 650 & 650 & 1260 & 500 & 0 & 260 & 1040 & 260 \\
\hline 10 & 650 & 260 & 500 & 260 & 650 & 650 & 650 & 1300 & 650 & 650 & 1260 & 500 & 0 & 260 & 1040 & 260 \\
\hline 11 & 650 & 260 & 500 & 260 & 650 & 650 & 650 & 1300 & 650 & 650 & 1260 & 500 & 0 & 260 & 1040 & 260 \\
\hline 12 & 600 & 240 & 500 & 240 & 600 & 600 & 600 & 1200 & 600 & 600 & 1240 & 500 & 0 & 240 & 960 & 240 \\
\hline 13 & 600 & 240 & 500 & 240 & 600 & 600 & 600 & 1200 & 600 & 600 & 1240 & 500 & 0 & 240 & 960 & 240 \\
\hline 14 & 600 & 232 & 478 & 229 & 569 & 580 & 563 & 1113 & 553 & 541 & 1063 & 434 & 0 & 221 & 856 & 207 \\
\hline 15 & 550 & 220 & 500 & 220 & 547 & 550 & 542 & 1073 & 533 & 522 & 1103 & 457 & 0 & 213 & 827 & 200 \\
\hline 16 & 550 & 220 & 500 & 220 & 547 & 550 & 542 & 1073 & 533 & 522 & 1103 & 457 & 0 & 213 & 827 & 200 \\
\hline 17 & 550 & 220 & 500 & 220 & 547 & 550 & 542 & 1073 & 533 & 522 & 1103 & 457 & 0 & 213 & 827 & 200 \\
\hline 18 & 500 & 200 & 500 & 200 & 500 & 500 & 500 & 1000 & 500 & 500 & 1174 & 495 & 0 & 200 & 800 & 197 \\
\hline 19 & 500 & 200 & 500 & 200 & 500 & 500 & 500 & 1000 & 500 & 500 & 1174 & 495 & 0 & 200 & 800 & 197 \\
\hline 20 & 500 & 200 & 500 & 200 & 500 & 500 & 500 & 1000 & 500 & 500 & 1174 & 495 & 0 & 200 & 800 & 197 \\
\hline 21 & 450 & 180 & 500 & 180 & 450 & 450 & 450 & 900 & 450 & 450 & 1180 & 500 & 0 & 180 & 720 & 180 \\
\hline 22 & 450 & 180 & 500 & 180 & 450 & 450 & 450 & 900 & 450 & 450 & 1180 & 500 & 0 & 180 & 720 & 180 \\
\hline 23 & 450 & 180 & 500 & 180 & 450 & 450 & 450 & 900 & 450 & 450 & 1180 & 500 & 0 & 180 & 720 & 180 \\
\hline 24 & 350 & 140 & 500 & 140 & 350 & 350 & 350 & 700 & 350 & 350 & 1140 & 500 & 0 & 140 & 560 & 140 \\
\hline Total & 12,350 & 4,932 & 12,478 & 4,929 & 12,310 & 12,330 & 12,289 & 24,532 & 12,252 & 12,207 & 29,334 & 12,290 & 0 & 4,900 & 19,497 & 4,838 \\
\hline
\end{tabular}


'J-140 Out' Results

\begin{tabular}{|c|c|c|c|c|c|c|}
\hline \multirow[b]{2}{*}{ Node } & \multicolumn{2}{|c|}{ Demand Supplied } & \multirow[b]{2}{*}{$\begin{array}{l}\text { Demand } \\
\text { Effected }\end{array}$} & \multicolumn{2}{|c|}{ Population Served } & \multirow[b]{2}{*}{$\begin{array}{c}\text { Population } \\
\text { Effected }\end{array}$} \\
\hline & $\begin{array}{c}\text { Normal } \\
\text { Conditions }\end{array}$ & $\begin{array}{c}\text { Failure } \\
\text { Scenario } \\
\text { J-140 Out }\end{array}$ & & $\begin{array}{c}\text { Normal } \\
\text { Conditions }\end{array}$ & $\begin{array}{l}\text { Failure } \\
\text { Scenario } \\
\text { J-140 Out }\end{array}$ & \\
\hline (1) & (2) & (3) & (4) & (5) & (6) & (7) \\
\hline $\mathrm{J}-20$ & 12350 & 12350 & 0 & 3069 & 3069 & 0 \\
\hline $\mathrm{J}-30$ & 4940 & 4932 & 8 & 1421 & 1419 & 2 \\
\hline J-40 & 4940 & 12478 & -7538 & 6100 & 15407 & -9308 \\
\hline $\mathrm{J}-50$ & 4940 & 4929 & 11 & 5953 & 5940 & 13 \\
\hline $\mathrm{J}-60$ & 12350 & 12310 & 40 & 2297 & 2289 & 7 \\
\hline J-70 & 12350 & 12330 & 20 & 827 & 826 & 1 \\
\hline $\mathrm{J}-80$ & 12350 & 12289 & 61 & 4189 & 4168 & 21 \\
\hline $\mathrm{J}-90$ & 24700 & 24532 & 168 & 6082 & 6041 & 41 \\
\hline J-100 & 12350 & 12252 & 98 & 716 & 710 & 6 \\
\hline$J-110$ & 12350 & 12207 & 143 & 4642 & 4588 & 54 \\
\hline$J-120$ & 4940 & 29334 & -24394 & 4949 & 29389 & -24439 \\
\hline $\mathrm{J}-130$ & 4940 & 12290 & -7350 & 5170 & 12861 & -7692 \\
\hline$J-140$ & 4940 & 0 & 4940 & 5248 & 0 & 5248 \\
\hline$J-150$ & 4940 & 4900 & 40 & 4330 & 4295 & 35 \\
\hline J-160 & 19760 & 19497 & 263 & 1487 & 1467 & 20 \\
\hline $\mathrm{J}-170$ & 4940 & 4838 & 102 & 1901 & 1862 & 39 \\
\hline
\end{tabular}




\section{Failure Scenario 'J-150 Out'}

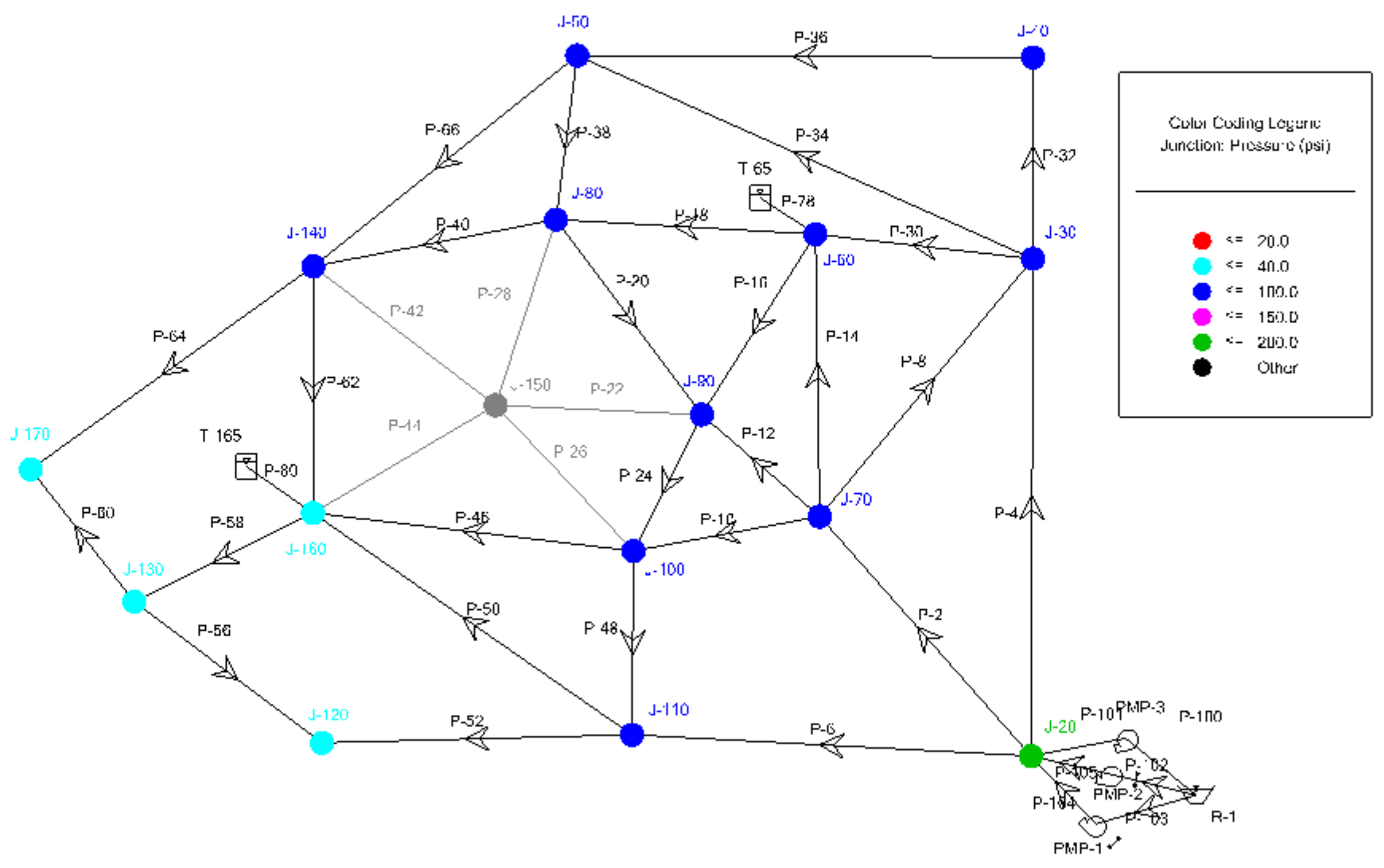




\section{Demand Supplied}

\begin{tabular}{|c|c|c|c|c|c|c|c|c|c|c|c|c|c|c|c|c|}
\hline $\begin{array}{c}\text { Time } \\
\text { (hours) }\end{array}$ & $\mathrm{J}-20$ & $\mathrm{~J}-30$ & $\mathrm{~J}-40$ & $\mathrm{~J}-50$ & $\mathrm{~J}-60$ & $\mathrm{~J}-70$ & $\mathrm{~J}-80$ & J-90 & $\mathrm{J}-100$ & $\mathrm{~J}-110$ & $\mathrm{~J}-120$ & $\mathrm{~J}-130$ & $\mathrm{~J}-140$ & $\mathrm{~J}-150$ & $\mathrm{~J}-160$ & J-170 \\
\hline 0 & 350 & 140 & 500 & 140 & 350 & 350 & 350 & 700 & 350 & 350 & 1140 & 500 & 140 & 0 & 560 & 140 \\
\hline 1 & 350 & 140 & 500 & 140 & 350 & 350 & 350 & 700 & 350 & 350 & 1140 & 500 & 140 & 0 & 560 & 140 \\
\hline 2 & 350 & 140 & 500 & 140 & 350 & 350 & 350 & 700 & 350 & 350 & 1140 & 500 & 140 & 0 & 560 & 140 \\
\hline 3 & 300 & 120 & 500 & 120 & 300 & 300 & 300 & 600 & 300 & 300 & 1120 & 500 & 120 & 0 & 480 & 120 \\
\hline 4 & 300 & 120 & 500 & 120 & 300 & 300 & 300 & 600 & 300 & 300 & 1120 & 500 & 120 & 0 & 480 & 120 \\
\hline 5 & 300 & 120 & 500 & 120 & 300 & 300 & 300 & 600 & 300 & 300 & 1120 & 500 & 120 & 0 & 480 & 120 \\
\hline 6 & 600 & 240 & 500 & 240 & 600 & 600 & 600 & 1200 & 600 & 600 & 1240 & 500 & 240 & 0 & 960 & 240 \\
\hline 7 & 600 & 240 & 500 & 240 & 600 & 600 & 600 & 1200 & 600 & 600 & 1240 & 500 & 240 & 0 & 960 & 240 \\
\hline 8 & 600 & 240 & 500 & 240 & 600 & 600 & 600 & 1200 & 600 & 600 & 1240 & 500 & 240 & 0 & 960 & 240 \\
\hline 9 & 650 & 260 & 500 & 260 & 650 & 650 & 650 & 1300 & 650 & 650 & 1260 & 500 & 260 & 0 & 1040 & 260 \\
\hline 10 & 650 & 260 & 500 & 260 & 650 & 650 & 650 & 1300 & 650 & 650 & 1260 & 500 & 260 & 0 & 1040 & 260 \\
\hline 11 & 650 & 260 & 500 & 260 & 650 & 650 & 650 & 1300 & 650 & 650 & 1260 & 500 & 260 & 0 & 1040 & 260 \\
\hline 12 & 600 & 240 & 500 & 240 & 600 & 600 & 600 & 1200 & 600 & 600 & 1240 & 500 & 240 & 0 & 960 & 240 \\
\hline 13 & 600 & 240 & 500 & 240 & 600 & 600 & 600 & 1200 & 600 & 600 & 1240 & 500 & 240 & 0 & 960 & 240 \\
\hline 14 & 600 & 231 & 474 & 227 & 566 & 578 & 558 & 1114 & 555 & 543 & 1071 & 438 & 220 & 0 & 859 & 210 \\
\hline 15 & 550 & 220 & 497 & 218 & 545 & 550 & 538 & 1073 & 534 & 524 & 1111 & 461 & 212 & 0 & 830 & 203 \\
\hline 16 & 550 & 220 & 497 & 218 & 545 & 550 & 538 & 1073 & 534 & 524 & 1111 & 461 & 212 & 0 & 830 & 203 \\
\hline 17 & 550 & 220 & 497 & 218 & 545 & 550 & 538 & 1073 & 534 & 524 & 1111 & 461 & 212 & 0 & 830 & 203 \\
\hline 18 & 500 & 200 & 500 & 200 & 500 & 500 & 500 & 1000 & 500 & 500 & 1180 & 498 & 200 & 0 & 800 & 199 \\
\hline 19 & 500 & 200 & 500 & 200 & 500 & 500 & 500 & 1000 & 500 & 500 & 1180 & 498 & 200 & 0 & 800 & 199 \\
\hline 20 & 500 & 200 & 500 & 200 & 500 & 500 & 500 & 1000 & 500 & 500 & 1180 & 498 & 200 & 0 & 800 & 199 \\
\hline 21 & 450 & 180 & 500 & 180 & 450 & 450 & 450 & 900 & 450 & 450 & 1180 & 500 & 180 & 0 & 720 & 180 \\
\hline 22 & 450 & 180 & 500 & 180 & 450 & 450 & 450 & 900 & 450 & 450 & 1180 & 500 & 180 & 0 & 720 & 180 \\
\hline 23 & 450 & 180 & 500 & 180 & 450 & 450 & 450 & 900 & 450 & 450 & 1180 & 500 & 180 & 0 & 720 & 180 \\
\hline 24 & 350 & 140 & 500 & 140 & 350 & 350 & 350 & 700 & 350 & 350 & 1140 & 500 & 140 & 0 & 560 & 140 \\
\hline Total & 12350 & 4,931 & 12,465 & 4,921 & 12,301 & 12,328 & 12,272 & 24,533 & 12,257 & 12,215 & 29,384 & 12,315 & 4,896 & 0 & 19,509 & 4,856 \\
\hline
\end{tabular}




\section{'J-150 Out' Results}

\begin{tabular}{|c|c|c|c|c|c|c|}
\hline \multirow[b]{2}{*}{ Node } & \multicolumn{2}{|c|}{ Demand Supplied } & \multirow[b]{2}{*}{$\begin{array}{l}\text { Demand } \\
\text { Effected }\end{array}$} & \multicolumn{2}{|c|}{ Population Served } & \multirow[b]{2}{*}{$\begin{array}{c}\text { Population } \\
\text { Effected }\end{array}$} \\
\hline & $\begin{array}{c}\text { Normal } \\
\text { Conditions }\end{array}$ & $\begin{array}{c}\text { Failure } \\
\text { Scenario } \\
\text { J-150 Out }\end{array}$ & & $\begin{array}{c}\text { Normal } \\
\text { Conditions }\end{array}$ & $\begin{array}{c}\text { Failure } \\
\text { Scenario } \\
\text { J-150 Out }\end{array}$ & \\
\hline (1) & (2) & (3) & (4) & (5) & (6) & (7) \\
\hline$J-20$ & 12350 & 12350 & 0 & 3069 & 3069 & 0 \\
\hline $\mathrm{J}-30$ & 4940 & 4931 & 9 & 1421 & 1419 & 3 \\
\hline$J-40$ & 4940 & 12465 & -7525 & 6100 & 15391 & -9292 \\
\hline$J-50$ & 4940 & 4921 & 19 & 5953 & 5931 & 23 \\
\hline$J-60$ & 12350 & 12301 & 49 & 2297 & 2288 & 9 \\
\hline J-70 & 12350 & 12328 & 22 & 827 & 826 & 1 \\
\hline J-80 & 12350 & 12272 & 78 & 4189 & 4162 & 26 \\
\hline J-90 & 24700 & 24533 & 167 & 6082 & 6041 & 41 \\
\hline$J-100$ & 12350 & 12257 & 93 & 716 & 711 & 5 \\
\hline $\mathrm{J}-110$ & 12350 & 12215 & 135 & 4642 & 4591 & 51 \\
\hline$J-120$ & 4940 & 29384 & -24444 & 4949 & 29439 & -24489 \\
\hline $\mathrm{J}-130$ & 4940 & 12315 & -7375 & 5170 & 12888 & -7718 \\
\hline$J-140$ & 4940 & 4896 & 44 & 5248 & 5202 & 47 \\
\hline J-150 & 4940 & 0 & 4940 & 4330 & 0 & 4330 \\
\hline $\mathrm{J}-160$ & 19760 & 19509 & 251 & 1487 & 1468 & 19 \\
\hline J-170 & 4940 & 4856 & 84 & 1901 & 1869 & 32 \\
\hline
\end{tabular}




\section{Failure Scenario 'J-160 Out'}

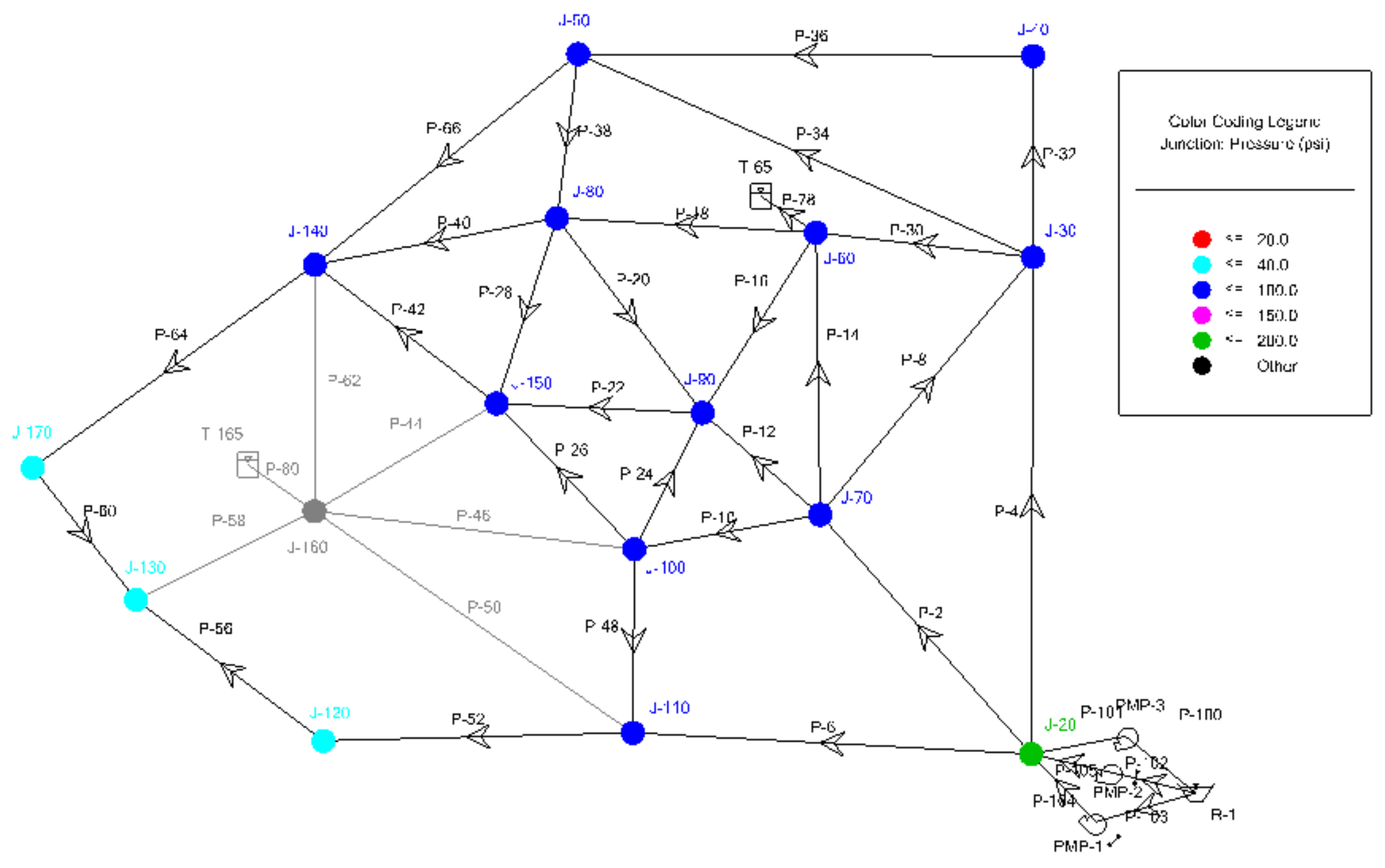




\section{Demand Supplied}

\begin{tabular}{|c|c|c|c|c|c|c|c|c|c|c|c|c|c|c|c|c|}
\hline $\begin{array}{c}\text { Time } \\
\text { (hours) }\end{array}$ & $J-20$ & $\mathrm{~J}-30$ & $J-40$ & $J-50$ & $J-60$ & $\mathrm{~J}-70$ & $\mathrm{~J}-80$ & J-90 & $\mathrm{J}-100$ & $\mathrm{~J}-110$ & $\mathrm{~J}-120$ & $\mathrm{~J}-130$ & $\mathrm{~J}-140$ & $\mathrm{~J}-150$ & $J-160$ & $\mathrm{~J}-170$ \\
\hline 0 & 350 & 140 & 500 & 140 & 350 & 350 & 350 & 700 & 350 & 350 & 1140 & 500 & 140 & 140 & 0 & 140 \\
\hline 1 & 350 & 140 & 500 & 140 & 350 & 350 & 350 & 700 & 350 & 350 & 1140 & 500 & 140 & 140 & 0 & 140 \\
\hline 2 & 350 & 140 & 500 & 140 & 350 & 350 & 350 & 700 & 350 & 350 & 1140 & 500 & 140 & 140 & 0 & 140 \\
\hline 3 & 300 & 120 & 500 & 120 & 300 & 300 & 300 & 600 & 300 & 300 & 1120 & 500 & 120 & 120 & 0 & 120 \\
\hline 4 & 300 & 120 & 500 & 120 & 300 & 300 & 300 & 600 & 300 & 300 & 1120 & 500 & 120 & 120 & 0 & 120 \\
\hline 5 & 300 & 120 & 500 & 120 & 300 & 300 & 300 & 600 & 300 & 300 & 1120 & 500 & 120 & 120 & 0 & 120 \\
\hline 6 & 600 & 240 & 500 & 240 & 600 & 600 & 600 & 1200 & 600 & 600 & 1240 & 500 & 240 & 240 & 0 & 240 \\
\hline 7 & 600 & 240 & 500 & 240 & 600 & 600 & 600 & 1200 & 600 & 600 & 1240 & 500 & 240 & 240 & 0 & 240 \\
\hline 8 & 600 & 240 & 500 & 240 & 600 & 600 & 600 & 1200 & 600 & 600 & 1240 & 500 & 240 & 240 & 0 & 240 \\
\hline 9 & 650 & 260 & 500 & 260 & 650 & 650 & 650 & 1300 & 650 & 650 & 1260 & 500 & 260 & 260 & 0 & 260 \\
\hline 10 & 650 & 260 & 500 & 260 & 650 & 650 & 650 & 1300 & 650 & 650 & 1260 & 500 & 260 & 260 & 0 & 260 \\
\hline 11 & 650 & 260 & 500 & 260 & 650 & 650 & 650 & 1300 & 650 & 650 & 1260 & 500 & 260 & 260 & 0 & 260 \\
\hline 12 & 600 & 240 & 500 & 240 & 600 & 600 & 600 & 1200 & 600 & 600 & 1240 & 500 & 240 & 240 & 0 & 240 \\
\hline 13 & 600 & 240 & 500 & 240 & 600 & 600 & 600 & 1200 & 600 & 600 & 1240 & 500 & 240 & 240 & 0 & 240 \\
\hline 14 & 600 & 240 & 500 & 240 & 600 & 600 & 600 & 1200 & 600 & 595 & 1064 & 424 & 240 & 240 & 0 & 204 \\
\hline 15 & 550 & 220 & 500 & 220 & 550 & 550 & 550 & 1100 & 550 & 550 & 1144 & 464 & 220 & 220 & 0 & 205 \\
\hline 16 & 550 & 220 & 500 & 220 & 550 & 550 & 550 & 1100 & 550 & 550 & 1144 & 464 & 220 & 220 & 0 & 205 \\
\hline 17 & 550 & 220 & 500 & 220 & 550 & 550 & 550 & 1100 & 550 & 550 & 1144 & 464 & 220 & 220 & 0 & 205 \\
\hline 18 & 500 & 200 & 500 & 200 & 500 & 500 & 500 & 1000 & 500 & 500 & 1200 & 500 & 200 & 200 & 0 & 200 \\
\hline 19 & 500 & 200 & 500 & 200 & 500 & 500 & 500 & 1000 & 500 & 500 & 1200 & 500 & 200 & 200 & 0 & 200 \\
\hline 20 & 500 & 200 & 500 & 200 & 500 & 500 & 500 & 1000 & 500 & 500 & 1200 & 500 & 200 & 200 & 0 & 200 \\
\hline 21 & 450 & 180 & 500 & 180 & 450 & 450 & 450 & 900 & 450 & 450 & 1180 & 500 & 180 & 180 & 0 & 180 \\
\hline 22 & 450 & 180 & 500 & 180 & 450 & 450 & 450 & 900 & 450 & 450 & 1180 & 500 & 180 & 180 & 0 & 180 \\
\hline 23 & 450 & 180 & 500 & 180 & 450 & 450 & 450 & 900 & 450 & 450 & 1180 & 500 & 180 & 180 & 0 & 180 \\
\hline 24 & 350 & 140 & 500 & 140 & 350 & 350 & 350 & 700 & 350 & 350 & 1140 & 500 & 140 & 140 & 0 & 140 \\
\hline Total & 12350 & 4,940 & 12,500 & 4,940 & 12,350 & 12,350 & 12,350 & 24,700 & 12,350 & 12,345 & 29,536 & 12,316 & 4,940 & 4,940 & 0 & 4,859 \\
\hline
\end{tabular}




\begin{tabular}{|c|c|c|c|c|c|c|}
\hline \multirow[b]{2}{*}{ Node } & \multicolumn{2}{|c|}{ Demand Supplied } & \multirow[b]{2}{*}{$\begin{array}{l}\text { Demand } \\
\text { Effected }\end{array}$} & \multicolumn{2}{|c|}{ Population Served } & \multirow[b]{2}{*}{$\begin{array}{l}\text { Population } \\
\text { Effected }\end{array}$} \\
\hline & $\begin{array}{c}\text { Normal } \\
\text { Conditions }\end{array}$ & $\begin{array}{l}\text { Failure } \\
\text { Scenario } \\
\text { J-160 Out }\end{array}$ & & $\begin{array}{c}\text { Normal } \\
\text { Conditions }\end{array}$ & $\begin{array}{l}\text { Failure } \\
\text { Scenario } \\
\text { J-160 Out }\end{array}$ & \\
\hline (1) & (2) & (3) & (4) & (5) & (6) & (7) \\
\hline$J-20$ & 12350 & 12350 & 0 & 3069 & 3069 & 0 \\
\hline$J-30$ & 4940 & 4940 & 0 & 1421 & 1421 & 0 \\
\hline $\mathrm{J}-40$ & 4940 & 12500 & -7560 & 6100 & 15435 & -9335 \\
\hline$J-50$ & 4940 & 4940 & 0 & 5953 & 5953 & 0 \\
\hline$J-60$ & 12350 & 12350 & 0 & 2297 & 2297 & 0 \\
\hline $\mathrm{J}-70$ & 12350 & 12350 & 0 & 827 & 827 & 0 \\
\hline $\mathrm{J}-80$ & 12350 & 12350 & 0 & 4189 & 4189 & 0 \\
\hline J-90 & 24700 & 24700 & 0 & 6082 & 6082 & 0 \\
\hline$J-100$ & 12350 & 12350 & 0 & 716 & 716 & 0 \\
\hline $\mathrm{J}-110$ & 12350 & 12345 & 5 & 4642 & 4640 & 2 \\
\hline$J-120$ & 4940 & 29536 & -24596 & 4949 & 29591 & -24642 \\
\hline $\mathrm{J}-130$ & 4940 & 12316 & -7376 & 5170 & 12889 & -7719 \\
\hline$J-140$ & 4940 & 4940 & 0 & 5248 & 5248 & 0 \\
\hline J-150 & 4940 & 4940 & 0 & 4330 & 4330 & 0 \\
\hline$J-160$ & 19760 & 0 & 19760 & 1487 & 0 & 1487 \\
\hline $\mathrm{J}-170$ & 4940 & 4859 & 81 & 1901 & 1870 & 31 \\
\hline
\end{tabular}




\section{Failure Scenario 'J-170 Out'}

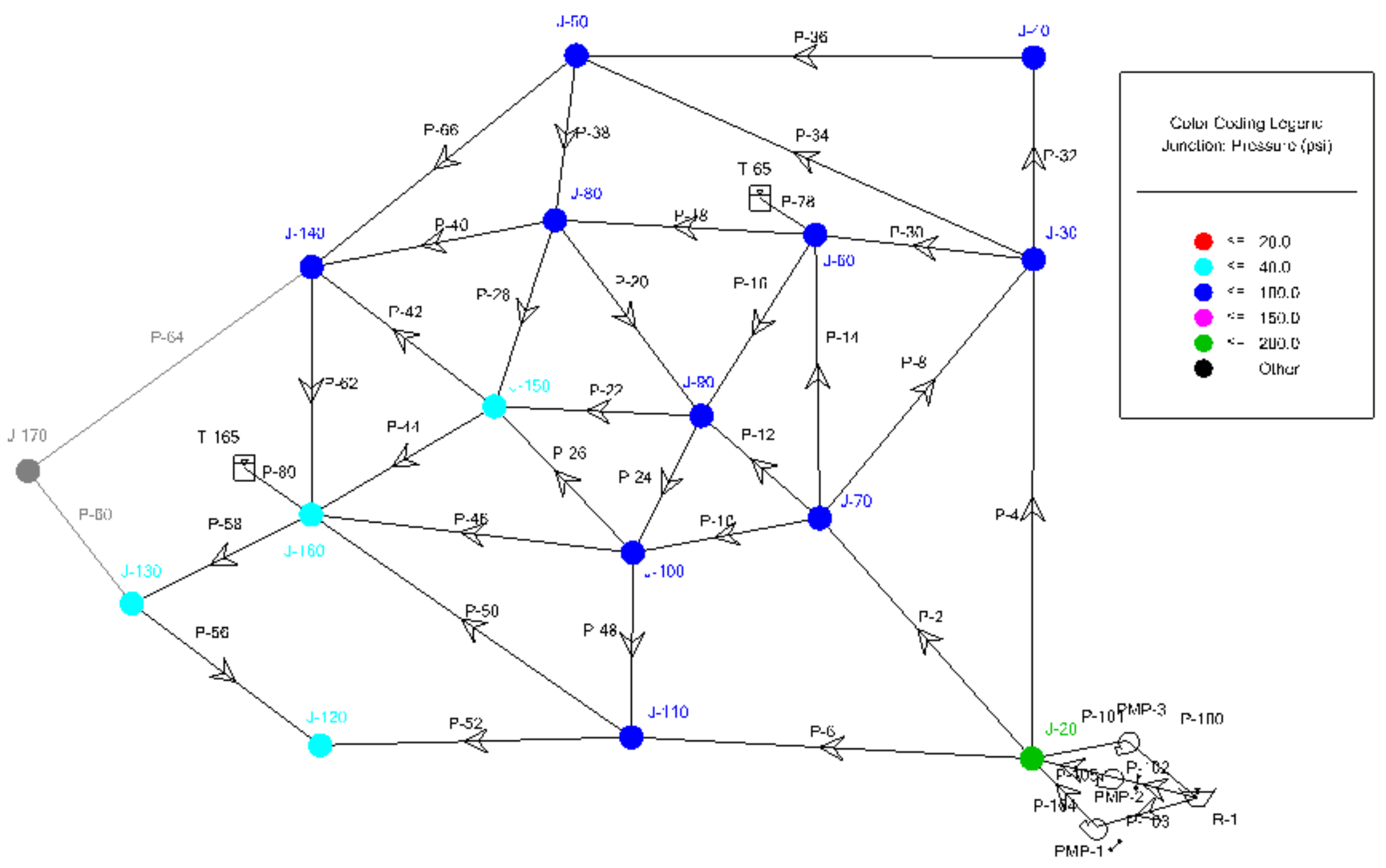




\section{Demand Supplied}

\begin{tabular}{|c|c|c|c|c|c|c|c|c|c|c|c|c|c|c|c|c|}
\hline $\begin{array}{c}\text { Time } \\
\text { (hours) }\end{array}$ & $\mathrm{J}-20$ & $\mathrm{~J}-30$ & $J-40$ & $J-50$ & $J-60$ & J-70 & $\mathrm{J}-80$ & J-90 & $\mathrm{J}-100$ & $\mathrm{~J}-110$ & $\mathrm{~J}-120$ & $\mathrm{~J}-130$ & $\mathrm{~J}-140$ & $\mathrm{~J}-150$ & $\mathrm{~J}-160$ & $\mathrm{~J}-170$ \\
\hline 0 & 350 & 140 & 500 & 140 & 350 & 350 & 350 & 700 & 350 & 350 & 1140 & 500 & 140 & 140 & 560 & 0 \\
\hline 1 & 350 & 140 & 500 & 140 & 350 & 350 & 350 & 700 & 350 & 350 & 1140 & 500 & 140 & 140 & 560 & 0 \\
\hline 2 & 350 & 140 & 500 & 140 & 350 & 350 & 350 & 700 & 350 & 350 & 1140 & 500 & 140 & 140 & 560 & 0 \\
\hline 3 & 300 & 120 & 500 & 120 & 300 & 300 & 300 & 600 & 300 & 300 & 1120 & 500 & 120 & 120 & 480 & 0 \\
\hline 4 & 300 & 120 & 500 & 120 & 300 & 300 & 300 & 600 & 300 & 300 & 1120 & 500 & 120 & 120 & 480 & 0 \\
\hline 5 & 300 & 120 & 500 & 120 & 300 & 300 & 300 & 600 & 300 & 300 & 1120 & 500 & 120 & 120 & 480 & 0 \\
\hline 6 & 600 & 240 & 500 & 240 & 600 & 600 & 600 & 1200 & 600 & 600 & 1240 & 500 & 240 & 240 & 960 & 0 \\
\hline 7 & 600 & 240 & 500 & 240 & 600 & 600 & 600 & 1200 & 600 & 600 & 1240 & 500 & 240 & 240 & 960 & 0 \\
\hline 8 & 600 & 240 & 500 & 240 & 600 & 600 & 600 & 1200 & 600 & 600 & 1240 & 500 & 240 & 240 & 960 & 0 \\
\hline 9 & 650 & 260 & 500 & 260 & 650 & 650 & 650 & 1300 & 650 & 650 & 1260 & 500 & 260 & 260 & 1040 & 0 \\
\hline 10 & 650 & 260 & 500 & 260 & 650 & 650 & 650 & 1300 & 650 & 650 & 1260 & 500 & 260 & 260 & 1040 & 0 \\
\hline 11 & 650 & 260 & 500 & 260 & 650 & 650 & 650 & 1300 & 650 & 650 & 1260 & 500 & 260 & 260 & 1040 & 0 \\
\hline 12 & 600 & 240 & 500 & 240 & 600 & 600 & 600 & 1200 & 600 & 600 & 1240 & 500 & 240 & 240 & 960 & 0 \\
\hline 13 & 600 & 240 & 500 & 240 & 600 & 600 & 600 & 1200 & 600 & 600 & 1240 & 500 & 240 & 240 & 960 & 0 \\
\hline 14 & 600 & 230 & 471 & 226 & 563 & 574 & 554 & 1104 & 551 & 547 & 1082 & 443 & 220 & 220 & 868 & 0 \\
\hline 15 & 550 & 220 & 494 & 217 & 541 & 550 & 534 & 1064 & 531 & 527 & 1121 & 466 & 212 & 212 & 838 & 0 \\
\hline 16 & 550 & 220 & 494 & 217 & 541 & 550 & 534 & 1064 & 531 & 527 & 1121 & 466 & 212 & 212 & 838 & 0 \\
\hline 17 & 550 & 220 & 494 & 217 & 541 & 550 & 534 & 1064 & 531 & 527 & 1121 & 466 & 212 & 212 & 838 & 0 \\
\hline 18 & 500 & 200 & 500 & 200 & 500 & 500 & 500 & 1000 & 500 & 500 & 1190 & 500 & 200 & 200 & 800 & 0 \\
\hline 19 & 500 & 200 & 500 & 200 & 500 & 500 & 500 & 1000 & 500 & 500 & 1190 & 500 & 200 & 200 & 800 & 0 \\
\hline 20 & 500 & 200 & 500 & 200 & 500 & 500 & 500 & 1000 & 500 & 500 & 1190 & 500 & 200 & 200 & 800 & 0 \\
\hline 21 & 450 & 180 & 500 & 180 & 450 & 450 & 450 & 900 & 450 & 450 & 1180 & 500 & 180 & 180 & 720 & 0 \\
\hline 22 & 450 & 180 & 500 & 180 & 450 & 450 & 450 & 900 & 450 & 450 & 1180 & 500 & 180 & 180 & 720 & 0 \\
\hline 23 & 450 & 180 & 500 & 180 & 450 & 450 & 450 & 900 & 450 & 450 & 1180 & 500 & 180 & 180 & 720 & 0 \\
\hline 24 & 350 & 140 & 500 & 140 & 350 & 350 & 350 & 700 & 350 & 350 & 1140 & 500 & 140 & 140 & 560 & 0 \\
\hline Total & 12,350 & 4,930 & 12,453 & 4,917 & 12,286 & 12,324 & 12,256 & 24,496 & 12,244 & 12,228 & 29,455 & 12,341 & 4,896 & 4,896 & 19,542 & 0 \\
\hline
\end{tabular}


'J-170 Out' Results

\begin{tabular}{|c|c|c|c|c|c|c|}
\hline \multirow[b]{2}{*}{ Node } & \multicolumn{2}{|c|}{ Demand Supplied } & \multirow[b]{2}{*}{$\begin{array}{l}\text { Demand } \\
\text { Effected }\end{array}$} & \multicolumn{2}{|c|}{ Population Served } & \multirow[b]{2}{*}{$\begin{array}{c}\text { Population } \\
\text { Effected }\end{array}$} \\
\hline & $\begin{array}{c}\text { Normal } \\
\text { Conditions }\end{array}$ & $\begin{array}{l}\text { Failure } \\
\text { Scenario } \\
\text { J-170 Out }\end{array}$ & & $\begin{array}{c}\text { Normal } \\
\text { Conditions }\end{array}$ & $\begin{array}{l}\text { Failure } \\
\text { Scenario } \\
\text { J-170 Out }\end{array}$ & \\
\hline (1) & (2) & (3) & (4) & (5) & (6) & (7) \\
\hline $\mathrm{J}-20$ & 12350 & 12350 & 0 & 3069 & 3069 & 0 \\
\hline$J-30$ & 4940 & 4930 & 10 & 1421 & 1419 & 3 \\
\hline$J-40$ & 4940 & 12453 & -7513 & 6100 & 15377 & -9277 \\
\hline$J-50$ & 4940 & 4917 & 23 & 5953 & 5926 & 28 \\
\hline $\mathrm{J}-60$ & 12350 & 12286 & 64 & 2297 & 2285 & 12 \\
\hline $\mathrm{J}-70$ & 12350 & 12324 & 26 & 827 & 826 & 2 \\
\hline$J-80$ & 12350 & 12256 & 94 & 4189 & 4157 & 32 \\
\hline J-90 & 24700 & 24496 & 204 & 6082 & 6032 & 50 \\
\hline $\mathrm{J}-100$ & 12350 & 12244 & 106 & 716 & 710 & 6 \\
\hline $\mathrm{J}-110$ & 12350 & 12228 & 122 & 4642 & 4596 & 46 \\
\hline$J-120$ & 4940 & 29455 & -24515 & 4949 & 29510 & -24561 \\
\hline $\mathrm{J}-130$ & 4940 & 12341 & -7401 & 5170 & 12915 & -7745 \\
\hline$J-140$ & 4940 & 4896 & 44 & 5248 & 5202 & 47 \\
\hline$J-150$ & 4940 & 4896 & 44 & 4330 & 4292 & 39 \\
\hline$J-160$ & 19760 & 19542 & 218 & 1487 & 1471 & 16 \\
\hline $\mathrm{J}-170$ & 4940 & 0 & 4940 & 1901 & 0 & 1901 \\
\hline
\end{tabular}




\title{
Appendix D: Disaster Scenario 2
}

\author{
Normal Operating Conditions \\ Failure Scenario 'J-20 Out' \\ Failure Scenario 'J-30 Out' \\ Failure Scenario 'J-40 Out' \\ Failure Scenario 'J-50 Out' \\ Failure Scenario 'J-60 Out' \\ Failure Scenario 'J-70 Out' \\ Failure Scenario 'J-80 Out' \\ Failure Scenario 'J-90 Out' \\ Failure Scenario 'J-100 Out' \\ Failure Scenario 'J-100 Out' \\ Failure Scenario 'J-110 Out' \\ Failure Scenario 'J-120 Out' \\ Failure Scenario 'J-130 Out' \\ Failure Scenario 'J-140 Out' \\ Failure Scenario 'J-150 Out' \\ Failure Scenario 'J-160 Out' \\ Failure Scenario 'J-170 Out'
}




\section{Normal Operating Conditions}

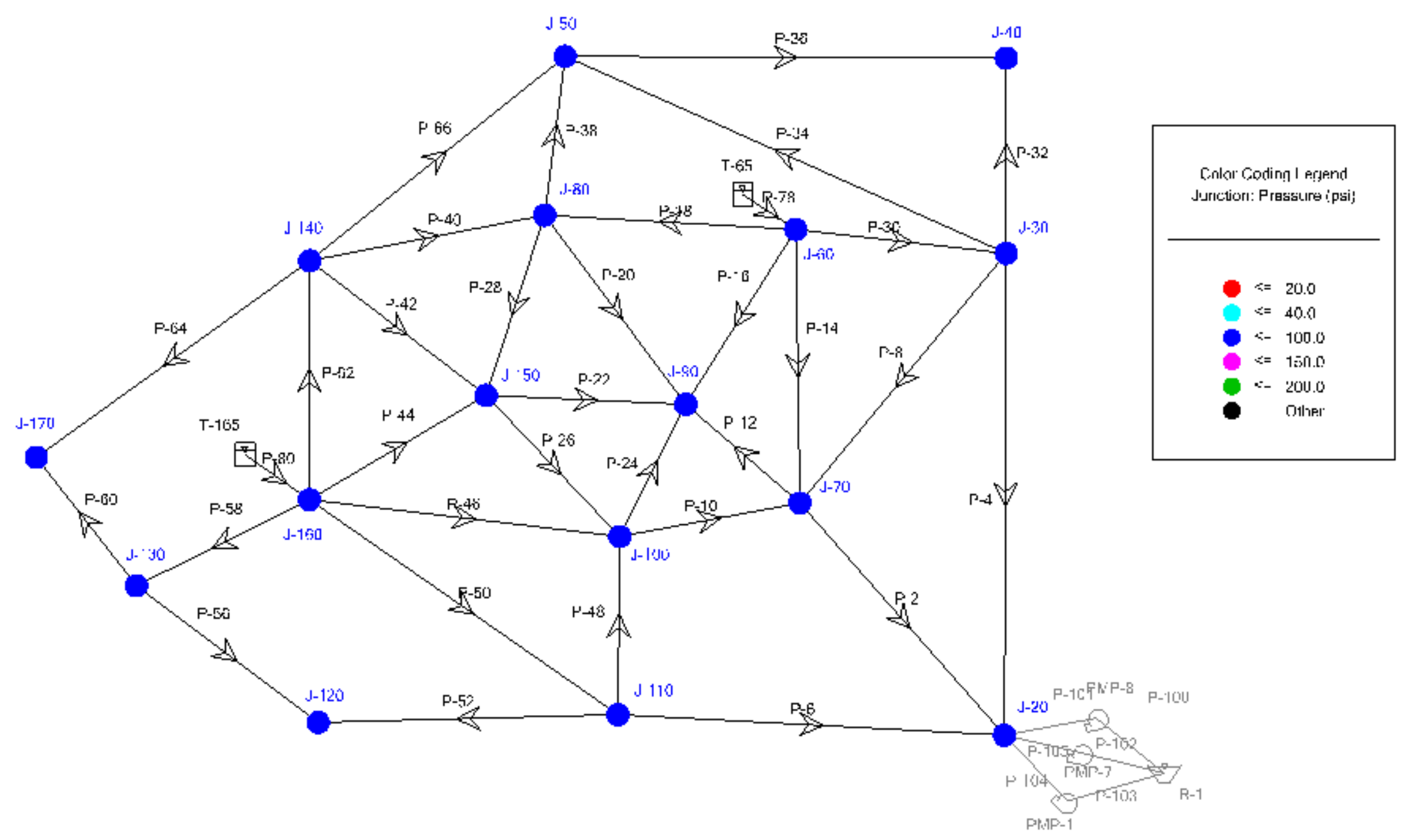


Pipe Information Imported into Matlab from WaterCAD

\begin{tabular}{|c|c|c|c|c|c|c|c|c|c|}
\hline No. & Pipe & $\begin{array}{l}\text { Length } \\
(\mathrm{ft})\end{array}$ & $\begin{array}{c}\text { C- } \\
\text { Factor }\end{array}$ & $\begin{array}{l}\text { Dia. } \\
\text { (in.) }\end{array}$ & $\begin{array}{l}\text { Start } \\
\text { Node }\end{array}$ & $\begin{array}{l}\text { Stop } \\
\text { Node }\end{array}$ & $\begin{array}{l}\text { Start } \\
\text { Node }\end{array}$ & $\begin{array}{l}\text { Stop } \\
\text { Node }\end{array}$ & $\begin{array}{l}\text { Flow } \\
\text { (gpm) }\end{array}$ \\
\hline 1 & P-2 & 12,000 & 70 & 16 & $\mathrm{~J}-70$ & $\mathrm{~J}-20$ & 6 & 1 & 263 \\
\hline 2 & P-4 & 12,000 & 120 & 12 & $J-30$ & $J-20$ & 2 & 1 & 230 \\
\hline 3 & P-6 & 12,000 & 70 & 12 & $\mathrm{~J}-110$ & $\mathrm{~J}-20$ & 10 & 1 & 157 \\
\hline 4 & P-8 & 9,000 & 70 & 12 & $J-30$ & $\mathrm{~J}-70$ & 2 & 6 & 55 \\
\hline 5 & P-10 & 600 & 70 & 12 & J-100 & J-70 & 9 & 6 & 134 \\
\hline 6 & P-12 & 600 & 70 & 10 & $\mathrm{~J}-70$ & J-90 & 6 & 8 & 142 \\
\hline 7 & P-14 & 600 & 70 & 12 & $J-60$ & J-70 & 5 & 6 & 865 \\
\hline 8 & P-16 & 600 & 70 & 10 & $J-60$ & J-90 & 5 & 8 & 560 \\
\hline 9 & P-18 & 600 & 70 & 12 & $\mathrm{~J}-60$ & $J-80$ & 5 & 7 & 818 \\
\hline 10 & P-20 & 600 & 70 & 10 & $\mathrm{~J}-80$ & J-90 & 7 & 8 & 215 \\
\hline 11 & P-22 & 600 & 70 & 10 & J-150 & J-90 & 14 & 8 & 216 \\
\hline 12 & P-24 & 600 & 70 & 10 & $\mathrm{~J}-100$ & J-90 & 9 & 8 & 168 \\
\hline 13 & P-26 & 600 & 70 & 12 & $\mathrm{~J}-150$ & $\mathrm{~J}-100$ & 14 & 9 & 204 \\
\hline 14 & P-28 & 600 & 70 & 10 & $J-150$ & $\mathrm{~J}-80$ & 14 & 7 & 13 \\
\hline 15 & P-30 & 600 & 120 & 10 & $\mathrm{~J}-60$ & $\mathrm{~J}-30$ & 5 & 2 & 872 \\
\hline 16 & P-32 & 600 & 120 & 10 & $\mathrm{~J}-30$ & $J-40$ & 2 & 3 & 176 \\
\hline 17 & P-34 & 600 & 120 & 10 & $\mathrm{~J}-30$ & $J-50$ & 2 & 4 & 150 \\
\hline 18 & P-36 & 600 & 120 & 10 & $J-50$ & $\mathrm{~J}-40$ & 4 & 3 & 84 \\
\hline 19 & P-38 & 600 & 120 & 10 & $\mathrm{~J}-80$ & $J-50$ & 7 & 4 & 165 \\
\hline 20 & $P-40$ & 600 & 120 & 10 & $\mathrm{~J}-140$ & $\mathrm{~J}-80$ & 13 & 7 & 198 \\
\hline 21 & P-42 & 600 & 120 & 8 & J-140 & $J-150$ & 13 & 14 & 109 \\
\hline 22 & P-44 & 600 & 120 & 8 & J-160 & $\mathrm{J}-150$ & 15 & 14 & 583 \\
\hline 23 & P-46 & 600 & 120 & 8 & $\mathrm{~J}-160$ & $\mathrm{~J}-100$ & 15 & 9 & 600 \\
\hline 24 & P-48 & 600 & 70 & 8 & $\mathrm{~J}-110$ & $\mathrm{~J}-100$ & 10 & 9 & 148 \\
\hline 25 & $P-50$ & 600 & 120 & 10 & J-160 & $\mathrm{J}-110$ & 15 & 10 & 955 \\
\hline 26 & P-52 & 600 & 120 & 8 & J-120 & $\mathrm{J}-110$ & 11 & 10 & 0 \\
\hline 27 & P-56 & 600 & 120 & 8 & J-130 & $\mathrm{J}-120$ & 12 & 11 & 260 \\
\hline 28 & P-58 & 600 & 120 & 10 & J-160 & $\mathrm{J}-130$ & 15 & 12 & 808 \\
\hline 29 & P-60 & 600 & 120 & 8 & $\mathrm{~J}-130$ & $\mathrm{~J}-170$ & 12 & 16 & 287 \\
\hline 30 & P-62 & 600 & 120 & 8 & J-160 & $\mathrm{J}-140$ & 15 & 13 & 569 \\
\hline 31 & P-64 & 12,000 & 120 & 8 & J-170 & $\mathrm{J}-140$ & 16 & 13 & 27 \\
\hline 32 & P-66 & 12,000 & 120 & 8 & J-140 & $J-50$ & 13 & 4 & 29 \\
\hline 33 & P-78 & 100 & 120 & 12 & $T-65$ & $J-60$ & 17 & 5 & 3,765 \\
\hline 34 & P-80 & 100 & 120 & 12 & $\mathrm{~T}-165$ & $J-160$ & 18 & 15 & 4,555 \\
\hline \multicolumn{10}{|c|}{ Matlab Input } \\
\hline
\end{tabular}




\section{Junction Information Imported into Matlab}

\begin{tabular}{cc|cccc}
\hline Junction & Matlab ID & Demand (gpm) & Node Outflow (gpm) & Inflow (gpm) & Population \\
\hline J-20 & 1 & 650 & 0 & 650 & 3069 \\
J-30 & 2 & 260 & 611 & 872 & 1421 \\
J-40 & 3 & 260 & 0 & 260 & 6100 \\
J-50 & 4 & 260 & 84 & 344 & 5953 \\
J-60 & 5 & 650 & 3115 & 3765 & 2297 \\
J-70 & 6 & 650 & 405 & 1054 & 827 \\
J-80 & 7 & 650 & 380 & 1029 & 4189 \\
J-90 & 8 & 1300 & 0 & 1301 & 6082 \\
J-100 & 9 & 650 & 302 & 952 & 716 \\
J-110 & 10 & 650 & 305 & 955 & 4642 \\
J-120 & 11 & 260 & 0 & 260 & 4949 \\
J-130 & 12 & 260 & 547 & 808 & 5170 \\
J-140 & 13 & 260 & 336 & 596 & 5248 \\
J-150 & 14 & 260 & 433 & 692 & 4330 \\
J-160 & 15 & 1040 & 3515 & 4555 & 1487 \\
J-170 & 16 & 260 & 27 & 287 & 1901 \\
T-65 & 17 & 0 & 3765 & 0 & 0 \\
T-165 & 18 & 0 & 4555 & 0 & 0 \\
& & & & Matlab Input &
\end{tabular}


Flow Distribution Results: Demand Affected

\begin{tabular}{|c|c|c|c|c|c|c|c|c|c|c|c|c|c|c|c|c|}
\hline & $\mathrm{J}-20$ & $\mathrm{~J}-30$ & $\mathrm{~J}-40$ & $\mathrm{~J}-50$ & $\mathrm{~J}-60$ & $\mathrm{~J}-70$ & $\mathrm{~J}-80$ & $\mathrm{~J}-90$ & $\mathrm{~J}-100$ & $\mathrm{~J}-110$ & $\mathrm{~J}-120$ & $\mathrm{~J}-130$ & $\mathrm{~J}-140$ & $\mathrm{~J}-150$ & $\mathrm{~J}-160$ & $\mathrm{~J}-170$ \\
\hline $\mathrm{J}-20$ & 650 & 4 & 0 & 0 & 24 & 5 & 2 & 0 & 3 & 1 & 0 & 2 & 2 & 4 & 20 & 0 \\
\hline $\mathrm{J}-30$ & 0 & 260 & 0 & 4 & 126 & 4 & 4 & 0 & 2 & 0 & 0 & 1 & 2 & 1 & 6 & 0 \\
\hline $\mathrm{J}-40$ & 0 & 91 & 260 & 13 & 106 & 7 & 15 & 0 & 3 & 1 & 0 & 2 & 7 & 4 & 20 & 0 \\
\hline $\mathrm{J}-50$ & 0 & 69 & 0 & 260 & 80 & 5 & 44 & 0 & 2 & 1 & 0 & 2 & 12 & 5 & 22 & 0 \\
\hline $\mathrm{J}-60$ & 0 & 39 & 0 & 1 & 650 & 22 & 20 & 0 & 5 & 1 & 0 & 1 & 6 & 3 & 12 & 0 \\
\hline $\mathrm{J}-70$ & 0 & 31 & 0 & 2 & 525 & 650 & 18 & 0 & 71 & 4 & 0 & 6 & 10 & 28 & 67 & 1 \\
\hline $\mathrm{J}-80$ & 0 & 36 & 0 & 20 & 538 & 20 & 650 & 0 & 8 & 4 & 0 & 6 & 103 & 19 & 73 & 1 \\
\hline J-90 & 0 & 33 & 0 & 5 & 288 & 43 & 40 & 1300 & 39 & 7 & 0 & 11 & 24 & 61 & 113 & 2 \\
\hline $\mathrm{J}-100$ & 0 & 15 & 0 & 1 & 145 & 87 & 9 & 0 & 650 & 6 & 0 & 11 & 7 & 124 & 142 & 1 \\
\hline $\mathrm{J}-110$ & 0 & 3 & 0 & 1 & 20 & 4 & 4 & 0 & 6 & 650 & 0 & 41 & 7 & 10 & 1240 & 2 \\
\hline $\mathrm{J}-120$ & 0 & 1 & 0 & 0 & 5 & 1 & 1 & 0 & 1 & 7 & 260 & 11 & 1 & 2 & 46 & 1 \\
\hline $\mathrm{J}-130$ & 0 & 1 & 0 & 0 & 4 & 1 & 1 & 0 & 1 & 5 & 0 & 260 & 1 & 2 & 234 & 1 \\
\hline $\mathrm{J}-140$ & 0 & 4 & 0 & 1 & 41 & 3 & 25 & 0 & 2 & 2 & 0 & 3 & 260 & 4 & 36 & 0 \\
\hline $\mathrm{J}-150$ & 0 & 2 & 0 & 0 & 14 & 5 & 3 & 0 & 17 & 1 & 0 & 2 & 3 & 260 & 31 & 0 \\
\hline $\mathrm{J}-160$ & 0 & 2 & 0 & 0 & 15 & 3 & 3 & 0 & 6 & 54 & 0 & 89 & 7 & 9 & 1040 & 2 \\
\hline $\mathrm{J}-170$ & 0 & 1 & 0 & 0 & 5 & 1 & 1 & 0 & 1 & 2 & 0 & 10 & 1 & 2 & 42 & 260 \\
\hline Total & 650 & 593 & 260 & 310 & 2,588 & 860 & 840 & 1,300 & 818 & 746 & 260 & 458 & 454 & 539 & 3,146 & 273 \\
\hline
\end{tabular}


Flow Distribution Results: Population Affected

\begin{tabular}{c|cccccccccccccccc} 
& $\mathrm{J}-20$ & $\mathrm{~J}-30$ & $\mathrm{~J}-40$ & $\mathrm{~J}-50$ & $\mathrm{~J}-60$ & $\mathrm{~J}-70$ & $\mathrm{~J}-80$ & $\mathrm{~J}-90$ & $\mathrm{~J}-100$ & $\mathrm{~J}-110$ & $\mathrm{~J}-120$ & $\mathrm{~J}-130$ & $\mathrm{~J}-140$ & $\mathrm{~J}-150$ & $\mathrm{~J}-160$ & $\mathrm{~J}-170$ \\
\hline $\mathrm{J}-20$ & 3069 & 19 & 0 & 2 & 115 & 25 & 12 & 0 & 15 & 6 & 0 & 10 & 10 & 18 & 94 & 2 \\
$\mathrm{~J}-30$ & 0 & 1421 & 0 & 21 & 691 & 23 & 24 & 0 & 9 & 2 & 0 & 3 & 12 & 8 & 33 & 1 \\
$\mathrm{~J}-40$ & 0 & 2140 & 6100 & 302 & 2487 & 153 & 342 & 0 & 75 & 29 & 0 & 47 & 170 & 95 & 480 & 8 \\
$\mathrm{~J}-50$ & 0 & 1579 & 0 & 5953 & 1835 & 113 & 1008 & 0 & 55 & 29 & 0 & 47 & 282 & 113 & 512 & 7 \\
$\mathrm{~J}-60$ & 0 & 139 & 0 & 5 & 2297 & 77 & 71 & 0 & 18 & 2 & 0 & 4 & 22 & 12 & 43 & 1 \\
$\mathrm{~J}-70$ & 0 & 40 & 0 & 3 & 669 & 827 & 23 & 0 & 91 & 4 & 0 & 7 & 12 & 36 & 86 & 1 \\
$\mathrm{~J}-80$ & 0 & 232 & 0 & 131 & 3468 & 129 & 4189 & 0 & 52 & 24 & 0 & 40 & 664 & 125 & 472 & 5 \\
$\mathrm{~J}-90$ & 0 & 155 & 0 & 22 & 1349 & 201 & 185 & 6082 & 183 & 31 & 0 & 51 & 111 & 287 & 529 & 8 \\
$\mathrm{~J}-100$ & 0 & 16 & 0 & 1 & 160 & 95 & 10 & 0 & 716 & 7 & 0 & 12 & 7 & 136 & 156 & 1 \\
$\mathrm{~J}-110$ & 0 & 23 & 0 & 4 & 139 & 30 & 29 & 0 & 44 & 4642 & 0 & 296 & 50 & 70 & 8853 & 17 \\
$\mathrm{~J}-120$ & 0 & 18 & 0 & 3 & 99 & 19 & 18 & 0 & 23 & 128 & 4949 & 211 & 26 & 36 & 882 & 18 \\
$\mathrm{~J}-130$ & 0 & 12 & 0 & 2 & 73 & 16 & 15 & 0 & 23 & 95 & 0 & 5170 & 27 & 37 & 4661 & 25 \\
$\mathrm{~J}-140$ & 0 & 89 & 0 & 28 & 834 & 53 & 513 & 0 & 30 & 33 & 0 & 55 & 5248 & 90 & 730 & 6 \\
$\mathrm{~J}-150$ & 0 & 30 & 0 & 6 & 237 & 79 & 50 & 0 & 289 & 24 & 0 & 39 & 46 & 4330 & 519 & 4 \\
$\mathrm{~J}-160$ & 0 & 3 & 0 & 1 & 21 & 5 & 5 & 0 & 9 & 77 & 0 & 127 & 10 & 13 & 1487 & 3 \\
$\mathrm{~J}-170$ & 0 & 6 & 0 & 1 & 34 & 6 & 6 & 0 & 8 & 16 & 0 & 74 & 9 & 12 & 307 & 1901 \\
\hline Total & 3,069 & 5,923 & 6,100 & 6,486 & 14,510 & 1,851 & 6,499 & 6,082 & 1,640 & 5,149 & 4,949 & 6,194 & 6,707 & 5,419 & 19,844 & 2,009
\end{tabular}




\section{Normal Operating Condition}

\begin{tabular}{|c|c|c|c|c|c|c|c|c|c|c|c|c|c|c|c|c|}
\hline $\begin{array}{c}\text { Time } \\
\text { (hours) }\end{array}$ & $\mathrm{J}-20$ & J-30 & J-40 & J-50 & $J-60$ & $\mathrm{~J}-70$ & J-80 & J-90 & $\mathrm{J}-100$ & $\mathrm{~J}-110$ & $\mathrm{~J}-120$ & $\mathrm{~J}-130$ & J-140 & $\mathrm{J}-150$ & $\mathrm{~J}-160$ & J-170 \\
\hline 0 & 350 & 140 & 140 & 140 & 350 & 350 & 350 & 700 & 350 & 350 & 140 & 140 & 140 & 140 & 560 & 140 \\
\hline 1 & 350 & 140 & 140 & 140 & 350 & 350 & 350 & 700 & 350 & 350 & 140 & 140 & 140 & 140 & 560 & 140 \\
\hline 2 & 350 & 140 & 140 & 140 & 350 & 350 & 350 & 700 & 350 & 350 & 140 & 140 & 140 & 140 & 560 & 140 \\
\hline 3 & 300 & 120 & 120 & 120 & 300 & 300 & 300 & 600 & 300 & 300 & 120 & 120 & 120 & 120 & 480 & 120 \\
\hline 4 & 300 & 120 & 120 & 120 & 300 & 300 & 300 & 600 & 300 & 300 & 120 & 120 & 120 & 120 & 480 & 120 \\
\hline 5 & 300 & 120 & 120 & 120 & 300 & 300 & 300 & 600 & 300 & 300 & 120 & 120 & 120 & 120 & 480 & 120 \\
\hline 6 & 600 & 240 & 240 & 240 & 600 & 600 & 600 & 1200 & 600 & 600 & 240 & 240 & 240 & 240 & 960 & 240 \\
\hline 7 & 600 & 240 & 240 & 240 & 600 & 600 & 600 & 1200 & 600 & 600 & 240 & 240 & 240 & 240 & 960 & 240 \\
\hline 8 & 600 & 240 & 240 & 240 & 600 & 600 & 600 & 1200 & 600 & 600 & 240 & 240 & 240 & 240 & 960 & 240 \\
\hline 9 & 650 & 260 & 260 & 260 & 650 & 650 & 650 & 1300 & 650 & 650 & 260 & 260 & 260 & 260 & 1040 & 260 \\
\hline 10 & 650 & 260 & 260 & 260 & 650 & 650 & 650 & 1300 & 650 & 650 & 260 & 260 & 260 & 260 & 1040 & 260 \\
\hline 11 & 650 & 260 & 260 & 260 & 650 & 650 & 650 & 1300 & 650 & 650 & 260 & 260 & 260 & 260 & 1040 & 260 \\
\hline 12 & 600 & 240 & 240 & 240 & 600 & 600 & 600 & 1200 & 600 & 600 & 240 & 240 & 240 & 240 & 960 & 240 \\
\hline 13 & 600 & 240 & 240 & 240 & 600 & 600 & 600 & 1200 & 600 & 600 & 240 & 240 & 240 & 240 & 960 & 240 \\
\hline 14 & 600 & 240 & 240 & 240 & 600 & 600 & 600 & 1200 & 600 & 600 & 240 & 240 & 240 & 240 & 960 & 240 \\
\hline 15 & 550 & 220 & 220 & 220 & 550 & 550 & 550 & 1100 & 550 & 550 & 220 & 220 & 220 & 220 & 880 & 220 \\
\hline 16 & 550 & 220 & 220 & 220 & 550 & 550 & 550 & 1100 & 550 & 550 & 220 & 220 & 220 & 220 & 880 & 220 \\
\hline 17 & 550 & 220 & 220 & 220 & 550 & 550 & 550 & 1100 & 550 & 550 & 220 & 220 & 220 & 220 & 880 & 220 \\
\hline 18 & 500 & 200 & 200 & 200 & 500 & 500 & 500 & 1000 & 500 & 500 & 200 & 200 & 200 & 200 & 800 & 200 \\
\hline 19 & 500 & 200 & 200 & 200 & 500 & 500 & 500 & 1000 & 500 & 500 & 200 & 200 & 200 & 200 & 800 & 200 \\
\hline 20 & 500 & 200 & 200 & 200 & 500 & 500 & 500 & 1000 & 500 & 500 & 200 & 200 & 200 & 200 & 800 & 200 \\
\hline 21 & 450 & 180 & 180 & 180 & 450 & 450 & 450 & 900 & 450 & 450 & 180 & 180 & 180 & 180 & 720 & 180 \\
\hline 22 & 450 & 180 & 180 & 180 & 450 & 450 & 450 & 900 & 450 & 450 & 180 & 180 & 180 & 180 & 720 & 180 \\
\hline 23 & 450 & 180 & 180 & 180 & 450 & 450 & 450 & 900 & 450 & 450 & 180 & 180 & 180 & 180 & 720 & 180 \\
\hline 24 & 350 & 140 & 140 & 140 & 350 & 350 & 350 & 700 & 350 & 350 & 140 & 140 & 140 & 140 & 560 & 140 \\
\hline Total &, 350 & 4,940 & 4,940 & 4,940 & 12,350 & 12,350 & 2,350 & 24,700 & 12,350 & 12,350 & 4,940 & 4,940 & 4,940 & 4,940 & 19,760 & 4,940 \\
\hline
\end{tabular}




\section{Failure Scenario ' $J$-20 Out'}

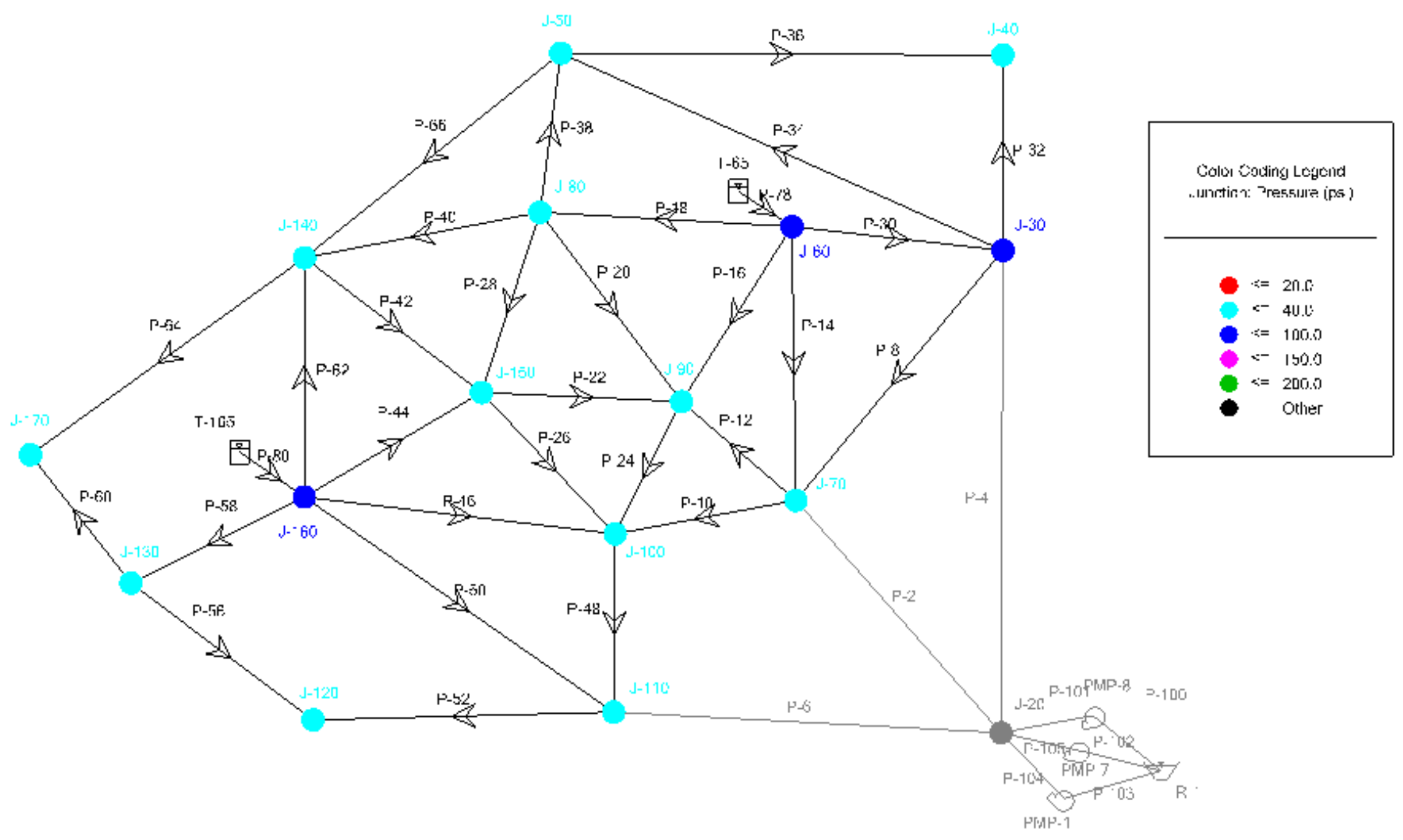




\section{Demand Supplied}

\begin{tabular}{|c|c|c|c|c|c|c|c|c|c|c|c|c|c|c|c|c|}
\hline $\begin{array}{c}\text { Time } \\
\text { (hours) }\end{array}$ & $\mathrm{J}-20$ & J-30 & $\mathrm{J}-40$ & $J-50$ & J-60 & $\mathrm{J}-70$ & $\mathrm{~J}-80$ & $\mathrm{~J}-90$ & $\mathrm{~J}-100$ & $\mathrm{~J}-110$ & $\mathrm{~J}-120$ & $\mathrm{~J}-130$ & $\mathrm{~J}-140$ & $\mathrm{~J}-150$ & $\mathrm{~J}-160$ & J-170 \\
\hline 0 & 0 & 140 & 500 & 140 & 350 & 350 & 350 & 700 & 350 & 350 & 1140 & 500 & 140 & 140 & 560 & 140 \\
\hline 1 & 0 & 140 & 500 & 140 & 350 & 350 & 350 & 700 & 350 & 350 & 1140 & 500 & 140 & 140 & 560 & 140 \\
\hline 2 & 0 & 140 & 500 & 140 & 350 & 350 & 350 & 700 & 350 & 350 & 1140 & 500 & 140 & 140 & 560 & 140 \\
\hline 3 & 0 & 120 & 500 & 120 & 300 & 300 & 300 & 600 & 300 & 300 & 1120 & 500 & 120 & 120 & 480 & 120 \\
\hline 4 & 0 & 120 & 500 & 120 & 300 & 300 & 300 & 600 & 300 & 300 & 1120 & 500 & 120 & 120 & 480 & 120 \\
\hline 5 & 0 & 120 & 500 & 120 & 300 & 300 & 300 & 600 & 300 & 300 & 1120 & 500 & 120 & 120 & 480 & 120 \\
\hline 6 & 0 & 240 & 500 & 240 & 600 & 600 & 600 & 1200 & 600 & 600 & 1240 & 500 & 240 & 240 & 960 & 240 \\
\hline 7 & 0 & 240 & 500 & 240 & 600 & 600 & 600 & 1200 & 600 & 600 & 1240 & 500 & 240 & 240 & 960 & 240 \\
\hline 8 & 0 & 240 & 500 & 240 & 600 & 600 & 600 & 1200 & 600 & 600 & 1240 & 500 & 240 & 240 & 960 & 240 \\
\hline 9 & 0 & 260 & 500 & 260 & 650 & 650 & 650 & 1300 & 650 & 650 & 1260 & 500 & 260 & 260 & 1040 & 260 \\
\hline 10 & 0 & 260 & 500 & 260 & 650 & 650 & 650 & 1300 & 650 & 650 & 1260 & 500 & 260 & 260 & 1040 & 260 \\
\hline 11 & 0 & 260 & 500 & 260 & 650 & 650 & 650 & 1300 & 650 & 650 & 1260 & 500 & 260 & 260 & 1040 & 260 \\
\hline 12 & 0 & 240 & 500 & 240 & 600 & 600 & 600 & 1200 & 600 & 600 & 1240 & 500 & 240 & 240 & 960 & 240 \\
\hline 13 & 0 & 240 & 500 & 240 & 600 & 600 & 600 & 1200 & 600 & 600 & 1240 & 500 & 240 & 240 & 960 & 240 \\
\hline 14 & 0 & 240 & 500 & 240 & 600 & 600 & 600 & 1200 & 600 & 600 & 1240 & 500 & 240 & 240 & 960 & 240 \\
\hline 15 & 0 & 220 & 500 & 220 & 550 & 550 & 550 & 1100 & 550 & 550 & 1220 & 500 & 220 & 220 & 880 & 220 \\
\hline 16 & 0 & 220 & 500 & 220 & 550 & 550 & 550 & 1100 & 550 & 550 & 1220 & 500 & 220 & 220 & 880 & 220 \\
\hline 17 & 0 & 220 & 500 & 220 & 550 & 550 & 550 & 1100 & 550 & 550 & 1211 & 500 & 220 & 220 & 880 & 220 \\
\hline 18 & 0 & 200 & 500 & 200 & 500 & 500 & 500 & 1000 & 500 & 500 & 1186 & 500 & 200 & 200 & 800 & 200 \\
\hline 19 & 0 & 200 & 500 & 200 & 500 & 500 & 500 & 1000 & 500 & 500 & 1175 & 500 & 200 & 200 & 800 & 200 \\
\hline 20 & 0 & 200 & 500 & 200 & 500 & 500 & 500 & 1000 & 500 & 500 & 1165 & 496 & 200 & 200 & 800 & 198 \\
\hline 21 & 0 & 180 & 500 & 180 & 450 & 450 & 450 & 900 & 450 & 449 & 1141 & 494 & 180 & 180 & 720 & 178 \\
\hline 22 & 0 & 180 & 500 & 180 & 450 & 450 & 450 & 900 & 450 & 445 & 1132 & 490 & 180 & 180 & 720 & 176 \\
\hline 23 & 0 & 179 & 496 & 179 & 450 & 447 & 447 & 892 & 446 & 441 & 1123 & 486 & 179 & 179 & 718 & 175 \\
\hline 24 & 0 & 139 & 496 & 139 & 350 & 348 & 347 & 694 & 347 & 343 & 1086 & 485 & 139 & 139 & 557 & 136 \\
\hline Total & 0 & 4,938 & 12,492 & 4,938 & 12,350 & 12,345 & 12,344 & 24,686 & 12,343 & 12,328 & 29,659 & 12,451 & 4,938 & 4,938 & 19,755 & 4,923 \\
\hline
\end{tabular}




\section{'J-20 Out' Results}

\begin{tabular}{|c|c|c|c|c|c|c|}
\hline \multirow[b]{2}{*}{ Node } & \multicolumn{2}{|c|}{ Demand Supplied } & \multirow[b]{2}{*}{$\begin{array}{l}\text { Demand } \\
\text { Effected }\end{array}$} & \multicolumn{2}{|c|}{ Population Served } & \multirow[b]{2}{*}{$\begin{array}{c}\text { Population } \\
\text { Effected }\end{array}$} \\
\hline & $\begin{array}{c}\text { Normal } \\
\text { Conditions }\end{array}$ & $\begin{array}{c}\text { Failure } \\
\text { Scenario } \\
\text { J-20 Out }\end{array}$ & & $\begin{array}{c}\text { Normal } \\
\text { Conditions }\end{array}$ & $\begin{array}{c}\text { Failure } \\
\text { Scenario } \\
\mathrm{J}-20 \text { Out }\end{array}$ & \\
\hline (1) & (2) & (3) & (4) & (5) & (6) & (7) \\
\hline $\mathrm{J}-20$ & 12350 & 0 & 12350 & 3069 & 0 & 3069 \\
\hline $\mathrm{J}-30$ & 4940 & 4938 & 2 & 1421 & 1421 & 1 \\
\hline$J-40$ & 4940 & 12492 & -7552 & 6100 & 15425 & -9325 \\
\hline $\mathrm{J}-50$ & 4940 & 4938 & 2 & 5953 & 5951 & 2 \\
\hline$J-60$ & 12350 & 12350 & 0 & 2297 & 2297 & 0 \\
\hline $\mathrm{J}-70$ & 12350 & 12345 & 5 & 827 & 827 & 0 \\
\hline$J-80$ & 12350 & 12344 & 6 & 4189 & 4187 & 2 \\
\hline$J-90$ & 24700 & 24686 & 14 & 6082 & 6079 & 3 \\
\hline$J-100$ & 12350 & 12343 & 7 & 716 & 716 & 0 \\
\hline$J-110$ & 12350 & 12328 & 22 & 4642 & 4634 & 8 \\
\hline $\mathrm{J}-120$ & 4940 & 29659 & -24719 & 4949 & 29714 & -24765 \\
\hline$J-130$ & 4940 & 12451 & -7511 & 5170 & 13030 & -7860 \\
\hline$J-140$ & 4940 & 4938 & 2 & 5248 & 5246 & 2 \\
\hline $\mathrm{J}-150$ & 4940 & 4938 & 2 & 4330 & 4329 & 2 \\
\hline $\mathrm{J}-160$ & 19760 & 19755 & 5 & 1487 & 1487 & 0 \\
\hline $\mathrm{J}-170$ & 4940 & 4923 & 17 & 1901 & 1895 & 7 \\
\hline
\end{tabular}


Failure Scenario 'J-30 Out'

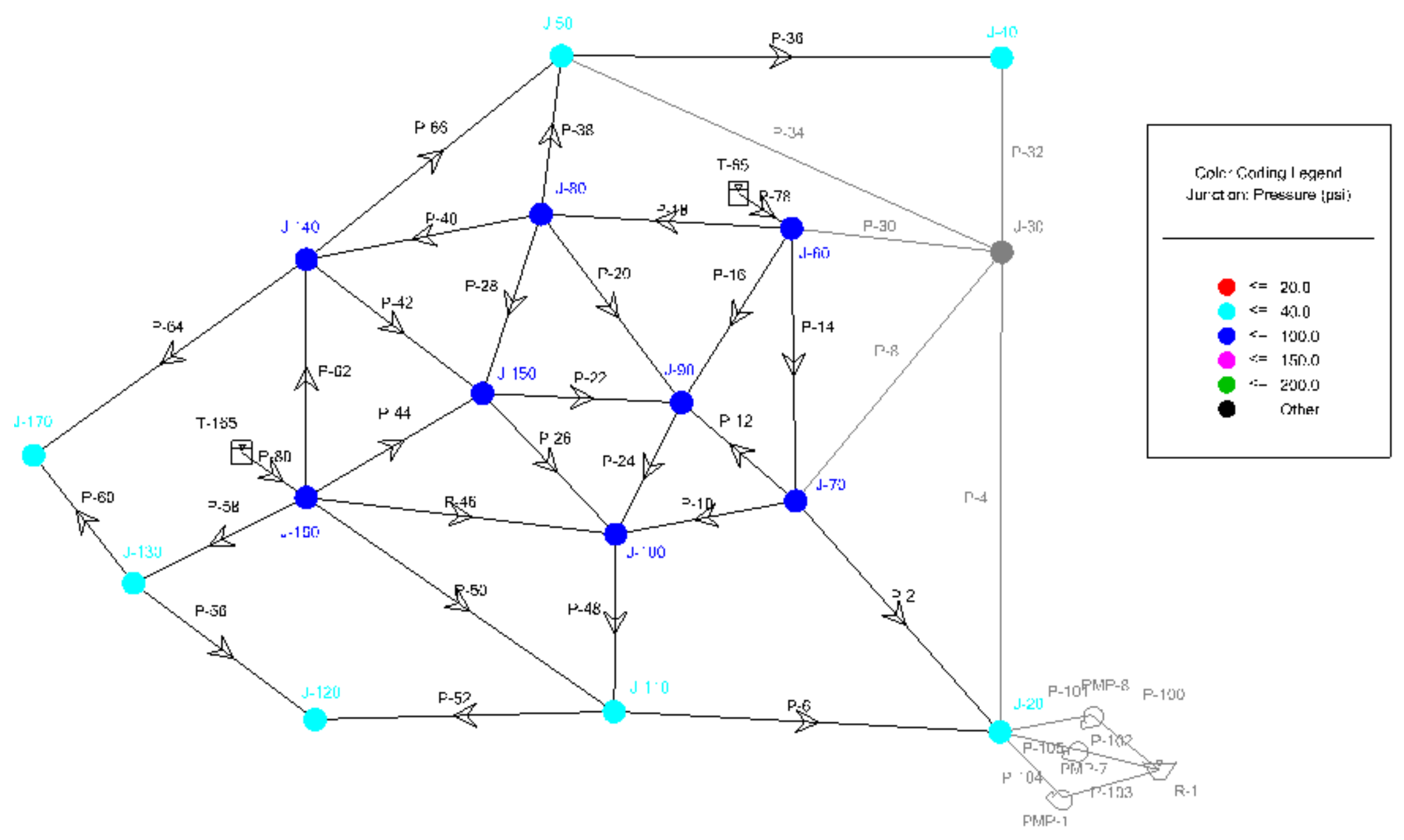




\section{Demand Supplied}

\begin{tabular}{|c|c|c|c|c|c|c|c|c|c|c|c|c|c|c|c|c|}
\hline $\begin{array}{c}\text { Time } \\
\text { (hours) }\end{array}$ & $\mathrm{J}-20$ & $\mathrm{~J}-30$ & $\mathrm{~J}-40$ & J-50 & $J-60$ & J-70 & $\mathrm{J}-80$ & J-90 & $\mathrm{J}-100$ & $\mathrm{~J}-110$ & $\mathrm{~J}-120$ & $\mathrm{~J}-130$ & $\mathrm{~J}-140$ & $\mathrm{~J}-150$ & $\mathrm{~J}-160$ & J-170 \\
\hline 0 & 350 & 0 & 500 & 140 & 350 & 350 & 350 & 700 & 350 & 350 & 1140 & 500 & 140 & 140 & 560 & 140 \\
\hline 1 & 350 & 0 & 500 & 140 & 350 & 350 & 350 & 700 & 350 & 350 & 1140 & 500 & 140 & 140 & 560 & 140 \\
\hline 2 & 350 & 0 & 500 & 140 & 350 & 350 & 350 & 700 & 350 & 350 & 1140 & 500 & 140 & 140 & 560 & 140 \\
\hline 3 & 300 & 0 & 500 & 120 & 300 & 300 & 300 & 600 & 300 & 300 & 1120 & 500 & 120 & 120 & 480 & 120 \\
\hline 4 & 300 & 0 & 500 & 120 & 300 & 300 & 300 & 600 & 300 & 300 & 1120 & 500 & 120 & 120 & 480 & 120 \\
\hline 5 & 300 & 0 & 500 & 120 & 300 & 300 & 300 & 600 & 300 & 300 & 1120 & 500 & 120 & 120 & 480 & 120 \\
\hline 6 & 600 & 0 & 500 & 240 & 600 & 600 & 600 & 1200 & 600 & 600 & 1240 & 500 & 240 & 240 & 960 & 240 \\
\hline 7 & 600 & 0 & 500 & 240 & 600 & 600 & 600 & 1200 & 600 & 600 & 1240 & 500 & 240 & 240 & 960 & 240 \\
\hline 8 & 600 & 0 & 500 & 240 & 600 & 600 & 600 & 1200 & 600 & 600 & 1240 & 500 & 240 & 240 & 960 & 240 \\
\hline 9 & 650 & 0 & 500 & 260 & 650 & 650 & 650 & 1300 & 650 & 650 & 1260 & 500 & 260 & 260 & 1040 & 260 \\
\hline 10 & 650 & 0 & 500 & 260 & 650 & 650 & 650 & 1300 & 650 & 650 & 1260 & 500 & 260 & 260 & 1040 & 260 \\
\hline 11 & 650 & 0 & 500 & 260 & 650 & 650 & 650 & 1300 & 650 & 650 & 1260 & 500 & 260 & 260 & 1040 & 260 \\
\hline 12 & 600 & 0 & 500 & 240 & 600 & 600 & 600 & 1200 & 600 & 600 & 1240 & 500 & 240 & 240 & 960 & 240 \\
\hline 13 & 600 & 0 & 500 & 240 & 600 & 600 & 600 & 1200 & 600 & 600 & 1240 & 500 & 240 & 240 & 960 & 240 \\
\hline 14 & 600 & 0 & 500 & 240 & 600 & 600 & 600 & 1200 & 600 & 600 & 1237 & 500 & 240 & 240 & 960 & 240 \\
\hline 15 & 550 & 0 & 500 & 220 & 550 & 550 & 550 & 1100 & 550 & 550 & 1213 & 500 & 220 & 220 & 880 & 220 \\
\hline 16 & 550 & 0 & 500 & 220 & 550 & 550 & 550 & 1100 & 550 & 550 & 1201 & 500 & 220 & 220 & 880 & 220 \\
\hline 17 & 546 & 0 & 500 & 220 & 550 & 550 & 550 & 1100 & 550 & 550 & 1189 & 499 & 220 & 220 & 880 & 219 \\
\hline 18 & 496 & 0 & 499 & 200 & 500 & 500 & 500 & 1000 & 500 & 500 & 1165 & 497 & 200 & 200 & 800 & 199 \\
\hline 19 & 491 & 0 & 494 & 199 & 500 & 500 & 500 & 1000 & 500 & 495 & 1154 & 492 & 200 & 200 & 800 & 197 \\
\hline 20 & 487 & 0 & 490 & 197 & 500 & 498 & 498 & 995 & 497 & 491 & 1144 & 488 & 199 & 199 & 800 & 195 \\
\hline 21 & 438 & 0 & 488 & 177 & 450 & 447 & 446 & 892 & 446 & 440 & 1121 & 485 & 178 & 178 & 718 & 175 \\
\hline 22 & 434 & 0 & 484 & 175 & 450 & 443 & 442 & 885 & 442 & 437 & 1112 & 481 & 177 & 177 & 712 & 173 \\
\hline 23 & 431 & 0 & 480 & 174 & 450 & 439 & 439 & 877 & 439 & 433 & 1102 & 477 & 175 & 175 & 706 & 172 \\
\hline 24 & 337 & 0 & 481 & 136 & 350 & 342 & 342 & 683 & 341 & 337 & 1067 & 477 & 137 & 137 & 548 & 134 \\
\hline Total & 12,260 & 0 & 12,416 & 4,918 & 12,350 & 12,319 & 12,317 & 24,632 & 12,315 & 12,283 & 29,465 & 12,396 & 4,926 & 4,926 & 19,724 & 4,904 \\
\hline
\end{tabular}




\begin{tabular}{|c|c|c|c|c|c|c|}
\hline \multirow[b]{2}{*}{ Node } & \multicolumn{2}{|c|}{ Demand Supplied } & \multirow[b]{2}{*}{$\begin{array}{l}\text { Demand } \\
\text { Effected }\end{array}$} & \multicolumn{2}{|c|}{ Population Served } & \multirow[b]{2}{*}{$\begin{array}{c}\text { Population } \\
\text { Effected }\end{array}$} \\
\hline & $\begin{array}{c}\text { Normal } \\
\text { Conditions }\end{array}$ & $\begin{array}{l}\text { Failure } \\
\text { Scenario } \\
\text { J-30 Out }\end{array}$ & & \begin{tabular}{||c} 
Normal \\
Conditions
\end{tabular} & $\begin{array}{l}\text { Failure } \\
\text { Scenario } \\
\text { J-30 Out }\end{array}$ & \\
\hline (1) & (2) & (3) & (4) & (5) & (6) & (7) \\
\hline$J-20$ & 12350 & 12260 & 90 & 3069 & 3047 & 22 \\
\hline $\mathrm{J}-30$ & 4940 & 0 & 4940 & 1421 & 0 & 1421 \\
\hline $\mathrm{J}-40$ & 4940 & 12416 & -7476 & 6100 & 15331 & -9231 \\
\hline $\mathrm{J}-50$ & 4940 & 4918 & 22 & 5953 & 5927 & 27 \\
\hline $\mathrm{J}-60$ & 12350 & 12350 & 0 & 2297 & 2297 & 0 \\
\hline $\mathrm{J}-70$ & 12350 & 12319 & 31 & 827 & 825 & 2 \\
\hline $\mathrm{J}-80$ & 12350 & 12317 & 33 & 4189 & 4177 & 11 \\
\hline $\mathrm{J}-90$ & 24700 & 24632 & 68 & 6082 & 6066 & 17 \\
\hline$J-100$ & 12350 & 12315 & 35 & 716 & 714 & 2 \\
\hline $\mathrm{J}-110$ & 12350 & 12283 & 67 & 4642 & 4617 & 25 \\
\hline$J-120$ & 4940 & 29465 & -24525 & 4949 & 29520 & -24571 \\
\hline $\mathrm{J}-130$ & 4940 & 12396 & -7456 & 5170 & 12972 & -7803 \\
\hline $\mathrm{J}-140$ & 4940 & 4926 & 14 & 5248 & 5234 & 15 \\
\hline $\mathrm{J}-150$ & 4940 & 4926 & 14 & 4330 & 4318 & 12 \\
\hline$J-160$ & 19760 & 19724 & 36 & 1487 & 1484 & 3 \\
\hline $\mathrm{J}-170$ & 4940 & 4904 & 36 & 1901 & 1888 & 14 \\
\hline
\end{tabular}




\section{Failure Scenario 'J-40 Out'}

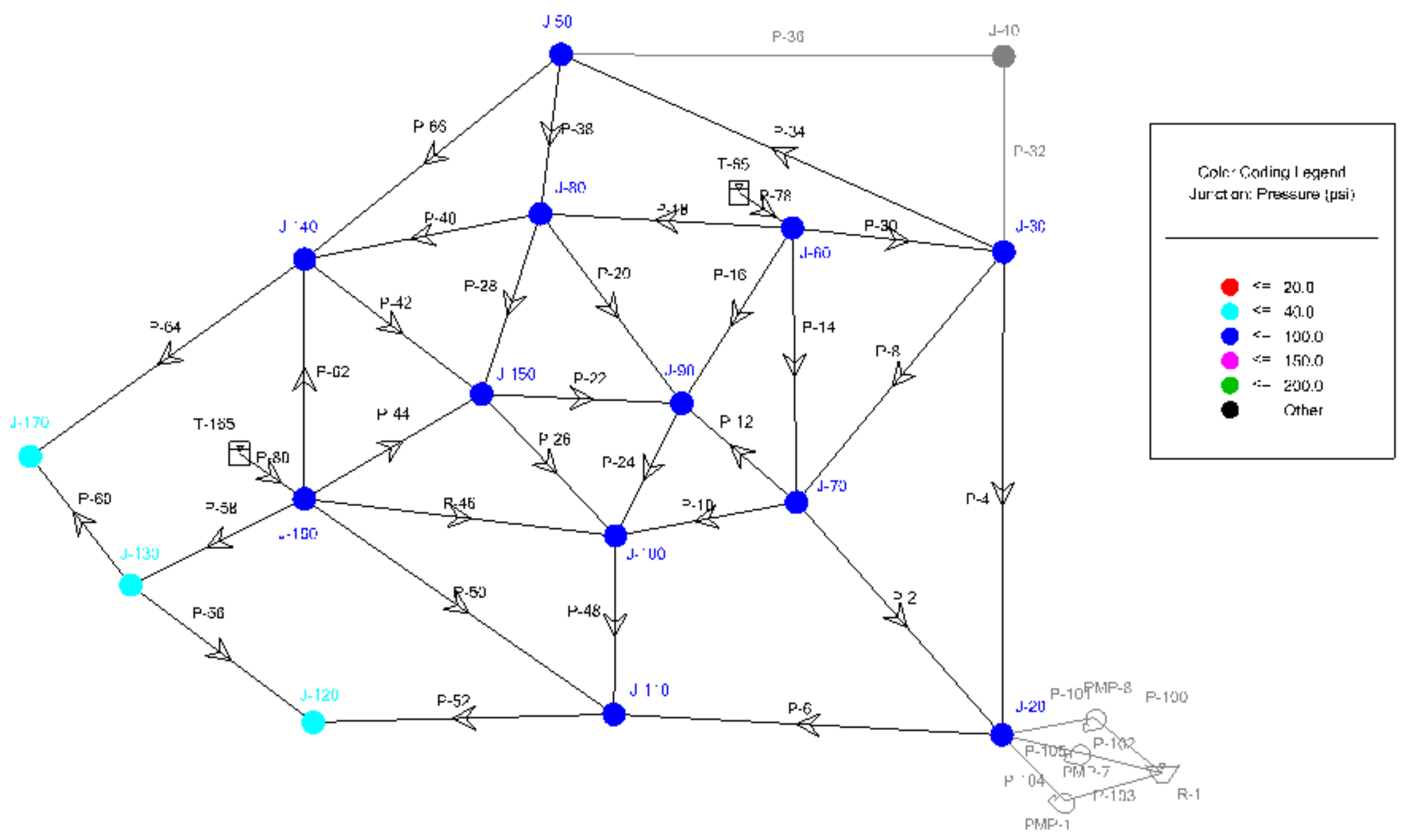




\section{Demand Supplied}

\begin{tabular}{|c|c|c|c|c|c|c|c|c|c|c|c|c|c|c|c|c|}
\hline $\begin{array}{l}\text { Time } \\
\text { (hours) }\end{array}$ & $\mathrm{J}-20$ & J-30 & $\mathrm{J}-40$ & J-50 & J-60 & J-70 & $\mathrm{J}-80$ & J-90 & $\mathrm{J}-100$ & $\mathrm{~J}-110$ & $\mathrm{~J}-120$ & $\mathrm{~J}-130$ & $\mathrm{~J}-140$ & $\mathrm{~J}-150$ & $\mathrm{~J}-160$ & J-170 \\
\hline 0 & 350 & 140 & 0 & 140 & 350 & 350 & 350 & 700 & 350 & 350 & 1140 & 500 & 140 & 140 & 560 & 140 \\
\hline 1 & 350 & 140 & 0 & 140 & 350 & 350 & 350 & 700 & 350 & 350 & 1140 & 500 & 140 & 140 & 560 & 140 \\
\hline 2 & 350 & 140 & 0 & 140 & 350 & 350 & 350 & 700 & 350 & 350 & 1140 & 500 & 140 & 140 & 560 & 140 \\
\hline 3 & 300 & 120 & 0 & 120 & 300 & 300 & 300 & 600 & 300 & 300 & 1120 & 500 & 120 & 120 & 480 & 120 \\
\hline 4 & 300 & 120 & 0 & 120 & 300 & 300 & 300 & 600 & 300 & 300 & 1120 & 500 & 120 & 120 & 480 & 120 \\
\hline 5 & 300 & 120 & 0 & 120 & 300 & 300 & 300 & 600 & 300 & 300 & 1120 & 500 & 120 & 120 & 480 & 120 \\
\hline 6 & 600 & 240 & 0 & 240 & 600 & 600 & 600 & 1200 & 600 & 600 & 1240 & 500 & 240 & 240 & 960 & 240 \\
\hline 7 & 600 & 240 & 0 & 240 & 600 & 600 & 600 & 1200 & 600 & 600 & 1240 & 500 & 240 & 240 & 960 & 240 \\
\hline 8 & 600 & 240 & 0 & 240 & 600 & 600 & 600 & 1200 & 600 & 600 & 1240 & 500 & 240 & 240 & 960 & 240 \\
\hline 9 & 650 & 260 & 0 & 260 & 650 & 650 & 650 & 1300 & 650 & 650 & 1260 & 500 & 260 & 260 & 1040 & 260 \\
\hline 10 & 650 & 260 & 0 & 260 & 650 & 650 & 650 & 1300 & 650 & 650 & 1260 & 500 & 260 & 260 & 1040 & 260 \\
\hline 11 & 650 & 260 & 0 & 260 & 650 & 650 & 650 & 1300 & 650 & 650 & 1260 & 500 & 260 & 260 & 1040 & 260 \\
\hline 12 & 600 & 240 & 0 & 240 & 600 & 600 & 600 & 1200 & 600 & 600 & 1240 & 500 & 240 & 240 & 960 & 240 \\
\hline 13 & 600 & 240 & 0 & 240 & 600 & 600 & 600 & 1200 & 600 & 600 & 1240 & 500 & 240 & 240 & 960 & 240 \\
\hline 14 & 600 & 240 & 0 & 240 & 600 & 600 & 600 & 1200 & 600 & 600 & 1240 & 500 & 240 & 240 & 960 & 240 \\
\hline 15 & 550 & 220 & 0 & 220 & 550 & 550 & 550 & 1100 & 550 & 550 & 1220 & 500 & 220 & 220 & 880 & 220 \\
\hline 16 & 550 & 220 & 0 & 220 & 550 & 550 & 550 & 1100 & 550 & 550 & 1220 & 500 & 220 & 220 & 880 & 220 \\
\hline 17 & 550 & 220 & 0 & 220 & 550 & 550 & 550 & 1100 & 550 & 550 & 1210 & 500 & 220 & 220 & 880 & 220 \\
\hline 18 & 500 & 200 & 0 & 200 & 500 & 500 & 500 & 1000 & 500 & 500 & 1186 & 500 & 200 & 200 & 800 & 200 \\
\hline 19 & 500 & 200 & 0 & 200 & 500 & 500 & 500 & 1000 & 500 & 500 & 1175 & 500 & 200 & 200 & 800 & 200 \\
\hline 20 & 500 & 200 & 0 & 200 & 500 & 500 & 500 & 1000 & 500 & 500 & 1165 & 496 & 200 & 200 & 800 & 198 \\
\hline 21 & 450 & 180 & 0 & 180 & 450 & 450 & 450 & 900 & 450 & 449 & 1142 & 494 & 180 & 180 & 720 & 178 \\
\hline 22 & 446 & 180 & 0 & 180 & 450 & 450 & 450 & 900 & 450 & 445 & 1133 & 490 & 180 & 180 & 720 & 176 \\
\hline 23 & 442 & 179 & 0 & 179 & 450 & 446 & 447 & 892 & 446 & 442 & 1123 & 486 & 179 & 179 & 719 & 175 \\
\hline 24 & 345 & 139 & 0 & 139 & 350 & 347 & 348 & 695 & 347 & 344 & 1087 & 486 & 139 & 139 & 557 & 136 \\
\hline ta & 2,333 & 4,938 & 0 & 4,938 & 12,350 & 12,343 & 12,345 & 24,687 & 12,343 & 12,330 & 29,661 & 12,452 & 4,938 & 4,938 & 19,756 & 4,923 \\
\hline
\end{tabular}




\begin{tabular}{|c|c|c|c|c|c|c|}
\hline \multirow[b]{2}{*}{ Node } & \multicolumn{2}{|c|}{ Demand Supplied } & \multirow[b]{2}{*}{$\begin{array}{l}\text { Demand } \\
\text { Effected }\end{array}$} & \multicolumn{2}{|c|}{ Population Served } & \multirow[b]{2}{*}{$\begin{array}{c}\text { Population } \\
\text { Effected }\end{array}$} \\
\hline & $\begin{array}{c}\text { Normal } \\
\text { Conditions }\end{array}$ & $\begin{array}{l}\text { Failure } \\
\text { Scenario } \\
\text { J-40 Out }\end{array}$ & & $\begin{array}{c}\text { Normal } \\
\text { Conditions }\end{array}$ & $\begin{array}{l}\text { Failure } \\
\text { Scenario } \\
\text { J-40 Out }\end{array}$ & \\
\hline (1) & (2) & (3) & (4) & (5) & $(6)$ & (7) \\
\hline $\mathrm{J}-20$ & 12350 & 12333 & 17 & 3069 & 3065 & 4 \\
\hline $\mathrm{J}-30$ & 4940 & 4938 & 2 & 1421 & 1421 & 1 \\
\hline $\mathrm{J}-40$ & 4940 & 0 & 4940 & 6100 & 0 & 6100 \\
\hline$J-50$ & 4940 & 4938 & 2 & 5953 & 5951 & 2 \\
\hline$J-60$ & 12350 & 12350 & 0 & 2297 & 2297 & 0 \\
\hline $\mathrm{J}-70$ & 12350 & 12343 & 7 & 827 & 827 & 0 \\
\hline $\mathrm{J}-80$ & 12350 & 12345 & 5 & 4189 & 4187 & 2 \\
\hline $\mathrm{J}-90$ & 24700 & 24687 & 13 & 6082 & 6079 & 3 \\
\hline$J-100$ & 12350 & 12343 & 7 & 716 & 716 & 0 \\
\hline J-110 & 12350 & 12330 & 20 & 4642 & 4635 & 8 \\
\hline $\mathrm{J}-120$ & 4940 & 29661 & -24721 & 4949 & 29716 & -24767 \\
\hline $\mathrm{J}-130$ & 4940 & 12452 & -7512 & 5170 & 13031 & -7861 \\
\hline$J-140$ & 4940 & 4938 & 2 & 5248 & 5246 & 2 \\
\hline$J-150$ & 4940 & 4938 & 2 & 4330 & 4329 & 2 \\
\hline$J-160$ & 19760 & 19756 & 4 & 1487 & 1487 & 0 \\
\hline $\mathrm{J}-170$ & 4940 & 4923 & 17 & 1901 & 1895 & 7 \\
\hline
\end{tabular}




\section{Failure Scenario ' $J$-50 Out'}

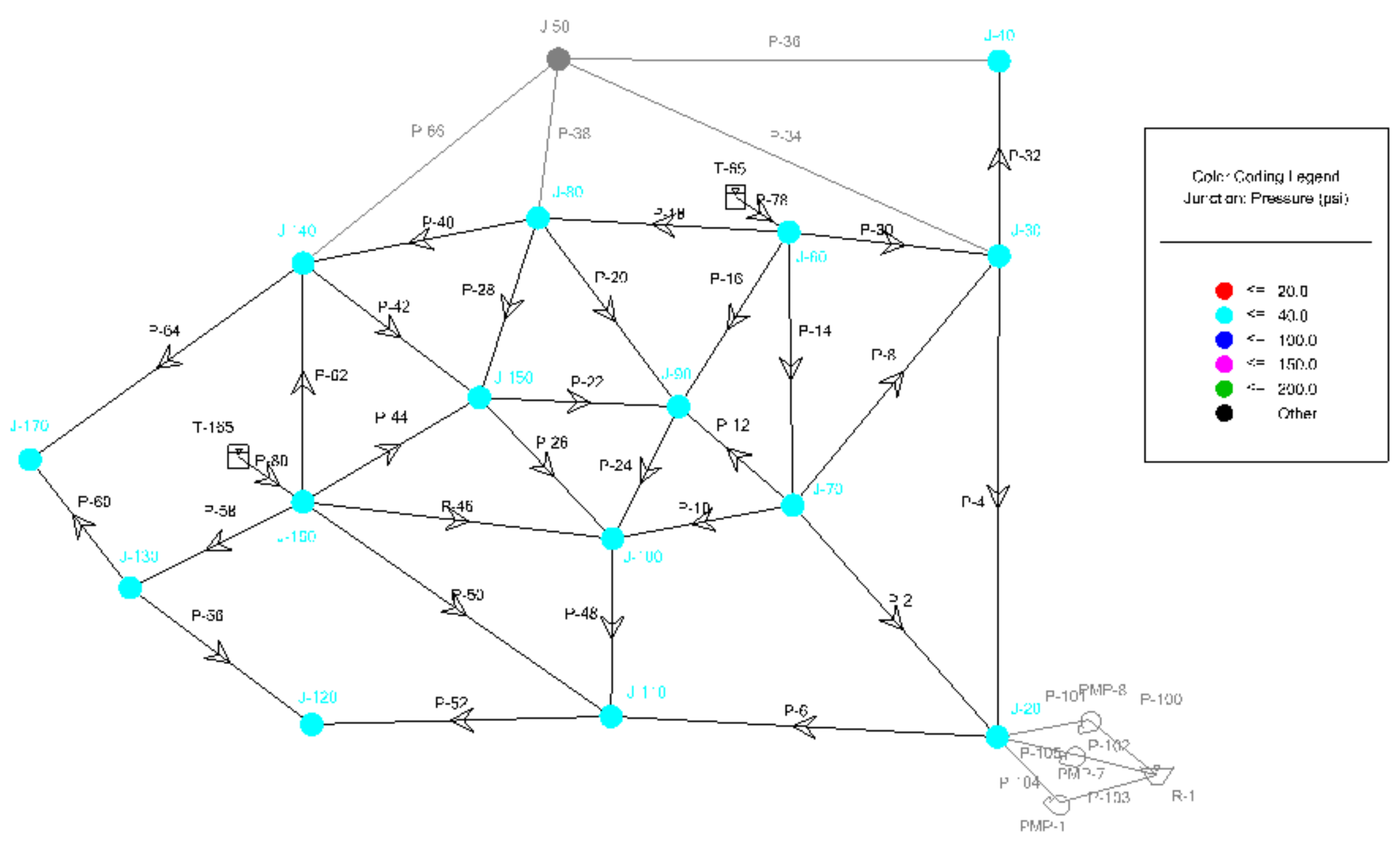




\section{Demand Supplied}

\begin{tabular}{|c|c|c|c|c|c|c|c|c|c|c|c|c|c|c|c|c|}
\hline $\begin{array}{l}\text { Time } \\
\text { (hours) }\end{array}$ & $\mathrm{J}-20$ & $\mathrm{~J}-30$ & $\mathrm{~J}-40$ & $\mathrm{~J}-50$ & J-60 & J-70 & $\mathrm{J}-80$ & J-90 & $\mathrm{J}-100$ & $\mathrm{~J}-110$ & $\mathrm{~J}-120$ & $\mathrm{~J}-130$ & J-140 & J-150 & $\mathrm{J}-160$ & J-170 \\
\hline 0 & 350 & 140 & 500 & 0 & 350 & 350 & 350 & 700 & 350 & 350 & 1140 & 500 & 140 & 140 & 560 & 140 \\
\hline 1 & 350 & 140 & 500 & 0 & 350 & 350 & 350 & 700 & 350 & 350 & 1140 & 500 & 140 & 140 & 560 & 140 \\
\hline 2 & 350 & 140 & 500 & 0 & 350 & 350 & 350 & 700 & 350 & 350 & 1140 & 500 & 140 & 140 & 560 & 140 \\
\hline 3 & 300 & 120 & 500 & 0 & 300 & 300 & 300 & 600 & 300 & 300 & 1120 & 500 & 120 & 20 & 80 & 120 \\
\hline 4 & 300 & 120 & 500 & 0 & 300 & 300 & 300 & 600 & 300 & 300 & 1120 & 500 & 120 & 120 & 480 & 120 \\
\hline 5 & 300 & 120 & 500 & 0 & 300 & 300 & 300 & 600 & 300 & 300 & 1120 & 500 & 120 & 120 & 480 & 120 \\
\hline 6 & 600 & 240 & 500 & 0 & 600 & 600 & 600 & 1200 & 600 & 600 & 1240 & 500 & 240 & 240 & 960 & 240 \\
\hline 7 & 600 & 240 & 500 & 0 & 600 & 600 & 600 & 1200 & 600 & 600 & 1240 & 500 & 240 & 240 & 960 & 240 \\
\hline 8 & 600 & 240 & 500 & 0 & 600 & 600 & 600 & 1200 & 600 & 600 & 1240 & 500 & 0 & 10 & 60 & 240 \\
\hline 9 & 650 & 260 & 500 & 0 & 650 & 650 & 650 & 1300 & 650 & 650 & 1260 & 500 & 260 & 260 & 1040 & 260 \\
\hline 10 & 650 & 260 & 500 & 0 & 650 & 650 & 650 & 1300 & 650 & 650 & 1260 & 500 & 260 & 260 & 1040 & 260 \\
\hline 11 & 650 & 260 & 500 & 0 & 650 & 650 & 650 & 1300 & 650 & 650 & 1260 & 500 & 260 & 260 & 1040 & 260 \\
\hline 12 & 600 & 240 & 500 & 0 & 600 & 600 & 600 & 1200 & 600 & 600 & 1240 & 500 & 240 & 240 & 960 & 240 \\
\hline 13 & 600 & 240 & 500 & 0 & 600 & 600 & 600 & 1200 & 600 & 600 & 1240 & 500 & 240 & 40 & 60 & 240 \\
\hline 14 & 600 & 240 & 500 & 0 & 600 & 600 & 600 & 1200 & 600 & 600 & 1240 & 500 & 240 & 240 & 960 & 240 \\
\hline 15 & 550 & 220 & 500 & 0 & 550 & 550 & 550 & 1100 & 550 & 550 & 1220 & 500 & 220 & 220 & 880 & 220 \\
\hline 16 & 550 & 220 & 500 & 0 & 550 & 550 & 550 & 1100 & 550 & 550 & 1213 & 500 & 220 & 220 & 880 & 220 \\
\hline 17 & 550 & 220 & 500 & 0 & 550 & 550 & 550 & 1100 & 550 & 550 & 1201 & 500 & 220 & 220 & 880 & 220 \\
\hline 18 & 500 & 200 & 500 & 0 & 500 & 500 & 500 & 1000 & 500 & 500 & 1177 & 500 & 200 & 200 & 800 & 200 \\
\hline 19 & 500 & 200 & 500 & 0 & 500 & 500 & 500 & 1000 & 500 & 500 & 1166 & 497 & 200 & 200 & 800 & 199 \\
\hline 20 & 496 & 200 & 499 & 0 & 500 & 500 & 500 & 1000 & 500 & 496 & 1155 & 492 & 200 & 200 & 800 & 197 \\
\hline 21 & 445 & 180 & 496 & 0 & 450 & 449 & 450 & 898 & 449 & 445 & 1132 & 490 & 180 & 180 & 720 & 176 \\
\hline 22 & 441 & 178 & 492 & 0 & 450 & 446 & 446 & 891 & 445 & 441 & 1122 & 486 & 178 & 178 & 718 & 175 \\
\hline 23 & 437 & 177 & 488 & 0 & 450 & 442 & 443 & 883 & 442 & 437 & 1113 & 482 & 177 & 177 & 712 & 173 \\
\hline 24 & 341 & 137 & 488 & 0 & 349 & 344 & 344 & 687 & 343 & 340 & 1077 & 481 & 138 & 137 & 552 & 135 \\
\hline 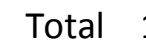 & 310 & 32 & 190 & 0 & 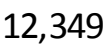 & 2.33 & 2,333 & 4,659 & 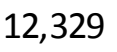 & & 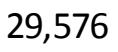 & a & 933 & 32 & 74 & 91 \\
\hline
\end{tabular}




\section{'J-50 Out' Results}

\begin{tabular}{|c|c|c|c|c|c|c|}
\hline \multirow[b]{2}{*}{ Node } & \multicolumn{2}{|c|}{ Demand Supplied } & \multirow[b]{2}{*}{$\begin{array}{l}\text { Demand } \\
\text { Effected }\end{array}$} & \multicolumn{2}{|c|}{ Population Served } & \multirow[b]{2}{*}{$\begin{array}{c}\text { Population } \\
\text { Effected }\end{array}$} \\
\hline & $\begin{array}{c}\text { Normal } \\
\text { Conditions }\end{array}$ & $\begin{array}{l}\text { Failure } \\
\text { Scenario } \\
\text { J-50 Out }\end{array}$ & & $\begin{array}{c}\text { Normal } \\
\text { Conditions }\end{array}$ & $\begin{array}{c}\text { Failure } \\
\text { Scenario } \\
\text { J-50 Out }\end{array}$ & \\
\hline (1) & (2) & (3) & (4) & (5) & (6) & (7) \\
\hline$J-20$ & 12350 & 12310 & 40 & 3069 & 3059 & 10 \\
\hline $\mathrm{J}-30$ & 4940 & 4932 & 8 & 1421 & 1419 & 2 \\
\hline $\mathrm{J}-40$ & 4940 & 12463 & -7523 & 6100 & 15389 & -9289 \\
\hline$J-50$ & 4940 & 0 & 4940 & 5953 & 0 & 5953 \\
\hline $\mathrm{J}-60$ & 12350 & 12349 & 1 & 2297 & 2297 & 0 \\
\hline $\mathrm{J}-70$ & 12350 & 12331 & 19 & 827 & 826 & 1 \\
\hline $\mathrm{J}-80$ & 12350 & 12333 & 17 & 4189 & 4183 & 6 \\
\hline $\mathrm{J}-90$ & 24700 & 24659 & 41 & 6082 & 6072 & 10 \\
\hline $\mathrm{J}-100$ & 12350 & 12329 & 21 & 716 & 715 & 1 \\
\hline $\mathrm{J}-110$ & 12350 & 12309 & 41 & 4642 & 4627 & 15 \\
\hline $\mathrm{J}-120$ & 4940 & 29576 & -24636 & 4949 & 29631 & -24682 \\
\hline $\mathrm{J}-130$ & 4940 & 12428 & -7488 & 5170 & 13006 & -7836 \\
\hline $\mathrm{J}-140$ & 4940 & 4933 & 7 & 5248 & 5241 & 7 \\
\hline $\mathrm{J}-150$ & 4940 & 4932 & 8 & 4330 & 4323 & 7 \\
\hline $\mathrm{J}-160$ & 19760 & 19742 & 18 & 1487 & 1486 & 1 \\
\hline $\mathrm{J}-170$ & 4940 & 4915 & 25 & 1901 & 1892 & 10 \\
\hline
\end{tabular}




\section{Failure Scenario 'J-60 Out'}

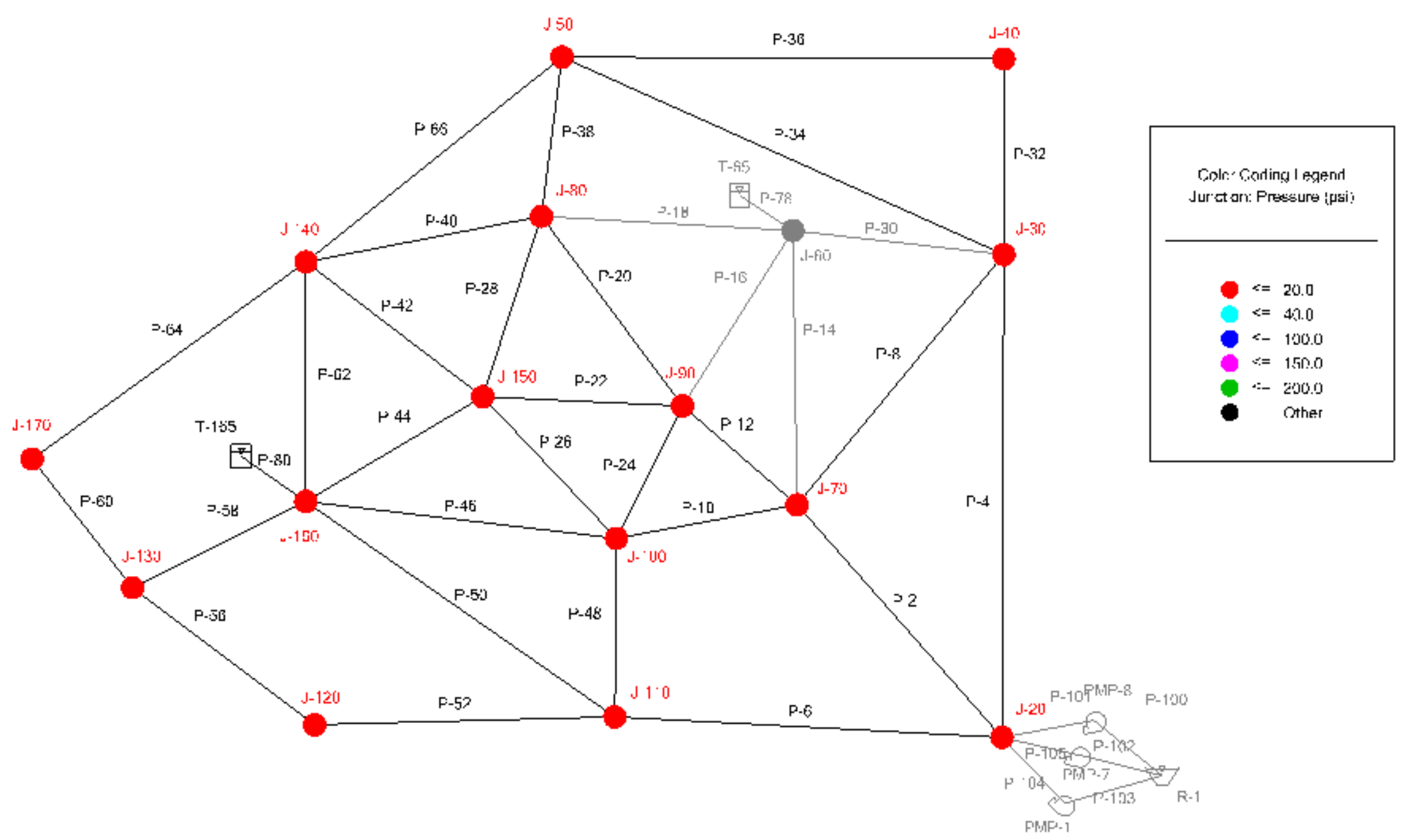




\section{Demand Supplied}

\begin{tabular}{|c|c|c|c|c|c|c|c|c|c|c|c|c|c|c|c|c|}
\hline $\begin{array}{c}\text { Time } \\
\text { (hours) }\end{array}$ & $\mathrm{J}-20$ & $J-30$ & $\mathrm{~J}-40$ & J-50 & $\mathrm{J}-60$ & $\mathrm{~J}-70$ & $\mathrm{~J}-80$ & J-90 & $\mathrm{J}-100$ & $\mathrm{~J}-110$ & $\mathrm{~J}-120$ & $\mathrm{~J}-130$ & $\mathrm{~J}-140$ & $\mathrm{~J}-150$ & $\mathrm{~J}-160$ & $\mathrm{~J}-170$ \\
\hline 0 & 350 & 140 & 500 & 140 & 0 & 350 & 350 & 700 & 350 & 350 & 1140 & 500 & 140 & 140 & 560 & 140 \\
\hline 1 & 350 & 140 & 500 & 140 & 0 & 350 & 350 & 700 & 350 & 350 & 1140 & 500 & 140 & 140 & 560 & 140 \\
\hline 2 & 350 & 140 & 500 & 140 & 0 & 350 & 350 & 700 & 350 & 350 & 1140 & 500 & 140 & 140 & 560 & 140 \\
\hline 3 & 300 & 120 & 500 & 120 & 0 & 300 & 300 & 600 & 300 & 300 & 1120 & 500 & 120 & 120 & 480 & 120 \\
\hline 4 & 300 & 120 & 500 & 120 & 0 & 300 & 300 & 600 & 300 & 300 & 1120 & 500 & 120 & 120 & 480 & 120 \\
\hline 5 & 300 & 120 & 500 & 120 & 0 & 300 & 300 & 600 & 300 & 300 & 1120 & 500 & 120 & 120 & 480 & 120 \\
\hline 6 & 557 & 223 & 464 & 223 & 0 & 563 & 565 & 1127 & 575 & 599 & 1213 & 500 & 231 & 230 & 960 & 240 \\
\hline 7 & 548 & 219 & 456 & 220 & 0 & 554 & 556 & 1108 & 565 & 589 & 1193 & 499 & 227 & 227 & 960 & 237 \\
\hline 8 & 539 & 216 & 449 & 216 & 0 & 544 & 547 & 1090 & 556 & 579 & 1173 & 491 & 223 & 223 & 960 & 233 \\
\hline 9 & 561 & 224 & 431 & 225 & 0 & 567 & 569 & 1135 & 581 & 609 & 1157 & 478 & 233 & 233 & 1040 & 245 \\
\hline 10 & 551 & 220 & 423 & 221 & 0 & 557 & 559 & 1114 & 570 & 598 & 1136 & 469 & 229 & 228 & 1032 & 241 \\
\hline 11 & 540 & 216 & 415 & 217 & 0 & 546 & 549 & 1094 & 560 & 587 & 1116 & 461 & 225 & 224 & 1013 & 236 \\
\hline 12 & 501 & 200 & 417 & 201 & 0 & 506 & 508 & 1014 & 517 & 539 & 1091 & 457 & 208 & 207 & 924 & 217 \\
\hline 13 & 492 & 197 & 410 & 197 & 0 & 497 & 499 & 995 & 508 & 529 & 1072 & 449 & 204 & 203 & 908 & 213 \\
\hline 14 & 483 & 193 & 402 & 194 & 0 & 488 & 490 & 977 & 499 & 519 & 1052 & 440 & 200 & 200 & 891 & 209 \\
\hline 15 & 445 & 178 & 404 & 178 & 0 & 449 & 450 & 898 & 457 & 473 & 1028 & 437 & 184 & 183 & 807 & 190 \\
\hline 16 & 0 & 0 & 0 & 0 & 0 & 0 & 0 & 0 & 0 & 0 & 0 & 0 & 0 & 0 & 0 & 0 \\
\hline 17 & 0 & 0 & 0 & 0 & 0 & 0 & 0 & 0 & 0 & 0 & 0 & 0 & 0 & 0 & 0 & 0 \\
\hline 18 & 0 & 0 & 0 & 0 & 0 & 0 & 0 & 0 & 0 & 0 & 0 & 0 & 0 & 0 & 0 & 0 \\
\hline 19 & 0 & 0 & 0 & 0 & 0 & 0 & 0 & 0 & 0 & 0 & 0 & 0 & 0 & 0 & 0 & 0 \\
\hline 20 & 0 & 0 & 0 & 0 & 0 & 0 & 0 & 0 & 0 & 0 & 0 & 0 & 0 & 0 & 0 & 0 \\
\hline 21 & 0 & 0 & 0 & 0 & 0 & 0 & 0 & 0 & 0 & 0 & 0 & 0 & 0 & 0 & 0 & 0 \\
\hline 22 & 0 & 0 & 0 & 0 & 0 & 0 & 0 & 0 & 0 & 0 & 0 & 0 & 0 & 0 & 0 & 0 \\
\hline 23 & 0 & 0 & 0 & 0 & 0 & 0 & 0 & 0 & 0 & 0 & 0 & 0 & 0 & 0 & 0 & 0 \\
\hline 24 & 0 & 0 & 0 & 0 & 0 & 0 & 0 & 0 & 0 & 0 & 0 & 0 & 0 & 0 & 0 & 0 \\
\hline Total & 7,167 & 2,866 & 7,271 & 2,872 & 0 & 7,221 & 7,242 & 14,452 & 7,338 & 7,571 & 18,011 & 7,681 & 2,944 & 2,938 & 12,615 & 3,041 \\
\hline
\end{tabular}




\section{'J-60 Out' Results}

\begin{tabular}{|c|c|c|c|c|c|c|}
\hline \multirow[b]{2}{*}{ Node } & \multicolumn{2}{|c|}{ Demand Supplied } & \multirow[b]{2}{*}{$\begin{array}{l}\text { Demand } \\
\text { Effected }\end{array}$} & \multicolumn{2}{|c|}{ Population Served } & \multirow[b]{2}{*}{$\begin{array}{c}\text { Population } \\
\text { Effected }\end{array}$} \\
\hline & $\begin{array}{c}\text { Normal } \\
\text { Conditions }\end{array}$ & $\begin{array}{l}\text { Failure } \\
\text { Scenario } \\
\text { J-60 Out }\end{array}$ & & \begin{tabular}{||c} 
Normal \\
Conditions
\end{tabular} & $\begin{array}{c}\text { Failure } \\
\text { Scenario } \\
\text { J-60 Out }\end{array}$ & \\
\hline (1) & (2) & (3) & (4) & (5) & (6) & (7) \\
\hline $\mathrm{J}-20$ & 12350 & 7167 & 5183 & 3069 & 1781 & 1288 \\
\hline $\mathrm{J}-30$ & 4940 & 2866 & 2074 & 1421 & 825 & 597 \\
\hline $\mathrm{J}-40$ & 4940 & 7271 & -2331 & 6100 & 8978 & -2878 \\
\hline$J-50$ & 4940 & 2872 & 2068 & 5953 & 3461 & 2492 \\
\hline $\mathrm{J}-60$ & 12350 & 0 & 12350 & 2297 & 0 & 2297 \\
\hline $\mathrm{J}-70$ & 12350 & 7221 & 5129 & 827 & 484 & 344 \\
\hline $\mathrm{J}-80$ & 12350 & 7242 & 5108 & 4189 & 2456 & 1732 \\
\hline J-90 & 24700 & 14452 & 10248 & 6082 & 3559 & 2524 \\
\hline $\mathrm{J}-100$ & 12350 & 7338 & 5012 & 716 & 426 & 291 \\
\hline $\mathrm{J}-110$ & 12350 & 7571 & 4779 & 4642 & 2846 & 1796 \\
\hline $\mathrm{J}-120$ & 4940 & 18011 & -13071 & 4949 & 18044 & -13095 \\
\hline $\mathrm{J}-130$ & 4940 & 7681 & -2741 & 5170 & 8038 & -2868 \\
\hline $\mathrm{J}-140$ & 4940 & 2944 & 1996 & 5248 & 3128 & 2121 \\
\hline $\mathrm{J}-150$ & 4940 & 2938 & 2002 & 4330 & 2575 & 1755 \\
\hline $\mathrm{J}-160$ & 19760 & 12615 & 7145 & 1487 & 949 & 538 \\
\hline $\mathrm{J}-170$ & 4940 & 3041 & 1899 & 1901 & 1170 & 731 \\
\hline
\end{tabular}




\section{Failure Scenario 'J-70 Out'}

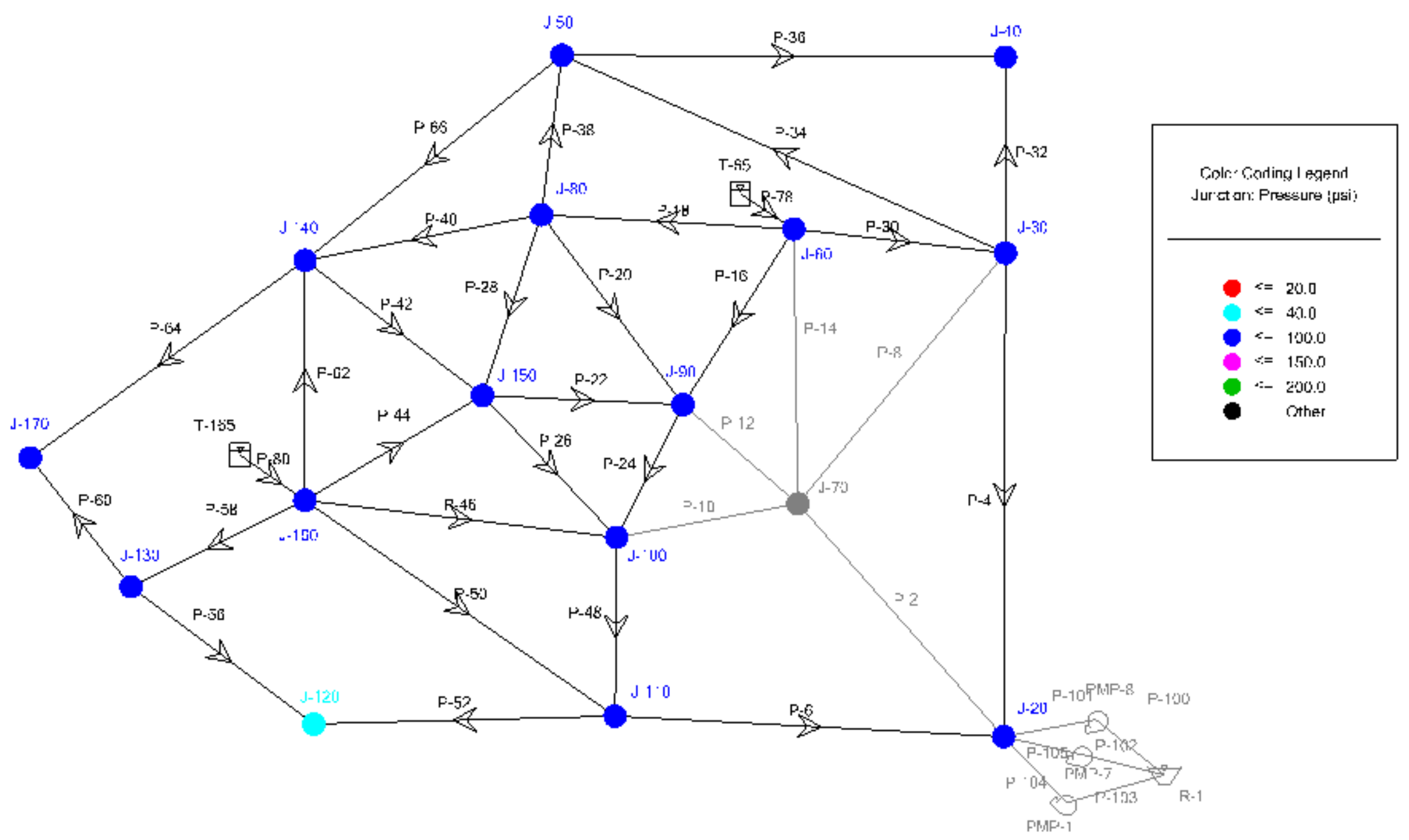




\section{Demand Supplied}

\begin{tabular}{|c|c|c|c|c|c|c|c|c|c|c|c|c|c|c|c|c|}
\hline $\begin{array}{c}\text { Time } \\
\text { (hours) }\end{array}$ & $\mathrm{J}-20$ & $J-30$ & $\mathrm{~J}-40$ & $\mathrm{~J}-50$ & $\mathrm{~J}-60$ & J-70 & $\mathrm{J}-80$ & J-90 & $\mathrm{J}-100$ & $\mathrm{~J}-110$ & $\mathrm{~J}-120$ & $\mathrm{~J}-130$ & $\mathrm{~J}-140$ & $\mathrm{~J}-150$ & $\mathrm{~J}-160$ & J-170 \\
\hline 0 & 350 & 140 & 500 & 140 & 350 & 0 & 350 & 700 & 350 & 350 & 1140 & 500 & 140 & 140 & 560 & 140 \\
\hline 1 & 350 & 140 & 500 & 140 & 350 & 0 & 350 & 700 & 350 & 350 & 1140 & 500 & 140 & 140 & 560 & 140 \\
\hline 2 & 350 & 140 & 500 & 140 & 350 & 0 & 350 & 700 & 350 & 350 & 1140 & 500 & 140 & 140 & 560 & 140 \\
\hline 3 & 300 & 120 & 500 & 120 & 300 & 0 & 300 & 600 & 300 & 300 & 1120 & 500 & 120 & 120 & 480 & 120 \\
\hline 4 & 300 & 120 & 500 & 120 & 300 & 0 & 300 & 600 & 300 & 300 & 1120 & 500 & 120 & 120 & 480 & 120 \\
\hline 5 & 300 & 120 & 500 & 120 & 300 & 0 & 300 & 600 & 300 & 300 & 1120 & 500 & 120 & 120 & 480 & 120 \\
\hline 6 & 600 & 240 & 500 & 240 & 600 & 0 & 600 & 1200 & 600 & 600 & 1240 & 500 & 240 & 240 & 960 & 240 \\
\hline 7 & 600 & 240 & 500 & 240 & 600 & 0 & 600 & 1200 & 600 & 600 & 1240 & 500 & 240 & 240 & 960 & 240 \\
\hline 8 & 600 & 240 & 500 & 240 & 600 & 0 & 600 & 1200 & 600 & 600 & 1240 & 500 & 240 & 240 & 960 & 240 \\
\hline 9 & 650 & 260 & 500 & 260 & 650 & 0 & 650 & 1300 & 650 & 650 & 1260 & 500 & 260 & 260 & 1040 & 260 \\
\hline 10 & 650 & 260 & 500 & 260 & 650 & 0 & 650 & 1300 & 650 & 650 & 1260 & 500 & 260 & 260 & 1040 & 260 \\
\hline 11 & 650 & 260 & 500 & 260 & 650 & 0 & 650 & 1300 & 650 & 650 & 1260 & 500 & 260 & 260 & 1040 & 260 \\
\hline 12 & 600 & 240 & 500 & 240 & 600 & 0 & 600 & 1200 & 600 & 600 & 1240 & 500 & 240 & 240 & 960 & 240 \\
\hline 13 & 600 & 240 & 500 & 240 & 600 & 0 & 600 & 1200 & 600 & 600 & 1240 & 500 & 240 & 240 & 960 & 240 \\
\hline 14 & 600 & 240 & 500 & 240 & 600 & 0 & 600 & 1200 & 600 & 600 & 1240 & 500 & 240 & 240 & 960 & 240 \\
\hline 15 & 550 & 220 & 500 & 220 & 550 & 0 & 550 & 1100 & 550 & 550 & 1220 & 500 & 220 & 220 & 880 & 220 \\
\hline 16 & 550 & 220 & 500 & 220 & 550 & 0 & 550 & 1100 & 550 & 550 & 1209 & 500 & 220 & 220 & 880 & 220 \\
\hline 17 & 548 & 220 & 500 & 220 & 550 & 0 & 550 & 1100 & 550 & 550 & 1198 & 500 & 220 & 220 & 880 & 220 \\
\hline 18 & 499 & 200 & 500 & 200 & 500 & 0 & 500 & 1000 & 500 & 500 & 1174 & 500 & 200 & 200 & 800 & 200 \\
\hline 19 & 494 & 200 & 500 & 200 & 500 & 0 & 500 & 1000 & 500 & 499 & 1164 & 496 & 200 & 200 & 800 & 198 \\
\hline 20 & 490 & 200 & 500 & 200 & 500 & 0 & 500 & 1000 & 500 & 495 & 1153 & 492 & 200 & 200 & 800 & 197 \\
\hline 21 & 441 & 180 & 500 & 180 & 450 & 0 & 450 & 900 & 450 & 444 & 1131 & 490 & 180 & 180 & 720 & 176 \\
\hline 22 & 437 & 180 & 498 & 179 & 450 & 0 & 448 & 894 & 446 & 440 & 1121 & 486 & 179 & 179 & 719 & 175 \\
\hline 23 & 434 & 178 & 494 & 178 & 450 & 0 & 445 & 886 & 443 & 437 & 1112 & 482 & 178 & 177 & 713 & 173 \\
\hline 24 & 340 & 139 & 494 & 138 & 350 & 0 & 346 & 690 & 344 & 340 & 1077 & 482 & 138 & 138 & 553 & 135 \\
\hline Total & 12,283 & 4,937 & 12,486 & 4,935 & 12,350 & 0 & 12,339 & 24,670 & 12,333 & 12,305 & 29,559 & 12,428 & 4,935 & 4,934 & 19,745 & 4,914 \\
\hline
\end{tabular}




\begin{tabular}{|c|c|c|c|c|c|c|}
\hline \multirow[b]{2}{*}{ Node } & \multicolumn{2}{|c|}{ Demand Supplied } & \multirow[b]{2}{*}{$\begin{array}{l}\text { Demand } \\
\text { Effected }\end{array}$} & \multicolumn{2}{|c|}{ Population Served } & \multirow[b]{2}{*}{$\begin{array}{c}\text { Population } \\
\text { Effected }\end{array}$} \\
\hline & $\begin{array}{c}\text { Normal } \\
\text { Conditions }\end{array}$ & $\begin{array}{l}\text { Failure } \\
\text { Scenario } \\
\text { J-70 Out }\end{array}$ & & $\begin{array}{c}\text { Normal } \\
\text { Conditions }\end{array}$ & $\begin{array}{l}\text { Failure } \\
\text { Scenario } \\
\text { J-70 Out }\end{array}$ & \\
\hline (1) & (2) & (3) & (4) & (5) & (6) & (7) \\
\hline $\mathrm{J}-20$ & 12350 & 12283 & 67 & 3069 & 3052 & 17 \\
\hline $\mathrm{J}-30$ & 4940 & 4937 & 3 & 1421 & 1421 & 1 \\
\hline $\mathrm{J}-40$ & 4940 & 12486 & -7546 & 6100 & 15417 & -9318 \\
\hline $\mathrm{J}-50$ & 4940 & 4935 & 5 & 5953 & 5947 & 6 \\
\hline$J-60$ & 12350 & 12350 & 0 & 2297 & 2297 & 0 \\
\hline $\mathrm{J}-70$ & 12350 & 0 & 12350 & 827 & 0 & 827 \\
\hline $\mathrm{J}-80$ & 12350 & 12339 & 11 & 4189 & 4185 & 4 \\
\hline J-90 & 24700 & 24670 & 30 & 6082 & 6075 & 7 \\
\hline$J-100$ & 12350 & 12333 & 17 & 716 & 715 & 1 \\
\hline $\mathrm{J}-110$ & 12350 & 12305 & 45 & 4642 & 4625 & 17 \\
\hline $\mathrm{J}-120$ & 4940 & 29559 & -24619 & 4949 & 29614 & -24665 \\
\hline$J-130$ & 4940 & 12428 & -7488 & 5170 & 13006 & -7836 \\
\hline $\mathrm{J}-140$ & 4940 & 4935 & 5 & 5248 & 5243 & 5 \\
\hline $\mathrm{J}-150$ & 4940 & 4934 & 6 & 4330 & 4325 & 5 \\
\hline$J-160$ & 19760 & 19745 & 15 & 1487 & 1486 & 1 \\
\hline $\mathrm{J}-170$ & 4940 & 4914 & 26 & 1901 & 1891 & 10 \\
\hline
\end{tabular}




\section{Failure Scenario 'J-80 Out'}

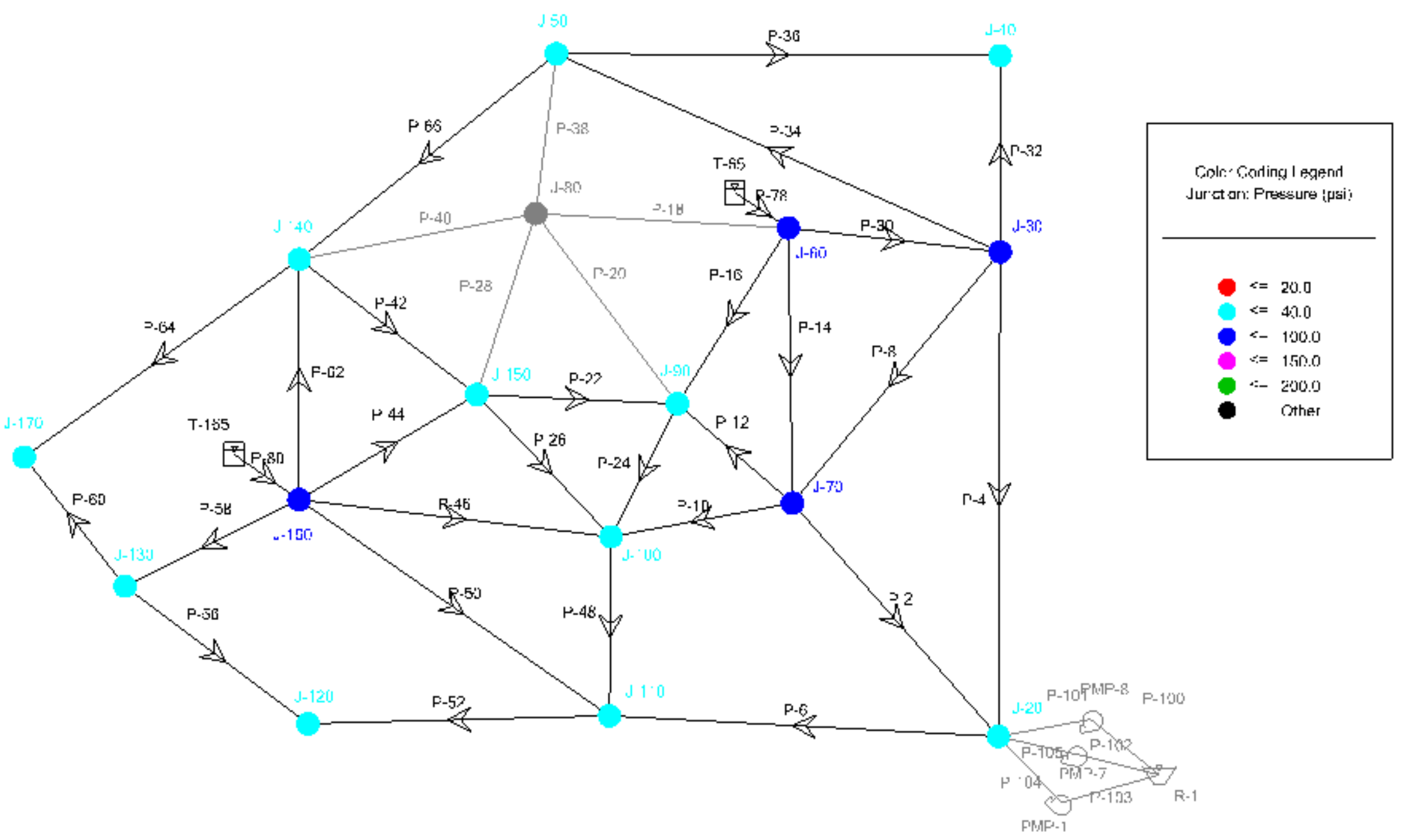




\section{Demand Supplied}

\begin{tabular}{|c|c|c|c|c|c|c|c|c|c|c|c|c|c|c|c|c|}
\hline $\begin{array}{c}\text { Time } \\
\text { (hours) }\end{array}$ & $\mathrm{J}-20$ & $\mathrm{~J}-30$ & $J-40$ & $J-50$ & $J-60$ & $\mathrm{~J}-70$ & $\mathrm{~J}-80$ & J-90 & $\mathrm{J}-100$ & $\mathrm{~J}-110$ & $\mathrm{~J}-120$ & $\mathrm{~J}-130$ & $\mathrm{~J}-140$ & $\mathrm{~J}-150$ & $\mathrm{~J}-160$ & $\mathrm{~J}-170$ \\
\hline 0 & 350 & 140 & 500 & 140 & 350 & 350 & 0 & 700 & 350 & 350 & 1140 & 500 & 140 & 140 & 560 & 140 \\
\hline 1 & 350 & 140 & 500 & 140 & 350 & 350 & 0 & 700 & 350 & 350 & 1140 & 500 & 140 & 140 & 560 & 140 \\
\hline 2 & 350 & 140 & 500 & 140 & 350 & 350 & 0 & 700 & 350 & 350 & 1140 & 500 & 140 & 140 & 560 & 140 \\
\hline 3 & 300 & 120 & 500 & 120 & 300 & 300 & 0 & 600 & 300 & 300 & 1120 & 500 & 120 & 120 & 480 & 120 \\
\hline 4 & 300 & 120 & 500 & 120 & 300 & 300 & 0 & 600 & 300 & 300 & 1120 & 500 & 120 & 120 & 480 & 120 \\
\hline 5 & 300 & 120 & 500 & 120 & 300 & 300 & 0 & 600 & 300 & 300 & 1120 & 500 & 120 & 120 & 480 & 120 \\
\hline 6 & 600 & 240 & 500 & 240 & 600 & 600 & 0 & 1200 & 600 & 600 & 1240 & 500 & 240 & 240 & 960 & 240 \\
\hline 7 & 600 & 240 & 500 & 240 & 600 & 600 & 0 & 1200 & 600 & 600 & 1240 & 500 & 240 & 240 & 960 & 240 \\
\hline 8 & 600 & 240 & 500 & 240 & 600 & 600 & 0 & 1200 & 600 & 600 & 1240 & 500 & 240 & 240 & 960 & 240 \\
\hline 9 & 650 & 260 & 500 & 260 & 650 & 650 & 0 & 1300 & 650 & 650 & 1260 & 500 & 260 & 260 & 1040 & 260 \\
\hline 10 & 650 & 260 & 500 & 260 & 650 & 650 & 0 & 1300 & 650 & 650 & 1260 & 500 & 260 & 260 & 1040 & 260 \\
\hline 11 & 650 & 260 & 500 & 260 & 650 & 650 & 0 & 1300 & 650 & 650 & 1260 & 500 & 260 & 260 & 1040 & 260 \\
\hline 12 & 600 & 240 & 500 & 240 & 600 & 600 & 0 & 1200 & 600 & 600 & 1240 & 500 & 240 & 240 & 960 & 240 \\
\hline 13 & 600 & 240 & 500 & 240 & 600 & 600 & 0 & 1200 & 600 & 600 & 1240 & 500 & 240 & 240 & 960 & 240 \\
\hline 14 & 600 & 240 & 500 & 240 & 600 & 600 & 0 & 1200 & 600 & 600 & 1240 & 500 & 240 & 240 & 960 & 240 \\
\hline 15 & 550 & 220 & 500 & 220 & 550 & 550 & 0 & 1100 & 550 & 550 & 1220 & 500 & 220 & 220 & 880 & 220 \\
\hline 16 & 550 & 220 & 500 & 220 & 550 & 550 & 0 & 1100 & 550 & 550 & 1213 & 500 & 220 & 220 & 880 & 220 \\
\hline 17 & 550 & 220 & 500 & 220 & 550 & 550 & 0 & 1100 & 550 & 550 & 1201 & 500 & 220 & 220 & 880 & 220 \\
\hline 18 & 500 & 200 & 500 & 200 & 500 & 500 & 0 & 1000 & 500 & 500 & 1177 & 500 & 200 & 200 & 800 & 200 \\
\hline 19 & 500 & 200 & 500 & 200 & 500 & 500 & 0 & 1000 & 500 & 500 & 1167 & 497 & 200 & 200 & 800 & 199 \\
\hline 20 & 497 & 200 & 500 & 200 & 500 & 500 & 0 & 1000 & 500 & 497 & 1157 & 493 & 200 & 200 & 800 & 197 \\
\hline 21 & 447 & 180 & 500 & 180 & 450 & 450 & 0 & 900 & 450 & 446 & 1134 & 490 & 180 & 180 & 720 & 176 \\
\hline 22 & 443 & 179 & 497 & 179 & 450 & 448 & 0 & 894 & 447 & 442 & 1124 & 486 & 179 & 179 & 719 & 175 \\
\hline 23 & 439 & 178 & 493 & 177 & 450 & 444 & 0 & 886 & 443 & 439 & 1115 & 482 & 177 & 177 & 713 & 174 \\
\hline 24 & 343 & 138 & 493 & 138 & 350 & 346 & 0 & 690 & 345 & 342 & 1079 & 482 & 138 & 138 & 553 & 135 \\
\hline Total & 12,319 & 4,935 & 12,483 & 4,934 & 12,350 & 12,338 & 0 & 24,670 & 12,335 & 12,316 & 29,587 & 12,430 & 4,934 & 4,934 & 19,745 & 4,916 \\
\hline
\end{tabular}




\begin{tabular}{|c|c|c|c|c|c|c|}
\hline \multirow[b]{2}{*}{ Node } & \multicolumn{2}{|c|}{ Demand Supplied } & \multirow[b]{2}{*}{$\begin{array}{l}\text { Demand } \\
\text { Effected }\end{array}$} & \multicolumn{2}{|c|}{ Population Served } & \multirow[b]{2}{*}{$\begin{array}{c}\text { Population } \\
\text { Effected }\end{array}$} \\
\hline & $\begin{array}{c}\text { Normal } \\
\text { Conditions }\end{array}$ & $\begin{array}{l}\text { Failure } \\
\text { Scenario } \\
\text { J-80 Out }\end{array}$ & & $\begin{array}{c}\text { Normal } \\
\text { Conditions }\end{array}$ & $\begin{array}{l}\text { Failure } \\
\text { Scenario } \\
\text { J-80 Out }\end{array}$ & \\
\hline$(1)$ & (2) & $(3)$ & (4) & $(5)$ & (6) & (7) \\
\hline $\mathrm{J}-20$ & 12350 & 12319 & 12350 & 3069 & 3061 & 8 \\
\hline $\mathrm{J}-30$ & 4940 & 4935 & 4520 & 1421 & 1420 & 1 \\
\hline $\mathrm{J}-40$ & 4940 & 12483 & 3440 & 6100 & 15414 & -9314 \\
\hline$J-50$ & 4940 & 4934 & 4520 & 5953 & 5946 & 7 \\
\hline $\mathrm{J}-60$ & 12350 & 12350 & 11300 & 2297 & 2297 & 0 \\
\hline $\mathrm{J}-70$ & 12350 & 12338 & 11300 & 827 & 827 & 1 \\
\hline $\mathrm{J}-80$ & 12350 & 0 & 11300 & 4189 & 0 & 4189 \\
\hline $\mathrm{J}-90$ & 24700 & 24670 & 22600 & 6082 & 6075 & 7 \\
\hline$J-100$ & 12350 & 12335 & 11300 & 716 & 715 & 1 \\
\hline$J-110$ & 12350 & 12316 & 11300 & 4642 & 4629 & 13 \\
\hline $\mathrm{J}-120$ & 4940 & 29587 & 1563 & 4949 & 29642 & -24693 \\
\hline $\mathrm{J}-130$ & 4940 & 12430 & 3445 & 5170 & 13008 & -7838 \\
\hline $\mathrm{J}-140$ & 4940 & 4934 & 4520 & 5248 & 5242 & 6 \\
\hline$J-150$ & 4940 & 4934 & 4520 & 4330 & 4325 & 5 \\
\hline$J-160$ & 19760 & 19745 & 18080 & 1487 & 1486 & 1 \\
\hline $\mathrm{J}-170$ & 4940 & 4916 & 4521 & 1901 & 1892 & 9 \\
\hline
\end{tabular}




\section{Failure Scenario 'J-90 Out'}

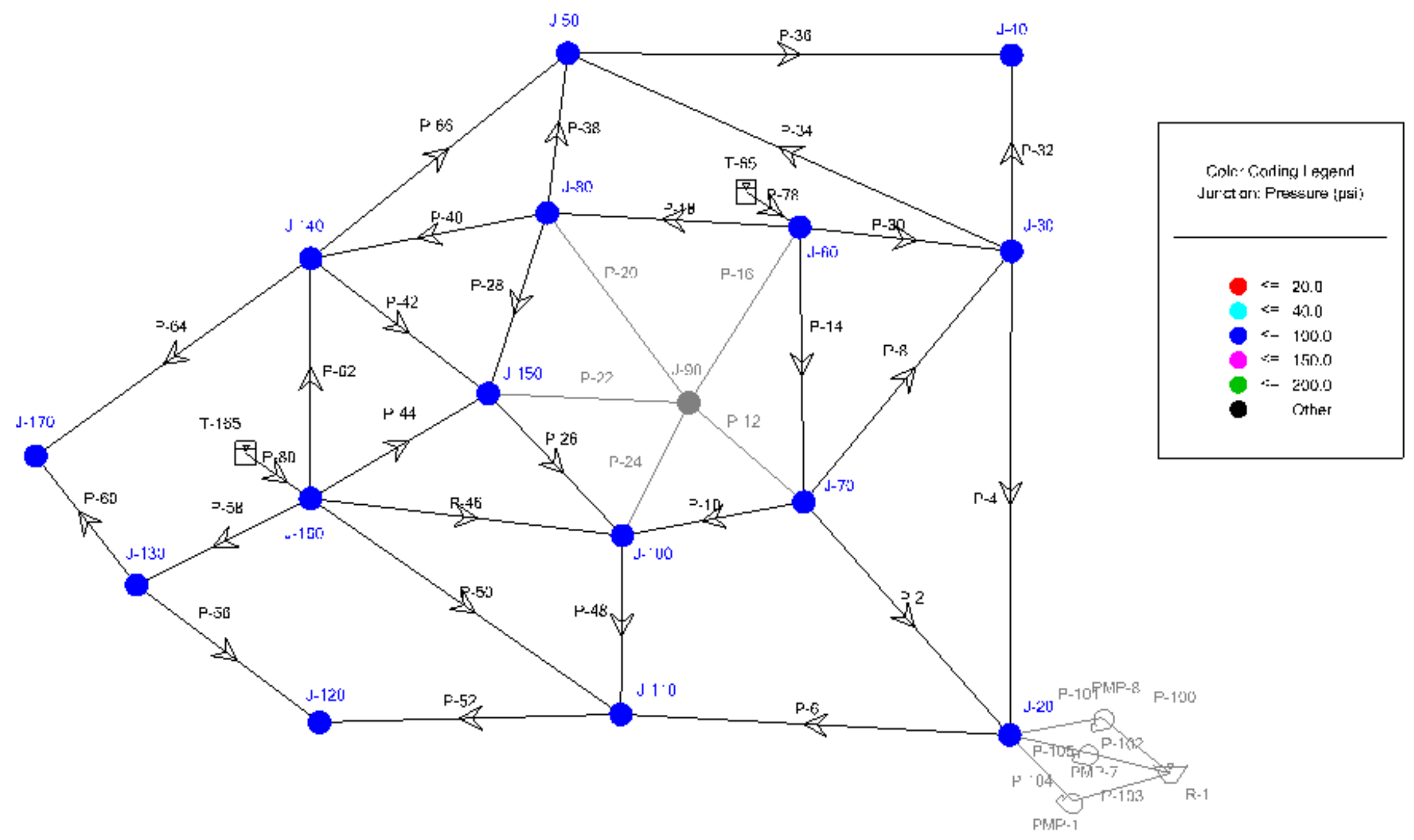




\section{Demand Supplied}

\begin{tabular}{|c|c|c|c|c|c|c|c|c|c|c|c|c|c|c|c|c|}
\hline $\begin{array}{c}\text { Time } \\
\text { (hours) }\end{array}$ & $J-20$ & J-30 & $\mathrm{J}-40$ & J-50 & $J-60$ & $\mathrm{~J}-70$ & $\mathrm{~J}-80$ & J-90 & $\mathrm{J}-100$ & $\mathrm{~J}-110$ & $\mathrm{~J}-120$ & J-130 & $\mathrm{J}-140$ & $\mathrm{~J}-150$ & $\mathrm{~J}-160$ & $\mathrm{~J}-170$ \\
\hline 0 & 350 & 140 & 500 & 140 & 350 & 350 & 350 & 0 & 350 & 350 & 1140 & 500 & 140 & 140 & 560 & 140 \\
\hline 1 & 350 & 140 & 500 & 140 & 350 & 350 & 350 & 0 & 350 & 350 & 1140 & 500 & 140 & 140 & 560 & 140 \\
\hline 2 & 350 & 140 & 500 & 140 & 350 & 350 & 350 & 0 & 350 & 350 & 1140 & 500 & 140 & 140 & 560 & 140 \\
\hline 3 & 300 & 120 & 500 & 120 & 300 & 300 & 300 & 0 & 300 & 300 & 1120 & 500 & 120 & 120 & 480 & 120 \\
\hline 4 & 300 & 120 & 500 & 120 & 300 & 300 & 300 & 0 & 300 & 300 & 1120 & 500 & 120 & 120 & 480 & 120 \\
\hline 5 & 300 & 120 & 500 & 120 & 300 & 300 & 300 & 0 & 300 & 300 & 1120 & 500 & 120 & 120 & 480 & 120 \\
\hline 6 & 600 & 240 & 500 & 240 & 600 & 600 & 600 & 0 & 600 & 600 & 1240 & 500 & 240 & 240 & 960 & 240 \\
\hline 7 & 600 & 240 & 500 & 240 & 600 & 600 & 600 & 0 & 600 & 600 & 1240 & 500 & 240 & 240 & 960 & 240 \\
\hline 8 & 600 & 240 & 500 & 240 & 600 & 600 & 600 & 0 & 600 & 600 & 1240 & 500 & 240 & 240 & 960 & 240 \\
\hline 9 & 650 & 260 & 500 & 260 & 650 & 650 & 650 & 0 & 650 & 650 & 1260 & 500 & 260 & 260 & 1040 & 260 \\
\hline 10 & 650 & 260 & 500 & 260 & 650 & 650 & 650 & 0 & 650 & 650 & 1260 & 500 & 260 & 260 & 1040 & 260 \\
\hline 11 & 650 & 260 & 500 & 260 & 650 & 650 & 650 & 0 & 650 & 650 & 1260 & 500 & 260 & 260 & 1040 & 260 \\
\hline 12 & 600 & 240 & 500 & 240 & 600 & 600 & 600 & 0 & 600 & 600 & 1240 & 500 & 240 & 240 & 960 & 240 \\
\hline 13 & 600 & 240 & 500 & 240 & 600 & 600 & 600 & 0 & 600 & 600 & 1240 & 500 & 240 & 240 & 960 & 240 \\
\hline 14 & 600 & 240 & 500 & 240 & 600 & 600 & 600 & 0 & 600 & 600 & 1240 & 500 & 240 & 240 & 960 & 240 \\
\hline 15 & 550 & 220 & 500 & 220 & 550 & 550 & 550 & 0 & 550 & 550 & 1220 & 500 & 220 & 220 & 880 & 220 \\
\hline 16 & 550 & 220 & 500 & 220 & 550 & 550 & 550 & 0 & 550 & 550 & 1220 & 500 & 220 & 220 & 880 & 220 \\
\hline 17 & 550 & 220 & 500 & 220 & 550 & 550 & 550 & 0 & 550 & 550 & 1220 & 500 & 220 & 220 & 880 & 220 \\
\hline 18 & 500 & 200 & 500 & 200 & 500 & 500 & 500 & 0 & 500 & 500 & 1198 & 500 & 200 & 200 & 800 & 200 \\
\hline 19 & 500 & 200 & 500 & 200 & 500 & 500 & 500 & 0 & 500 & 500 & 1188 & 500 & 200 & 200 & 800 & 200 \\
\hline 20 & 500 & 200 & 500 & 200 & 500 & 500 & 500 & 0 & 500 & 500 & 1179 & 500 & 200 & 200 & 800 & 200 \\
\hline 21 & 450 & 180 & 500 & 180 & 450 & 450 & 450 & 0 & 450 & 450 & 1155 & 500 & 180 & 180 & 720 & 180 \\
\hline 22 & 450 & 180 & 500 & 180 & 450 & 450 & 450 & 0 & 450 & 450 & 1146 & 496 & 180 & 180 & 720 & 178 \\
\hline 23 & 448 & 180 & 500 & 180 & 450 & 450 & 450 & 0 & 450 & 447 & 1138 & 492 & 180 & 180 & 720 & 177 \\
\hline 24 & 350 & 140 & 500 & 140 & 350 & 350 & 350 & 0 & 350 & 348 & 1101 & 492 & 140 & 140 & 560 & 138 \\
\hline Total & 12,348 & 4,940 & 12,500 & 4,940 & 12,350 & 12,350 & 12,350 & 0 & 12,350 & 12,345 & 29,765 & 12,480 & 4,940 & 4,940 & 19,760 & 4,933 \\
\hline
\end{tabular}


'J-90 Out' Results

\begin{tabular}{|c|c|c|c|c|c|c|}
\hline \multirow[b]{2}{*}{ Node } & \multicolumn{2}{|c|}{ Demand Supplied } & \multirow[b]{2}{*}{$\begin{array}{l}\text { Demand } \\
\text { Effected }\end{array}$} & \multicolumn{2}{|c|}{ Population Served } & \multirow[b]{2}{*}{$\begin{array}{l}\text { Population } \\
\text { Effected }\end{array}$} \\
\hline & $\begin{array}{c}\text { Normal } \\
\text { Conditions }\end{array}$ & $\begin{array}{c}\text { Failure } \\
\text { Scenario } \\
\text { J-90 Out }\end{array}$ & & $\begin{array}{c}\text { Normal } \\
\text { Conditions }\end{array}$ & $\begin{array}{c}\text { Failure } \\
\text { Scenario } \\
\text { J-90 Out }\end{array}$ & \\
\hline (1) & (2) & (3) & (4) & (5) & (6) & (7) \\
\hline $\mathrm{J}-20$ & 12350 & 12348 & 2 & 3069 & 3068 & 0 \\
\hline $\mathrm{J}-30$ & 4940 & 4940 & 0 & 1421 & 1421 & 0 \\
\hline $\mathrm{J}-40$ & 4940 & 12500 & -7560 & 6100 & 15435 & -9335 \\
\hline$J-50$ & 4940 & 4940 & 0 & 5953 & 5953 & 0 \\
\hline$J-60$ & 12350 & 12350 & 0 & 2297 & 2297 & 0 \\
\hline $\mathrm{J}-70$ & 12350 & 12350 & 0 & 827 & 827 & 0 \\
\hline $\mathrm{J}-80$ & 12350 & 12350 & 0 & 4189 & 4189 & 0 \\
\hline$J-90$ & 24700 & 0 & 24700 & 6082 & 0 & 6082 \\
\hline $\mathrm{J}-100$ & 12350 & 12350 & 0 & 716 & 716 & 0 \\
\hline $\mathrm{J}-110$ & 12350 & 12345 & 5 & 4642 & 4640 & 2 \\
\hline $\mathrm{J}-120$ & 4940 & 29765 & -24825 & 4949 & 29820 & -24871 \\
\hline$J-130$ & 4940 & 12480 & -7540 & 5170 & 13060 & -7891 \\
\hline J-140 & 4940 & 4940 & 0 & 5248 & 5248 & 0 \\
\hline J-150 & 4940 & 4940 & 0 & 4330 & 4330 & 0 \\
\hline J-160 & 19760 & 19760 & 0 & 1487 & 1487 & 0 \\
\hline$J-170$ & 4940 & 4933 & 7 & 1901 & 1899 & 3 \\
\hline
\end{tabular}




\section{Failure Scenario 'J-100 Out'}

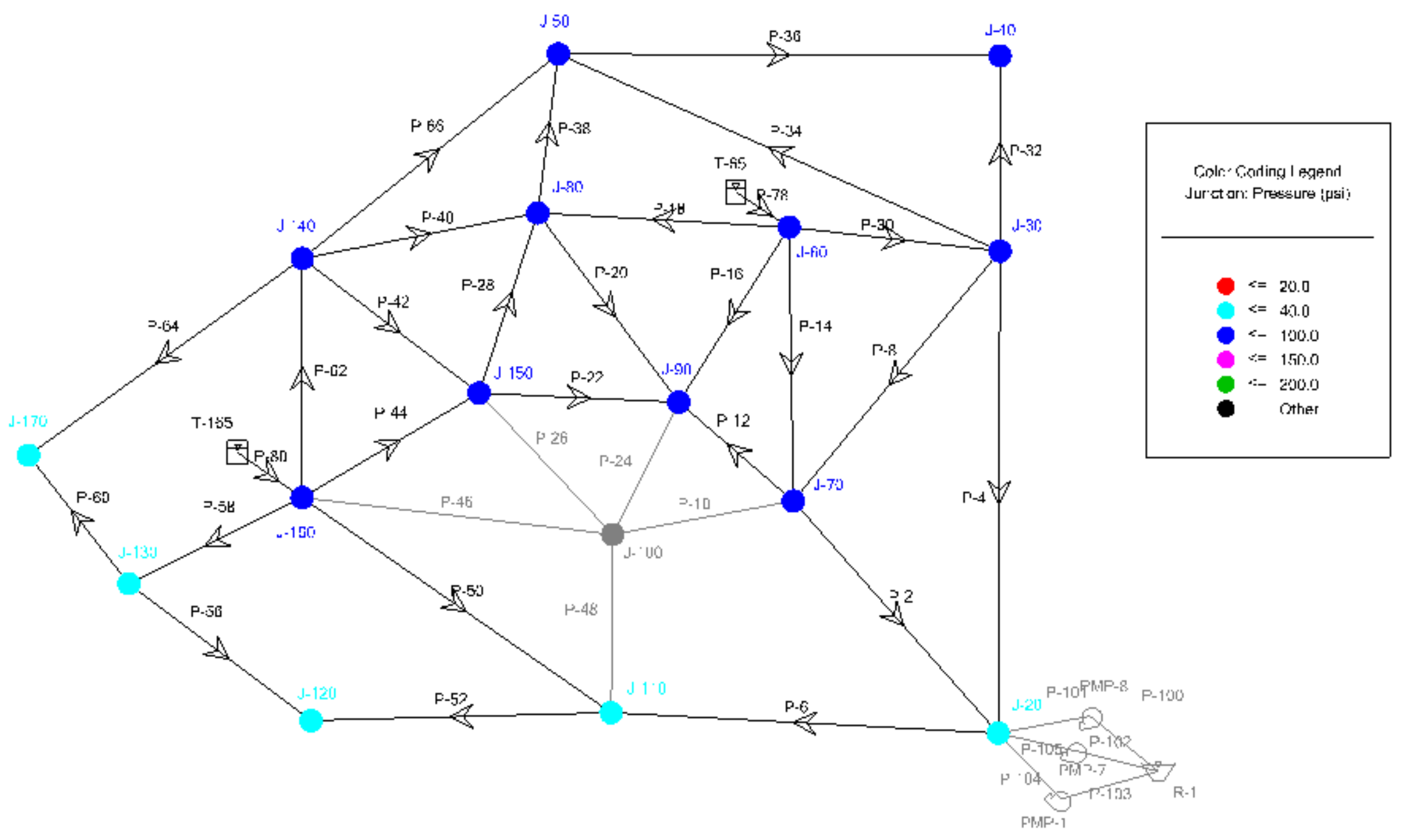




\section{Demand Supplied}

\begin{tabular}{|c|c|c|c|c|c|c|c|c|c|c|c|c|c|c|c|c|}
\hline $\begin{array}{c}\text { Time } \\
\text { (hours) }\end{array}$ & $\mathrm{J}-20$ & J-30 & $\mathrm{J}-40$ & $\mathrm{~J}-50$ & $\mathrm{~J}-60$ & $\mathrm{~J}-70$ & $\mathrm{~J}-80$ & J-90 & $\mathrm{J}-100$ & $\mathrm{~J}-110$ & $\mathrm{~J}-120$ & $\mathrm{~J}-130$ & $\mathrm{~J}-140$ & $\mathrm{~J}-150$ & $\mathrm{~J}-160$ & $\mathrm{~J}-170$ \\
\hline 0 & 350 & 140 & 500 & 140 & 350 & 350 & 350 & 700 & 0 & 350 & 1140 & 500 & 140 & 140 & 560 & 140 \\
\hline 1 & 350 & 140 & 500 & 140 & 350 & 350 & 350 & 700 & 0 & 350 & 1140 & 500 & 140 & 140 & 560 & 140 \\
\hline 2 & 350 & 140 & 500 & 140 & 350 & 350 & 350 & 700 & 0 & 350 & 1140 & 500 & 140 & 140 & 560 & 140 \\
\hline 3 & 300 & 120 & 500 & 120 & 300 & 300 & 300 & 600 & 0 & 300 & 1120 & 500 & 120 & 120 & 480 & 120 \\
\hline 4 & 300 & 120 & 500 & 120 & 300 & 300 & 300 & 600 & 0 & 300 & 1120 & 500 & 120 & 120 & 480 & 120 \\
\hline 5 & 300 & 120 & 500 & 120 & 300 & 300 & 300 & 600 & 0 & 300 & 1120 & 500 & 120 & 120 & 480 & 120 \\
\hline 6 & 600 & 240 & 500 & 240 & 600 & 600 & 600 & 1200 & 0 & 600 & 1240 & 500 & 240 & 240 & 960 & 240 \\
\hline 7 & 600 & 240 & 500 & 240 & 600 & 600 & 600 & 1200 & 0 & 600 & 1240 & 500 & 240 & 240 & 960 & 240 \\
\hline 8 & 600 & 240 & 500 & 240 & 600 & 600 & 600 & 1200 & 0 & 600 & 1240 & 500 & 240 & 240 & 960 & 240 \\
\hline 9 & 650 & 260 & 500 & 260 & 650 & 650 & 650 & 1300 & 0 & 650 & 1260 & 500 & 260 & 260 & 1040 & 260 \\
\hline 10 & 650 & 260 & 500 & 260 & 650 & 650 & 650 & 1300 & 0 & 650 & 1260 & 500 & 260 & 260 & 1040 & 260 \\
\hline 11 & 650 & 260 & 500 & 260 & 650 & 650 & 650 & 1300 & 0 & 650 & 1260 & 500 & 260 & 260 & 1040 & 260 \\
\hline 12 & 600 & 240 & 500 & 240 & 600 & 600 & 600 & 1200 & 0 & 600 & 1240 & 500 & 240 & 240 & 960 & 240 \\
\hline 13 & 600 & 240 & 500 & 240 & 600 & 600 & 600 & 1200 & 0 & 600 & 1240 & 500 & 240 & 240 & 960 & 240 \\
\hline 14 & 600 & 240 & 500 & 240 & 600 & 600 & 600 & 1200 & 0 & 600 & 1240 & 500 & 240 & 240 & 960 & 240 \\
\hline 15 & 550 & 220 & 500 & 220 & 550 & 550 & 550 & 1100 & 0 & 550 & 1220 & 500 & 220 & 220 & 880 & 220 \\
\hline 16 & 550 & 220 & 500 & 220 & 550 & 550 & 550 & 1100 & 0 & 550 & 1220 & 500 & 220 & 220 & 880 & 220 \\
\hline 17 & 550 & 220 & 500 & 220 & 550 & 550 & 550 & 1100 & 0 & 550 & 1209 & 500 & 220 & 220 & 880 & 220 \\
\hline 18 & 500 & 200 & 500 & 200 & 500 & 500 & 500 & 1000 & 0 & 500 & 1184 & 500 & 200 & 200 & 800 & 200 \\
\hline 19 & 500 & 200 & 500 & 200 & 500 & 500 & 500 & 1000 & 0 & 500 & 1174 & 500 & 200 & 200 & 800 & 200 \\
\hline 20 & 499 & 200 & 500 & 200 & 500 & 500 & 500 & 1000 & 0 & 499 & 1164 & 497 & 200 & 200 & 800 & 199 \\
\hline 21 & 448 & 180 & 500 & 180 & 450 & 450 & 450 & 900 & 0 & 447 & 1140 & 494 & 180 & 180 & 720 & 178 \\
\hline 22 & 445 & 180 & 499 & 180 & 450 & 450 & 450 & 899 & 0 & 444 & 1131 & 490 & 180 & 180 & 720 & 176 \\
\hline 23 & 441 & 178 & 495 & 178 & 450 & 446 & 446 & 891 & 0 & 440 & 1122 & 486 & 179 & 179 & 720 & 175 \\
\hline 24 & 344 & 139 & 495 & 139 & 350 & 347 & 347 & 694 & 0 & 342 & 1085 & 486 & 139 & 139 & 558 & 136 \\
\hline Total & 12,327 & 4,937 & 12,489 & 4,937 & 12,350 & 12,343 & 12,343 & 24,684 & 0 & 12,322 & 29,649 & 12,453 & 4,938 & 4,938 & 19,758 & 4,924 \\
\hline
\end{tabular}


'J-100 Out' Results

\begin{tabular}{|c|c|c|c|c|c|c|}
\hline \multirow[b]{2}{*}{ Node } & \multicolumn{2}{|c|}{ Demand Supplied } & \multirow[b]{2}{*}{$\begin{array}{l}\text { Demand } \\
\text { Effected }\end{array}$} & \multicolumn{2}{|c|}{ Population Served } & \multirow[b]{2}{*}{$\begin{array}{c}\text { Population } \\
\text { Effected }\end{array}$} \\
\hline & $\begin{array}{c}\text { Normal } \\
\text { Conditions }\end{array}$ & $\begin{array}{l}\text { Failure } \\
\text { Scenario } \\
\text { J-100 Out }\end{array}$ & & $\begin{array}{c}\text { Normal } \\
\text { Conditions }\end{array}$ & $\begin{array}{l}\text { Failure } \\
\text { Scenario } \\
\text { J-100 Out }\end{array}$ & \\
\hline (1) & (2) & (3) & (4) & (5) & (6) & (7) \\
\hline $\mathrm{J}-20$ & 12350 & 12327 & 23 & 3069 & 3063 & 6 \\
\hline $\mathrm{J}-30$ & 4940 & 4937 & 3 & 1421 & 1421 & 1 \\
\hline $\mathrm{J}-40$ & 4940 & 12489 & -7549 & 6100 & 15421 & -9321 \\
\hline$J-50$ & 4940 & 4937 & 3 & 5953 & 5950 & 4 \\
\hline $\mathrm{J}-60$ & 12350 & 12350 & 0 & 2297 & 2297 & 0 \\
\hline $\mathrm{J}-70$ & 12350 & 12343 & 7 & 827 & 827 & 0 \\
\hline $\mathrm{J}-80$ & 12350 & 12343 & 7 & 4189 & 4186 & 2 \\
\hline $\mathrm{J}-90$ & 24700 & 24684 & 16 & 6082 & 6078 & 4 \\
\hline $\mathrm{J}-100$ & 12350 & 0 & 12350 & 716 & 0 & 716 \\
\hline $\mathrm{J}-110$ & 12350 & 12322 & 28 & 4642 & 4632 & 11 \\
\hline $\mathrm{J}-120$ & 4940 & 29649 & -24709 & 4949 & 29704 & -24755 \\
\hline $\mathrm{J}-130$ & 4940 & 12453 & -7513 & 5170 & 13032 & -7862 \\
\hline $\mathrm{J}-140$ & 4940 & 4938 & 2 & 5248 & 5246 & 2 \\
\hline J-150 & 4940 & 4938 & 2 & 4330 & 4329 & 2 \\
\hline $\mathrm{J}-160$ & 19760 & 19758 & 2 & 1487 & 1487 & 0 \\
\hline J-170 & 4940 & 4924 & 16 & 1901 & 1895 & 6 \\
\hline
\end{tabular}




\section{Failure Scenario 'J-110 Out'}

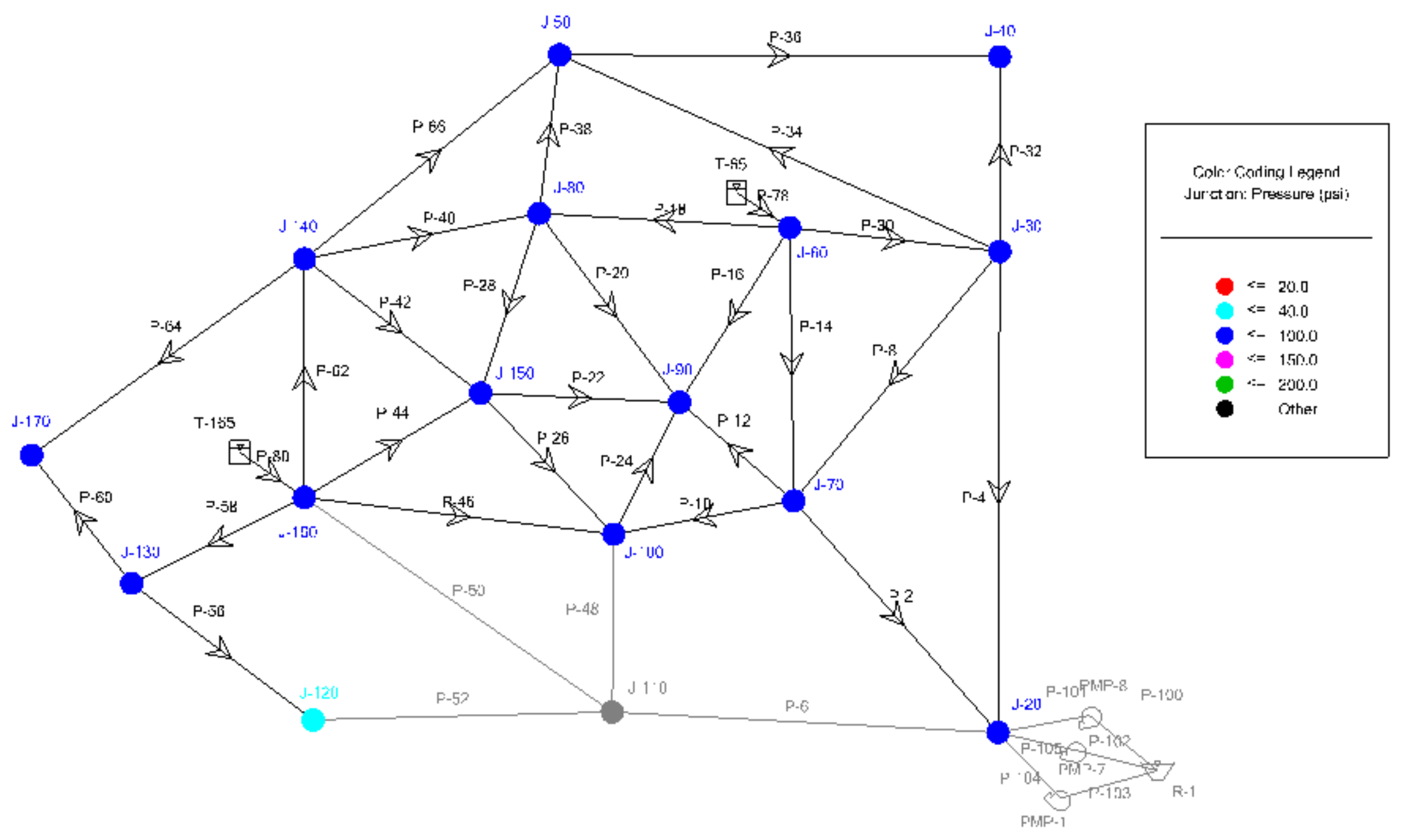




\section{Demand Supplied}

\begin{tabular}{|c|c|c|c|c|c|c|c|c|c|c|c|c|c|c|c|c|}
\hline $\begin{array}{c}\text { Time } \\
\text { (hours) }\end{array}$ & $J-20$ & $\mathrm{~J}-30$ & $\mathrm{~J}-40$ & $J-50$ & $\mathrm{~J}-60$ & $\mathrm{~J}-70$ & $\mathrm{~J}-80$ & J-90 & $\mathrm{J}-100$ & $\mathrm{~J}-110$ & $\mathrm{~J}-120$ & $\mathrm{~J}-130$ & $\mathrm{~J}-140$ & $\mathrm{~J}-150$ & $\mathrm{~J}-160$ & $\mathrm{~J}-170$ \\
\hline 0 & 350 & 140 & 500 & 140 & 350 & 350 & 350 & 700 & 350 & 0 & 1140 & 500 & 140 & 140 & 560 & 140 \\
\hline 1 & 350 & 140 & 500 & 140 & 350 & 350 & 350 & 700 & 350 & 0 & 1140 & 500 & 140 & 140 & 560 & 140 \\
\hline 2 & 350 & 140 & 500 & 140 & 350 & 350 & 350 & 700 & 350 & 0 & 1140 & 500 & 140 & 140 & 560 & 140 \\
\hline 3 & 300 & 120 & 500 & 120 & 300 & 300 & 300 & 600 & 300 & 0 & 1120 & 500 & 120 & 120 & 480 & 120 \\
\hline 4 & 300 & 120 & 500 & 120 & 300 & 300 & 300 & 600 & 300 & 0 & 1120 & 500 & 120 & 120 & 480 & 120 \\
\hline 5 & 300 & 120 & 500 & 120 & 300 & 300 & 300 & 600 & 300 & 0 & 1120 & 500 & 120 & 120 & 480 & 120 \\
\hline 6 & 600 & 240 & 500 & 240 & 600 & 600 & 600 & 1200 & 600 & 0 & 1233 & 500 & 240 & 240 & 960 & 240 \\
\hline 7 & 600 & 240 & 500 & 240 & 600 & 600 & 600 & 1200 & 600 & 0 & 1222 & 500 & 240 & 240 & 960 & 240 \\
\hline 8 & 600 & 240 & 500 & 240 & 600 & 600 & 600 & 1200 & 600 & 0 & 1212 & 500 & 240 & 240 & 960 & 240 \\
\hline 9 & 650 & 260 & 500 & 260 & 650 & 650 & 650 & 1300 & 650 & 0 & 1212 & 500 & 260 & 260 & 1040 & 260 \\
\hline 10 & 650 & 260 & 500 & 260 & 650 & 650 & 650 & 1300 & 650 & 0 & 1201 & 500 & 260 & 260 & 1040 & 260 \\
\hline 11 & 650 & 260 & 500 & 260 & 650 & 650 & 650 & 1300 & 650 & 0 & 1189 & 500 & 260 & 260 & 1040 & 260 \\
\hline 12 & 600 & 240 & 500 & 240 & 600 & 600 & 600 & 1200 & 600 & 0 & 1168 & 500 & 240 & 240 & 960 & 240 \\
\hline 13 & 600 & 240 & 500 & 240 & 600 & 600 & 600 & 1200 & 600 & 0 & 1157 & 500 & 240 & 240 & 960 & 240 \\
\hline 14 & 600 & 240 & 500 & 240 & 600 & 600 & 600 & 1200 & 600 & 0 & 1146 & 500 & 240 & 240 & 960 & 240 \\
\hline 15 & 550 & 220 & 500 & 220 & 550 & 550 & 550 & 1100 & 550 & 0 & 1125 & 500 & 220 & 220 & 880 & 220 \\
\hline 16 & 550 & 220 & 500 & 220 & 550 & 550 & 550 & 1100 & 550 & 0 & 1114 & 500 & 220 & 220 & 880 & 220 \\
\hline 17 & 550 & 220 & 500 & 220 & 550 & 550 & 550 & 1100 & 550 & 0 & 1104 & 496 & 220 & 220 & 880 & 218 \\
\hline 18 & 500 & 200 & 500 & 200 & 500 & 500 & 500 & 1000 & 500 & 0 & 1084 & 494 & 200 & 200 & 800 & 198 \\
\hline 19 & 500 & 200 & 500 & 200 & 500 & 500 & 500 & 1000 & 500 & 0 & 1075 & 490 & 200 & 200 & 800 & 196 \\
\hline 20 & 500 & 200 & 500 & 200 & 500 & 500 & 500 & 1000 & 500 & 0 & 1066 & 486 & 200 & 200 & 800 & 194 \\
\hline 21 & 450 & 180 & 500 & 180 & 450 & 450 & 450 & 900 & 450 & 0 & 1046 & 484 & 180 & 180 & 720 & 174 \\
\hline 22 & 446 & 180 & 499 & 180 & 450 & 450 & 450 & 900 & 450 & 0 & 1037 & 480 & 180 & 180 & 720 & 173 \\
\hline 23 & 442 & 179 & 495 & 178 & 450 & 447 & 447 & 893 & 447 & 0 & 1029 & 476 & 179 & 179 & 720 & 171 \\
\hline 24 & 345 & 139 & 495 & 139 & 350 & 348 & 348 & 695 & 348 & 0 & 999 & 476 & 139 & 139 & 560 & 133 \\
\hline Total & 12,333 & 4,938 & 12,489 & 4,937 & 12,350 & 12,345 & 12,345 & 24,688 & 12,345 & 0 & 28,199 & 12,382 & 4,938 & 4,938 & 19,760 & 4,897 \\
\hline
\end{tabular}


'J-110 Out' Results

\begin{tabular}{|c|c|c|c|c|c|c|}
\hline \multirow[b]{2}{*}{ Node } & \multicolumn{2}{|c|}{ Demand Supplied } & \multirow[b]{2}{*}{$\begin{array}{l}\text { Demand } \\
\text { Effected }\end{array}$} & \multicolumn{2}{|c|}{ Population Served } & \multirow[b]{2}{*}{$\begin{array}{l}\text { Population } \\
\text { Effected }\end{array}$} \\
\hline & $\begin{array}{c}\text { Normal } \\
\text { Conditions }\end{array}$ & $\begin{array}{l}\text { Failure } \\
\text { Scenario } \\
\text { J-110 Out }\end{array}$ & & $\begin{array}{c}\text { Normal } \\
\text { Conditions }\end{array}$ & $\begin{array}{c}\text { Failure } \\
\text { Scenario } \\
\text { J-110 Out }\end{array}$ & \\
\hline (1) & (2) & (3) & (4) & (5) & (6) & (7) \\
\hline $\mathrm{J}-20$ & 12350 & 12333 & 17 & 3069 & 3065 & 4 \\
\hline$J-30$ & 4940 & 4938 & 2 & 1421 & 1421 & 1 \\
\hline $\mathrm{J}-40$ & 4940 & 12489 & -7549 & 6100 & 15421 & -9321 \\
\hline $\mathrm{J}-50$ & 4940 & 4937 & 3 & 5953 & 5950 & 4 \\
\hline $\mathrm{J}-60$ & 12350 & 12350 & 0 & 2297 & 2297 & 0 \\
\hline $\mathrm{J}-70$ & 12350 & 12345 & 5 & 827 & 827 & 0 \\
\hline $\mathrm{J}-80$ & 12350 & 12345 & 5 & 4189 & 4187 & 2 \\
\hline J-90 & 24700 & 24688 & 12 & 6082 & 6079 & 3 \\
\hline$J-100$ & 12350 & 12345 & 5 & 716 & 716 & 0 \\
\hline$J-110$ & 12350 & 0 & 12350 & 4642 & 0 & 4642 \\
\hline$J-120$ & 4940 & 28199 & -23259 & 4949 & 28251 & -23302 \\
\hline$J-130$ & 4940 & 12382 & -7442 & 5170 & 12958 & -7788 \\
\hline$J-140$ & 4940 & 4938 & 2 & 5248 & 5246 & 2 \\
\hline$J-150$ & 4940 & 4938 & 2 & 4330 & 4329 & 2 \\
\hline$J-160$ & 19760 & 19760 & 0 & 1487 & 1487 & 0 \\
\hline J-170 & 4940 & 4897 & 43 & 1901 & 1885 & 17 \\
\hline
\end{tabular}




\section{Failure Scenario 'J-120 Out'}

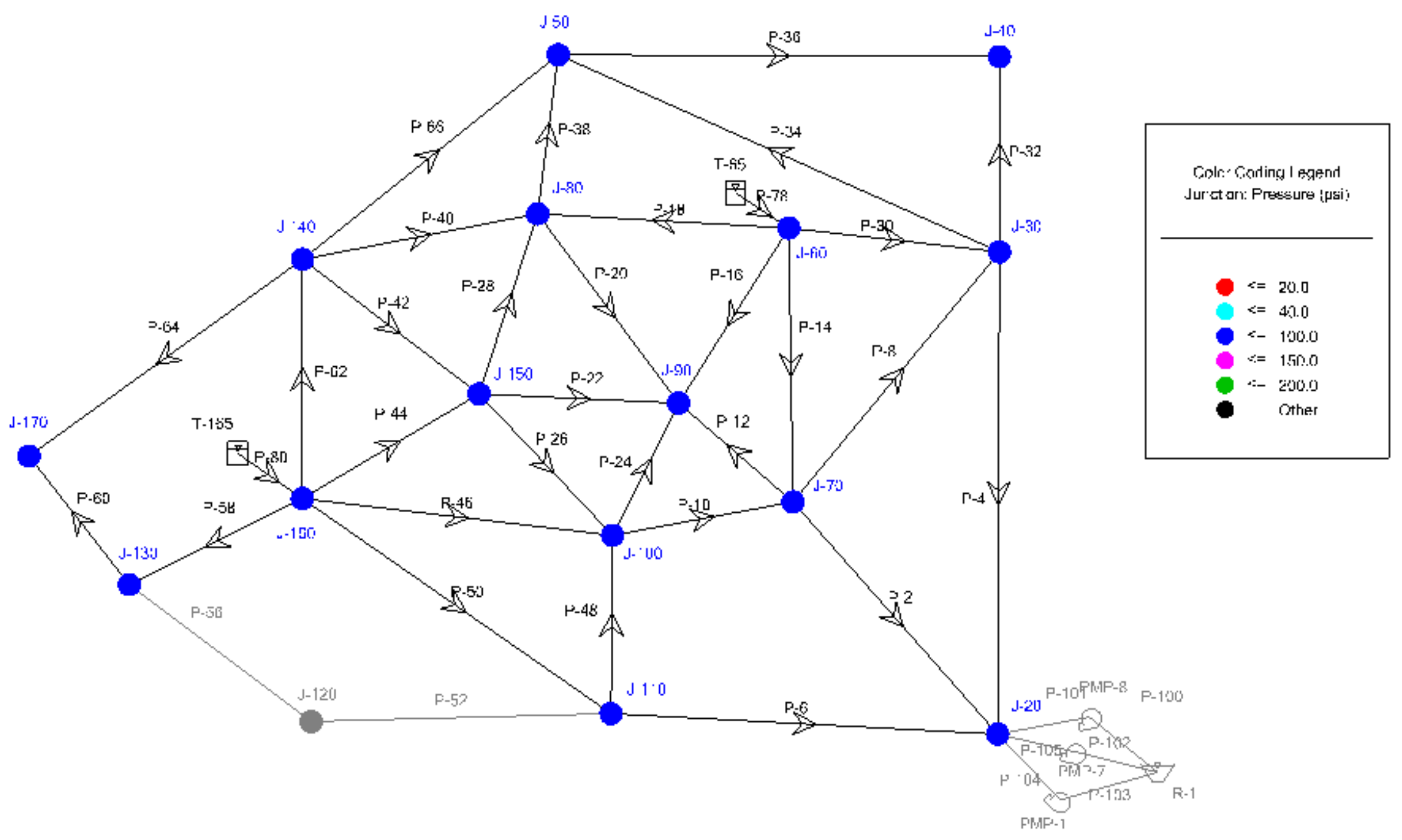




\section{Demand Supplied}

\begin{tabular}{|c|c|c|c|c|c|c|c|c|c|c|c|c|c|c|c|c|}
\hline $\begin{array}{c}\text { Time } \\
\text { (hours) }\end{array}$ & $\mathrm{J}-20$ & $\mathrm{~J}-30$ & $\mathrm{~J}-40$ & J-50 & J-60 & $\mathrm{J}-70$ & $\mathrm{~J}-80$ & J-90 & $\mathrm{J}-100$ & $\mathrm{~J}-110$ & $\mathrm{~J}-120$ & $\mathrm{~J}-130$ & $\mathrm{~J}-140$ & $\mathrm{~J}-150$ & $\mathrm{~J}-160$ & $\mathrm{~J}-170$ \\
\hline 0 & 350 & 140 & 500 & 140 & 350 & 350 & 350 & 700 & 350 & 350 & 0 & 500 & 140 & 140 & 560 & 140 \\
\hline 1 & 350 & 140 & 500 & 140 & 350 & 350 & 350 & 700 & 350 & 350 & 0 & 500 & 140 & 140 & 560 & 140 \\
\hline 2 & 350 & 140 & 500 & 140 & 350 & 350 & 350 & 700 & 350 & 350 & 0 & 500 & 140 & 140 & 560 & 140 \\
\hline 3 & 300 & 120 & 500 & 120 & 300 & 300 & 300 & 600 & 300 & 300 & 0 & 500 & 120 & 120 & 480 & 120 \\
\hline 4 & 300 & 120 & 500 & 120 & 300 & 300 & 300 & 600 & 300 & 300 & 0 & 500 & 120 & 120 & 480 & 120 \\
\hline 5 & 300 & 120 & 500 & 120 & 300 & 300 & 300 & 600 & 300 & 300 & 0 & 500 & 120 & 120 & 480 & 120 \\
\hline 6 & 600 & 240 & 500 & 240 & 600 & 600 & 600 & 1200 & 600 & 600 & 0 & 500 & 240 & 240 & 960 & 240 \\
\hline 7 & 600 & 240 & 500 & 240 & 600 & 600 & 600 & 1200 & 600 & 600 & 0 & 500 & 240 & 240 & 960 & 240 \\
\hline 8 & 600 & 240 & 500 & 240 & 600 & 600 & 600 & 1200 & 600 & 600 & 0 & 500 & 240 & 240 & 960 & 240 \\
\hline 9 & 650 & 260 & 500 & 260 & 650 & 650 & 650 & 1300 & 650 & 650 & 0 & 500 & 260 & 260 & 1040 & 260 \\
\hline 10 & 650 & 260 & 500 & 260 & 650 & 650 & 650 & 1300 & 650 & 650 & 0 & 500 & 260 & 260 & 1040 & 260 \\
\hline 11 & 650 & 260 & 500 & 260 & 650 & 650 & 650 & 1300 & 650 & 650 & 0 & 500 & 260 & 260 & 1040 & 260 \\
\hline 12 & 600 & 240 & 500 & 240 & 600 & 600 & 600 & 1200 & 600 & 600 & 0 & 500 & 240 & 240 & 960 & 240 \\
\hline 13 & 600 & 240 & 500 & 240 & 600 & 600 & 600 & 1200 & 600 & 600 & 0 & 500 & 240 & 240 & 960 & 240 \\
\hline 14 & 600 & 240 & 500 & 240 & 600 & 600 & 600 & 1200 & 600 & 600 & 0 & 500 & 240 & 240 & 960 & 240 \\
\hline 15 & 550 & 220 & 500 & 220 & 550 & 550 & 550 & 1100 & 550 & 550 & 0 & 500 & 220 & 220 & 880 & 220 \\
\hline 16 & 550 & 220 & 500 & 220 & 550 & 550 & 550 & 1100 & 550 & 550 & 0 & 500 & 220 & 220 & 880 & 220 \\
\hline 17 & 550 & 220 & 500 & 220 & 550 & 550 & 550 & 1100 & 550 & 550 & 0 & 500 & 220 & 220 & 880 & 220 \\
\hline 18 & 500 & 200 & 500 & 200 & 500 & 500 & 500 & 1000 & 500 & 500 & 0 & 500 & 200 & 200 & 800 & 200 \\
\hline 19 & 500 & 200 & 500 & 200 & 500 & 500 & 500 & 1000 & 500 & 500 & 0 & 500 & 200 & 200 & 800 & 200 \\
\hline 20 & 500 & 200 & 500 & 200 & 500 & 500 & 500 & 1000 & 500 & 500 & 0 & 500 & 200 & 200 & 800 & 200 \\
\hline 21 & 450 & 180 & 500 & 180 & 450 & 450 & 450 & 900 & 450 & 450 & 0 & 500 & 180 & 180 & 720 & 180 \\
\hline 22 & 450 & 180 & 500 & 180 & 450 & 450 & 450 & 900 & 450 & 450 & 0 & 500 & 180 & 180 & 720 & 180 \\
\hline 23 & 450 & 180 & 500 & 180 & 450 & 450 & 450 & 900 & 450 & 450 & 0 & 500 & 180 & 180 & 720 & 180 \\
\hline 24 & 350 & 140 & 500 & 140 & 350 & 350 & 350 & 700 & 350 & 350 & 0 & 500 & 140 & 140 & 560 & 140 \\
\hline Total & 12,350 & 4,940 & 12,500 & 4,940 & 12,350 & 12,350 & 12,350 & 24,700 & 12,350 & 12,350 & 0 & 12,500 & 4,940 & 4,940 & 19,760 & 4,940 \\
\hline
\end{tabular}




\section{'J-120 Out' Results}

\begin{tabular}{|c|c|c|c|c|c|c|}
\hline \multirow[b]{2}{*}{ Node } & \multicolumn{2}{|c|}{ Demand Supplied } & \multirow[b]{2}{*}{$\begin{array}{l}\text { Demand } \\
\text { Effected }\end{array}$} & \multicolumn{2}{|c|}{ Population Served } & \multirow[b]{2}{*}{$\begin{array}{l}\text { Population } \\
\text { Effected }\end{array}$} \\
\hline & $\begin{array}{c}\text { Normal } \\
\text { Conditions }\end{array}$ & $\begin{array}{l}\text { Failure } \\
\text { Scenario } \\
\text { J-120 Out }\end{array}$ & & $\begin{array}{c}\text { Normal } \\
\text { Conditions }\end{array}$ & $\begin{array}{l}\text { Failure } \\
\text { Scenario } \\
\text { J-120 Out }\end{array}$ & \\
\hline (1) & (2) & (3) & (4) & (5) & (6) & (7) \\
\hline $\mathrm{J}-20$ & 12350 & 12350 & 0 & 3069 & 3069 & 0 \\
\hline $\mathrm{J}-30$ & 4940 & 4940 & 0 & 1421 & 1421 & 0 \\
\hline $\mathrm{J}-40$ & 4940 & 12500 & -7560 & 6100 & 15435 & -9335 \\
\hline$J-50$ & 4940 & 4940 & 0 & 5953 & 5953 & 0 \\
\hline$J-60$ & 12350 & 12350 & 0 & 2297 & 2297 & 0 \\
\hline $\mathrm{J}-70$ & 12350 & 12350 & 0 & 827 & 827 & 0 \\
\hline $\mathrm{J}-80$ & 12350 & 12350 & 0 & 4189 & 4189 & 0 \\
\hline J-90 & 24700 & 24700 & 0 & 6082 & 6082 & 0 \\
\hline $\mathrm{J}-100$ & 12350 & 12350 & 0 & 716 & 716 & 0 \\
\hline $\mathrm{J}-110$ & 12350 & 12350 & 0 & 4642 & 4642 & 0 \\
\hline$J-120$ & 4940 & 0 & 4940 & 4949 & 0 & 4949 \\
\hline$J-130$ & 4940 & 12500 & -7560 & 5170 & 13081 & -7912 \\
\hline $\mathrm{J}-140$ & 4940 & 4940 & 0 & 5248 & 5248 & 0 \\
\hline$J-150$ & 4940 & 4940 & 0 & 4330 & 4330 & 0 \\
\hline $\mathrm{J}-160$ & 19760 & 19760 & 0 & 1487 & 1487 & 0 \\
\hline $\mathrm{J}-170$ & 4940 & 4940 & 0 & 1901 & 1901 & 0 \\
\hline
\end{tabular}




\section{Failure Scenario 'J-130 Out'}

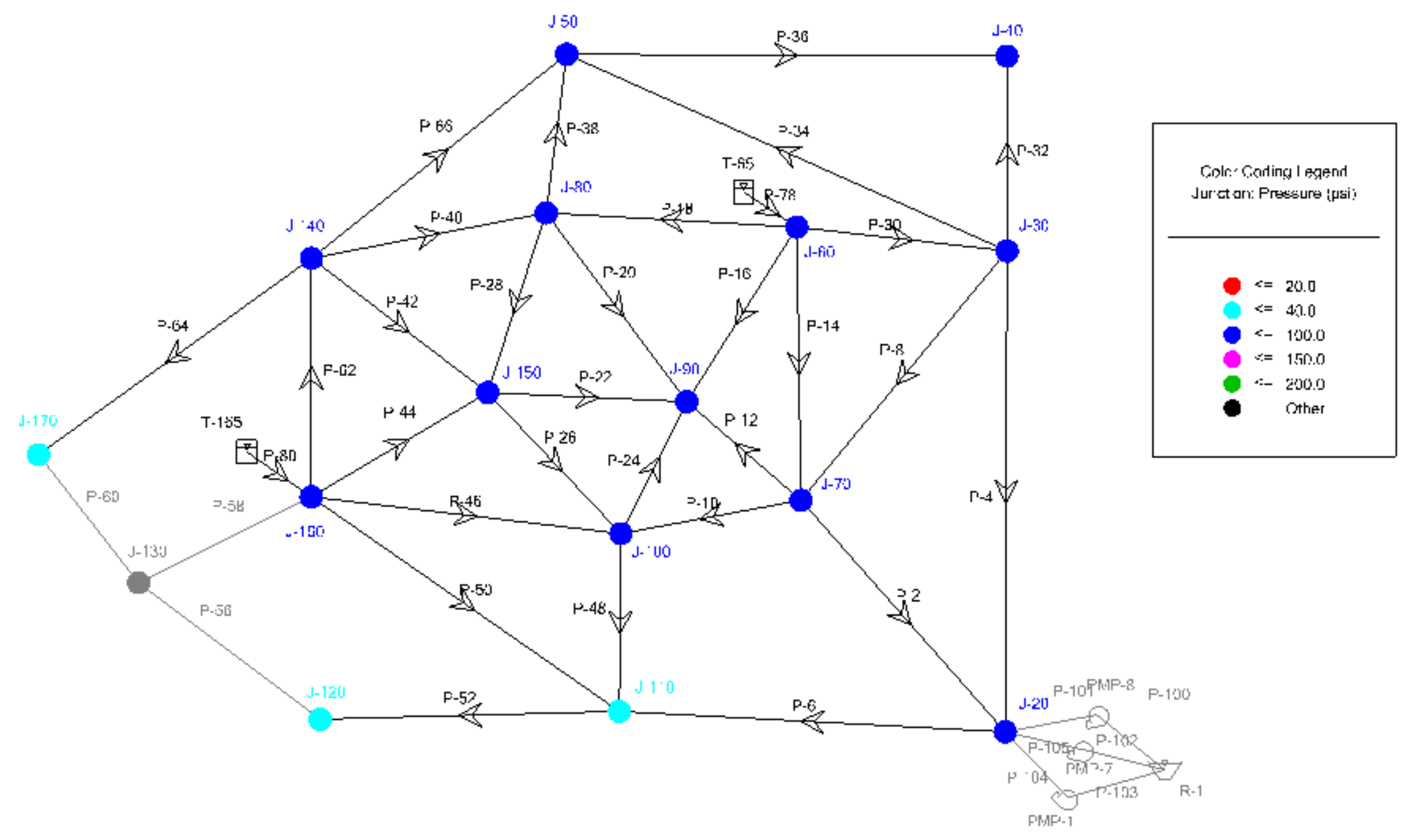




\section{Demand Supplied}

\begin{tabular}{|c|c|c|c|c|c|c|c|c|c|c|c|c|c|c|c|c|}
\hline $\begin{array}{c}\text { Time } \\
\text { (hours) }\end{array}$ & $J-20$ & J-30 & $\mathrm{J}-40$ & J-50 & $J-60$ & $\mathrm{~J}-70$ & $\mathrm{~J}-80$ & J-90 & $\mathrm{J}-100$ & $\mathrm{~J}-110$ & $\mathrm{~J}-120$ & $\mathrm{~J}-130$ & $\mathrm{~J}-140$ & $\mathrm{~J}-150$ & $\mathrm{~J}-160$ & J-170 \\
\hline 0 & 350 & 140 & 500 & 140 & 350 & 350 & 350 & 700 & 350 & 350 & 1140 & 0 & 140 & 140 & 560 & 140 \\
\hline 1 & 350 & 140 & 500 & 140 & 350 & 350 & 350 & 700 & 350 & 350 & 1140 & 0 & 140 & 140 & 560 & 140 \\
\hline 2 & 350 & 140 & 500 & 140 & 350 & 350 & 350 & 700 & 350 & 350 & 1140 & 0 & 140 & 140 & 560 & 140 \\
\hline 3 & 300 & 120 & 500 & 120 & 300 & 300 & 300 & 600 & 300 & 300 & 1120 & 0 & 120 & 120 & 480 & 120 \\
\hline 4 & 300 & 120 & 500 & 120 & 300 & 300 & 300 & 600 & 300 & 300 & 1120 & 0 & 120 & 120 & 480 & 120 \\
\hline 5 & 300 & 120 & 500 & 120 & 300 & 300 & 300 & 600 & 300 & 300 & 1120 & 0 & 120 & 120 & 480 & 120 \\
\hline 6 & 600 & 240 & 500 & 240 & 600 & 600 & 600 & 1200 & 600 & 600 & 1240 & 0 & 240 & 240 & 960 & 240 \\
\hline 7 & 600 & 240 & 500 & 240 & 600 & 600 & 600 & 1200 & 600 & 600 & 1240 & 0 & 240 & 240 & 960 & 240 \\
\hline 8 & 600 & 240 & 500 & 240 & 600 & 600 & 600 & 1200 & 600 & 600 & 1236 & 0 & 240 & 240 & 960 & 240 \\
\hline 9 & 650 & 260 & 500 & 260 & 650 & 650 & 650 & 1300 & 650 & 650 & 1233 & 0 & 260 & 260 & 1040 & 258 \\
\hline 10 & 650 & 260 & 500 & 260 & 650 & 650 & 650 & 1300 & 650 & 650 & 1222 & 0 & 260 & 260 & 1040 & 255 \\
\hline 11 & 650 & 260 & 500 & 260 & 650 & 650 & 650 & 1300 & 650 & 650 & 1210 & 0 & 260 & 260 & 1040 & 253 \\
\hline 12 & 600 & 240 & 500 & 240 & 600 & 600 & 600 & 1200 & 600 & 600 & 1190 & 0 & 240 & 240 & 960 & 235 \\
\hline 13 & 600 & 240 & 500 & 240 & 600 & 600 & 600 & 1200 & 600 & 600 & 1179 & 0 & 240 & 240 & 960 & 233 \\
\hline 14 & 600 & 240 & 500 & 240 & 600 & 600 & 600 & 1200 & 600 & 600 & 1168 & 0 & 240 & 240 & 960 & 231 \\
\hline 15 & 550 & 220 & 500 & 220 & 550 & 550 & 550 & 1100 & 550 & 550 & 1148 & 0 & 220 & 220 & 880 & 214 \\
\hline 16 & 550 & 220 & 500 & 220 & 550 & 550 & 550 & 1100 & 550 & 550 & 1138 & 0 & 220 & 220 & 880 & 212 \\
\hline 17 & 550 & 220 & 500 & 220 & 550 & 550 & 550 & 1100 & 550 & 550 & 1127 & 0 & 220 & 220 & 880 & 210 \\
\hline 18 & 500 & 200 & 500 & 200 & 500 & 500 & 500 & 1000 & 500 & 500 & 1108 & 0 & 200 & 200 & 800 & 192 \\
\hline 19 & 500 & 200 & 500 & 200 & 500 & 500 & 500 & 1000 & 500 & 500 & 1099 & 0 & 200 & 200 & 800 & 191 \\
\hline 20 & 497 & 200 & 500 & 200 & 500 & 500 & 500 & 1000 & 500 & 496 & 1089 & 0 & 200 & 200 & 800 & 189 \\
\hline 21 & 447 & 180 & 500 & 180 & 450 & 450 & 450 & 900 & 450 & 446 & 1071 & 0 & 180 & 180 & 720 & 171 \\
\hline 22 & 443 & 179 & 497 & 179 & 450 & 448 & 449 & 896 & 448 & 442 & 1062 & 0 & 180 & 180 & 720 & 170 \\
\hline 23 & 440 & 178 & 493 & 178 & 450 & 445 & 445 & 889 & 445 & 438 & 1054 & 0 & 178 & 178 & 720 & 169 \\
\hline 24 & 343 & 139 & 494 & 139 & 350 & 346 & 347 & 693 & 346 & 342 & 1026 & 0 & 139 & 139 & 560 & 134 \\
\hline Total & 12,320 & 4,936 & 12,484 & 4,936 & 12,350 & 12,339 & 12,341 & 24,678 & 12,339 & 12,314 & 28,620 & 0 & 4,937 & 4,937 & 19,760 & 4,817 \\
\hline
\end{tabular}




\section{'J-130 Out' Results}

\begin{tabular}{|c|c|c|c|c|c|c|}
\hline \multirow[b]{2}{*}{ Node } & \multicolumn{2}{|c|}{ Demand Supplied } & \multirow[b]{2}{*}{$\begin{array}{l}\text { Demand } \\
\text { Effected }\end{array}$} & \multicolumn{2}{|c|}{ Population Served } & \multirow[b]{2}{*}{$\begin{array}{c}\text { Population } \\
\text { Effected }\end{array}$} \\
\hline & $\begin{array}{c}\text { Normal } \\
\text { Conditions }\end{array}$ & $\begin{array}{l}\text { Failure } \\
\text { Scenario } \\
\text { J-130 Out }\end{array}$ & & $\begin{array}{c}\text { Normal } \\
\text { Conditions }\end{array}$ & $\begin{array}{c}\text { Failure } \\
\text { Scenario J- } \\
130 \text { Out }\end{array}$ & \\
\hline (1) & (2) & (3) & (4) & (5) & (6) & (7) \\
\hline$J-20$ & 12350 & 12320 & 30 & 3069 & 3062 & 7 \\
\hline$J-30$ & 4940 & 4936 & 4 & 1421 & 1420 & 1 \\
\hline$J-40$ & 4940 & 12484 & -7544 & 6100 & 15415 & -9315 \\
\hline$J-50$ & 4940 & 4936 & 4 & 5953 & 5949 & 5 \\
\hline$J-60$ & 12350 & 12350 & 0 & 2297 & 2297 & 0 \\
\hline $\mathrm{J}-70$ & 12350 & 12339 & 11 & 827 & 827 & 1 \\
\hline$J-80$ & 12350 & 12341 & 9 & 4189 & 4186 & 3 \\
\hline$J-90$ & 24700 & 24678 & 22 & 6082 & 6077 & 5 \\
\hline$J-100$ & 12350 & 12339 & 11 & 716 & 715 & 1 \\
\hline$J-110$ & 12350 & 12314 & 36 & 4642 & 4629 & 14 \\
\hline$J-120$ & 4940 & 28620 & -23680 & 4949 & 28673 & -23724 \\
\hline $\mathrm{J}-130$ & 4940 & 0 & 4940 & 5170 & 0 & 5170 \\
\hline J-140 & 4940 & 4937 & 3 & 5248 & 5245 & 3 \\
\hline$J-150$ & 4940 & 4937 & 3 & 4330 & 4328 & 3 \\
\hline $\mathrm{J}-160$ & 19760 & 19760 & 0 & 1487 & 1487 & 0 \\
\hline $\mathrm{J}-170$ & 4940 & 4817 & 123 & 1901 & 1854 & 47 \\
\hline
\end{tabular}




\section{Failure Scenario 'J-140 Out'}

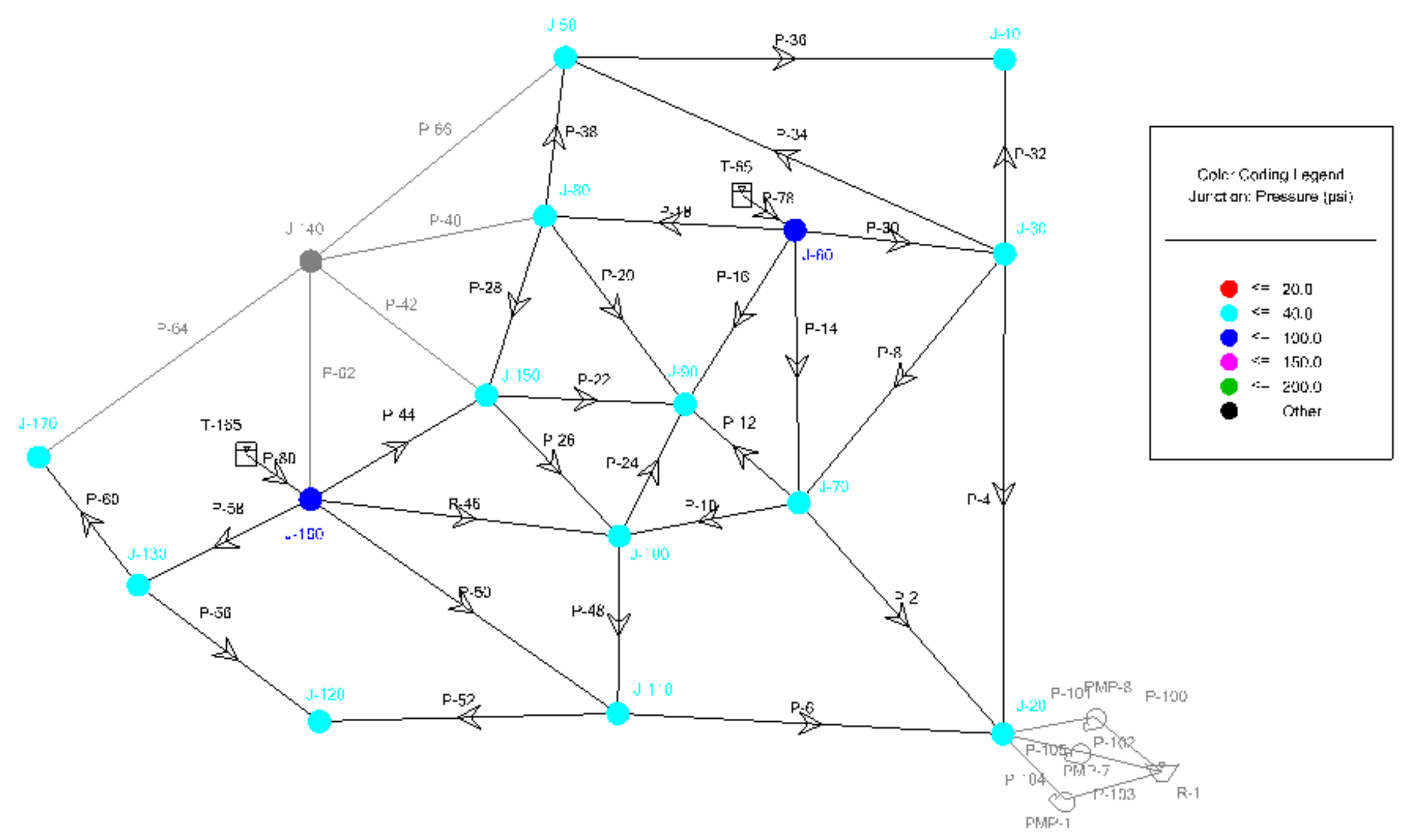




\section{Demand Supplied}

\begin{tabular}{|c|c|c|c|c|c|c|c|c|c|c|c|c|c|c|c|c|}
\hline $\begin{array}{c}\text { Time } \\
\text { (hours) }\end{array}$ & $\mathrm{J}-20$ & $\mathrm{~J}-30$ & $\mathrm{~J}-40$ & $J-50$ & $J-60$ & $\mathrm{~J}-70$ & $\mathrm{~J}-80$ & J-90 & $\mathrm{J}-100$ & $\mathrm{~J}-110$ & $\mathrm{~J}-120$ & $\mathrm{~J}-130$ & $\mathrm{~J}-140$ & $\mathrm{~J}-150$ & $\mathrm{~J}-160$ & $\mathrm{~J}-170$ \\
\hline 0 & 350 & 140 & 500 & 140 & 350 & 350 & 350 & 700 & 350 & 350 & 1140 & 500 & 0 & 140 & 560 & 140 \\
\hline 1 & 350 & 140 & 500 & 140 & 350 & 350 & 350 & 700 & 350 & 350 & 1140 & 500 & 0 & 140 & 560 & 140 \\
\hline 2 & 350 & 140 & 500 & 140 & 350 & 350 & 350 & 700 & 350 & 350 & 1140 & 500 & 0 & 140 & 560 & 140 \\
\hline 3 & 300 & 120 & 500 & 120 & 300 & 300 & 300 & 600 & 300 & 300 & 1120 & 500 & 0 & 120 & 480 & 120 \\
\hline 4 & 300 & 120 & 500 & 120 & 300 & 300 & 300 & 600 & 300 & 300 & 1120 & 500 & 0 & 120 & 480 & 120 \\
\hline 5 & 300 & 120 & 500 & 120 & 300 & 300 & 300 & 600 & 300 & 300 & 1120 & 500 & 0 & 120 & 480 & 120 \\
\hline 6 & 600 & 240 & 500 & 240 & 600 & 600 & 600 & 1200 & 600 & 600 & 1240 & 500 & 0 & 240 & 960 & 240 \\
\hline 7 & 600 & 240 & 500 & 240 & 600 & 600 & 600 & 1200 & 600 & 600 & 1240 & 500 & 0 & 240 & 960 & 240 \\
\hline 8 & 600 & 240 & 500 & 240 & 600 & 600 & 600 & 1200 & 600 & 600 & 1240 & 500 & 0 & 240 & 960 & 240 \\
\hline 9 & 650 & 260 & 500 & 260 & 650 & 650 & 650 & 1300 & 650 & 650 & 1260 & 500 & 0 & 260 & 1040 & 260 \\
\hline 10 & 650 & 260 & 500 & 260 & 650 & 650 & 650 & 1300 & 650 & 650 & 1260 & 500 & 0 & 260 & 1040 & 260 \\
\hline 11 & 650 & 260 & 500 & 260 & 650 & 650 & 650 & 1300 & 650 & 650 & 1260 & 500 & 0 & 260 & 1040 & 260 \\
\hline 12 & 600 & 240 & 500 & 240 & 600 & 600 & 600 & 1200 & 600 & 600 & 1240 & 500 & 0 & 240 & 960 & 240 \\
\hline 13 & 600 & 240 & 500 & 240 & 600 & 600 & 600 & 1200 & 600 & 600 & 1240 & 500 & 0 & 240 & 960 & 240 \\
\hline 14 & 600 & 240 & 500 & 240 & 600 & 600 & 600 & 1200 & 600 & 600 & 1240 & 500 & 0 & 240 & 960 & 240 \\
\hline 15 & 550 & 220 & 500 & 220 & 550 & 550 & 550 & 1100 & 550 & 550 & 1220 & 500 & 0 & 220 & 880 & 220 \\
\hline 16 & 550 & 220 & 500 & 220 & 550 & 550 & 550 & 1100 & 550 & 550 & 1212 & 500 & 0 & 220 & 880 & 220 \\
\hline 17 & 550 & 220 & 500 & 220 & 550 & 550 & 550 & 1100 & 550 & 550 & 1200 & 500 & 0 & 220 & 880 & 220 \\
\hline 18 & 500 & 200 & 500 & 200 & 500 & 500 & 500 & 1000 & 500 & 500 & 1176 & 500 & 0 & 200 & 800 & 199 \\
\hline 19 & 500 & 200 & 500 & 200 & 500 & 500 & 500 & 1000 & 500 & 500 & 1165 & 496 & 0 & 200 & 800 & 198 \\
\hline 20 & 495 & 200 & 500 & 200 & 500 & 500 & 500 & 997 & 499 & 496 & 1154 & 491 & 0 & 200 & 800 & 196 \\
\hline 21 & 444 & 180 & 498 & 179 & 450 & 449 & 449 & 895 & 447 & 445 & 1131 & 489 & 0 & 179 & 720 & 176 \\
\hline 22 & 441 & 178 & 493 & 178 & 450 & 445 & 445 & 887 & 444 & 441 & 1121 & 485 & 0 & 178 & 720 & 174 \\
\hline 23 & 437 & 176 & 489 & 176 & 450 & 441 & 441 & 880 & 440 & 437 & 1112 & 481 & 0 & 176 & 714 & 173 \\
\hline 24 & 341 & 137 & 489 & 137 & 348 & 343 & 344 & 685 & 343 & 341 & 1076 & 480 & 0 & 137 & 553 & 134 \\
\hline Total & 12,308 & 4,931 & 12,469 & 4,930 & 12,348 & 12,328 & 12,329 & 24,644 & 12,323 & 12,310 & 29,567 & 12,422 & 0 & 4,930 & 19,747 & 4,910 \\
\hline
\end{tabular}


'J-140 Out' Results

\begin{tabular}{|c|c|c|c|c|c|c|}
\hline \multirow[b]{2}{*}{ Node } & \multicolumn{2}{|c|}{ Demand Supplied } & \multirow[b]{2}{*}{$\begin{array}{l}\text { Demand } \\
\text { Effected }\end{array}$} & \multicolumn{2}{|c|}{ Population Served } & \multirow[b]{2}{*}{$\begin{array}{c}\text { Population } \\
\text { Effected }\end{array}$} \\
\hline & $\begin{array}{c}\text { Normal } \\
\text { Conditions }\end{array}$ & $\begin{array}{c}\text { Failure } \\
\text { Scenario } \\
\text { J-140 Out }\end{array}$ & & $\begin{array}{c}\text { Normal } \\
\text { Conditions }\end{array}$ & $\begin{array}{c}\text { Failure } \\
\text { Scenario } \\
\text { J-140 Out }\end{array}$ & \\
\hline$(1)$ & (2) & (3) & (4) & $(5)$ & (6) & (7) \\
\hline $\mathrm{J}-20$ & 12350 & 12308 & 42 & 3069 & 3059 & 10 \\
\hline $\mathrm{J}-30$ & 4940 & 4931 & 9 & 1421 & 1419 & 3 \\
\hline $\mathrm{J}-40$ & 4940 & 12469 & -7529 & 6100 & 15396 & -9297 \\
\hline$J-50$ & 4940 & 4930 & 10 & 5953 & 5941 & 12 \\
\hline $\mathrm{J}-60$ & 12350 & 12348 & 2 & 2297 & 2296 & 0 \\
\hline $\mathrm{J}-70$ & 12350 & 12328 & 22 & 827 & 826 & 1 \\
\hline $\mathrm{J}-80$ & 12350 & 12329 & 21 & 4189 & 4181 & 7 \\
\hline $\mathrm{J}-90$ & 24700 & 24644 & 56 & 6082 & 6068 & 14 \\
\hline$J-100$ & 12350 & 12323 & 27 & 716 & 715 & 2 \\
\hline$J-110$ & 12350 & 12310 & 40 & 4642 & 4627 & 15 \\
\hline$J-120$ & 4940 & 29567 & -24627 & 4949 & 29622 & -24673 \\
\hline$J-130$ & 4940 & 12422 & -7482 & 5170 & 13000 & -7830 \\
\hline $\mathrm{J}-140$ & 4940 & 0 & 4940 & 5248 & 0 & 5248 \\
\hline $\mathrm{J}-150$ & 4940 & 4930 & 10 & 4330 & 4322 & 9 \\
\hline $\mathrm{J}-160$ & 19760 & 19747 & 13 & 1487 & 1486 & 1 \\
\hline $\mathrm{J}-170$ & 4940 & 4910 & 30 & 1901 & 1890 & 12 \\
\hline
\end{tabular}




\section{Failure Scenario 'J-150 Out'}

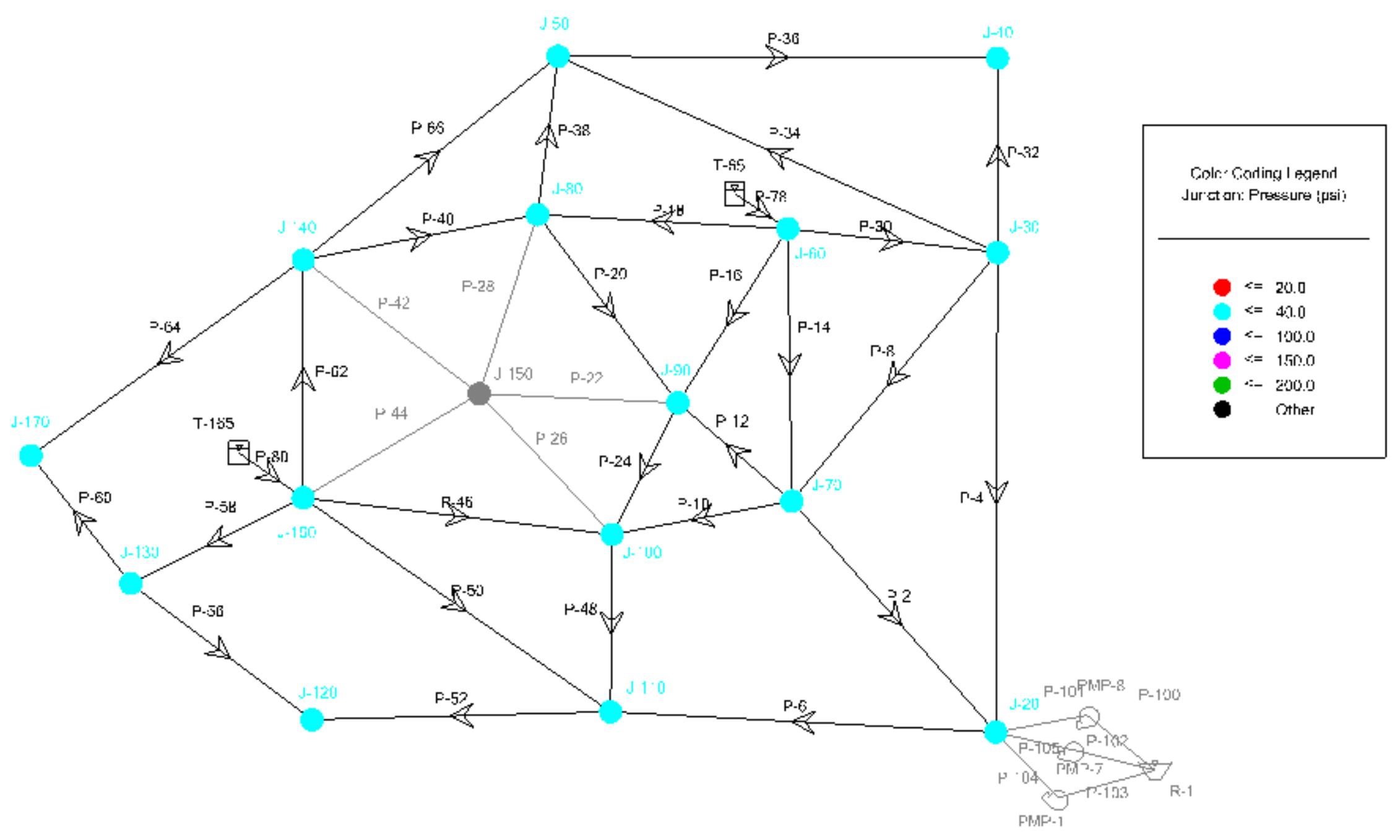




\section{Demand Supplied}

\begin{tabular}{|c|c|c|c|c|c|c|c|c|c|c|c|c|c|c|c|c|}
\hline $\begin{array}{c}\text { Time } \\
\text { (hours) }\end{array}$ & $\mathrm{J}-20$ & $\mathrm{~J}-30$ & $J-40$ & $J-50$ & $J-60$ & $\mathrm{~J}-70$ & $\mathrm{~J}-80$ & J-90 & $\mathrm{J}-100$ & $\mathrm{~J}-110$ & $\mathrm{~J}-120$ & $\mathrm{~J}-130$ & $\mathrm{~J}-140$ & $\mathrm{~J}-150$ & $\mathrm{~J}-160$ & $\mathrm{~J}-170$ \\
\hline 0 & 350 & 140 & 500 & 140 & 350 & 350 & 350 & 700 & 350 & 350 & 1140 & 500 & 140 & 0 & 560 & 140 \\
\hline 1 & 350 & 140 & 500 & 140 & 350 & 350 & 350 & 700 & 350 & 350 & 1140 & 500 & 140 & 0 & 560 & 140 \\
\hline 2 & 350 & 140 & 500 & 140 & 350 & 350 & 350 & 700 & 350 & 350 & 1140 & 500 & 140 & 0 & 560 & 140 \\
\hline 3 & 300 & 120 & 500 & 120 & 300 & 300 & 300 & 600 & 300 & 300 & 1120 & 500 & 120 & 0 & 480 & 120 \\
\hline 4 & 300 & 120 & 500 & 120 & 300 & 300 & 300 & 600 & 300 & 300 & 1120 & 500 & 120 & 0 & 480 & 120 \\
\hline 5 & 300 & 120 & 500 & 120 & 300 & 300 & 300 & 600 & 300 & 300 & 1120 & 500 & 120 & 0 & 480 & 120 \\
\hline 6 & 600 & 240 & 500 & 240 & 600 & 600 & 600 & 1200 & 600 & 600 & 1240 & 500 & 240 & 0 & 960 & 240 \\
\hline 7 & 600 & 240 & 500 & 240 & 600 & 600 & 600 & 1200 & 600 & 600 & 1240 & 500 & 240 & 0 & 960 & 240 \\
\hline 8 & 600 & 240 & 500 & 240 & 600 & 600 & 600 & 1200 & 600 & 600 & 1240 & 500 & 240 & 0 & 960 & 240 \\
\hline 9 & 650 & 260 & 500 & 260 & 650 & 650 & 650 & 1300 & 650 & 650 & 1260 & 500 & 260 & 0 & 1040 & 260 \\
\hline 10 & 650 & 260 & 500 & 260 & 650 & 650 & 650 & 1300 & 650 & 650 & 1260 & 500 & 260 & 0 & 1040 & 260 \\
\hline 11 & 650 & 260 & 500 & 260 & 650 & 650 & 650 & 1300 & 650 & 650 & 1260 & 500 & 260 & 0 & 1040 & 260 \\
\hline 12 & 600 & 240 & 500 & 240 & 600 & 600 & 600 & 1200 & 600 & 600 & 1240 & 500 & 240 & 0 & 960 & 240 \\
\hline 13 & 600 & 240 & 500 & 240 & 600 & 600 & 600 & 1200 & 600 & 600 & 1240 & 500 & 240 & 0 & 960 & 240 \\
\hline 14 & 600 & 240 & 500 & 240 & 600 & 600 & 600 & 1200 & 600 & 600 & 1240 & 500 & 240 & 0 & 960 & 240 \\
\hline 15 & 550 & 220 & 500 & 220 & 550 & 550 & 550 & 1100 & 550 & 550 & 1220 & 500 & 220 & 0 & 880 & 220 \\
\hline 16 & 550 & 220 & 500 & 220 & 550 & 550 & 550 & 1100 & 550 & 550 & 1214 & 500 & 220 & 0 & 880 & 220 \\
\hline 17 & 550 & 220 & 500 & 220 & 550 & 550 & 550 & 1100 & 550 & 550 & 1202 & 500 & 220 & 0 & 880 & 220 \\
\hline 18 & 500 & 200 & 500 & 200 & 500 & 500 & 500 & 1000 & 500 & 500 & 1178 & 500 & 200 & 0 & 800 & 200 \\
\hline 19 & 500 & 200 & 500 & 200 & 500 & 500 & 500 & 1000 & 500 & 500 & 1167 & 498 & 200 & 0 & 800 & 199 \\
\hline 20 & 495 & 200 & 500 & 200 & 500 & 499 & 500 & 997 & 499 & 496 & 1157 & 493 & 200 & 0 & 800 & 197 \\
\hline 21 & 444 & 180 & 498 & 179 & 450 & 448 & 449 & 895 & 447 & 445 & 1133 & 491 & 180 & 0 & 720 & 177 \\
\hline 22 & 441 & 178 & 493 & 178 & 450 & 444 & 445 & 887 & 444 & 441 & 1124 & 487 & 178 & 0 & 720 & 175 \\
\hline 23 & 437 & 176 & 489 & 176 & 449 & 440 & 442 & 880 & 440 & 437 & 1114 & 483 & 177 & 0 & 715 & 174 \\
\hline 24 & 341 & 137 & 489 & 137 & 348 & 343 & 343 & 685 & 343 & 341 & 1078 & 482 & 137 & 0 & 553 & 135 \\
\hline Total & 12,308 & 4,931 & 12,469 & 4,930 & 12,347 & 12,324 & 12,329 & 24,644 & 12,323 & 12,310 & 29,587 & 12,434 & 4,932 & 0 & 19,748 & 4,917 \\
\hline
\end{tabular}




\begin{tabular}{|c|c|c|c|c|c|c|}
\hline \multirow[b]{2}{*}{ Node } & \multicolumn{2}{|c|}{ Demand Supplied } & \multirow[b]{2}{*}{$\begin{array}{l}\text { Demand } \\
\text { Effected }\end{array}$} & \multicolumn{2}{|c|}{ Population Served } & \multirow[b]{2}{*}{$\begin{array}{c}\text { Population } \\
\text { Effected }\end{array}$} \\
\hline & $\begin{array}{c}\text { Normal } \\
\text { Conditions }\end{array}$ & $\begin{array}{l}\text { Failure } \\
\text { Scenario } \\
\text { J-150 Out }\end{array}$ & & $\begin{array}{c}\text { Normal } \\
\text { Conditions }\end{array}$ & $\begin{array}{l}\text { Failure } \\
\text { Scenario } \\
\text { J-150 Out }\end{array}$ & \\
\hline (1) & (2) & (3) & (4) & (5) & (6) & (7) \\
\hline $\mathrm{J}-20$ & 12350 & 12308 & 42 & 3069 & 3059 & 10 \\
\hline$J-30$ & 4940 & 4931 & 9 & 1421 & 1419 & 3 \\
\hline $\mathrm{J}-40$ & 4940 & 12469 & -7529 & 6100 & 15396 & -9297 \\
\hline$J-50$ & 4940 & 4930 & 10 & 5953 & 5941 & 12 \\
\hline J-60 & 12350 & 12347 & 3 & 2297 & 2296 & 1 \\
\hline J-70 & 12350 & 12324 & 26 & 827 & 826 & 2 \\
\hline$J-80$ & 12350 & 12329 & 21 & 4189 & 4181 & 7 \\
\hline J-90 & 24700 & 24644 & 56 & 6082 & 6068 & 14 \\
\hline $\mathrm{J}-100$ & 12350 & 12323 & 27 & 716 & 715 & 2 \\
\hline $\mathrm{J}-110$ & 12350 & 12310 & 40 & 4642 & 4627 & 15 \\
\hline $\mathrm{J}-120$ & 4940 & 29587 & -24647 & 4949 & 29642 & -24693 \\
\hline $\mathrm{J}-130$ & 4940 & 12434 & -7494 & 5170 & 13012 & -7842 \\
\hline $\mathrm{J}-140$ & 4940 & 4932 & 8 & 5248 & 5240 & 8 \\
\hline $\mathrm{J}-150$ & 4940 & 0 & 4940 & 4330 & 0 & 4330 \\
\hline$J-160$ & 19760 & 19748 & 12 & 1487 & 1486 & 1 \\
\hline $\mathrm{J}-170$ & 4940 & 4917 & 23 & 1901 & 1893 & 9 \\
\hline
\end{tabular}




\section{Failure Scenario 'J-160 Out'}

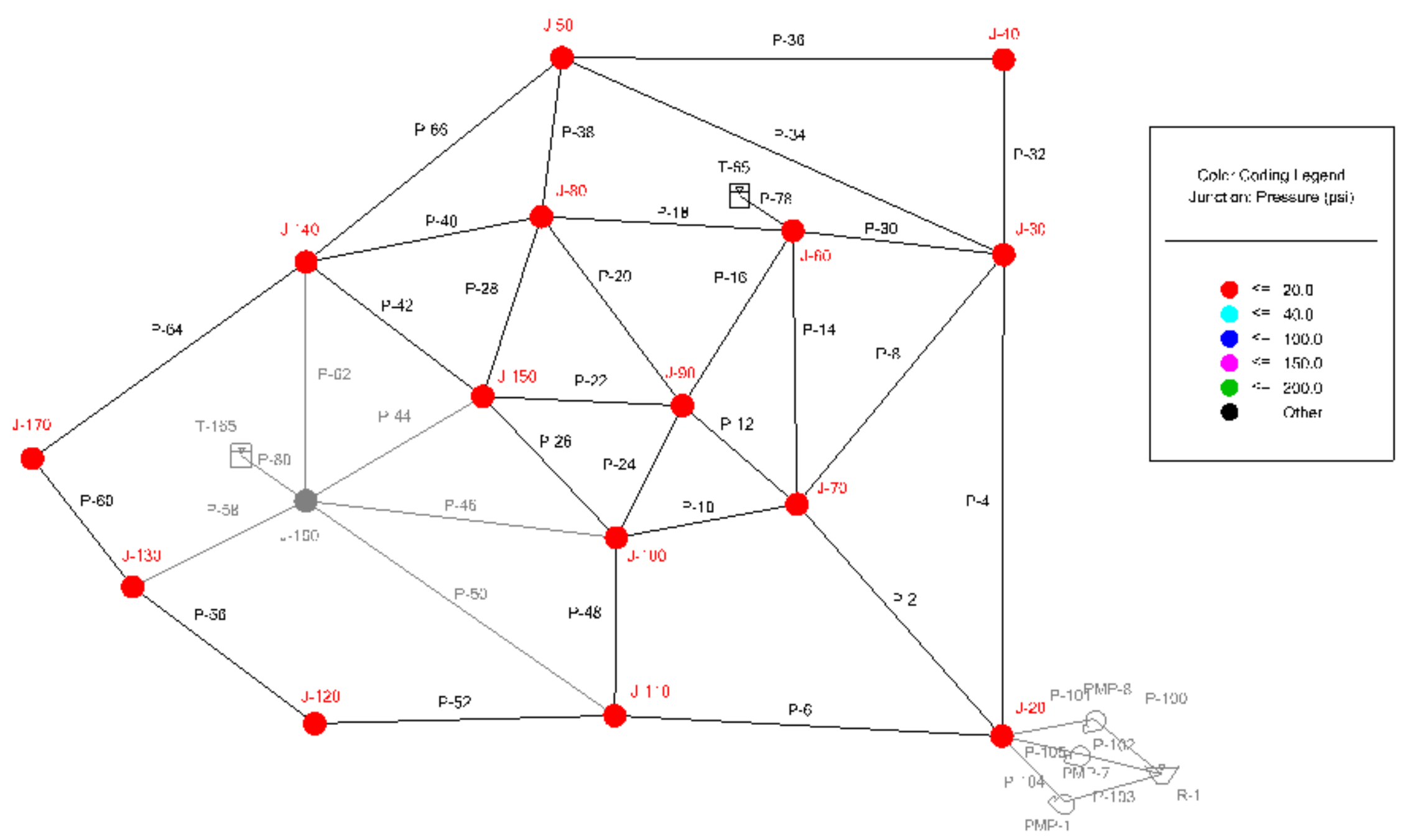




\section{Demand Supplied}

\begin{tabular}{|c|c|c|c|c|c|c|c|c|c|c|c|c|c|c|c|c|}
\hline $\begin{array}{c}\text { Time } \\
\text { (hours) }\end{array}$ & $\mathrm{J}-20$ & J-30 & $\mathrm{J}-40$ & $J-50$ & J-60 & $\mathrm{J}-70$ & $\mathrm{~J}-80$ & J-90 & $\mathrm{J}-100$ & $\mathrm{~J}-110$ & $\mathrm{~J}-120$ & $\mathrm{~J}-130$ & $\mathrm{~J}-140$ & $\mathrm{~J}-150$ & $\mathrm{~J}-160$ & $\mathrm{~J}-170$ \\
\hline 0 & 350 & 140 & 500 & 140 & 350 & 350 & 350 & 700 & 350 & 338 & 990 & 433 & 140 & 140 & 0 & 122 \\
\hline 1 & 350 & 140 & 500 & 140 & 350 & 350 & 350 & 700 & 350 & 334 & 980 & 429 & 140 & 140 & 0 & 121 \\
\hline 2 & 350 & 140 & 500 & 140 & 350 & 350 & 350 & 700 & 350 & 331 & 970 & 424 & 140 & 140 & 0 & 120 \\
\hline 3 & 300 & 120 & 500 & 120 & 300 & 300 & 300 & 600 & 300 & 287 & 968 & 431 & 120 & 120 & 0 & 104 \\
\hline 4 & 300 & 120 & 500 & 120 & 300 & 300 & 300 & 600 & 300 & 284 & 959 & 427 & 120 & 120 & 0 & 103 \\
\hline 5 & 300 & 120 & 500 & 120 & 300 & 300 & 300 & 600 & 300 & 282 & 949 & 423 & 120 & 120 & 0 & 102 \\
\hline 6 & 575 & 240 & 500 & 240 & 600 & 600 & 600 & 1200 & 594 & 476 & 870 & 350 & 239 & 239 & 0 & 169 \\
\hline 7 & 566 & 240 & 497 & 239 & 600 & 593 & 596 & 1182 & 585 & 468 & 856 & 344 & 236 & 236 & 0 & 167 \\
\hline 8 & 558 & 237 & 490 & 235 & 600 & 584 & 587 & 1164 & 576 & 461 & 843 & 339 & 232 & 232 & 0 & 164 \\
\hline 9 & 585 & 249 & 476 & 248 & 650 & 615 & 619 & 1225 & 606 & 478 & 817 & 323 & 244 & 244 & 0 & 170 \\
\hline 10 & 575 & 245 & 469 & 244 & 650 & 605 & 609 & 1205 & 596 & 471 & 804 & 318 & 241 & 240 & 0 & 167 \\
\hline 11 & 566 & 241 & 461 & 240 & 650 & 595 & 599 & 1186 & 586 & 463 & 790 & 313 & 237 & 236 & 0 & 164 \\
\hline 12 & 523 & 222 & 459 & 221 & 595 & 548 & 551 & 1092 & 541 & 432 & 789 & 317 & 218 & 218 & 0 & 154 \\
\hline 13 & 515 & 218 & 452 & 217 & 585 & 539 & 542 & 1075 & 532 & 425 & 776 & 312 & 215 & 214 & 0 & 151 \\
\hline 14 & 507 & 215 & 445 & 214 & 576 & 531 & 533 & 1058 & 523 & 418 & 763 & 307 & 211 & 211 & 0 & 149 \\
\hline 15 & 465 & 196 & 443 & 195 & 522 & 485 & 487 & 967 & 479 & 387 & 761 & 311 & 193 & 193 & 0 & 138 \\
\hline 16 & 458 & 193 & 436 & 192 & 514 & 478 & 480 & 952 & 471 & 381 & 749 & 306 & 190 & 190 & 0 & 136 \\
\hline 17 & 450 & 190 & 429 & 189 & 506 & 470 & 472 & 937 & 464 & 375 & 736 & 301 & 187 & 187 & 0 & 134 \\
\hline 18 & 0 & 0 & 0 & 0 & 0 & 0 & 0 & 0 & 0 & 0 & 0 & 0 & 0 & 0 & 0 & 0 \\
\hline 19 & 0 & 0 & 0 & 0 & 0 & 0 & 0 & 0 & 0 & 0 & 0 & 0 & 0 & 0 & 0 & 0 \\
\hline 20 & 0 & 0 & 0 & 0 & 0 & 0 & 0 & 0 & 0 & 0 & 0 & 0 & 0 & 0 & 0 & 0 \\
\hline 21 & 0 & 0 & 0 & 0 & 0 & 0 & 0 & 0 & 0 & 0 & 0 & 0 & 0 & 0 & 0 & 0 \\
\hline 22 & 0 & 0 & 0 & 0 & 0 & 0 & 0 & 0 & 0 & 0 & 0 & 0 & 0 & 0 & 0 & 0 \\
\hline 23 & 0 & 0 & 0 & 0 & 0 & 0 & 0 & 0 & 0 & 0 & 0 & 0 & 0 & 0 & 0 & 0 \\
\hline 24 & 0 & 0 & 0 & 0 & 0 & 0 & 0 & 0 & 0 & 0 & 0 & 0 & 0 & 0 & 0 & 0 \\
\hline Total & 8,293 & 3,466 & 8,557 & 3,454 & 8,998 & 8,593 & 8,625 & 17,143 & 8,503 & 7,091 & 15,370 & 6,408 & 3,423 & 3,420 & 0 & 2,535 \\
\hline
\end{tabular}


'J-160 Out' Results

\begin{tabular}{|c|c|c|c|c|c|c|}
\hline \multirow[b]{2}{*}{ Node } & \multicolumn{2}{|c|}{ Demand Supplied } & \multirow[b]{2}{*}{$\begin{array}{l}\text { Demand } \\
\text { Effected }\end{array}$} & \multicolumn{2}{|c|}{ Population Served } & \multirow[b]{2}{*}{$\begin{array}{l}\text { Population } \\
\text { Effected }\end{array}$} \\
\hline & $\begin{array}{c}\text { Normal } \\
\text { Conditions }\end{array}$ & $\begin{array}{c}\text { Failure } \\
\text { Scenario } \\
\text { J-160 Out }\end{array}$ & & $\begin{array}{c}\text { Normal } \\
\text { Conditions }\end{array}$ & $\begin{array}{l}\text { Failure } \\
\text { Scenario } \\
\text { J-160 Out }\end{array}$ & \\
\hline (1) & (2) & (3) & (4) & (5) & (6) & $(7)$ \\
\hline $\mathrm{J}-20$ & 12350 & 8293 & 4057 & 3069 & 2061 & 1008 \\
\hline$J-30$ & 4940 & 3466 & 1474 & 1421 & 997 & 424 \\
\hline $\mathrm{J}-40$ & 4940 & 8557 & -3617 & 6100 & 10566 & -4466 \\
\hline$J-50$ & 4940 & 3454 & 1486 & 5953 & 4163 & 1791 \\
\hline$J-60$ & 12350 & 8998 & 3352 & 2297 & 1673 & 623 \\
\hline $\mathrm{J}-70$ & 12350 & 8593 & 3757 & 827 & 576 & 252 \\
\hline $\mathrm{J}-80$ & 12350 & 8625 & 3725 & 4189 & 2925 & 1263 \\
\hline $\mathrm{J}-90$ & 24700 & 17143 & 7557 & 6082 & 4221 & 1861 \\
\hline $\mathrm{J}-100$ & 12350 & 8503 & 3847 & 716 & 493 & 223 \\
\hline $\mathrm{J}-110$ & 12350 & 7091 & 5259 & 4642 & 2665 & 1977 \\
\hline $\mathrm{J}-120$ & 4940 & 15370 & -10430 & 4949 & 15399 & -10449 \\
\hline $\mathrm{J}-130$ & 4940 & 6408 & -1468 & 5170 & 6706 & -1536 \\
\hline $\mathrm{J}-140$ & 4940 & 3423 & 1517 & 5248 & 3637 & 1612 \\
\hline $\mathrm{J}-150$ & 4940 & 3420 & 1520 & 4330 & 2998 & 1332 \\
\hline $\mathrm{J}-160$ & 19760 & 0 & 19760 & 1487 & 0 & 1487 \\
\hline $\mathrm{J}-170$ & 4940 & 2535 & 2405 & 1901 & 976 & 926 \\
\hline
\end{tabular}




\section{Failure Scenario 'J-170 Out'}

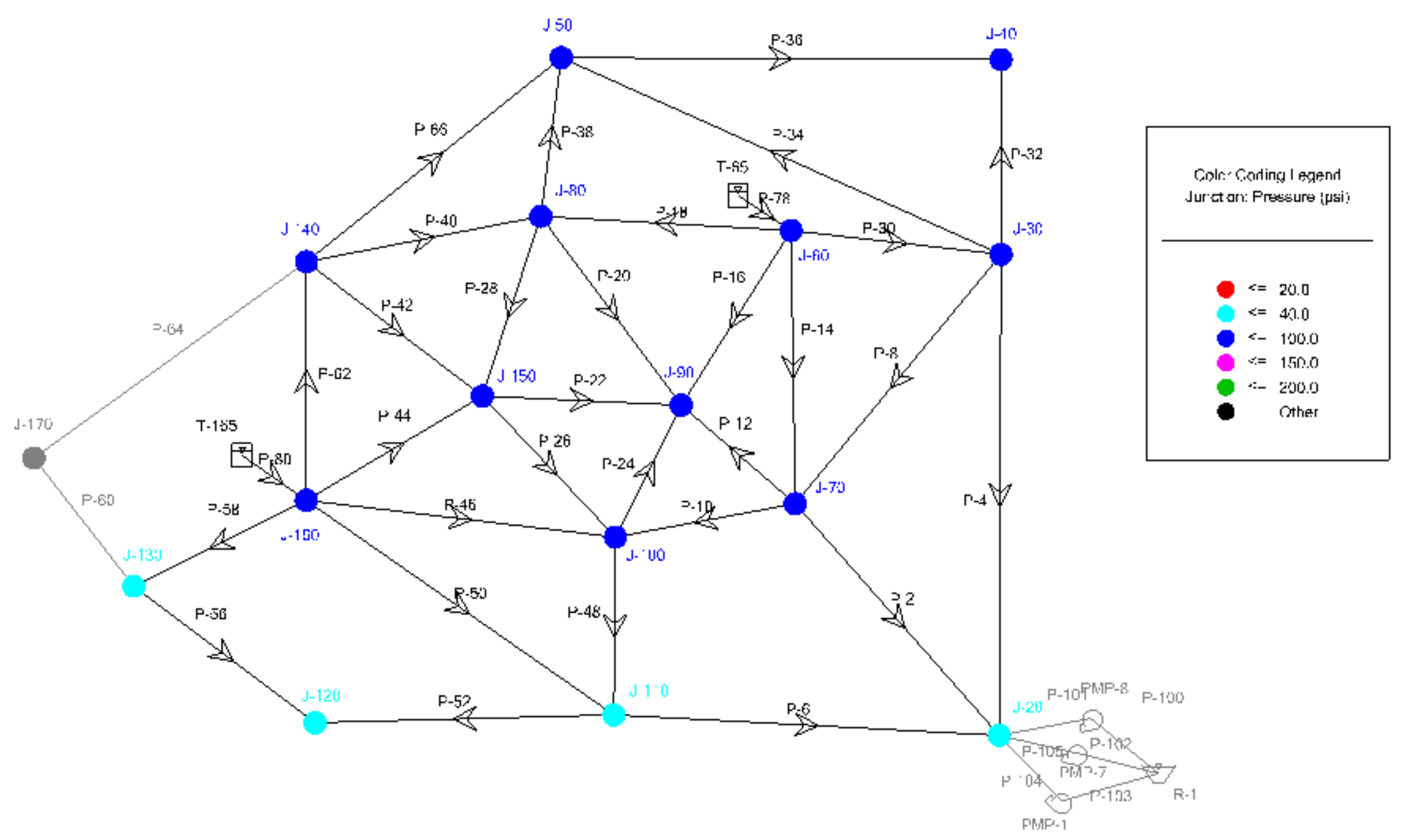




\section{Demand Supplied}

\begin{tabular}{|c|c|c|c|c|c|c|c|c|c|c|c|c|c|c|c|c|}
\hline $\begin{array}{c}\text { Time } \\
\text { (hours) }\end{array}$ & $\mathrm{J}-20$ & $J-30$ & $J-40$ & $J-50$ & $J-60$ & $\mathrm{~J}-70$ & $J-80$ & J-90 & $\mathrm{J}-100$ & $\mathrm{~J}-110$ & $\mathrm{~J}-120$ & J-130 & $\mathrm{J}-140$ & $\mathrm{~J}-150$ & $\mathrm{~J}-160$ & $\mathrm{~J}-170$ \\
\hline 0 & 350 & 140 & 500 & 140 & 350 & 350 & 350 & 700 & 350 & 350 & 1140 & 500 & 140 & 140 & 560 & 0 \\
\hline 1 & 350 & 140 & 500 & 140 & 350 & 350 & 350 & 700 & 350 & 350 & 1140 & 500 & 140 & 140 & 560 & 0 \\
\hline 2 & 350 & 140 & 500 & 140 & 350 & 350 & 350 & 700 & 350 & 350 & 1140 & 500 & 140 & 140 & 560 & 0 \\
\hline 3 & 300 & 120 & 500 & 120 & 300 & 300 & 300 & 600 & 300 & 300 & 1120 & 500 & 120 & 120 & 480 & 0 \\
\hline 4 & 300 & 120 & 500 & 120 & 300 & 300 & 300 & 600 & 300 & 300 & 1120 & 500 & 120 & 120 & 480 & 0 \\
\hline 5 & 300 & 120 & 500 & 120 & 300 & 300 & 300 & 600 & 300 & 300 & 1120 & 500 & 120 & 120 & 480 & 0 \\
\hline 6 & 600 & 240 & 500 & 240 & 600 & 600 & 600 & 1200 & 600 & 600 & 1240 & 500 & 240 & 240 & 960 & 0 \\
\hline 7 & 600 & 240 & 500 & 240 & 600 & 600 & 600 & 1200 & 600 & 600 & 1240 & 500 & 240 & 240 & 960 & 0 \\
\hline 8 & 600 & 240 & 500 & 240 & 600 & 600 & 600 & 1200 & 600 & 600 & 1240 & 500 & 240 & 240 & 960 & 0 \\
\hline 9 & 650 & 260 & 500 & 260 & 650 & 650 & 650 & 1300 & 650 & 650 & 1260 & 500 & 260 & 260 & 1040 & 0 \\
\hline 10 & 650 & 260 & 500 & 260 & 650 & 650 & 650 & 1300 & 650 & 650 & 1260 & 500 & 260 & 260 & 1040 & 0 \\
\hline 11 & 650 & 260 & 500 & 260 & 650 & 650 & 650 & 1300 & 650 & 650 & 1260 & 500 & 260 & 260 & 1040 & 0 \\
\hline 12 & 600 & 240 & 500 & 240 & 600 & 600 & 600 & 1200 & 600 & 600 & 1240 & 500 & 240 & 240 & 960 & 0 \\
\hline 13 & 600 & 240 & 500 & 240 & 600 & 600 & 600 & 1200 & 600 & 600 & 1240 & 500 & 240 & 240 & 960 & 0 \\
\hline 14 & 600 & 240 & 500 & 240 & 600 & 600 & 600 & 1200 & 600 & 600 & 1240 & 500 & 240 & 240 & 960 & 0 \\
\hline 15 & 550 & 220 & 500 & 220 & 550 & 550 & 550 & 1100 & 550 & 550 & 1220 & 500 & 220 & 220 & 880 & 0 \\
\hline 16 & 550 & 220 & 500 & 220 & 550 & 550 & 550 & 1100 & 550 & 550 & 1216 & 500 & 220 & 220 & 880 & 0 \\
\hline 17 & 550 & 220 & 500 & 220 & 550 & 550 & 550 & 1100 & 550 & 550 & 1204 & 500 & 220 & 220 & 880 & 0 \\
\hline 18 & 500 & 200 & 500 & 200 & 500 & 500 & 500 & 1000 & 500 & 500 & 1179 & 500 & 200 & 200 & 800 & 0 \\
\hline 19 & 500 & 200 & 500 & 200 & 500 & 500 & 500 & 1000 & 500 & 500 & 1169 & 499 & 200 & 200 & 800 & 0 \\
\hline 20 & 496 & 200 & 500 & 200 & 500 & 500 & 500 & 1000 & 500 & 496 & 1158 & 494 & 200 & 200 & 800 & 0 \\
\hline 21 & 445 & 180 & 498 & 180 & 450 & 449 & 450 & 898 & 449 & 445 & 1134 & 491 & 180 & 180 & 720 & 0 \\
\hline 22 & 441 & 178 & 494 & 178 & 450 & 445 & 446 & 890 & 445 & 441 & 1124 & 487 & 178 & 178 & 719 & 0 \\
\hline 23 & 438 & 177 & 490 & 177 & 450 & 442 & 442 & 883 & 441 & 438 & 1115 & 483 & 177 & 177 & 713 & 0 \\
\hline 24 & 341 & 137 & 490 & 137 & 349 & 344 & 344 & 687 & 343 & 341 & 1078 & 482 & 138 & 137 & 552 & 0 \\
\hline Total & 12,311 & 4,932 & 12,472 & 4,932 & 12,349 & 12,330 & 12,332 & 24,658 & 12,328 & 12,311 & 29,597 & 12,436 & 4,933 & 4,932 & 19,744 & 0 \\
\hline
\end{tabular}


'J-170 Out' Results

\begin{tabular}{|c|c|c|c|c|c|c|}
\hline \multirow[b]{2}{*}{ Node } & \multicolumn{2}{|c|}{ Demand Supplied } & \multirow[b]{2}{*}{$\begin{array}{l}\text { Demand } \\
\text { Effected }\end{array}$} & \multicolumn{2}{|c|}{ Population Served } & \multirow[b]{2}{*}{$\begin{array}{l}\text { Population } \\
\text { Effected }\end{array}$} \\
\hline & $\begin{array}{c}\text { Normal } \\
\text { Conditions }\end{array}$ & $\begin{array}{l}\text { Failure } \\
\text { Scenario } \\
\text { J-170 Out }\end{array}$ & & $\begin{array}{c}\text { Normal } \\
\text { Conditions }\end{array}$ & $\begin{array}{c}\text { Failure } \\
\text { Scenario } \\
\text { J-170 Out }\end{array}$ & \\
\hline (1) & (2) & (3) & (4) & (5) & (6) & (7) \\
\hline $\mathrm{J}-20$ & 12350 & 12311 & 39 & 3069 & 3059 & 10 \\
\hline $\mathrm{J}-30$ & 4940 & 4932 & 8 & 1421 & 1419 & 2 \\
\hline $\mathrm{J}-40$ & 4940 & 12472 & -7532 & 6100 & 15400 & -9300 \\
\hline $\mathrm{J}-50$ & 4940 & 4932 & 8 & 5953 & 5944 & 10 \\
\hline $\mathrm{J}-60$ & 12350 & 12349 & 1 & 2297 & 2297 & 0 \\
\hline J-70 & 12350 & 12330 & 20 & 827 & 826 & 1 \\
\hline$J-80$ & 12350 & 12332 & 18 & 4189 & 4182 & 6 \\
\hline J-90 & 24700 & 24658 & 42 & 6082 & 6072 & 10 \\
\hline $\mathrm{J}-100$ & 12350 & 12328 & 22 & 716 & 715 & 1 \\
\hline$J-110$ & 12350 & 12311 & 39 & 4642 & 4627 & 15 \\
\hline $\mathrm{J}-120$ & 4940 & 29597 & -24657 & 4949 & 29652 & -24703 \\
\hline $\mathrm{J}-130$ & 4940 & 12436 & -7496 & 5170 & 13014 & -7845 \\
\hline $\mathrm{J}-140$ & 4940 & 4933 & 7 & 5248 & 5241 & 7 \\
\hline$J-150$ & 4940 & 4932 & 8 & 4330 & 4323 & 7 \\
\hline$J-160$ & 19760 & 19744 & 16 & 1487 & 1486 & 1 \\
\hline $\mathrm{J}-170$ & 4940 & 0 & 4940 & 1901 & 0 & 1901 \\
\hline
\end{tabular}

